\author{
Universidade de São Paulo \\ Instituto de Física
}

\title{
Estudo da eletrocomunicação em Gymnotus carapo e \\ Gnathonemus petersii livres por tempos longos mediante protocolos realistas de estimulação
}

\author{
Caroline Garcia Forlim
}

Orientador: Prof. Dr. Reynaldo Daniel Pinto

Tese de doutorado apresentada ao Instituto de Física para a obtenção do título de Doutor em Ciências

Banca Examinadora:

Prof. Dr. Reynaldo Daniel Pinto (IFUSP)

Prof. Dr. Angel Ariel Caputi Cavalli (IIBCE-Uruguai)

Prof. Dr. Leonardo P. Maia (IFSC-USP)

Prof $^{\mathrm{a}} \mathrm{Dr}^{\mathrm{a}}$. Coraci Pereira Malta (IFUSP)

Prof $^{a}$ Dr $^{\mathrm{a}}$. Carla Goldman (IFUSP)

São Paulo 
FICHA CATALOGRÁFICA

Preparada pelo Serviço de Biblioteca e Informação do Instituto de Física da Universidade de São Paulo

Forlim, Caroline Garcia

Estudo da eletrocomunicação em Gymnotus carapo e Gnathonemus petersii livres por tempos longos mediante protocolos realistas de estimulação. São Paulo, 2013.

Tese (Doutorado) - Universidade de São Paulo. Instituto de Física de São Carlos. Dept ${ }^{\circ}$ de Física e Informática. Instituto de Física. Dept ${ }^{\circ}$. de Física Geral.

Orientador: Prof $^{\circ}$. Dr ${ }^{\circ}$. Reynaldo Daniel Pinto

Área de Concentração: Biofísica

Unitermos: 1. Peixes elétricos; 2. Teoria da Informação; 3. Neurociências 4. Computação aplicada.

USP/IF/SBI-004/2014 


\section{Agradecimentos}

Agradeço enormemente,

à minha família por sempre me apoirem em todos os momentos, aos professores de Sao Carlos, Roland Koberle, Leonardo Maia e Jan Slaets por nos acolherem tão bem quando nos mudamos para o campus de São Carlos e pelas discussões frutíferas, aos excelentes técnicos Lírio O. B. Almeida e Ivanilda Zucolotto, sem eles o trabalho teria sido muito mais difícil, ao Prof. José Carlos Sartorelli pelo apoio, incentivo e ensinamentos, ao Prof. Reynaldo Daniel Pinto pela oportunidade de trabalhar com os peixes elétricos e pelos inventos mirabolantes, a todos do Grupo de Neurocomputacion Biológica da Espanha por sempre me receberem com tanto carinho, em especial a Franciso de Borja Rodriguez e a Pablo Varona por terem me dado todo o apoio e condiçõess para trabalhar com os peixes elétricos.

à FAPESP, CNPq, CAPES e ao Governo espanhol pelos auxílios: MINECO TIN 2012-30883 e TIN 2010-19607 e 7a Convocatoria De PROYECTOS de COOPERACION INTERUNIVERSITARIA UAM-SANTANDER con America Latina. 


\section{Resumo}

A bioeletrogênese tem atraído a atenção da ciência desde a antiguidade. Capazes de produzir campos elétricos e também de sentir estes campos, os peixes elétricos pulsadores de campo fraco são um modelo de estudo praticamente com características únicas em Neuroetologia, já que permitem ao experimentador medir de maneira não invasiva os sinais espaço-temporais envolvidos em pelo menos duas capacidades complexas do sistema nervoso do animal: a eletrolocalização (em que é produzida uma imagem elétrica das proximidades) e a eletrocomunicação (em que os padrões de pulsos são usados para identificar conspecíficos, seu sexo, tamanho, resolver disputas de território, etc). Entretanto, como os pulsos geralmente são idênticos em indivíduos de uma mesma espécie e a amplitude do sinal medido depende da distância dos animais aos eletrodos usados, experimentos com animais livres para se movimentar são muito difíceis de realizar, mais ainda experimentos com mais de um animal interagindo. Por isso, na maioria dos trabalhos encontrados na literatura o comportamento elétrico dos animais é registrado durante curtos intervalos de tempo em que seus movimentos eram bastante restritos ou limitados a água bem rasa. Além disso, os estímulos eram geralmente compostos por pulsos quadrados ou períodos senoidais apresentados a intervalos regulares. Os protocolos experimentais usados eram sempre unidirecionais, ou seja, não dependiam nem se adaptavam à atividade dos peixes.

Para lidar com estas limitações, que acreditamos tornarem o comportamento dos animais muito diferente do que ocorre na natureza, desenvolvemos aparatos experimentais para registrar e estudar o comportamento elétrico e motor de peixes elétricos pulsadores nadando livremente por longos períodos de tempo e que podem ser facilmente adaptados para o estudo de diversas espécies. Utilizamos técnicas de interação em tempo real entre computadores e sistema nervoso vivo, adaptado de protocolos do tipo dynamic clamp, para produzir estímulos elétricos realistas e também estímulos luminosos. Mostramos protocolos de estimulação clássicos unidirecionais bem como bidirecionais, dependentes da atividade dos animais. Aplicamos técnicas de análise de dados baseadas na teoria da informação que permitiram associar a entropia da série de pulsos do órgão elétrico à movimentação do animal.

Aplicamos estes aparatos e técnicas para estudar peixes elétricos de campo fraco de espécies que pertencem a ordens diferentes e, portanto, são o resultado de histórias evolutivas distintas: o peixe 
sul americano G. carapo, da ordem dos Gymnotiformes e o peixe africano G. petersii, da ordem dos Mormyriformes. Obtivemos evidências de comunicação dos animais e estudamos quais os padrões mais prováveis de disparo em diferentes condições. Uma das espécies apresentou um longo transiente quando exposta a um novo ambiente, evidenciando que as técnicas tradicionais de restringir periodicamente o movimento do peixe não são adequadas para o estudo do comportamento desta espécie.

Nossos resultados apresentaram várias evidências de que os animais são capazes de distinguir estímulos realistas (gravados de conspecíficos), de estímulos aleatórios com propriedades estatísticas semelhantes e que há 2 valores de echo response validando a necessidade dos métodos de estímulo desenvolvidos. Também pudemos mostrar que protocolos de estimulação em tempo real bidirecionais, são mais efetivos em interagir com o código do peixe quando comparados com os protocolos unidirecionais tradicionais e que os animais são capazes de aprender a controlar seu comportamento motor e também sua frequência de disparo para evitar estímulos indesejados. 


\begin{abstract}
Bioloelectrogenesis is known since ancient times. Weakly electric fish are a wonderful model in Neuroethology because they produce and sense eletric fields. These unique features allow non invasive experiments to access complex spatio-temporal signals involved in 2 tasks called electrocommunication and electrolocation. Electrolocation is the ability to see the surrounding areas /objects by analyzing changes in the fish's own electric field and electrocommunication is the ability to identify conspecifics, fight for dominance etc. In this last task fish have their electric field distorted by conspecifics' eletric organ discharges.

Usually, within species, pulse-type weakly electric fish discharge pulses with similar waveform and the amplitude of the pulse depends on the distance to the recording electrodes being very difficult to measure the discharges in freely swimming animals, specially when 2 or more animals are interacting. For these reasons, most studies found in the literature are done with restrained animals or in shallow tanks. The most commom stimuli used are square/sine waves or very short pre-recorded discharges in classic protocol where the stimuli do not depend on the fish's activity.

To overcome these issues trying to perform more naturalistic experiments, we developed experimental setups to record the electric and motor behavior in freely pulse-type electric fish for long periods. Our setups have also the advantage of being easy to adapt making possible to study several species. We performed real time experiments with realistic electric and light stimuli using dynamic clamp techniques adapted to Neuroethology. We show both classic unidirectional protocols as well as bidirectional closed loop interaction, taking into account the fish's dynamic activity. Analyzes based on Information Theory revealed that the entropy of the electric organ discharges are correlated to the their movement.

We performed experiments using the setups and techniques mentioned before in 2 species that have evolved independently: G. Carapo (Gymnotidae) from South America and G. petersii (Mormyridae) from Africa. We show evidence of real communication and we study the inter pulse discharge probability in different behavioral circumstances. One specie showed a long transient behavior when introduced in new environment, hence, the traditional experiments with restrained animals might not be suitable to study natural behavior. Our results show several evidences that the fish can distinguish between realist stimuli from conspecifics and random ones, that there are 2 values of echo response instead of 1 , demonstrating the importance of our new setup and protocols. We could also show that closed loop protocols were more effective to stimulate and interact with the fish's
\end{abstract}


activity and that the animals are able to control their motor and electric behavior avoiding possibly harmful stimulation. 


\section{Sumário}

1 -Introduçã

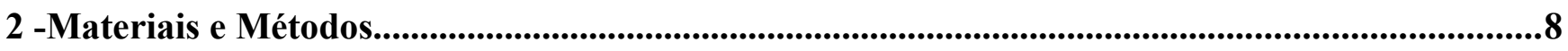

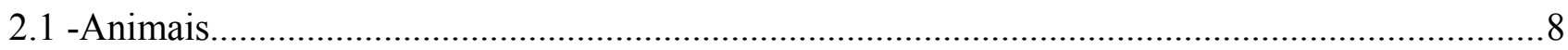

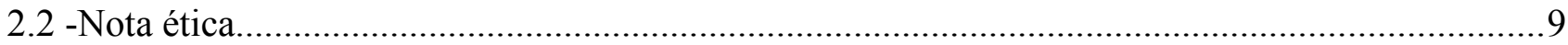

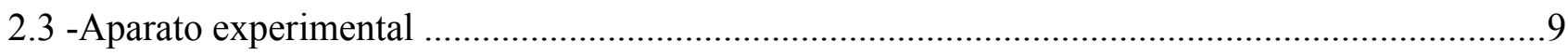

2.3.1-Para o estudo de Gymnotus carapo................................................................................10

2.3.2- Para o estudo de Gnathonemus petersii..............................................................................15

2.4 -Protocolos de estímulo......................................................................................................20

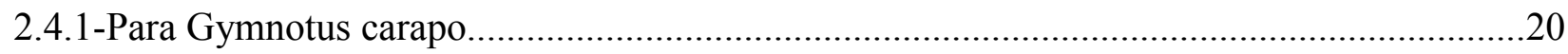

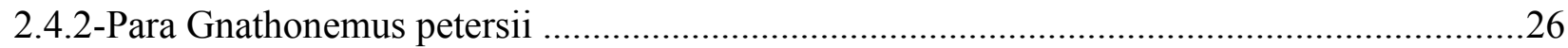

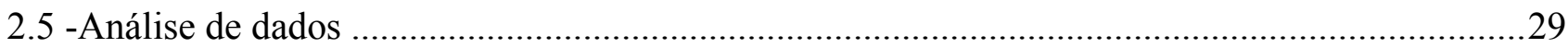

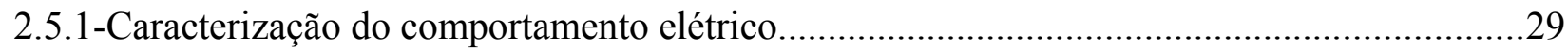

2.5.2-Posição no aquário e inferência da movimentação através das descargas elétricas................34

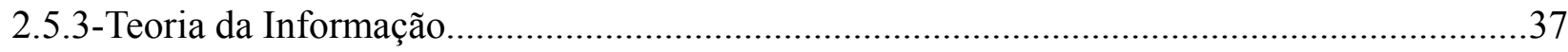

2.5.4-Análise estatística .................................................................................................... 40

3 -Resultados.........................................................................................................................................40

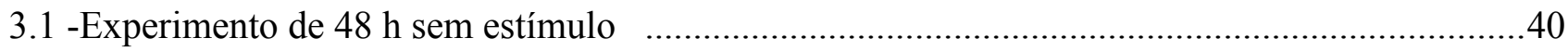

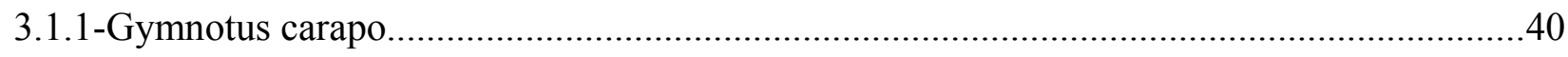

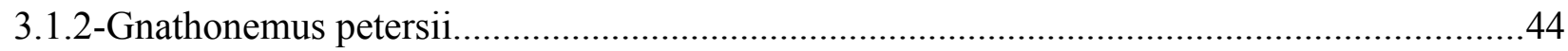

3.2 -Evolução dos valores de IPIs mais prováveis durante 1 mês..........................................................45

3.3 -Experimentos com estímulos elétricos em Gymnotus carapo......................................................50

3.3.1-Estímulos com sequências de IPIs reais e aleatórias ............................................................50

3.3.2-Tempo entre pulso de estímulo e pulso resposta de Gymnotus carapo ………...................72

3.3.3-Experimentos com pulsos que mudam de amplitude........................................................73

3.3.4-Análise do conjunto de palavras mais prováveis de Gymnotus carapo..................................79

3.4 -Experimentos com estímulos elétricos em Gnathonemus petersii................................................82

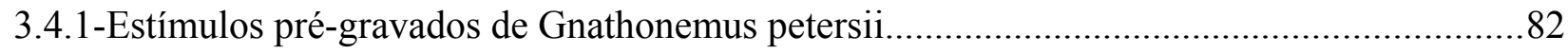

3.4.2-Estímulos dependentes da atividade elétrica de Gnathonemus petersii ...............................85

3.4.3-Tempo entre pulso de estímulo e pulso resposta de Gnathonemus petersii ..........................89

3.4.4-Estímulos dependentes da posição de Gnathonemus petersii no aquário................................92 
3.5 -Estímulos luminosos dependentes da atividade de Gnathonemus petersii............................94

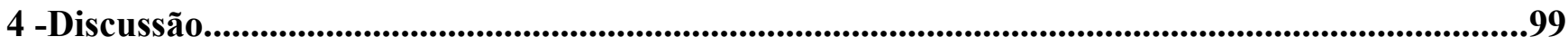

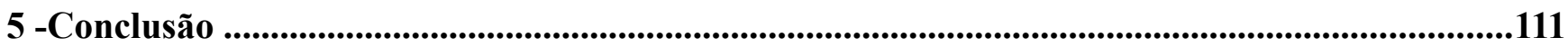

6 -Trabalhos decorrentes do doutorado...................................................................................114

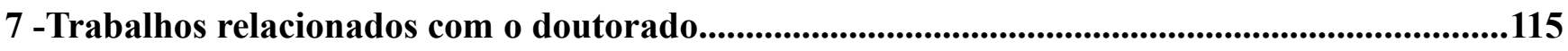

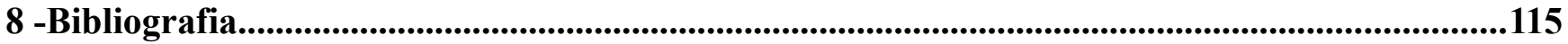

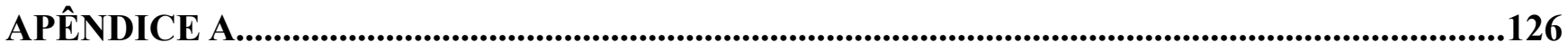

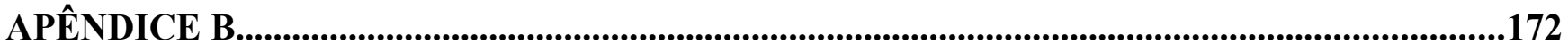

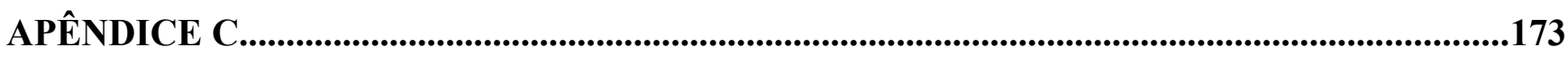

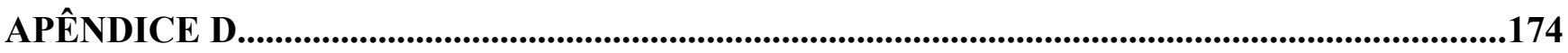

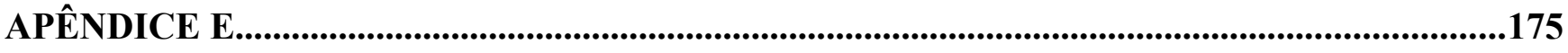

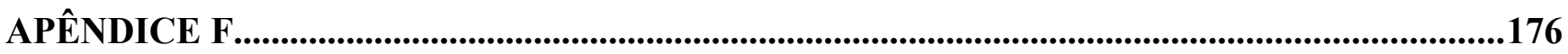




\section{1 - Introdução}

A produção de campos elétricos por organismos vivos, especialmente peixes, tem atraído a atenção de cientistas há muito tempo. Um exemplo é o trabalho de Faraday (1839) com a espécie Electrophorus electricus (na época chamada apenas de Gymnotus), popularmente conhecida como enguia elétrica e capaz de produzir descargas de até $600 \mathrm{~V}$. Tais animais são bastante famosos devido a utilizar sua forte descarga elétrica, que pode ser potencialmente fatal a humanos, para proteção e caça.

Peixes da ordem dos Siluriformes, Torpediniformes, Gymnotiformes e Osteoglossiformes produzem eletricidade através de um órgão elétrico (OE; Hopkins, 1988; Bullock et al., 2005).

$\mathrm{Na}$ ordem dos Siluriformes, na família Malapteruridae há 2 gêneros de bagres elétricos, Malapterurus e Paradoxoglanis, que produzem descargas de até $350 \mathrm{~V}$. Na ordem dos Torpediniformes, a família Torpedinidae de raias elétricas produz até $220 \mathrm{~V}$. Na ordem dos Gymnotiformes, a família Gymntotidae possui o gênero Electrophorus, das enguias elétricas, que produz descargas elétricas de mais de $500 \mathrm{~V}$, sendo o poraquê (Electrophorus electricus) o espécimem mais conhecido desse gênero. Todos esses peixes usam a eletricidade como mecanismos de defesa e estratégia de predação, nocauteando suas vítimas com descargas elétricas fortes. Por causas das fortes descargas são conhecidos como peixes elétricos de campo forte.

A ordem dos Gymnotiformes engloba 5 famílias: Sternopygidae,Apteronotidae, Gymnotidae, Rhamphichthyidae e Hypopomidae. Dentro família Sternopygidae, encontram-se o bastante estudado gênero Eingenmannia e dentro da família Apteronotidae, o mais conhecido é o Apteronotus albifrons, chamado de Ituí-cavalo. A familía Gymntidae possui outro gênero além do Electrophorus citado a cima, o Gymnotus, do qual estudamos o Gymnotus carapo (Fig.1), conhecido como tuvira. Os Gymnotiformes, com exceção do gênero Electrophorus, produzem descargas elétricas de baixa voltagem, $\sim 5 \mathrm{~V}$ usadas para comunicação, navegação e localização. As descargas podem ser do tipo pulso ou onda que são emitidas constantemente. Esses peixes são chamados de pulsadores ou onduladores de campo fraco. Em estudos mais recentes em Gymnotiformes realizado por Alves-Gomes (Alves-Gomes et al., 1995), essa ordem englobaria, na verdade, 7 famílias: Rhamphichthyidae, Hypopomidae, Sternopygidae, Apteronotidae, Electrophoridae, Gymnotidae e Eigenmanniidae. Os Gymnotiformes podem ser encontrados em toda América do Sul.

Osteoglossiformes é outra ordem onde são encontrados peixe elétricos de campo fraco. Possui 2 
famílias: Gymnarchidae, com apenas um exemplar, o ondulatório Gymnarchus niloticus, e Mormyridae, que é uma das maiores famílias com cerca de 200 espécies, incluindo o gênero Gnathonemus do qual estudamos o pulsador Gnathonemus petersii (Fig.1). Gnathonemus petersii pode ser encontrado desde a Nigéria, passando pela bacia do Congo chegando até o Norte de Angola e Zâmbia (Awaïss et al., 2010)

A ordem dos Gymntiformes e dos Osteoglossiformes, possue um sistema eletrogênico e eletrocensório, sendo capazes de produzir sinais elétricos gerados por um OE, receber esses sinais, bem como, sinais elétricos externos através de eletroreceptores que se distribuem por toda epiderme dos peixes (Lissmann, 1958; Bullock et al., 1969, von der Emde et al., 1998; Caputi et al., 2002). Esses 2 sistemas funcionam em conjunto da seguinte maneira: o OE gera pulsos elétricos, que se propagam nas vizinhanças do animal e seu sistema nervoso analisa pequenas perturbações, detectadas por um sistema sensorial especializado, que o ambiente produz no campo elétrico propagado (eletro-recepção). É interessante mencionar que dentro da subclasse de peixes teleósteos, outros grupos de animais desenvolveram sensibilidade a campos elétricos externos que permite detectar inimigos ou presas, apesar de não possuírem a capacidade de eletrogênese.

Acredita-se que a eletro-recepção é uma capacidade sensorial que apareceu há mais de 500 milhões de anos em muitas linhagens de vertebrados antigos, enquanto a eletrogênese, embora bastante antiga também, seja mais recente, tendo aparecido na história evolucionária com os peixes cartilaginosos. Nos teleósteos, a eletrogênese e a eletro-recepção se desenvolveram múltiplas vezes, e muitas delas de maneira independente, durante sua evolução, de acordo com a teoria filogenética (Alves-Gomes, 2001). Assim, peixes elétricos que pertencem a ordens taxonômicas distantes (Fig.1), e provêm de processos evolutivos distintos, como os Gymnotiformes (sul-americanos) e os Mormyriformes (africanos), beneficiam-se por contar com os dois sistemas simultaneamente: possuem mecanismos de produção de descargas de baixa amplitude em seus OEs, e de percepção de sinais elétricos (Zupanc, 2009).

O início do processo de eletro-recepção ocorre em uma infinidade de células especializadas eletroreceptores - que se distribuem por toda epiderme (Lissmann, 1958; Bullock et al., 1969, von der Emde et al., 1998; Caputi et al., 2002), e permite ao animal perceber tanto sinais elétricos autogerados como aqueles produzidos por outros animais. Os sinais produzidos pelos eletro-receptores são então integrados pelo sistema nervoso do animal que produz o sentido. De acordo com suas propriedades 
morfológicas e fisiológicas os eletro-receptores podem ser divididos em duas classes principais: os ampulários e os tuberosos. Os ampulários tem sua máxima resposta para sinais elétricos de baixa frequência ou mesmo corrente contínua e são encontrados na maioria das espécies capazes de eletrorecepção, enquanto os tuberosos são encontrados apenas nos peixes capazes de eletrogênese (com uma única exceção) e são especializados em sinais de mais alta frequência, sintonizados especialmente nas frequências dominantes que o OE produz (Alves-Gomes, 2001). Existem evidências de que nos teleósteos os dois tipos de eletro-receptores evoluíram e se perderam em algum ancestral, tendo evoluído novamente mais recentemente no grupo. Embora fisiologicamente similares, os eletroreceptores presentes nos Mormyriformes e nos Gymnotiformes são muito diferentes de um ponto de vista anatômico (Zakin, 1987; Zakon 2005), representando um exemplo de convergência evolutiva entre as espécies africanas e sul-americanas.

Em todos os peixes elétricos, com exceção da família Apteronotidinae, o OE tem origem em células derivadas de células musculares. Nos Apteronotidinae, tem origem em tecidos nervosos (Bullock et al., 1969). Quanto ao tipo de sinal elétrico produzido pelo OE, os peixes elétricos podem ser divididos em dois grupos: onduladores e pulsadores.

Os onduladores produzem descargas contínuas modulando sua frequência e a amplitude. Os pulsadores produzem pulsos curtos estereotipados (tipicamente com duração da ordem de ms) com intervalo entre pulsos (IPI, do inglês inter pulse interval) entre 5 e $600 \mathrm{~ms}$. Tais intervalos podem ser modulados de acordo com estímulos do ambiente. Em Gymnotus carapo (ordem Gymnotiforme), esses intervalos podem variar de $\sim 8 \mathrm{~ms}$ a $\sim 50 \mathrm{~ms}$ (Westby, 1975) e em Gnathonemus petersii (ordem Mormyriforme) de $\sim 10 \mathrm{~ms} \mathrm{a} \sim 600 \mathrm{~ms}$.

A duração dos pulsos é bastante similar entre os animais de uma mesma espécie, mas pode variar consideravelmente de espécie a espécie (Bullock et al., 2005): um pulso do sul-americano Gymnotus carapo dura tipicamente $\sim 2,5 \mathrm{~ms}$, enquanto um de Gnathonemus petersii dura $\sim 1 \mathrm{~ms}$ (Fig. 2). O OE também tem tamanho e localização diferentes entre as espécies (Bullock et al., 2005), i.e. em Gymnotus carapo está localizado aproximadamente nos 2/3 finais do corpo medindo entre 10 e $15 \mathrm{~cm}$ de comprimento, enquanto em Gnathonemus petersii, encontra-se entre o corpo e a cauda e possui de 1 a $2 \mathrm{~cm}$. 


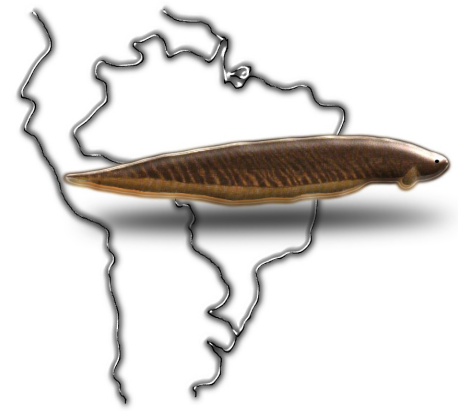

Tuvira

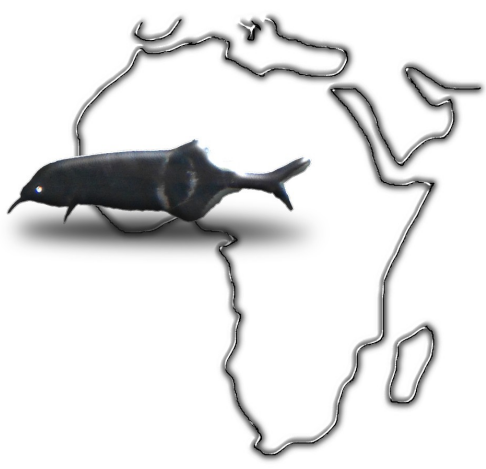

Peixe elefante

Fig. 1:Espécies abordadas neste trabalho: da América do Sul, Gymnotus carapo, conhecido popularmente como Tuvira e da África, Gnathonemus petersii, conhecido como Peixe elefante.

Intervalo entre pulsos (IPI)
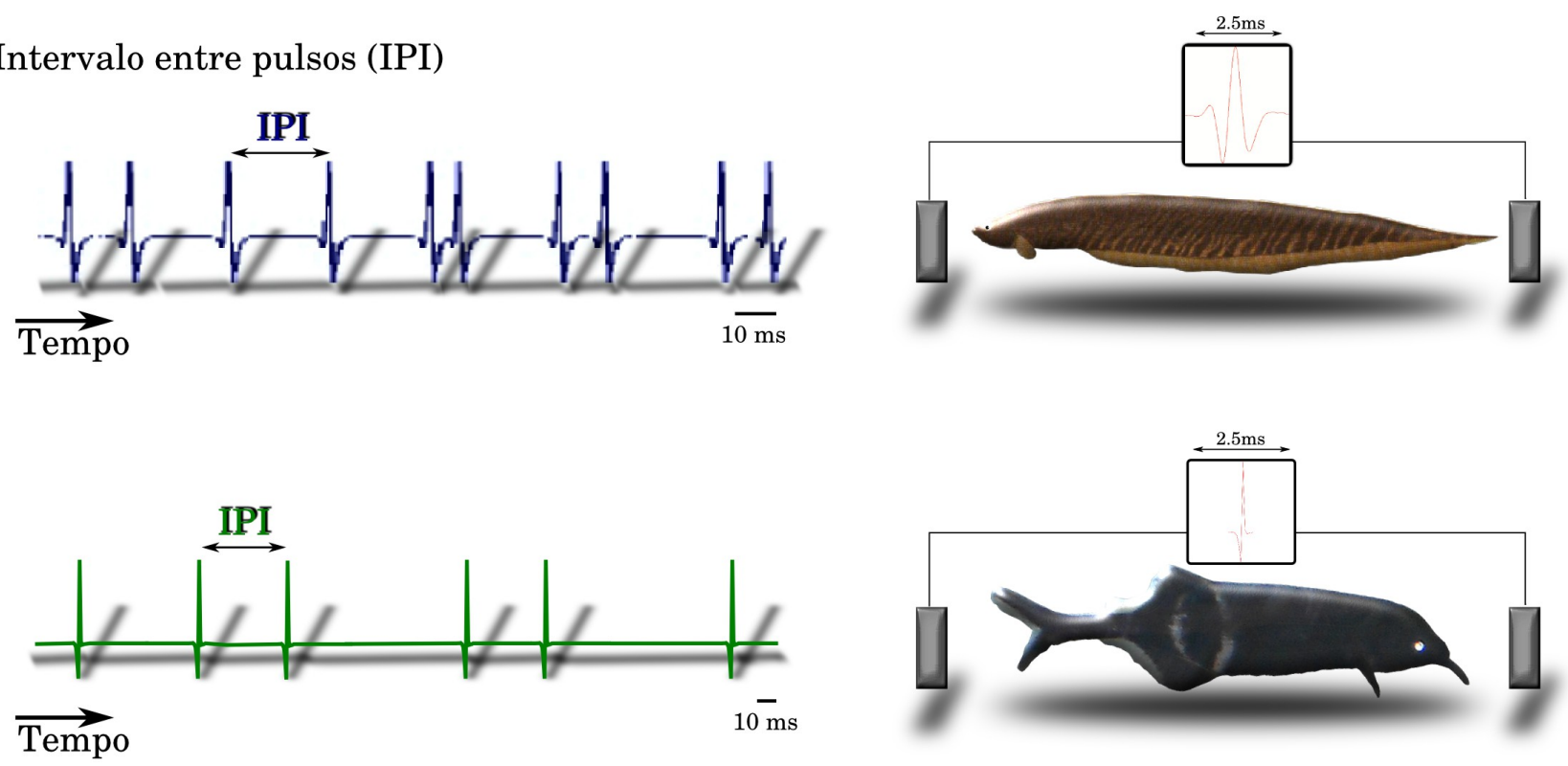

Fig. 2:Intervalos entre pulsos de Gymnotus carapo (azul) e Gnathonemus petersii (verde) e formato do pulso (vermelho). Os intervalos entre pulsos podem variar de $\sim 8 \mathrm{~ms}$ a $\sim 50 \mathrm{~ms}$ em Gymnotus carapo e de $\sim 10 \mathrm{~ms}$ a $\sim 600 \mathrm{~ms}$ em Gnathonemus petersii. O formato do pulso é estereotipado quando medido da cabeça à cauda, em Gymnotus carapo eles duram $\sim 2,5 \mathrm{~ms}$ e em Gnathonemus petersii $\sim 1 \mathrm{~ms}$. 
O OE produz um campo elétrico ao redor do peixe, em primeira aproximação, similar ao campo produzido por um dipolo. Objetos que estejam dentro do campo gerado pelo OE alteram a corrente induzida nos eletroreceptores. Desta maneira, o peixe constrói uma imagem elétrica de suas vizinhanças (Caputi e Budelli, 1995) e pode se locomover em condições precárias de iluminação, ter hábitos noturnos ou habitar águas turvas. Este processo de análise da região ao redor do peixe pela monitoração de um campo auto-produzido é chamado de eletrolocalização (Caputi \& Budelli, 1995; von der Emde et al., 1998; von der Emde \& Fetz, 2007; Engelmann et al., 2008; von der Emde et al. 2008; von der Emde et al., 2010). Nesse processo, objetos que tenham impedância menores do que a da água, "atraem" as linhas de corrente porque mais corrente flui através de um objeto com baixa impedância, levando a uma maior densidade de corrente entrando na pele do peixe (Fig.3-esquerda). O oposto acontece com objetos de alta impedância (Fig.3-direita).

Além da eletrolocalização os peixes também utilizam seus órgãos elétricos para eletrocomunicação. Durante a comunicação, 2 ou mais peixes emitem e recebem sinais elétricos e cada peixe tem seu campo elétrico distorcido e a corrente transcutânea alterada pelas descargas de outros animais (Westby, 1975; Westby, 1979; Caputi et al., 2002; Cuddy et al., 2012).
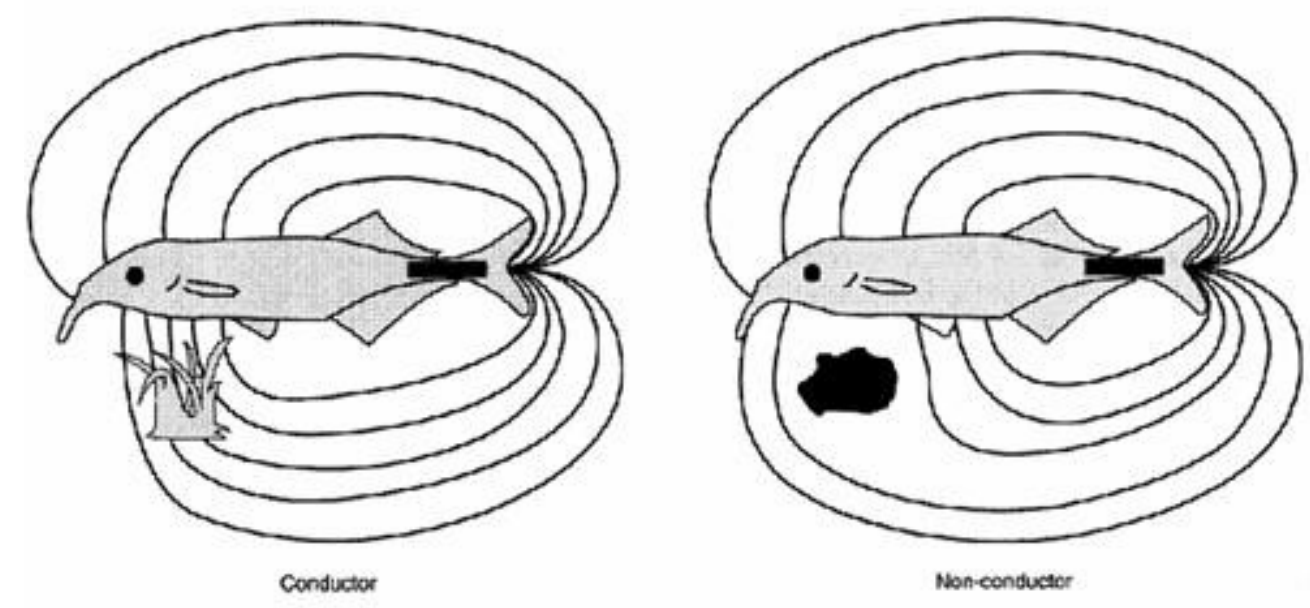

Fig. 3: Eletrolocalização em peixes elétricos de campo fraco. Objetos com impedância menores do que a da água, "atraem" as linhas de corrente levando a uma maior densidade de corrente entrando na pele do peixe (à esquerda). O oposto acontece com objetos de alta impedância (à direita). Figura extraída de von der Emde (1999). 
Além da eletrolocalização e eletrocomunicação, há 2 mecanismos bem estudados, o Jamming Avoidance Response (JAR), onde os peixes deveriam alterar as descargas do órgão elétrico (EODs, do inglês Electric Organ Discharges) para que não ocorressem coincidências de pulsos, ou seja, para que o pulso de um não se sobrepusesse ao pulso do outro (Capurro \& Malta, 2004). E o Novelty Response (NR), que consiste de acelerações transientes da taxa do OE por mudanças no input sensorial (Post \& von der Emde, 1999).

A eletrolocalização e a eletrocomunicação são mecanismos extremamente complicados devido ao processamento de uma enorme quantidade de informação sensorial espaço-temporal pelo sistema nervoso do animal (Caputi \& Nogueira, 2012).

O comportamento elétrico dos peixes durante horas ou dias também é pouco conhecido, principalmente no se que refere ao comportamento social de peixes sem dimorfismo sexual interagindo livremente em tempo real. Esse estudo era uma tarefa quase impossível (Bell et al., 1974; Westby, 1975) principalmente devido aos problemas relacionados com a separação das descargas dos peixes quando se movem livremente, já que os pulsos dos vários indivíduos se misturam no aquário (Schuster, 2001; Arnegard \& Carlson, 2005).

Esforços recentes vem sendo feitos para permitir medidas da atividade elétrica (Matias, 2011; Yu et al., 2012) e motora em peixes soltos (Jun et al., 2013). Entretanto, na maioria dos trabalhos encontrados na literatura, em que se observa a resposta do peixe a estímulos elétricos, geralmente os experimentos são realizados por um curto período de tempo em os peixes têm seus movimentos drasticamente restritos, o que altera seu comportamento natural e portanto afeta sua comunicação. Os estímulos seguem protocolos clássicos unidirecionais, onde o comportamento do animal não altera o estímulo. Além disso para simplificar os experimentos, geralmente são usados estímulos pouco realistas, como pulsos com formato de onda quadrada ou senoidal repetidos periodicamente.

Embora alguns progressos tenham sido obtidos com estes procedimentos pouco realistas, eles apresentam sérias limitações, já que naturalmente se observa uma grande variabilidade nos IPIs e os peixes são capazes de reconhecer o formato de onda de um conspecífico. Em trabalhos com interações entre aninais, geralmente são escolhidas espécies com dimorfismo sexual e/ou animais de tamanhos muito diferentes (Westby, 1979; Arnegard \& Carlson, 2005; Wong \& Hopkins, 2007; Hupe \&Lewis, 2008; Perrone at al., 2009) permitindo, assim, a separação dos pulsos de diferentes indivíduos com base em seu tamanho ou forma muito distinta. Estas técnicas, embora úteis para estudar diversos 
comportamentos relacionados à eletrolocalização, não são totalmente adequadas para o estudo de estratégias de comunicação.

Técnicas de estímulo bidirecionais dependentes da atividade do sistema vem sendo usadas em neurociência em experimentos de eletrofisiologia com o conceito de dynamic clamp desde a década de 40 (Marmont, 1949; Cole, 1955) até os dias de hoje ( Pinto et al., 2001; Prinz et al., 2004; Muniz et al., 2005; Nowotny et al. 2006; Muniz et al., 2009; Brochini et al., 2011; Rodrigues et al., 2011, Chamorro et al., 2012). O conceito clássico de dynamic clamp consistia de injeções de corrente dependentes da voltagem, em neurônios vivos, criando condutâncias artificiais. Essa técnica permitiu investigar propriedades das membranas e transmissão de informação em neurônios de redes híbridas (Szucs et al., 2000; Brochini et al., 2011; Pinto et al., 2001; Varona et al., 2001; Prinz et al., 2004 ).

Expandindo o conceito clássico de dynamic clamp, onde se monitorava apenas o potencial de membrana e usava-se injeção de corrente como estímulo, foi possível generalizá-lo para uma grande gama de protocolos bidirecionais em diferentes contextos experimentais em neurociência (Muniz et al., 2005; Muniz et al., 2011; Chamorro et al., 2012; dos Santos, 2013; Fernandez-Vargas, 2013), como por exemplo, microinjeções de neurotransmissores e neuromoduladores no centro gerador de padrão do estômago de Callinectis sapidus (dos Santos, 2013), o do coração de Carcinus maenas (Chamorro et al., 2012), estimulação mecânica dependente da atividade dos bursts no sistema de navegação de Clione limacina (Chamorro et al., 2012) e interface cérebro-máquina levando em conta a variabilidade entre indivíduos para otimizar diversos protocolos (Fernandez-Vargas, 2013). Em particular, para neuroetologia, pode permitir experimentos onde o foco é a atividade comportamental acionada pela interação do animal com seu ambiente (Chamorro et al., 2012, Muniz et al., 2011).

Nas interações bidirecionais citadas acima, o loop fechado de estímulo-resposta se dá pela monitoração da atividade biológica por sensores e por um algoritmo que tem seus parâmetros constantemente atualizados e estimados online para detectar eventos e iniciar/interromper os estímulos.

A possibilidade de estimular como função de eventos detectados em tempo real pode revelar dinâmicas escondidas sob protocolos tradicionais unidirecionais, bem como explorar plasticidade, aprendizagem, mecanismos de memória e exercer controle sob condições normais ou patológicas (Chamorro et al., 2012).

Neste contexto desenvolvemos aparatos experimentais capazes de detectar os pulsos elétricos dos animais enquanto estes podem se movimentar livremente por horas ou até vários dias. 
Desenvolvemos também protocolos de estímulo baseados em técnicas de dynamic clamp capazes de produzir estímulos luminosos ou estímulos elétricos realistas (com a forma de onda característica produzida pelo OE do animal) mas em que os IPI podiam ser escolhidos a partir de distribuições pré-

programadas pelo experimentador ou determinadas em tempo real e baseadas no comportamento do próprio animal ou de um conspecífico. Utilizamos este aparato para estudar o comportamento elétrico e motor de animais de espécies diferentes e pertencentes às maiores ordens de peixes elétricos de campo fraco: Gymnotus carapo e Gnathonemus. Mostramos que, através de nossas técnicas, podemos inferir a movimentação dos animais (e no futuro também sua posição em função do tempo), o que pode ser muito útil em experimentos que tenham como objetivo estudar a neuroetologia dos animais. Aplicamos ferramentas da teoria de informação, como cálculos de entropia dos pulsos emitidos pelo peixe e cálculos da informação mútua média ente os sinais de dois animais durante sua interação, e mostramos que estas técnicas podem ser utilizadas para caracterizar o comportamento dos animais.

\section{2 - Materiais e Métodos}

\section{1 - Animais}

Trabalhamos com 2 espécies de peixes elétricos pulsadores de campo fraco, o brasileiro Gymnotus carapo e o africano Gnathonemus petersii.

Gymnotus carapo foram obtidos em lojas de pesca das cidades de São Paulo e São Carlos, no estado de São Paulo e mantidos em aquários sem plantas de $31,5 \mathrm{~L}(30 \times 35 \times 30 \mathrm{~cm})$, expostos a iluminação natural com temperatura de $23 \pm 2^{\circ} \mathrm{C}$ e condutividade de $100 \pm 5 \mu \mathrm{S} / \mathrm{cm}$. Eles foram alimentados com minhocas (lumbricus terrestris), artêmias (artemia salina), peixes pequenos e tenébrios (tenebrio obscurus) de 2 a 4 vezes por semana. Utilizamos 25 adultos de sexo desconhecido e medindo 15 a $30 \mathrm{~cm}$ de comprimento, alguns peixes foram estudados mais de uma vez, usando protocolos distintos.

Os africanos Gnathonemus petersii foram adquiridos em lojas de aquário em Madri, Espanha e os peixes eram importados da África ou de criadouros na Ásia. Utilizamos 12 animais entre $9 \mathrm{~cm}$ e 15 
cm de comprimento. Eles foram mantidos em aquários individuais sem plantas de $30 \mathrm{~L}(40 \times 30 \times 25$ $\mathrm{cm})$ ou de $\sim 20 \mathrm{~L}(45 \times 22 \times 20 \mathrm{~cm})$, com iluminação natural e temperatura controlada em $25^{\circ} \mathrm{C}$. Foram alimentados de 2 a 5 vezes por semana com larvas vermelhas (Chironomidae tetans) e artêmias (Artemia salina) congeladas.

\section{2 - Nota ética}

Os procedimentos experimentais com Gymnotus carapo foram aprovados pelo Comitê de Ética em experimentos com animais da Universidade Federal de São Carlos - UFSCAR (Protocolo 007/2009). A aprovação pra os procedimentos experimentais com Gnathonemus petersii foi concedida no projeto MINECO TIN 2012-30883 do Ministério espanhol. Todos os procedimentos com animais seguiram as regras éticas sugeridas pela Society for Neuroscience (www.sfn.org).

\section{3 - Aparato experimental}

A forma mais simples de medir o campo elétrico gerado pelo OE dos peixes é através de um dipolo, ou seja, 2 eletrodos amplificados diferencialmente, com um dos eletrodos posicionado próximo à cabeça e outro próximo à cauda. Se o peixe não se mover, a amplitude medida dos pulsos será sempre a mesma em um mesmo dipolo, lembrando que os pulsos tem uma parte positiva e outra parte negativa. Quando o peixe se move e se distancia de um eletrodo a amplitude induzida se torna muito baixa, praticamente impossibilitando a detecção dos instantes de disparo. Para superar essa dificuldade e podermos medir peixes totalmente livres, nadando pelo aquário, colocamos múltiplos dipolos no aquário, 7 dipolos para medirmos Gymnotus carapo e 5 para medirmos Gnathonemus petersii. Os sinais medidos nos dipolos são então amplificados e elevados ao quadrado por amplificadores operacionais. O instante dos disparos dos peixes é determinado por um threshold no sinal elevado ao quadrado. Para estimular os peixes, usamos um dipolo para imitar um peixe falso, de $15 \mathrm{~cm}$ de comprimento para Gymnotus carapo e de $7 \mathrm{~cm}$ de comprimento para Gnathonemus petersii. Escolhemos essas medidas para os dipolos de estímulo no intuito de simular peixes de tamanho médio 
a grande.

No aparato de Gymnotus carapo, gravamos apenas os instantes de disparo e as amplitudes dos pulsos em todos os 7 dipolos a cada disparo. Usamos duas placas ADC, uma para medir os sinais do

peixe e do estímulo aquário e outra placa para enviar os estímulos. Já em Gnathonemus petersii gravamos todo o sinal do peixe elevado ao quadrado, o sinal de estímulo e mais os tempos de disparo dos pulsos e usamos a mesma placa para medir e estimular.

Os aparatos usados no experimentos em Gymnotus carapo e Gnathonemus petersii são explicados em detalhe a seguir.

\subsection{1- Para o estudo de Gymnotus carapo}

O aparato experimental usado (Fig. 4) foi um aquário $(40 \times 40 \times 45 \mathrm{~cm})$ com $64 \mathrm{~L}(40 \times 40 \times 40$ $\mathrm{cm}$ ) de água dentro de uma dupla gaiola de Faraday (folhas de alumínio de $1 \mathrm{~mm}$ ) para blindar o ruído elétrico. As duas gaiolas de Faraday foram separadas por $4 \mathrm{~cm}$ de ar e uma camada de $3 \mathrm{~cm}$ de espuma (densidade 28) para reduzir a propagação de ruídos sonoros. O aparato foi pendurado com cabos de aço nas vigas no prédio pra minimizar vibrações mecânicas.

O ciclo circadiano de iluminação natural foi simulado da seguinte maneira: no teto da caixa menor, que contém o aquário de medida, foram colocados 12 LEDs brancos de alta potência dispostos circularmente num raio de $12 \mathrm{~cm}$, a iluminação automaticamente liga na hora do nascer do Sol e desliga na hora do pôr do Sol. Esses tempos foram ajustados levando em conta os horários do nascer/pôr do Sol (Fig. 5) na localidade do laboratório.

Durante a permanência dos peixes no aquário de medidas o ar-condicionado do laboratório foi ajustado a $23^{\circ} \mathrm{C}$ para não alterar a temperatura da água e os peixes não foram alimentados, para evitar alterações na condutividade da água. 


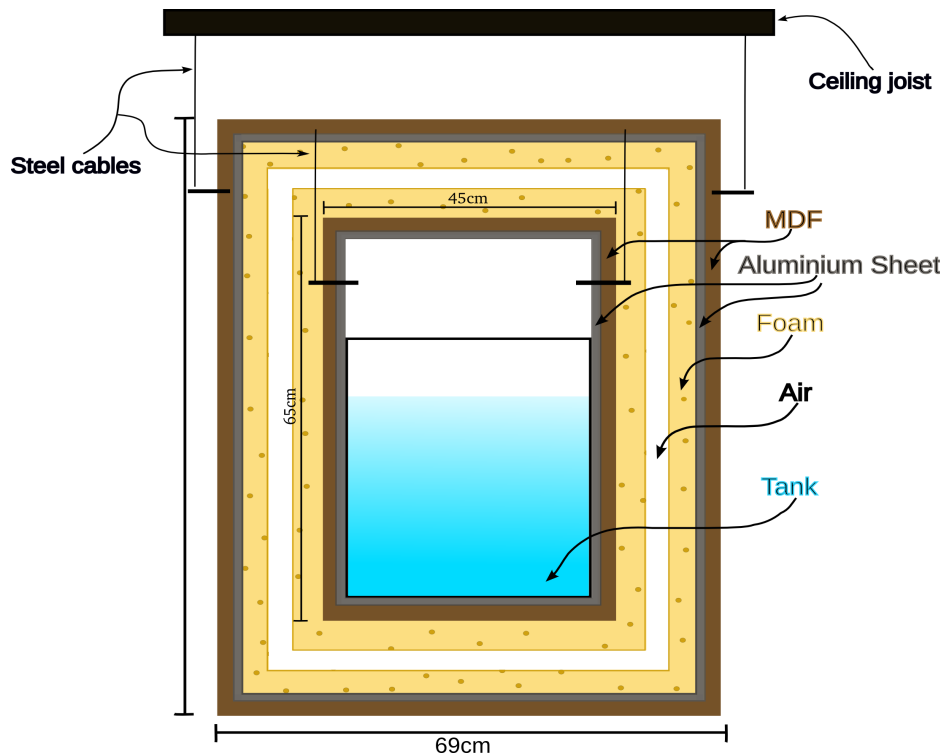

Fig. 4: Aquário de medidas. $O$ aparato consistiu de um aquário de $64 \mathrm{~L}(40 \times 40 \times 40 \mathrm{~cm})$. Usamos duas caixas de MDF de 20 $\mathrm{mm}$ de espessura como suporte para o aquário e para pendurá-lo no teto. Cada caixa foi revestida de folhas de alumínio de $1 \mathrm{~mm}$ de espessura formando uma gaiola de Faraday que blinda ruídos eletromagnéticos. Entre as caixas colocamos 2 camadas de espumas de $3 \mathrm{~cm}$ de espessura para atenuar ruídos sonoros. Para evitar vibrações mecânicas penduramos o aparato no teto usando cabos de aço.

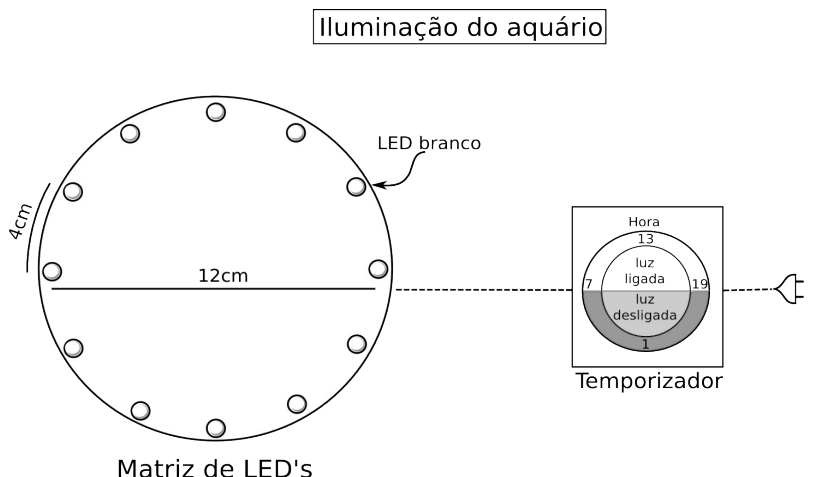

Fig. 5: Iluminação automática para simular periodos de dia/noite. Uma malha de 12 LEDs brancos foi ligada a um temporizador automático que acende/apaga a luz de acordo com o período programado. 
Para detectar os EODs dos peixes usamos 8 eletrodos de aço inox, 4 nas arestas do aquário na parte inferior e mais 4 eletrodos posicionados nas arestas de um plano $40 \mathrm{~cm}$ acima. (Fig. 6A). Um dos eletrodos do aquário da parte inferior foi usado como referência diferencial, de modo que medimos os EODs em 7 dipolos. Esses sinais foram amplificados diferencialmente (ganho $=100 \mathrm{x}$ ) e digitalizados a $50 \mathrm{kHz}$ por uma placa ADC. Podemos mudar o ganho para medirmos peixes de tamanho pequenos.

Os 7 sinais foram elevados ao quadrado, somados. Os tempos dos disparos foram detectados por um limiar, quando um pulso do peixe ultrapassava certo limiar gravávamos o instante dessa ocorrência e as amplitudes máxima positiva e negativa que esse pulso atingiu (Locally induced amplitude (LIA) na Fig. 6B).

Nos experimentos com estímulos, simulamos a presença de um peixe usandoum dipolo de 15 $\mathrm{cm}$ dentro de um pedaço de tubo de PVC posicionado no meio do aquário. Os estímulos foram gerados por uma placa DAC (Digitada 1200B, Axon Instruments, Union City, CA) e controlados por um software real-time (Pinto et al., 2001; Nowotny et al.,2006) que emitia pulsos com a forma de onda característica da espécie e com amplitude controlada entre 1 e $5 \mathrm{~V}$

Durante esses experimentos, o sinal resultante da soma dos 7 dipolos ao quadrado, contém tanto os pulsos do peixe como os pulsos de estímulo. Para separá-los e obter somente sinais do peixe, invertemos e elevamos ao quadrado o sinal do estímulo e somamos ao quadrado do sinal peixe+estímulos com um atraso de $1-3$ amostras devido ao circuito DAC-ADC (Fig. 6B).

A amplitude dos sinais em cada dipolo depende da posição do peixe em relação a ele, assim, quando o peixe se move a amplitude varia de um pulso a outro: se o peixe está se aproximando de um eletrodo a amplitude do sinal medido vai aumentando, assim como se o peixe está se afastando, a amplitude do sinal diminui. Já se o peixe está parado, a amplitude dos sinais nos dipolos permanece a mesma, então, calculando o desvio padrão das amplitudes dos pulsos em pequenas janelas de tempo (40 s ou 300 s)em cada dipolo e depois somando para todos os dipolos conseguimos uma estimativa da movimentação do peixe no aquário.

Pelas amplitudes dos pulsos podemos também inferir a posição e a direção do peixe no aquário, ou seja, qual eletrodo o peixe está mais próximo/alinhado. Explicações mais detalhadas estão na seção 2.5.2- pág. 27.

O aparato experimental usado para Gymnotus carapo foi implementado a partir de uma versão inicial desenvolvida durante o mestrado. Com o aparato duplicado, podemos também fazer 
experimentos em que os pulsos detectados de um peixe em um aquário sejam utilizados como estímulo para um peixe no segundo aquário em tempo real e vice-versa, como se cada um dos peixes estivesse dentro do tubo de PVC usado para estimular o outro. Tais experimentos são referidos posteriormente como "dois peixes interagindo em tempo real". Mais detalhes podem ser encontrados em Forlim (2008). 


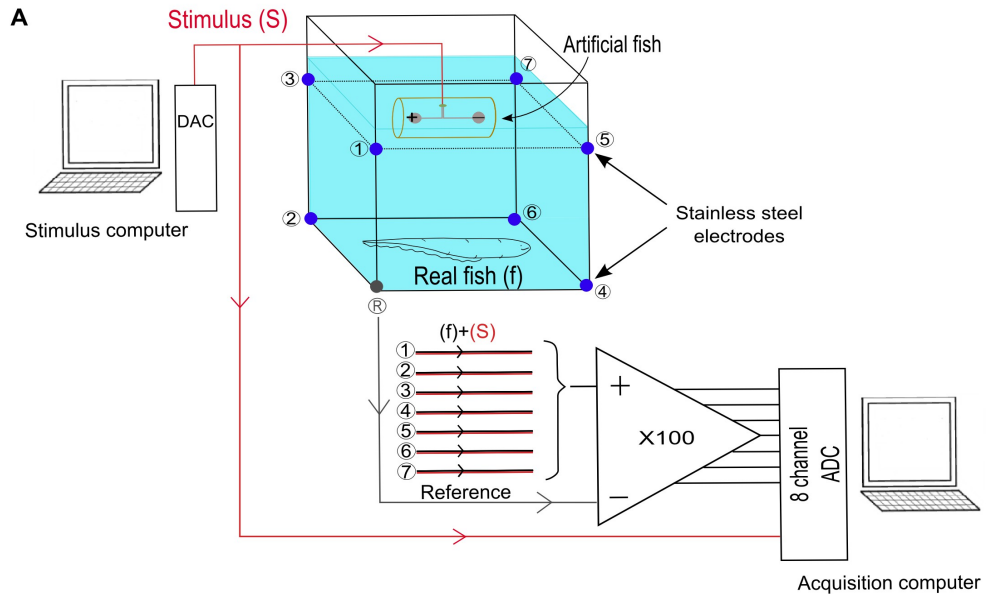

B

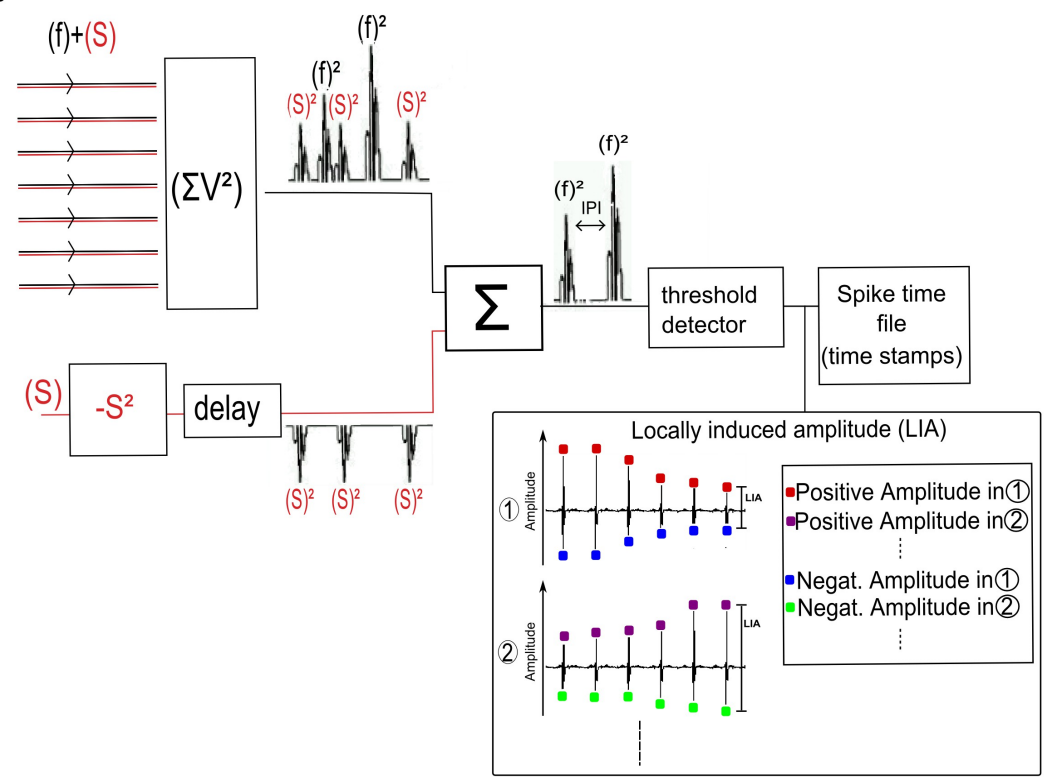

Fig. 6: Aparato experimental para Gymnotus carapo: medidas e estimulação. A - parte feita por hardware: EODs de um peixe real (f) e do estímulo (S) foram medidos usando 8 eletrodos [(1)(7), e (R)] em arranjo cúbico. Estes sinais foram amplificados diferencialmente (x 100, com referência em $(R))$ e digitalizados a $50 \mathrm{kHz}$ por uma placa ADC. O peixe artificial foi feito com um dipolo de $15 \mathrm{~cm}$ dentro de um tubo de PVC. Os estímulos eram enviados por uma placa DAC ligada a um computador em real time. $B$ - software de aquisição: o sinal contendo os pulsos de estímulo (S) foi elevado ao quadrado, invertido e atrasado de 1 - 3 amostras e então somado ao quadrado do sinal peixe real $(f)+$ estímulos $(S)$, sobrando assim somente os pulsos do peixe real (f). Esses pulsos foram detectados quando passavam de um limiar, seus tempos de disparo e as amplitudes positivas e negativas foram gravados para os 7 dipolos. Definimos a diferença entre a amplitude positiva e negativa como LIA (do inglês locally induced amplitude). 


\subsection{2- Para o estudo de Gnathonemus petersii}

O aparato experimental consistiu de um aquário de vidro $(40 \times 30 \times 30 \mathrm{~cm}) \mathrm{com} 301$ de água $(40 \times 30 \times 25 \mathrm{~cm})$ apoiado em uma mesa ao lado de uma janela que fornecia iluminação natural. A temperatura da água era mantida a $25^{\circ} \mathrm{C}$ por um aquecedor e não alimentávamos os peixes durante os experimentos para que não houvesse alterações na condutividade da água.

Para medir as EODs do peixe foram usados 8 eletrodos de fio de prata de $1 \mathrm{~cm}$ (Fig. 7). Quatro eletrodos foram colocados nos vértices do aquário, sendo um deles usado como referência (R), assim os sinais foram medidos por 3 dipolos. Para sermos capazes de medir todos os tamanhos de peixes em todas as posições enquanto o peixe se movia livremente, 2 dipolos foram adicionados na metade das paredes laterais (um dos dipolos está representado por 2 bolinhas vermelhas e o outro por 2 bolinhas amarelas). Esses sinais foram amplificados diferencialmente (ganho $=50 \mathrm{x}$ ou $100 \mathrm{x}$ ) e digitalizados a $20 \mathrm{kHz}$ por uma placa ADC (NI PCI-6251, National Instruments Corporation )e um computador hospedeiro.

Por hardware, os sinais do OE induzidos nos 5 dipolos foram somados e elevados ao quadrado obtendo assim apenas componentes positivas da forma de onda facilitando a detecção posteriormente. Os sinais foram gravados usando o software Dynamic Clamp (Muniz et al., 2005, Muniz et al., 2009, Varona et al., 2001, Chamorro et al., 2012) desenvolvido pelo Grupo de Neurocomputación Biológica (GNB) da Universidad Autónoma de Madrid, Espanha. Nesse aparato a separação entre pulsos do peixe e pulsos de estímulo é feita a posteriori. 


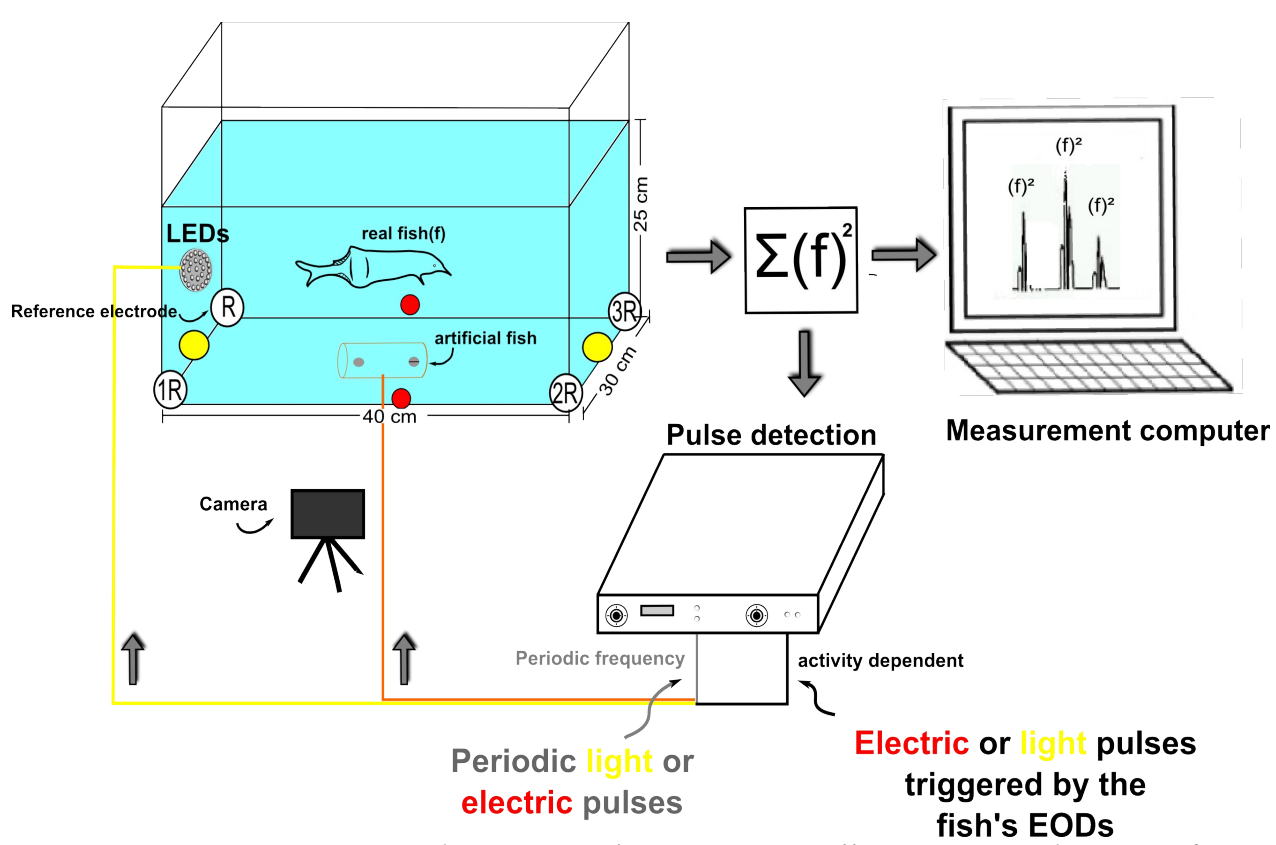

Fig. 7: Aparato experimental para Gnathonemus petersii. As EODs do peixe foram medidas em um aquário com 5 dipolos. Três com uma referência em comum $(R-1 R, 2 R$ e $3 R$ ) e mais 2 representados por bolas vermelhas e amarelas. Os sinais captados pelos dipolos foram amplificados, somados, elevados ao quadrado e enviados ao computador elou a um hardware que detectava os pulsos e podia enviar estímulos elétricos e luminosos com frequencia fixa ou dependente da atividade do peixe. Os pulsos luminosos foram enviados por um conjunto de LEDs de $31 \mathrm{~mm}$ de diâmetro e os pulsos elétricos por um peixe artificial feito a partir de um dipolo de $7 \mathrm{~cm}$. A posição do peixe foi gravada com uma câmera ligada ao computador e um software de deteç̧ão de imagem gravava a coordenada da posição da cabeça do peixe.

Os estímulos elétricos foram produzidos por software (Dynamic Clamp) ou por hardware e enviados a um peixe artificial construído com 1 dipolo de $7 \mathrm{~cm}$ com eletrodos de fío de prata de $0,5 \mathrm{~cm}$. Os pulsos elétricos utilizados para o estímulo tinham a forma de onda característica da espécie.

Os estímulos produzidos por software foram gerados por uma placa DAC (NI PCI-6251, National Instruments Corporation) e controlados pelo Dynamic Clamp. Eles consistiam de pulsos elétricos com amplitude de até $7 \mathrm{~V}$ com sequencia de IPIs pré-gravadas de outros peixes ou a partir da atividade do próprio peixe: um pulso no peixe artificial era produzido $t$ milissegundos após a detecção do pulso do peixe real (Fig. 9A).

A versão hardware do protocolo de estímulo, desenvolvida por Lírio O. B. Almeida, do Grupo de Neurobiofísica do Instituto de Física de São Carlos, fazia a detecção dos pulsos do peixe em tempo 
real e enviava depois de atraso de $t$ milissegundos estímulos elétricos ou luminosos. Para os estímulos luminosos, controlávamos uma série de LEDs, de potência total luminosa de $90 \mathrm{~lm}$, ( $\mathrm{n}^{\mathrm{o}}$ ref. RS 7158409; $\quad$ http://docs-europe.electrocomponents.com/webdocs/0eae/0900766b80eae9ff.pdf)dispostos em um círculo de $31 \mathrm{~mm}$ de diâmetro (Fig. 8) que eram ligados ou desligados com frequência periódica ou dependente da atividade do peixe (Fig.9B). O hardware foi desenvolvido como parte do projeto de cooperação Brasil-Espanha da $7^{\mathrm{a}}$ Convocatoria De PROYECTOS de COOPERACION INTERUNIVERSITARIA UAM-SANTANDER con America Latina.
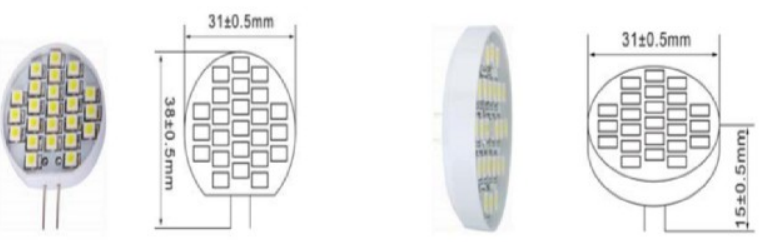

Fig. 8: LEDs usados como estímulo luminoso. Dispostos em um círculo de $31 \mathrm{~mm}$ de diâmetro. Potência luminosa total de $90 \mathrm{~lm}$ $\begin{array}{lllll}n^{\circ} & \text { ref. } & R S & 7158409 ; & \text { http://docs- }\end{array}$ europe.electrocomponents.com/webdocs/0eae/0900766b80eae9f f.pdf) 
A

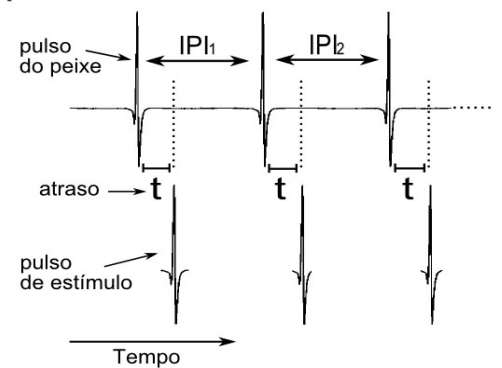

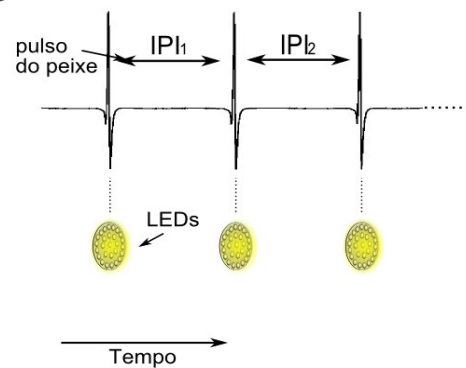

Fig. 9: Estímulos dependentes da atividade elétrica de Gnathonemus petersii. $A$-estímulos elétricos: um pulso de estímulo era enviado com um atraso de tempo $t$ depois de detectado um pulso do peixe. $B$ - estímulos luminosos: ao detectar um pulso do peixe o conjunto de LEDs emitia um pulso luminoso.

Também fizemos outro tipo de monitoramento que não da atividade elétrica, monitoramos a atividade motora seguindo os movimentos do peixe. Desenvolvemos um experimento de aprendizagem e estudo de estímulos aversivos, onde o peixe seria confinado em uma região do aquário determinada por uma barreira virtual.

Uma câmera de vídeo (Logitech C905) ligada ao computador, monitorava os movimentos do peixe e um programa desenvolvido pelo $G N B$ detectava e armazenava on line dados com as coordenadas da posição da cabeça do peixe (Chamorro et al., 2012), se a cabeça do peixe ultrapassase a barreira virtual, eram emitidos pulsos elétricos periódicos. A detecção do peixe era feita fazendo a subtração da imagem do fundo sem o peixe (calibração) com as imagens em que o peixe estava nadando (foram utilizadasam bibliotecas opencv, http://opencv.willowgarage.com). Essa técnica se mostrou eficaz porque a cena estática observada do aquário tem alto contraste em relação ao Gnathonemus petersii (Fig.10). 


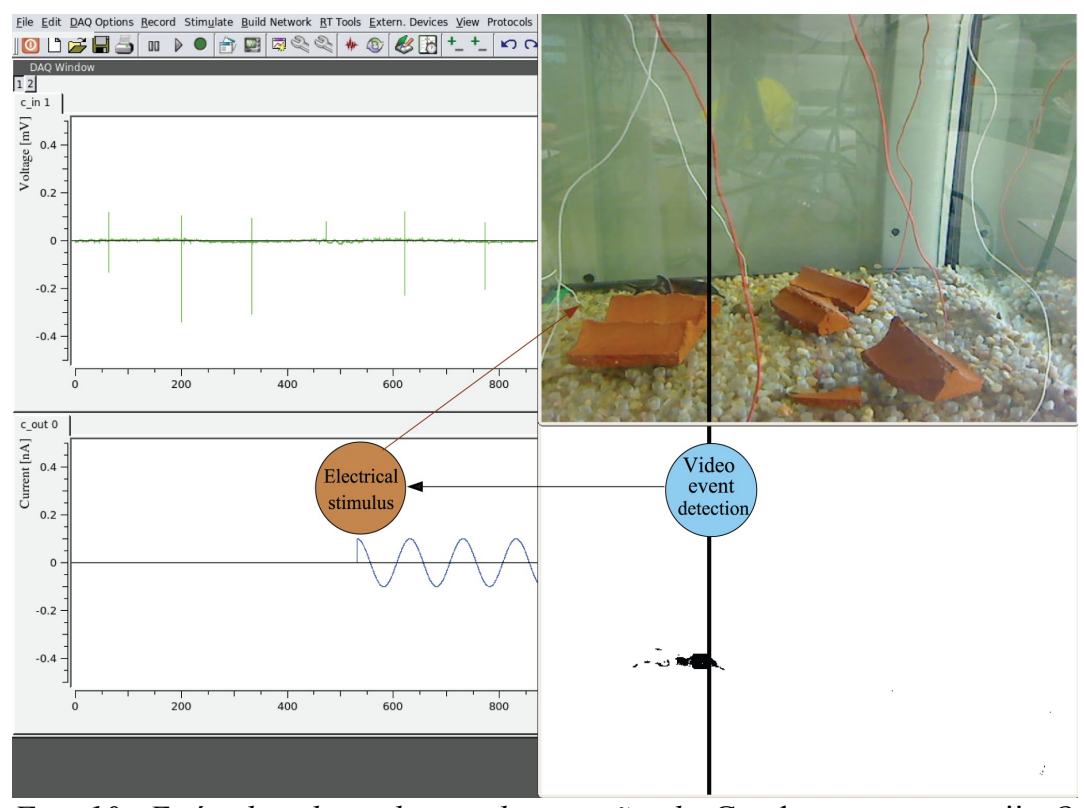

Fig. 10: Estímulos dependentes da posição de Gnathonemus petersii. $O$ fundo da imagem gravada pela câmera (superior direita) foi subtraido restando somente o peixe (inferior direita). A linha preta mostra a detecção da cabeça do peixe. Quando o peixe ultrapassa uma barreira virtual se enviam estímulos elétricos para o aquário(inferior esquerda). Junto com a posição do peixe gravou-se também sua atividade elétrica (superior esquerda). Figura extraída de Chamorro et. al 2012

\section{4 - Protocolos de estímulo}

\subsection{1- Para Gymnotus carapo}

Todos os pulsos de estímulo usados tinham o formato característico da espécie estudada e amplitude de 1 a $5 \mathrm{~V}$. A forma de onda do pulso usada foi caracterizada calculando a média de 100 pulsos gravados por um dipolo com uma de suas pontas perto da cabeça e a outra perto da cauda de um peixe imóvel. 


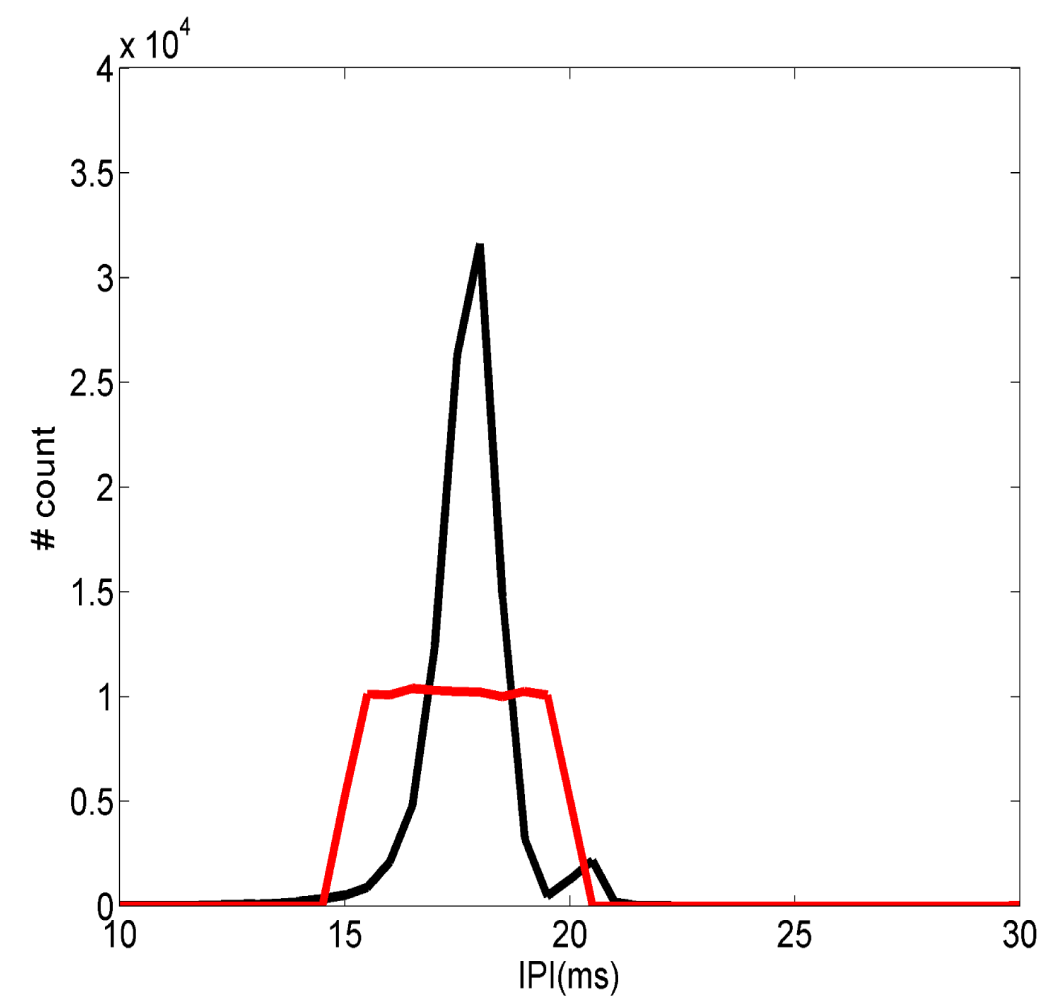

Fig. 11: Histograma dos IPIs de estímulo usados em Gymnotus carapo. A linha preta é o histograma dos IPIs pré-gravados de um peixe e a linha vermelha dos IPIs aleatórios entre 15 e 20 ms. IPIs de 18 ms são mais prováveis de ocorrer no estímulo pré-gravado, já os aleatórios apresentam distribuição uniforme em que todos os IPIs ocorrem com a mesma probabilidade entre 15 e $20 \mathrm{~ms}$.

Para Gymnotus carapo usamos protocolos de estimulação unidirecionais, ou seja, os estímulos não se adaptavam as mudanças da atividade dos peixes. As séries de IPIs usadas pra estimular os peixes foram escolhidas entre: 30 min pré-gravados de um peixe real (Fig. 11linha preta) que tinha acabado de ser colocado no aquário, 30 min de IPIs aleatórios entre 15-20 ms (Fig. 11linha vermelha). A evolução temporal dos estímulos de IPIs reais e aleatórios encontra-se na Fig. 12. O estímulo com IPIs aleatórios eram uniformemente distribuídos entre 15 e $20 \mathrm{~ms}$, ou seja, todos os IPIs tinham a mesma probabilidade de ocorrer neste intervalo, portanto, sem relações de causalidade. 

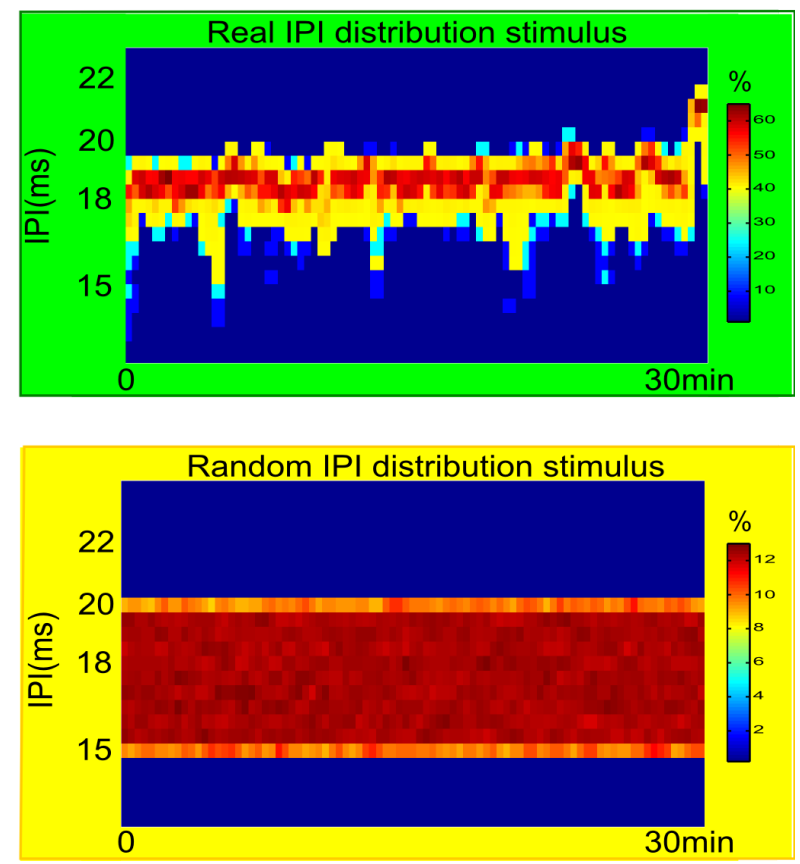

Fig. 12: Histogramas no tempo dos IPIs de estímulo em função do tempo usados em Gymnotus carapo. As cores indicam a probabilidade de ocorrência dos IPIs: vermelho significa que a probabilidade é alta, amarelo a probabilidade é um pouco mais baixa e azul escuro é quase nula. A cima: histograma dos IPIs pré-gravados de um peixe. Até os 28 min da série os IPIs mais prováveis estão ao redor de $18 \mathrm{~ms}$ e nos últimos $2 \mathrm{~min}$ ao redor de $21 \mathrm{~ms}$. A baixo: histograma dos IPIs aleatórios entre 15 e $20 \mathrm{~ms}$. Todos os IPIs tem a mesma probabilidade de ocorrência neste intervalo.

Modificamos a amplitude dos estímulos para simularmos afastamento (quando a amplitude diminui), aproximação (quando a amplitude aumenta) ou mesmo peixes de tamanhos diferentes, por exemplo, estímulos de $1 \mathrm{~V}$ representam peixes de tamanho menores do que os de $5 \mathrm{~V}$.

Para tal, usamos uma série $10 \mathrm{~min}$ da série de IPIs pré-gravada. Para variar a amplitude, dividimos essa série de IPIs em pequenas janelas de $20 \mathrm{~s}$. Em cada janela, sorteamos a amplitude do sinal do estímulo que poderia ser: constante de $1 \mathrm{~V}$, constante de $5 \mathrm{~V}$, aumentando linearmente de $1 \mathrm{~V}$ a $5 \mathrm{~V}$ ou então diminuindo linearmente de $5 \mathrm{~V}$ a $1 \mathrm{~V}$. 


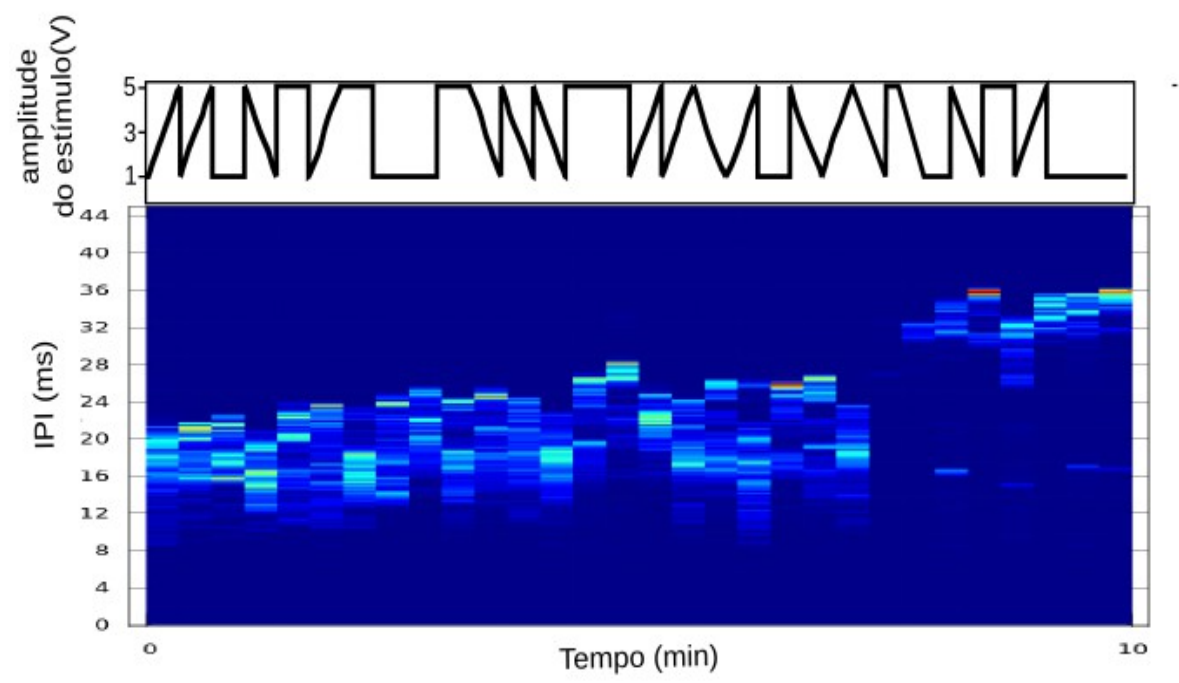

Fig. 13:Amplitude dos estímulos (preto). Eles podiam ser crescentes de $1 \mathrm{~V}$ a $5 \mathrm{~V}$, decrescentes de $5 \mathrm{~V}$ a $1 \mathrm{~V}$, constante de $1 \mathrm{~V}$ ou constante de $5 \mathrm{~V}$. Histogramas no tempo dos IPIs pré-gravados de um Gymnotus carapo vs tempo. Foi associado um código de cor para a probabilidade dos IPIs, vermelho (20\%), amarelo (15\%), ciano(10\%), azul escuro(0\%), de alta a baixa probabilidade. Nos primeiros 7 min, o peixe disparou IPIs de $8-28$ ms e nos 3 min finais, os IPIs se tornaram maiores de $28-40 \mathrm{~ms}$ com alguns perto de $16 \mathrm{~ms}$.

\subsection{2- Para Gnathonemus petersii}

Usamos pulsos de estímulo elétrico com a forma de onda característica da espécie e com amplitude de 1 a $7 \mathrm{~V}$ (quase 3x maior que a amplitude de um peixe de tamanho médio $\sim 12 \mathrm{~cm}$ ). Para gerar o pulso, pré-gravamos o formato da onda de um peixe imóvel através de um dipolo com uma de suas pontas perto da cabeça e a outra perto da cauda. Gravavamos 50 pulsos e calculamos a forma de onda média e usamos essa onda média em nossos experimentos.

Quando os estímulos foram enviados por hardware o formato da onda do pulso foi construído, usando circuitos eletrônicos analógicos, para ter a mesma forma e duração de um pulso característico da espécie e a amplitude podia ser controlada de 0 a $10 \mathrm{~V}$.

Estímulos luminosos também foram usados sendo estes controlados por hardware. Nossos estímulos luminosos consistiram de uma série de LEDs de potência total luminosa de $90 \mathrm{~lm}$, $\left(\mathrm{n}^{\mathrm{o}}\right.$ ref. RS 
7158409; http://docs-europe.electrocomponents.com/webdocs/0eae/0900766b80eae9ff.pdf) dispostos em um círculo de $31 \mathrm{~mm}$ de diâmetro (Fig. 8) que eram ligados ou desligados com frequência periódica ou dependente da atividade do peixe: um pulso de luz foi produzido imediatamente depois de detectado um pulso do peixe (Fig.9B).

A série longa de IPIs reais usada como estímulo foi previamente gravada durante 15 min de um peixe que tinha acabado de ser posto no aquário. Essa série tem IPIs de 20 a $500 \mathrm{~ms}$, apresentando uma distribuição de probabilidades com picos em $120 \mathrm{~ms}, 180 \mathrm{~ms}$ e $280 \mathrm{~ms}$ (Fig. 14). Sua evolução temporal pode ser vista na figura15.

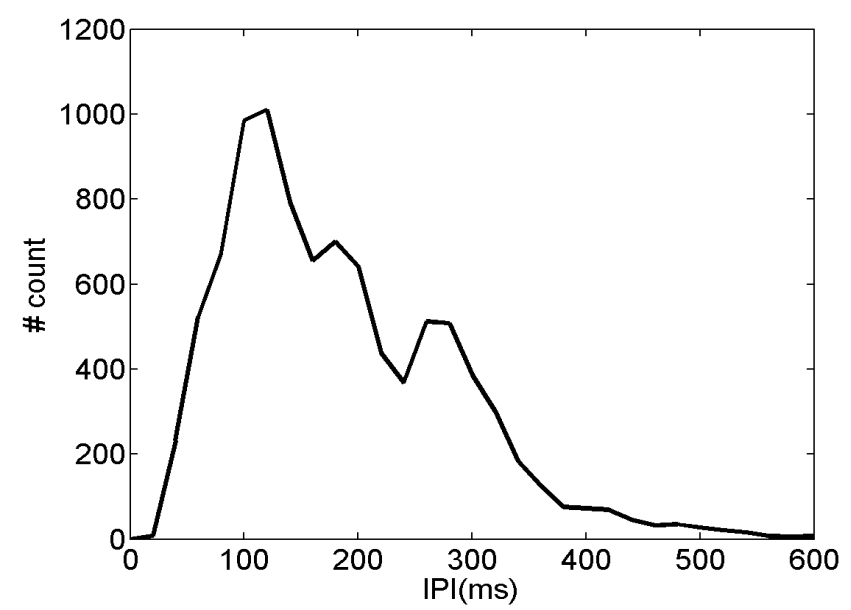

Fig. 14: Histograma da série de IPIs enviada a Gnathonemus petersii como estímulo. A série apresentou IPIs de 20 - 500 ms, sendo 120 ms, 180 ms e 280 ms os IPIs mais disparados. 


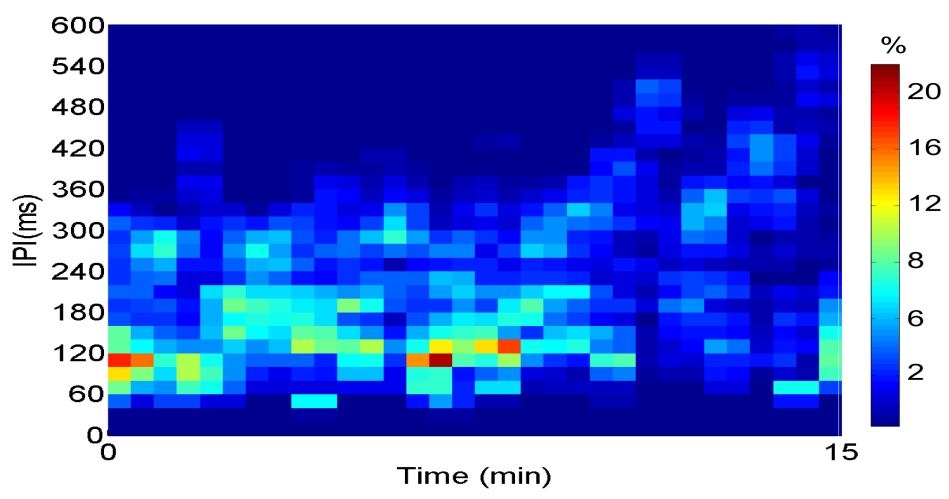

Fig.15: Histograma no tempo da série de IPIs pré-gravados de Gnathonemus petersii enviada aos peixes como estímulo. A cor vermelha significa IPIs com alta probabilidade de ocorrência, a amarela significa alta probabilidade mas menor que a vermelha, a azul clara significa probabilidade média e azul escuro baixíssima probabilidade de ocorrência. Nos primeiros $10 \mathrm{~min}$ da série, havia maior probabilidade de encontrarmos IPIs menores que $180 \mathrm{~ms}$, especialmente de $120 \mathrm{~ms}$. Nos últimos $5 \mathrm{~min}$ os IPIs ficaram maiores chegando a 600 ms. Nos últimos segundos da série o peixe voltou a disparar IPIs menores, entre $60-180 \mathrm{~ms}$.

Nos experimentos em que os estímulos elétricos dependiam da posição do peixe no aquário (Fig.10), usamos séries de 1s com IPIs periódicos com valores 1, 2, 3, 10, 40, 50, 90, 120 e 150 ms, bem como cossenos de $500 \mathrm{~Hz}$ e $1000 \mathrm{~Hz}$ com amplitudes de $1 \mathrm{~V}$ e $7 \mathrm{~V}$.

\section{5 - Análise de dados}

\subsection{1- Caracterização do comportamento elétrico}

Para analisarmos as reações dos peixes em relação às mudanças no ambiente e quando submetidos a diversos estímulos, medimos os intervalos entre os disparos do OE. O comportamento elétrico, ou seja, os IPIs, foi caracterizado usando histogramas de IPIs simples e no tempo, os quais nos permitem acompanhar como as probabilidades evoluem com o passar do tempo. Quando nos referimos ao passar do tempo, queremos dizer em pequenos intervalos ao longo do tempo, para tal dividimos as 
séries de dados em pequenas "janelas" de tempo.

Os tamanhos das janelas escolhidos dependentes do nível de detalhe que queremos ver as variações nas frequências e também do custo computacional, por exemplo, em experimentos que duram dias, usamos janelas maiores do que para experimentos que duram $30 \mathrm{~min}$.

Para os histogramas no tempo, dividimos a série de EODs em pequenas janelas de $20 \mathrm{~s}, 40 \mathrm{~s}$, $120 \mathrm{~s}$ ou $300 \mathrm{~s}$ dependendo do experimento e calculamos o histograma de IPIs simples para essas janelas, por exemplo, para janela de $40 \mathrm{~s}$, a primeira janela vai de $0 \mathrm{~s} \mathrm{a} 40 \mathrm{~s}$, a segunda janela 'anda' um passo que é a metade do tamanho total da janela, então ela vai de $20 \mathrm{~s}$ a $60 \mathrm{~s}$ e assim por diante até atingirmos o fim da série.

Para visualizarmos os histogramas dessas pequenas janelas, associamos um código de cor para as probabilidades dos IPIs, da maior para a menor: vermelho, amarelo, vermelho, ciano e azul-escuro.

Fizemos também histogramas usando o intervalo entre um pulso do estímulo e o pulso do peixe, ou seja, o intervalo em que o peixe dispara depois de ter recebido um estímulo (PST, do inglês Post Stimulus Time; Fig.16)

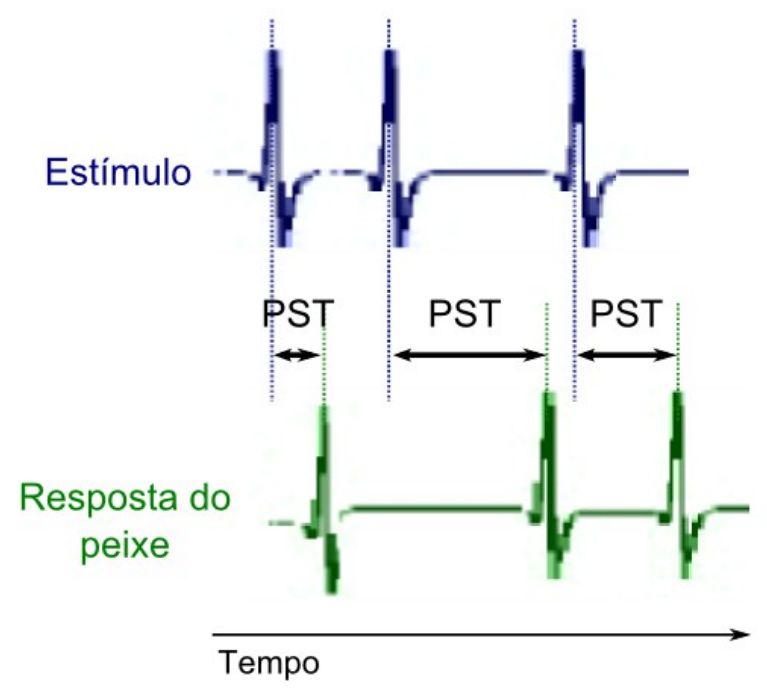

Fig. 16:Post Stimulus Time (PST).O PST foi definido como o tempo entre o peixe receber um estímulo (pulsos em azul) e responder a esse estímulo (pulsos em verde).

Para compararmos se 2 conjuntos de dados vêm de populações com a mesma distribuição, 
usamos análises de gráficos quantil-quantil (q-q plot). Os gráficos de q-q plots são uma ferramenta poderosa para comparar 2 ou mais conjuntos de medidas (Wilk \& Gnanadesikan, 1968; Cleveland, 1993).Um dos modos mais eficientes de comparar mudanças nas distribuições é comparar os quantis correspondentes, 2 distribuições são comparadas fazendo o gráfico dos quantis de uma distribuição contra os quantis de outra.

Os quantis são ferramentas de visualização de distribuições. O $f$ quantil, $q(f)$, de um conjunto de dados é o valor com a propriedade que aproxidamente uma fração $f$ dos dados são menores ou iguais a $q(f)$. O quantil 0,25 é chamado quantil inferior, o 0,5 quantil é a mediana e o 0,75 quantil é o quantil superior. Os quantis são uma excelente ferramenta porque os valores $f$ proporcionam um padrão para comparações, por exemplo, podemos comparar distribuições com os mesmos valores de $f$.

Supondo que existam 2 conjuntos de medidas para ser comparados, onde $x_{(1)}, x_{(2)} \ldots, x_{(n)}$ é o primeiro conjunto ordenado em ordem crescente e $y_{(1)}, y_{(2)} \ldots, y_{(m)}$ é o segundo conjunto também ordenado por ordem crescente. Supondo $m \leqslant n$. Se $m=n$, então $y_{(i)}$ e $x_{(i)}$ são ambos $\frac{(i-0,5)}{n}$ quantis dos seus respectivos conjuntos de dados, então o q-q plot será o gráfico de $y_{(i)}$ contra o de $x_{(i)}$, ou seja, os valores ordenados de um conjunto contra o de outro conjunto. Se $m<n$, então construimos o gráfico de $y_{(i)}$ contra o $\frac{(i-0,5)}{m}$ quantil dos dados $x$, que pode ser calculado com uma interpolação.

Junto com q-q plot, há também, como referência, uma linha reta preta em $45^{\circ}$. E outra linha reta vermelha, ligando o $1^{\circ}$ e $3^{\circ}$ quartis, e a linha pontilhada vermelha é a extrapolação da reta vermelha, para testar a linearidade dos conjuntos. Se os conjuntos de dados vêm de distribuições que só diferem na posição, os pontos estarão alinhados com a reta referência mas deslocados para cima ou para baixo. Se o q-q plot seguir a reta vermelha mas não for paralelo a reta de $45^{\circ}$, então os conjuntos vêm de distribuições parecidas mas com diferentes dispersões. Essa ferramenta tem a vantagem de que os conjuntos de dados não precisam ser do mesmo tamanho e que podemos testar múltiplos aspectos das distribuições como: mudanças na escala, na posição, na simetria e presença de outliers. 


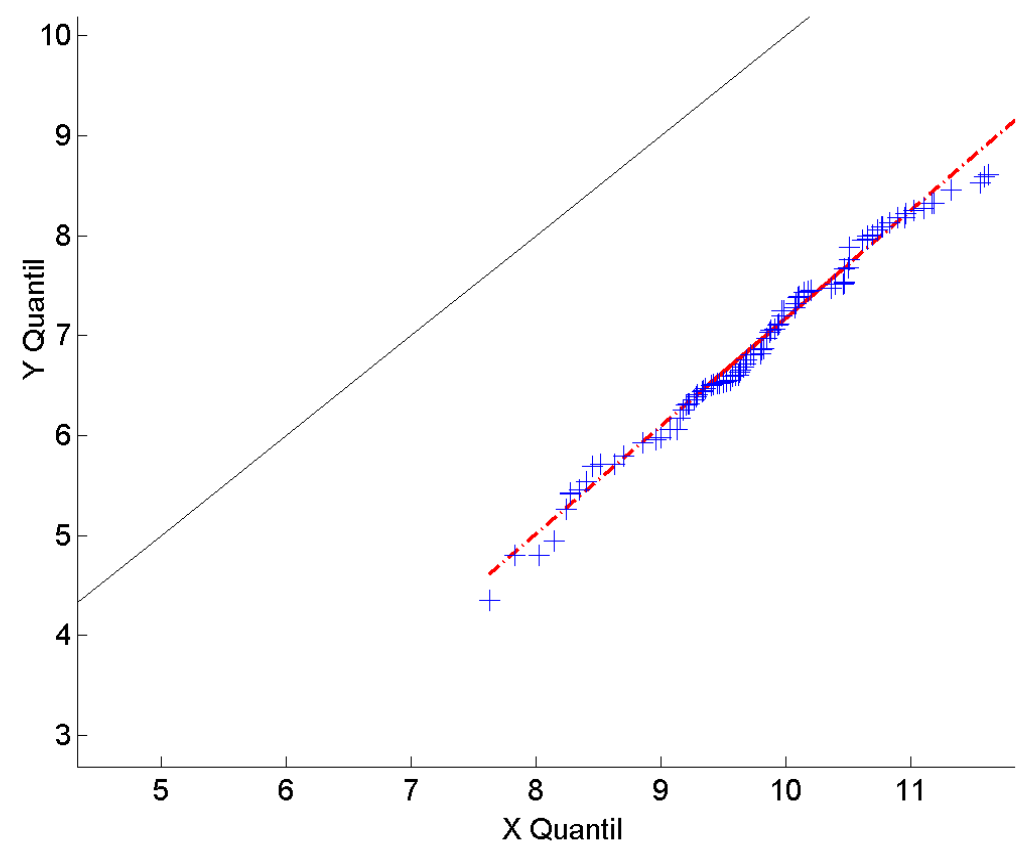

Fig. 17:Q-q plot de 2 conjuntos, $X$ e $Y$, de números aleatórios gerados com distribuição normal. $O$ conjunto $X$ com média 10 e desvio padrão 1 e o conjunto $Y$ com média 7 e desvio padrão 1.A linha preta é a reta $45^{\circ}$ onde $x=y$. Os pontos em azuis são elementos dos conjuntos X e Y, o par $\left(x_{i}, y_{i}\right)$ possui o mesmo quantil $i$ $0.5 / n$, sendo $n$ o tamanho do conjunto. A linha vermelha conecta o $1^{\circ}$ e o $3^{\circ}$ quartis, $e$ a linha pontilhada vermelha é uma extrapolação da linha vermelha. Como os pontos seguem a reta vermelha, podemos dizer que os dados vêm de uma população com distribuições parecidas, por serem lineares, o ângulo da reta nos dá o desvio padrão, que no caso é 1 . Por estarem paralelas a reta $x=y$, sabemos que as distribuições não possuem a mesma média. Os pontos se encontram abaixo da reta $x=y$, ou seja, $x_{i}$ é sempre maior que $y_{i}$ e a distância entre a reta $x=y$ e a reta vermelha é a distância entre as médias, no caso 3.

Todos os programas foram desenvolvidos em GNU Octave, Matlab (The Mathworks Inc., Natick, MA), Linux eLinux RTAI APIs.

\subsection{2- Posição no aquário e inferência da movimentação através das descargas elétricas}


O aparato experimental permite estudar o comportamento elétrico e motor ao mesmo tempo pois a voltagem induzida em cada eletrodo é sensível à posição de peixe no aquário. Usamos a soma do desvio padrão das amplitudes em todos os 7 dipolos, sendo esse calculado em janelas de $40 \mathrm{~s}$ ou $300 \mathrm{~s}$ como descrito na seção 2.5.1- pág. 24 para comparação direta com os histogramas de IPIs no tempo.

Inferimos a posição do peixe no aquário a partir da medida da amplitude máxima dos pulsos medida em cada eletrodo. Em geral quando o peixe está mais próximo de um certo eletrodo, a amplitude negativa e positiva do pulso medidas neste eletrodo é maior do que as medidas nos demais eletrodos. Quando a amplitude positiva foi maior que 95\% da negativa, inferimos que a cabeça do peixe estava mais próxima desse eletrodo. Entre os demais eletrodos verificamos qual possui a amplitude negativa mais alta (em módulo) e inferimos que a cauda está mais próximo deste eletrodo. Se as amplitudes dos demais eletrodos forem próximas entre si, isso significa que a cauda do peixe está perto do eletrodo de referência. Nós inferimos somente que o peixe está próximo a certo eletrodo mas não a qual distância ele estaria.

Na figura 18 mostramos 4 pulsos, de um experimento real, medidos nos 7 dipolos do aparato experimental de Gymnotus carapo. As bolinhas vermelhas representam a amplitude máxima positiva medida em cada pulso e as negras são as amplitudes máximas negativas em cada pulso, nas figuras vemos 4 pulsos sequências. Olhando para as medidas gravadas no eletrodo 4 vemos que o primeiro pulso tem amplitude positiva de $3,45 \mathrm{~V}$ e negativa de $-3,35 \mathrm{~V}$. A amplitude positiva é $3 \%$ maior que a amplitude negativa, então inferimos que a cabeça está mais próxima ao eletrodo 4. As amplitudes negativas nos demais eletrodos $(2-3,5-7)$ são parecidas e altas $(\sim 0.5 \mathrm{~V})$, então inferimos que a cauda do peixe está perto do eletrodo de referência. Os sinais medidos nos dipolos podem saturar se o peixe está muito próximo a algum eletrodo prejudicando as medidas das amplitudes levando a inferirmos erroneamente a posição da cabeça e da cauda.

Gravamos um vídeo do peixe se movendo livremente no aquário e colocamos círculos vermelhos indicando qual eletrodo a cabeça está mais próxima e círculos pretos indicando qual eletrodo a cauda está mais próximo. O vídeo, o programa e os arquivos com os tempos de disparo do peixe e as amplitudes medidas em cada eletrodo podem ser acessados em http://hal9k.ifsc.usp.br/ quel/

Todos os programas foram desenvolvidos em GNU Octave e Matlab (The Mathworks Inc., Natick, MA). 

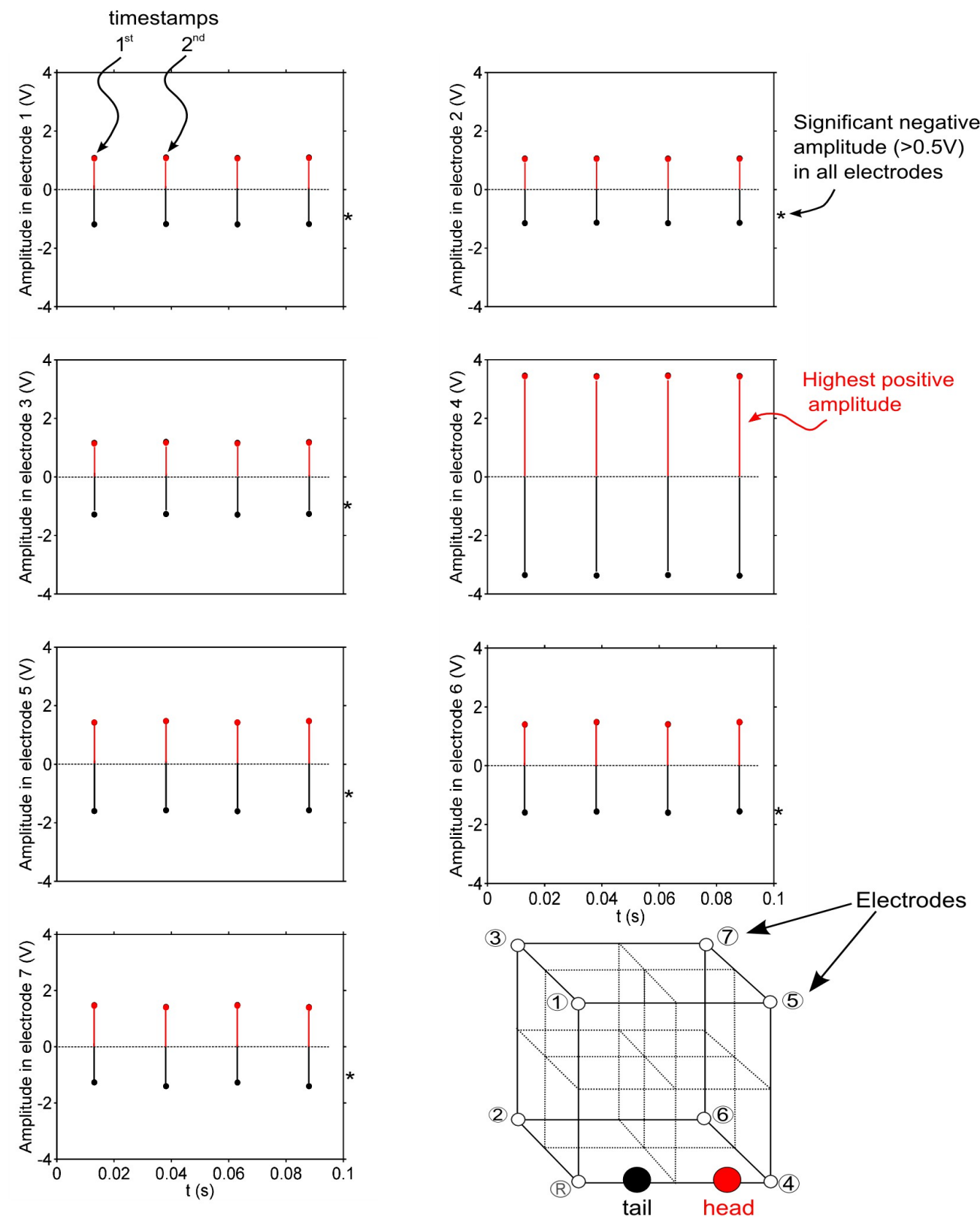

\section{Position inferred based on the pulse amplitudes}

Fig. 18: Como inferir a posição de Gymnotus carapo através das medidas das amplitudes nos 7 dipolos. Mostramos 4 pulsos medidos nos 7 dipolos. Em vermelho estão a parte positiva do pulso e em preto a parte negativa. $O$ cubo à direita mostra a localização dos eletrodos no aquário. Para inferirmos a qual eletrodo o peixe está mais próximo precisamos buscar a amplitude positiva mais alta, que neste exemplo foi medida no dipolo 4. O primeiro pulso nesse eletrodo tem amplitude positiva de 3,45 Ve negativa de -3,35 V. Como a amplitude positiva é maior que a negativa inferimos que a cabeça do peixe se encontra mais próxima ao eletrodo 4 (bola vermelha). Para inferirmos a posição da cauda, verificamos as amplitudes negativas nos demais eletrodos $2-3$ e $5-7$. Nesse exemplo elas são parecidas e bastante altas $(\sim 1,5 \mathrm{~V})$ em todos os dipolos, isso significa que a cauda está mais próximo a referência (bola preta). 


\subsection{3- Teoria da Informação}

Os peixes elétricos pulsadores variam a frequência do OE dependendo do ambiente e em contato com outros peixes, padrões de descargas dos peixes (Kramer \& Bauer, 1976; Carlson, 2002; Gebhardt et al., 2012) estão correlacionadas com eventos externos, que podem ser tanto um novo ambiente quanto a presença de conspecíficos. A Teoria da Informação leva em conta as probabilidades de eventos acontecerem, no caso dos peixes os eventos são os tempos de disparo do OE, e nos permite correlacioná-los com os diversos tipos de estímulo e quantificar essa relação ou dependência. A Informação mútua é mais interessante do que a correlação simples porque captura dependencias não lineares.

$\mathrm{Na}$ Teoria da Informação (Shanon, 1948) o significado de um evento (ou sem sinal) não é importante em si, mas sim a probabilidade $P(x)$ de que um determinado evento $x$ ocorra ( de Ruyter van Steveninck et at., 1998; Borst \& Theunissen, 1999; Rieke et al., 1999; Cover \& Thomas, 2006). A informação de um evento é definida como sendo $\log _{2} \frac{1}{P(x)}$, log na base 2 porque normalmente é usada a unidade arbitraria bits (0 ou 1) e a função log porque é a única função matemática capaz de transformar multiplicação de probabilidades em somas de informação como é necessário para a teoria. Quando um evento tem uma baixa probabilidade de ocorrer, a informação sobre o evento é maior que a informação de um evento que possui maior probabilidade de ocorrer.

Assumindo que tenhamos uma série de eventos $x$, pertencente ao conjunto ( $\operatorname{sinal}_{1}, \operatorname{sinal}_{2}, \ldots$, $\left.\operatorname{sinal}_{n}\right)=X$. A entropia é definida como o valor médio da informação de todos os eventos, e é expressa por

$$
H(X)=-\sum_{x} P(x) \log _{2} P(x)
$$

$H(X)$ é grande se o sistema possuir muitos estados com a mesma probabilidade de ocorrência (alta variabilidade), por outro lado será nula se e somente se o sistema permanecer em um único estado. A entropia é assim sempre maior ou igual a zero.

A Informação Mútua é um método de determinar se a variabilidade da resposta é correlacionada com a variabilidade do estímulo. Para calcular a informação mútua é necessário comparar as diversas 
respostas devido à aplicação de diferentes estímulos. A informação $i$ entre um estímulo $s$ pertencente a $S$ e uma resposta $r$ pertencente a $R$ é definida como

$$
i(s, r)=\log _{2}\left(\frac{p(s, r)}{p(s) p(r)}\right),
$$

onde $p(s, r)$ é a probabilidade conjunta de ocorrerem o estímulo $s$ e a resposta $r$. A Informação Mútua Média (AMI, inglês Average Mutual Information) é a média da informação contida em todos os possíveis eventos:

$$
A M I(S, R)=\sum_{s, r} p(s, r) i(s, r),
$$

que também pode ser expressa por

$$
A M I(S, R)=H(R)-H(R \mid S)
$$

onde $H(R \mid S)$ é a entropia condicional da resposta em função do estímulo. A Informação Mútua Média é sempre maior ou igual a zero. A AMI é simétrica, ou seja $\mathrm{AMI}(\mathrm{S}, \mathrm{R})=\mathrm{AMI}(\mathrm{R}, \mathrm{S})$, ela apenas mostra a informação que os sinais tem em comum sem indicar qual a direção em que a informação se propaga.

Na Figura 19 mostramos como obtemos a AMI para as séries temporais de EODs do estímulo e do peixe: $A(t)$ e $B(t)$. Como a AMI é simétrica pela troca de A e $\mathrm{B}$, utilizamos um parâmetro de atraso entre as séries de pulsos de A e B que permite inferirmos a causalidade: se ocorre um pico de AMI para atraso positivo (negativo) $\rightarrow$ B (A) responde a A (B). Quando o pico ocorre para atraso nulo, nada podemos afirmar sobre a causalidade. 


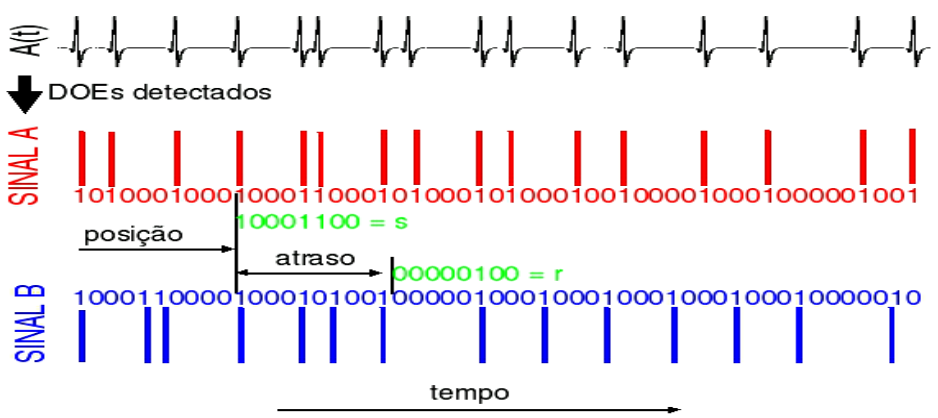

Fig. 19: Exemplo de um pequeno trecho do comportamento de disparos de dois peixes elétricos e o esquema utilizado para codificar a posição das EODs. SINAL A e SINAL B correspondem as EOD do estímulo e do peixe, respectivamente. As séries de disparo, por exemplo A(t), são divididas em um grande número de pequenos intervalos de igual duração $\Delta t$. Elas são, então, transformadas em longas strings de bits 0 ou 1: se dentro de um intervalo ocorreu um disparo um bit 1 é atribuido aquela posição, caso contrário, um bit 0 é atribuído. Partindo do início das duas strings (posição $=0)$ um número arbitrário de bits (no exemplo $=8$ bits) é extraído do SINAL A (estímulo $=s$ ) e o mesmo número de bits (resposta $=r$ ) é extraído do SINAL B pulando um intervalo de atraso (arbitrariamente escolhido para permitir uma relação de causalidade). Incrementando-se sucessivamente o contador posição obtêm-se um grande conjunto de pares (s,r) que é usado para calcular a AMI entre os sinais. $\Delta$ t e o número de bits usado em s e $r$ devem ser escolhidos de modo a maximizar a entropia dos conjuntos $\{s\}$ e $\{r\}$.

A série temporal dos disparos é inicialmente dividida em um grande número de pequenos intervalos de igual duração $\Delta \mathrm{t}$ e é então transformada em uma longa string de bits 0 ou 1 (se dentro de um intervalo $\Delta \mathrm{t}$ ocorreu um disparo, um bit 1 é atribuído àquela posição, caso contrário, um bit 0 é atribuído). Partindo do início das duas strings (posição $=0$ ) um número arbitrário de bits é extraído do SINAL A e atribuído ao elemento $s$ (posição) do conjunto $\{s\}$. Saltando um intervalo de atraso (arbitrariamente fixado para permitir uma relação de causalidade) o mesmo número de bits é extraído do SINAL B e atribuído ao elemento $r$ (posição) do conjunto $\{r\}$. Incrementando-se sucessivamente o contador posição obtêm-se um grande conjunto de pares $(s, r)$ que é usado para calcular a AMI entre os sinais. $\Delta$ t e o número de bits usados em $s$ e $r$ são arbitrários e serão escolhidos de modo a maximizar a entropia dos conjuntos $\{s\}$ e $\{r\}$.

Como a teoria da informação nada afirma sobre a direção do fluxo de informação, sempre que possível utilizaremos eventos que ocorrem em uma sequência causal (usando o parâmetro atraso).

Nós analisamos cada série de disparos em janelas de $\mathrm{T}=20 \mathrm{~s}$ até $300 \mathrm{~s}$ (como descrito na seção 
2.5.1- pág. 24), por exemplo para a janela de 300s, a primeira janela vai de 0 a $300 \mathrm{~s}$ a segunda de $150 \mathrm{~s}$ a $450 \mathrm{~s}$, assim por diante até o final da série.

Em nossas análises, em cada janela de $300 \mathrm{~s}$, formamos palavras de 4 a 8 bits dependendo do experimento. As probabilidades são calculadas em cima dessas palavras. As palavras (w) dos conjuntos de estímulos $\mathrm{S}(\mathrm{w})$ e de respostas $\mathrm{R}(\mathrm{w})$ são formadas de acordo com o seguinte exemplo (b bits): os bits de 1 a 8 da série binária formam a primeira palavra $\left(\mathrm{w}_{1}\right)$; os bits de 2 até 9 , a palavra $\left(\mathrm{w}_{2}\right)$ e assim, sucessivamente, até o final da série. A entropia é calculada usando a expressão (1) e a informação mútua média de acordo com a expressão (4).

Uma vez que a AMI não diz nada a respeito da direção do fluxo da informação (causalidade), também calculamos a AMI entre janelas de estímulo e janelas de resposta com um atraso de até $5 \mathrm{~s}$ entre elas.

Todos os programas foram desenvolvidos em C++ e em Matlab (The Mathworks Inc., Natick, MA).

\subsection{4- Análise estatística}

Para determinar se as populações eram provenientes de distribuições normais, usamos o teste de Shapiro-Wilk. O teste de Levene foi usado para determinar a homogenidade das variâncias. No caso de uma grande desvio da normalidade ou na heterogeneidade das variâncias, foram usados testes nãoparamétricos. Para compararmos 2 grupos, quando não pareados, usamos Mann-Whitney-U e Wilcoxon quando pareados. No caso de 3 ou mais grupos pareados, o teste de Friedman e testes de múltipla comparação.Em todos os testes foram considerados nível de significância de $5 \%$.

As análises estatísticas e programas foram desenvolvidos no Matlab (The Mathworks Inc., Natick, MA). 


\section{3 - Resultados}

\section{1 - Experimento de 48 h sem estímulo}

\subsection{1- Gymnotus carapo}

Os experimentos de longa duração ( $48 \mathrm{~h}$ ) foram feitas de maneira não invasiva respeitando o ciclo de luz dia/ noite. As medidas começaram logo após o peixe ser introduzido no aquário. Os tempos de cada disparo do órgão elétrico e a sua amplitude foram detectados e gravados. Depois do experimento os peixes foram devolvidos ao aquário residência. Foram usados 3 peixes no total.

Todos os peixes apresentaram um período transiente caracterizado por IPIs mais curtos com apenas um pico na distribuição de probabilidades durante o qual permaneceram em intensa movimentação no aquário (comportamento exploratório). $\mathrm{O}$ transiente durou em média $(10,2 \pm 4,8) \mathrm{h}$.

Passado o transiente exploratório, os peixes dispararam IPIs mais longos agora com dois picos na distribuição de IPIs. Os IPIs curtos estavam associados aos peixes em movimento, enquanto que os IPIs maiores estavam relacionados com os peixes parados no aquário.

A variabilidade dos IPIs, ou seja, a entropia, também estava associada com o movimento dos peixes, quando se moviam mais, a entropia aumentava (correlação de até $80 \%$ ). Já quando os peixes estavam parados, a entropia, em diversos momentos, caiu a 0 permanecendo próximo desse valor por horas, isso significa que os peixes estavam disparando IPIs regulares.

Os peixes apresentaram interrupções espontâneas dos disparos tanto no período transiente quanto quando já estavam habituados ao aquário. As interrupções mais longas (até 5,3 s) nos disparos ocorrem com maior frequência quando os peixes já estavam habituados ao aquário.

Mostramos um exemplo com os comportamentos descritos acima na Fig.20. Durante o período transiente o peixe apresentou IPI de $24-33 \mathrm{~ms}$ (Fig.20A). Depois de habituado ao aquário o peixe apresenta distribuição de IPIs com dois picos: em 27 ms e em $42 \mathrm{~ms}$ e a distribuição se tornou mais larga com IPIs disparados de 21 - 43 ms (Fig.20B). No histograma no tempo (explicado na seção 2.5.1- pág. 24) vemos um período transiente de aproximadamente $7 \mathrm{~h}$ com IPI médio de 27,5 ms, após o qual os IPIs passam a se alternar entre $27 \mathrm{~ms}$ e $42 \mathrm{~ms}$ depois que o peixe se habituou ao aquário (Fig. 20C). 

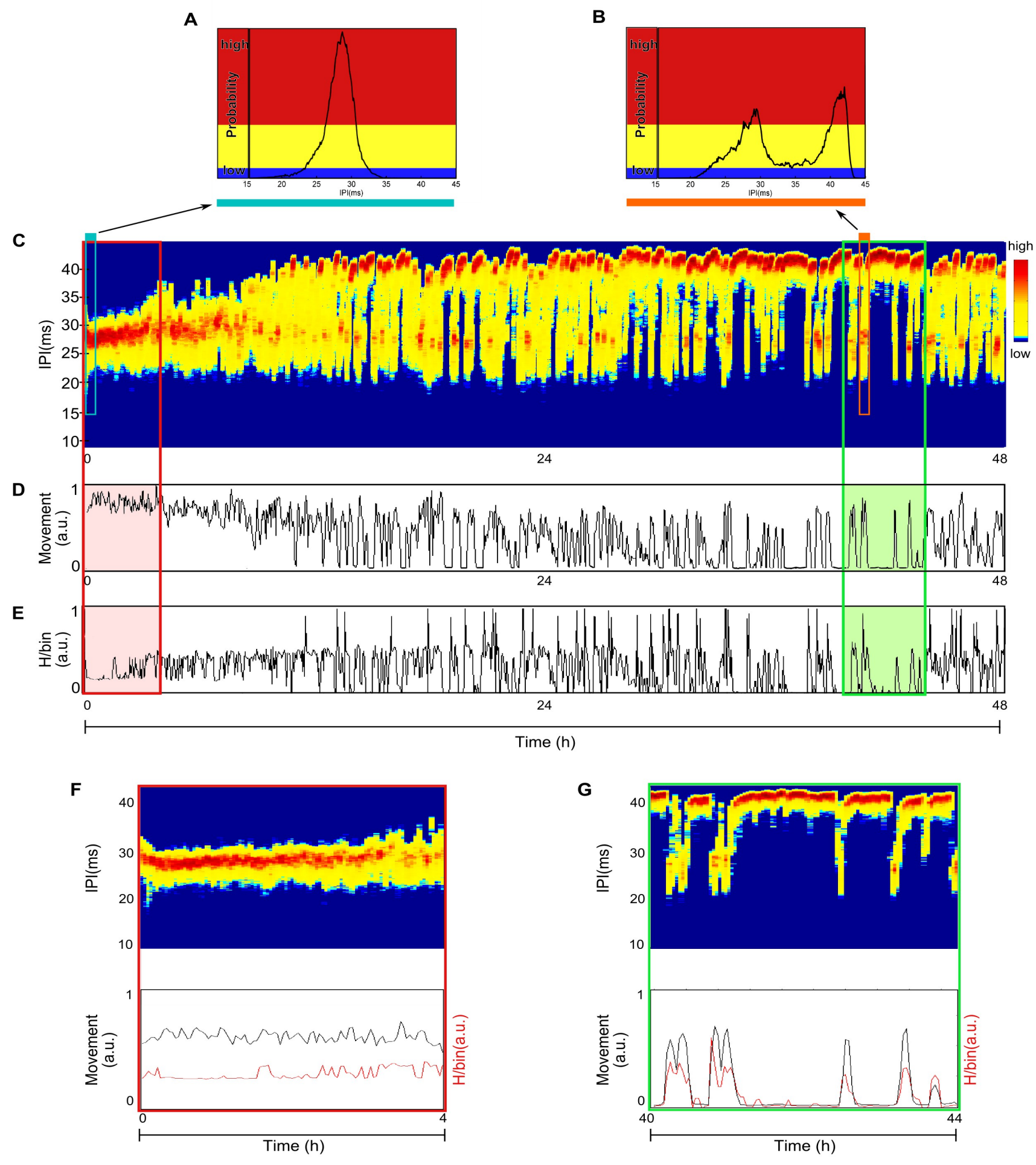
Fig.20: Atividade elétrica e motora gravada por 48 h com Gymnotus carapo sem estímulo. A e B - Histogramas de IPIs de um trecho do periodo transiente e de quando habituado respectivamente. O fundo de cor vermelha indica os IPIs disparados com alta probabilidade, amarelo mostra os IPIs disparados com média probabilidade e azul com baixissima probabilidade. No transiente, a distribuição de IPIs foi de $24-33 \mathrm{~ms}$, com IPI médio de 27,5 ms. Quando habituado ao aquário a distribuição dos IPIs se tornou maior de 21 - $43 \mathrm{~ms}$, com 2 valores mais prováveis: $27 \mathrm{~ms}$ e $42 \mathrm{~ms}$. CHistograma de IPIs no tempo (janela de tempo de $40 \mathrm{~s}$ ). O mesmo código de cores, explicado em A - B foi usado. Depois de um transiente de aproximadamente $7 \mathrm{~h}$ um houve um comportamento oscilatório de IPIs entre dois picos $27 \mathrm{~ms}$ e $43 \mathrm{~ms}$. D - movimento (desvio padrão das amplitudes dos pulos). Logo após a introdução do peixe no aquário sua movimentação foi intensa, depois de algumas horas o peixe relaxou e sua movimentação diminuiu, alternando em períodos de intenso movimento e parado (movimento $\sim 0$ ). E - entropia por bin versus tempo. Mudanças na entropia acompanharam a movimentação do peixe: quando este estava parado, a entropia era mais baixa chegando a zero, e quando ele começava a nadar a entropia aumentava. F - detalhe do histograma de IPIs durante o periodo de transiente evidenciando IPIs curtos de $\sim 30 \mathrm{~ms}$ (comportamento investigativo) e detalhe do movimento (linha preto) e da entropia por bin (linha vermelha) durante comportamento investigativo, em que o peixe se movimentava bastante e a entropia por bin era alta, ou seja, a variabilidade do sinal era grande. G-detalhe do histograma de IPIs onde o peixe já estava habituado ao aquário, com IPIs de 43 ms e detalhe do movimento em preto e da entropia por bin em vermelho durante comportamento relaxado, vimos que o desvio padrão foi a zero e a entropia por bin também, isso quer dizer que o peixe estava parado e com frequência de disparos do OE constante.

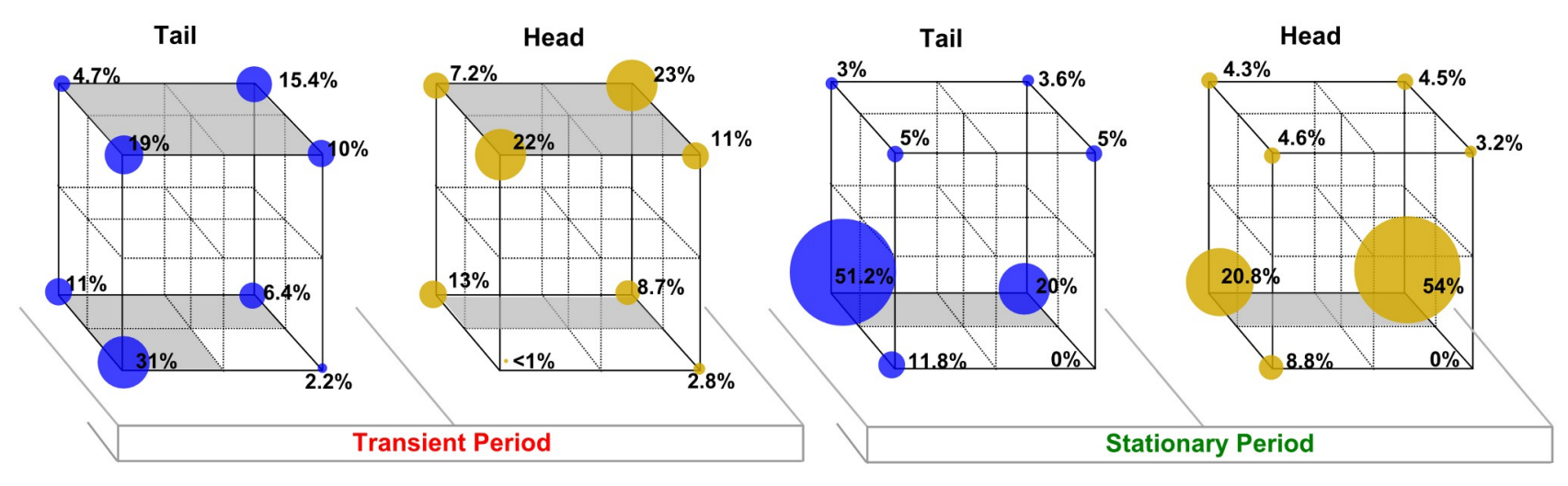

Fig. 21: Tempo que um exemplar de Gymnotus carapo ficou próximo a cada eletrodo no periodo transiente (à esquerda)e depois de habituado ao aquário (à direita). Esquerda: durante o período transiente o peixe nadou por todo o aquário (áreas em cinza). A parte menos visitada foi o eletrodo da direita na parede da frente do aquário, que o peixe passou com a cauda somente 2,2\% (círculo azul) do tempo e 2,8\% (círculo amarelo) do tempo com a cabeça. Direita: Depois de habituado o peixe preferiu o fundo do aquário com a cauda apontando para a parede esquerda em $51,2 \%$ (círculo azul) do tempo e a cabeça apontando para a parede direita em 54\% (círculo amarelo) do tempo. 
A movimentação do animal no aquário (Fig. 20D) também mudou ao longo do tempo. Durante as primeiras horas esta foi muito mais intensa e à medida que o peixe se habituava ao novo ambiente, ele passou a alternar momentos parados e momentos em movimento.

Quando o peixe se encontrava parado, notou-se que os intervalos entre disparos (IPIs) eram maiores $(\sim 42 \mathrm{~ms})$ do que quando estava nadando $(\sim 30 \mathrm{~ms})$.

As mudanças na entropia (Fig. 20E) acompanharam as mudanças na movimentação dos animais. Quando o peixe estava parado, a entropia era mais baixa chegando a zero (Fig. 20G), e quando ele começava a nadar a entropia também aumentava e vice-versa (Fig. 20F).

A correlação entre entropia e movimento para o período transiente (Fig. 22A) foi muito mais baixa, chegando no máximo a 35\% do que para o período já habituado (Fig. 22B) que chegou a 60 - 80 $\%$. Esse comportamento foi observado para todos os peixes medidos $(\mathrm{N}=3)$.

A

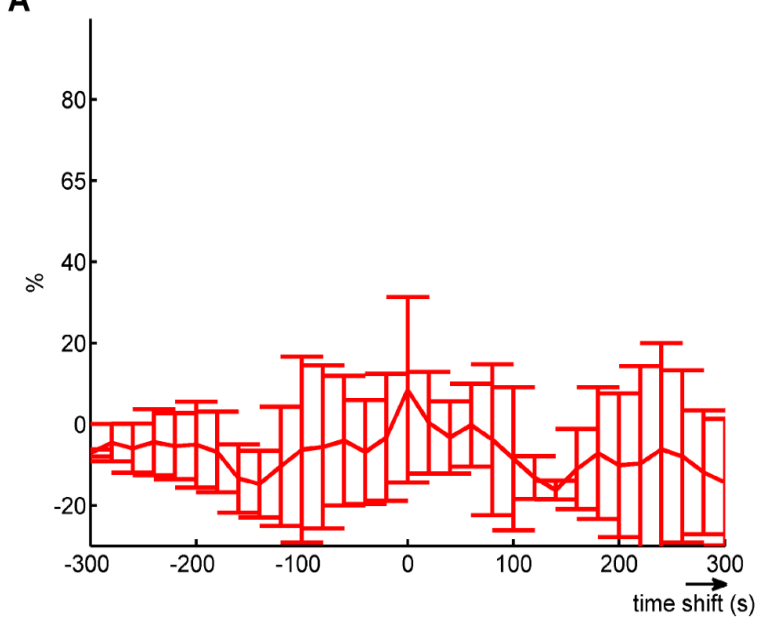

B

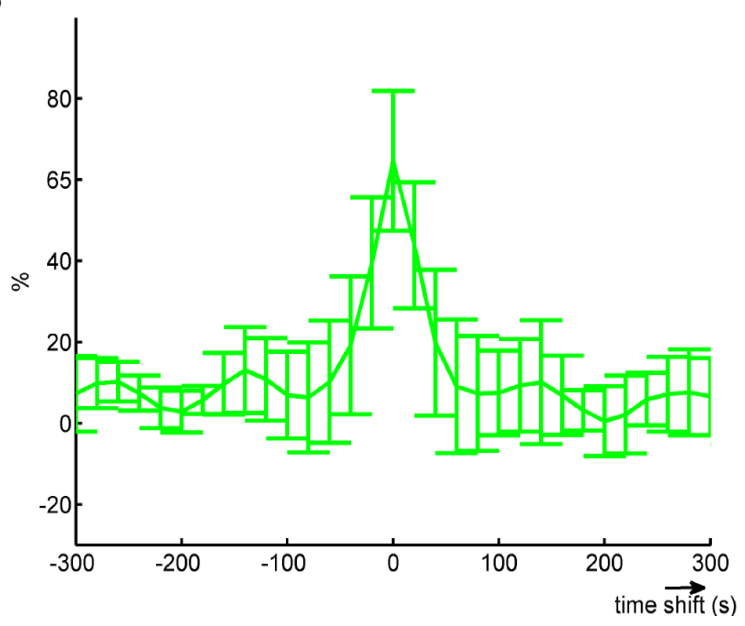

Fig. 22: Correlação média ( $N=3$ ) entre entropia e desvio padrão das amplitudes (movimento) de Gymnotus carapo. A-periodo transiente: a correlação apresentou em média valores baixos de no máx. 10\%, chegando a quase $35 \%$ para somente um indivíduo. $B$ - periodo habituada ao aquário. A entropia e o movimento estavam altamente correlacionados com valores de $60-80 \%$. Ao deslocarmos os sinais mais de $40 \mathrm{~s}$ notamos que a correlação cai a valores similares aos encontrados para o periodo transiente.

Inferindo a posição do peixe pelas amplitudes dos pulsos em cada eletrodo, como explicado em 2.5.2-pág.27 e na Fig. 18, verificamos que o peixe nadou por todo o aquário sem posição preferencial durante o período transiente (Fig. 21 - esquerda). Depois de habituado ao aquário o peixe mostrou 
preferência por ficar no fundo do aquário com a cauda à esquerda em 51,2 \% do tempo e com a cabeça à direita em 54\% do tempo (Fig. 21 - direita).

\subsection{2- Gnathonemus petersii}

As medidas longas (48 h) das EODs foram feitas de maneira não invasiva começando logo após os peixes serem introduzidos no aquário. A soma ao quadrado do sinal medido nos 5 dipolos foi gravada e os tempos de cada disparo do órgão elétrico foram detectados. Foram usados 3 peixes no total.

O comportamento elétrico dos peixes se caracterizou por IPIs altamente variáveis de 10 a 700 ms, em geral, as distribuições de IPIs apresentaram 2 ou 3 picos. Um desses valores era sempre abaixo de $100 \mathrm{~ms}$ e os demais entre 100 e $300 \mathrm{~ms}$ e, no caso de um terceiro valor mais provável, entre 300 e $500 \mathrm{~ms}$. Observamos um período circadiano de $12 \mathrm{~h}$ no qual aumenta a frequência de IPIs mais curtos durante a noite e de IPIs mais longos durante o dia, lembrando que esses peixes estão mais ativos durante a noite.

O comportamento elétrico muda consideravelmente quando os peixes começam a ficar doentes, como Gnathonemus petersii é uma espécie mais delicada do que Gymnotus carapo, eles adoecem mais facilmente mesmo sob um controle rigoroso das condições no aquário. Antes que os peixes tenham sintomas físicos de alguma doença, tais como pontos brancos, ou parem de comer e de se movimentar, eles deixam de emitir IPIs curtos e passam a emitir com maior frequência IPIs maiores de 400 a 700 ms.

Para ilustrar o comportamento de Gnathonemus petersii saudável, detalhamos o comportamento de um exemplar (Fig. 23). Nesse peixe vemos IPIs altamente variáveis de 15 a 500 ms (Fig. 23 Superior). Existem 3 classes principais de IPIs: $30 \mathrm{~ms}, 150 \mathrm{~ms}$ e $300 \mathrm{~ms}$. Observamos ciclos de aproximadamente $12 \mathrm{~h}$, como, por exemplo, de $4 \mathrm{~h}$ a $16 \mathrm{~h}$ onde o peixe tem maior probabilidade de disparar IPIs curtos entre $30 \mathrm{~ms}$ e $150 \mathrm{~ms}$ do que IPIs maiores ao redor de $300 \mathrm{~ms}$. Depois de 16 h até $26 \mathrm{~h}$, a probabilidade de disparar IPIs ao redor de $300 \mathrm{~ms}$ foi bem mais alta que no período anterior.

A entropia aumentou quando o peixe disparou mais IPIs curtos, perto de $30 \mathrm{~ms}$ (IPIs em vermelho e amarelo em Fig. 23-Superior e picos na Fig.23-Inferior). Esse aumento pode indicar que o peixe estava se movendo com mais intensidade como mostramos para Gymnotus carapo em Fig. 20 G. 
Nos ciclos de 12 h (4 - 16 h e $26-38$ h) onde há mais IPIs curtos, notamos que o valor da entropia oscila, e a amplitude dessas oscilações é maior do que no período de $16-26$ h e $38-48$ h que são períodos com IPIs mais longos.
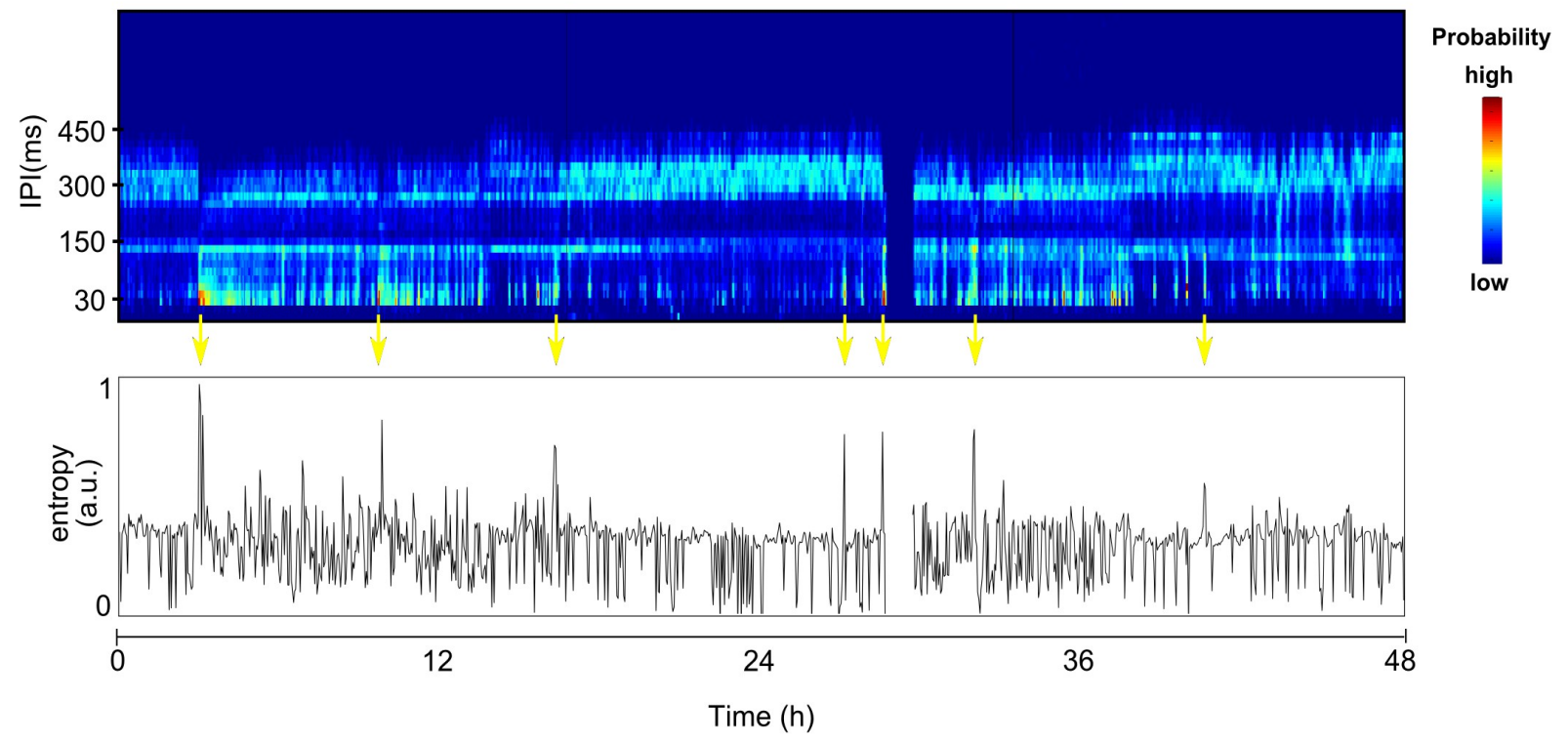

Fig. 23: Histograma de IPIs no tempo (janela de tempo de $120 \mathrm{~s}$ ) para um exemplar de Gnathonemus petersii sem estímulo. O código de cor indica a probabilidade de ocorrência dos IPIs: azul escuro significa baixíssima ocorrência (0\%), azul (5\%), ciano (10\%) amarelo(15\%) e vermelho (25\%)indicam IPIs de probabilidade mais alta. O peixe disparou IPIs entre $30-450 \mathrm{~ms}$. Notamos ciclos de mais ou menos $12 \mathrm{~h}$, como de $4 \mathrm{~h}$ a $16 \mathrm{~h}$ e $16 \mathrm{~h}$ a $26 \mathrm{~h}$ onde a probabilidade de disparar IPIs entre $30 \mathrm{~ms}$ e $150 \mathrm{~ms}$ é mais alta entre 4 - 16 h e a probabilidade de disparar IPIs mais longos entre $300 \mathrm{~ms}$ e $450 \mathrm{~ms}$. Depois de $30 \mathrm{~h}$ de medida o peixe ficou sem disparar por mais de $2 \mathrm{~h}$.

\section{2 - Evolução dos valores de IPIs mais prováveis durante 1 mês}

Todos os Gymnotus carapo, quando introduzidos em um novo ambiente, aumentaram sua frequência de disparo, ou seja, disparam mais IPIs curtos. Para investigar se os IPIs apresentariam sempre as mesmas distribuições de IPIs toda vez que o mesmo indivíduo fosse colocado no aquário de medidas, repetimos os experimentos a cada semana durante 1 mês. Os peixes eram retirados de seus aquários-dormitório e as medidas começavam logo após os peixes serem introduzidos no aquário. Estes experimentos duravam $30 \mathrm{~min}$. 
Não somente os valores mais prováveis dos IPIs (os picos) mudaram de experimento para experimento, a forma das distribuições também se alteraram. Em geral, nas primeiras semanas as distribuições apresentaram picos mais pronunciados e depois as distribuições aumentam de largura.

Mostramos um exemplo ilustrativo de Gymnotus carapo (Fig.24A). Na segunda semana o peixe disparou IPIs mais curtos do que na primeira semana mas passadas 4 semanas, os IPIs se tornaram maiores bem como a largura da distribuição. Cada peixe reagiu de maneira diferente, não é uma regra que na segunda semana o peixe dispare em média IPIs mais curtos do que na primeira semana. Essas mudanças nos IPIs também ocorreram de um dia para o outro, por exemplo, o peixe $\mathrm{C}$ mudou seus disparos médios de 22,2 ms para 24,8 ms e o peixe D mudou de 20,4 ms para 21,6 ms. As variações nos IPIs não são triviais nem parecem seguir nenhuma regra de proporcionalidade. 


\section{A}

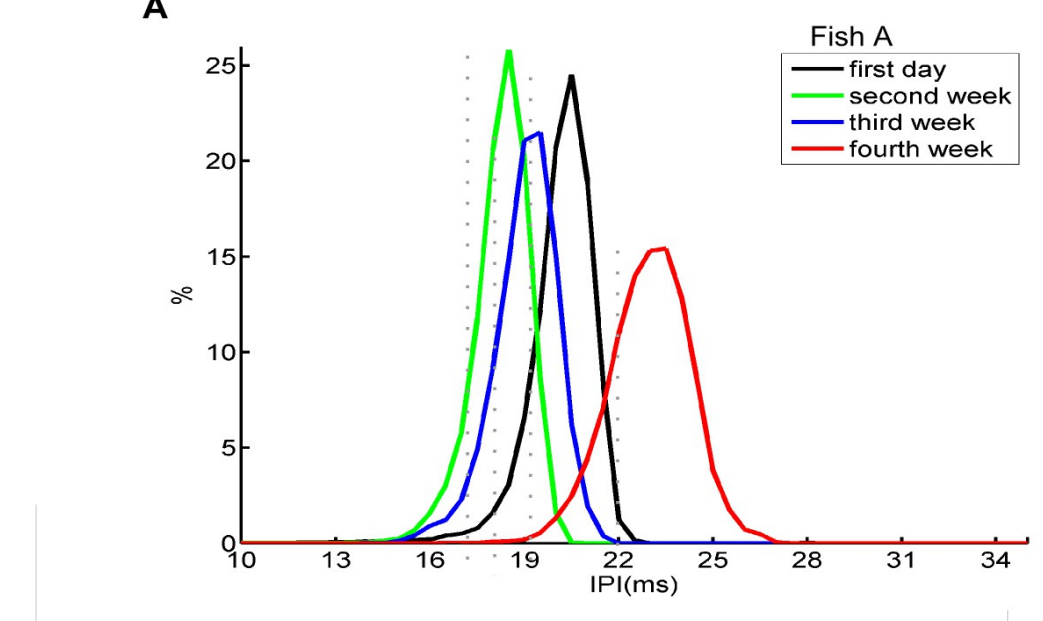

B

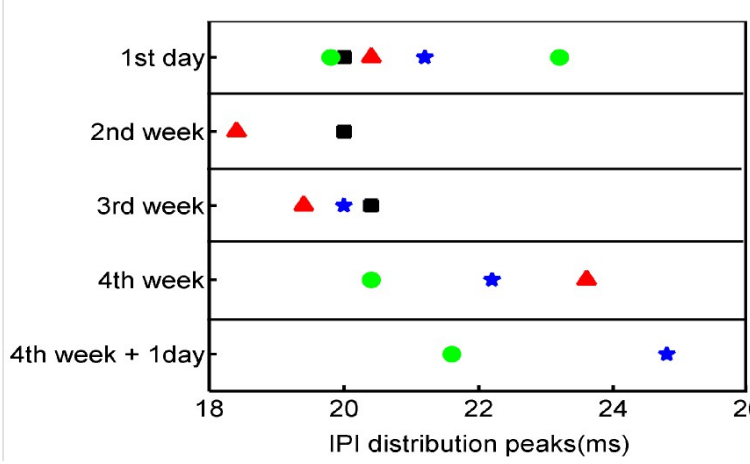

Fig. 24: Distribuição de IPIs e valores de IPIs mais prováveis para um exemplar de Gymnotus carapo. A - O peixe foi introduzido no aquário de medida pela primeira vez e medido durante $30 \mathrm{~min}$ (linha preta).O procedimento foi repetido duas, três e quatro semana depois (linhas verde, azul e vermelha). Na segunda e terceira semana o peixe disparou IPIs mais curtos do que no primeiro dia. Na quarta semana o peixe disparou IPIs mais longos $\sim 23,5 \mathrm{~ms}$. B - Valores dos picos das distribuições de IPIs para 4 peixes medidos semanalmente durante 1 mês usando o procedimento descrito em A. Duas a 3 semanas depois de chegar no laboratório a maioria dos peixes disparou IPIs mais longos se comparados com as semanas anteriores. Os IPIs mais prováveis mudaram de um dia para o outro também, o peixe $C$ disparava IPIs de 22,2 ms na quarta semana e no dia seguinte passou a disparar IPIs de 24,8 ms e o peixe D passou de 20,4 ms para 21,6 ms.

Em Gnathonemus petersii também não foi possível identificar cada peixe apenas por sua distribuição de IPIs em um mesmo ambiente. Os IPIs mais prováveis também não permaneceram os mesmos no período em que estiveram no laboratório, todos Gnathonemus petersii tenderam a aumentar 
o intervalo entre os pulos, por exemplo, o peixe A (Tabela 1) logo que chegou ao laboratório disparou mais IPIs de $40 \mathrm{~ms}$ e $95 \mathrm{~ms}$, e $\sim 3$ semanas depois no $23^{\circ}$ dia $69 \mathrm{~ms}, 188 \mathrm{~ms}$ e $230 \mathrm{~ms}$, e no $24^{\circ}$ dia 100 ms e $220 \mathrm{~ms}$. O peixe $\mathrm{B}$, que permaneceu mais tempo no laboratório, no $1^{\circ}$ dia que chegou disparava com maior probabilidade IPIs de $40 \mathrm{~ms}, 80 \mathrm{~ms}$ e $180 \mathrm{~ms}$ e no $47^{\circ}$ dia $100 \mathrm{~ms}, 220 \mathrm{~ms}$ e $260 \mathrm{~ms}$. 


\begin{tabular}{|c|c|c|}
\hline \multirow[t]{2}{*}{ Dia } & \multicolumn{2}{|c|}{ Picos da distribuição de IPIs (ms) } \\
\hline & Peixe A & Peixe B \\
\hline \multirow[t]{3}{*}{$1^{\circ}$} & 40 & 40 \\
\hline & 95 & 80 \\
\hline & & 180 \\
\hline \multirow[t]{2}{*}{$8^{\circ}$} & 180 & 60 \\
\hline & & 200 \\
\hline \multirow[t]{2}{*}{$22^{\circ}$} & 79 & - \\
\hline & 220 & \\
\hline \multirow[t]{3}{*}{$23^{\circ}$} & 69 & - \\
\hline & 188 & \\
\hline & 230 & \\
\hline \multirow[t]{2}{*}{$24^{\circ}$} & 100 & - \\
\hline & 220 & \\
\hline \multirow[t]{3}{*}{$38^{\circ}$} & - & 80 \\
\hline & & 140 \\
\hline & & 220 \\
\hline \multirow[t]{3}{*}{$39^{\circ}$} & - & 100 \\
\hline & & 160 \\
\hline & & 200 \\
\hline \multirow[t]{3}{*}{$46^{\circ}$} & - & 100 \\
\hline & & 160 \\
\hline & & 240 \\
\hline \multirow[t]{3}{*}{$47^{\circ}$} & - & 100 \\
\hline & & 220 \\
\hline & & 260 \\
\hline
\end{tabular}

Tabela 1:IPIs mais disparados, para 2 exemplares de Gnathonemus petersii, medidos de 1 a 47 dias depois que chegaram no laboratório. 


\section{3 - Experimentos com estímulos elétricos em Gymnotus carapo}

\subsection{1- Estímulos com sequências de IPIs reais e aleatórias}

Esses experimentos seguiram 2 protocolos, sendo a diferença entre eles a ordem em que os estímulos com IPIs reais e aleatórios foram apresentados a Gymnotus carapo, o protocolo 1 seguiu a seguinte sequência: 30 min sem estímulo (controle 1), 30 min com estímulo de IPIs pré-gravado de um peixe real (Fig. 11 - em preto e Fig. 12 - superior), 30 min sem estímulo (controle 2), 30 min com estímulo de IPIs aleatórios entre 15 a 20 ms ( Fig. 11 - em vermelho e Fig. 12 - inferior) e mais 30 min sem estímulo (controle 3), e o protocolo 2: 30 min sem estímulo (controle 1), 30 min com estímulo de IPIs aleatórios de 15 a $20 \mathrm{~ms}, 30 \mathrm{~min}$ sem estímulo (controle 2), 30 min com estímulo de IPIs prégravado de um peixe real e mais 30 min sem estímulo (controle 3). Foram usados no total 9 peixes submetidos ao protocolo 1, sendo 2 deles medidos 2 vezes em dias e horários diferentes. Mostramos um exemplo ilustrativo do experimento com protocolo 1 em Figs. 25 e 26. Foram usados no total 11 peixes submetidos ao protocolo 2 , no qual 1 foi medido 2 vezes em dias e horários distintos. Um exemplo do experimento com o protocolo 2 se encontra em Fig. 27.

Os peixes durante as sessões de controle, ou seja, quando não estavam sendo estimulados, apresentaram valores mais prováveis de IPIs maiores do que quando estimulados (tabela 2), já as larguras das distribuições de IPIs foram sempre menores durante os controles (Fig. 29). Quando se iniciavam ou terminavam as sessões de estímulo, os peixes alteravam abruptamente seus IPIs. No início das sessões de estímulo eles sempre diminuíam os IPIs e os aumentavam quando o estímulo era interrompido. Durante as sessões de estímulo a entropia era mais alta do que durante os controles. Nesses experimentos não houve mais a correspondência direta entre a entropia e a movimentação dos peixes como visto nos experimentos sem estímulo (seção 3.1.1- pág. 34).

A maioria dos peixes nadaram sem parar em todo os experimentos, todas as exceções aconteceram somente nas sessões de estímulo com IPIs aleatórios, nas quais 4 peixes pararam de movimentar-se por minutos, durante esses períodos os IPIs se tornaram regulares e a entropia caiu para perto de 0 .

Mostramos a seguir um exemplo ilustrativo com um exemplar de Gymnotus carapo submetido ao protocolo 1 e 2 . Um primeiro experimento com o protocolo 1 foi realizado logo após o peixe ter 
chegado ao laboratório (Fig. 25 A-D) e outro experimento, também usando o protocolo 1, foi feito com o mesmo peixe 2 semanas depois (Fig. 25 E-H). Para o controle 1, com IPIs entre 16 - $22 \mathrm{~ms} \mathrm{o}$ histograma de IPIs apresentou um pico em 20,5 ms (Fig. 25 A - preto) e mudou para uma distribuição bimodal (Fig. 25 A - verde) com picos em 17 ms e 19.5 ms em resposta à sessão de estímulos com IPIs reais. A resposta dada ao segundo controle (Fig. $25 \mathrm{~A}$ - azul) foi similar a dada ao primeiro controle com apenas 1 pico em 20,5 ms e com IPIs de 18 - 22 ms. Durante o estímulo de IPIs aleatórios (Fig. 25 A - amarelo) o peixe disparou mais IPIs de $20 \mathrm{~ms}$ em contraste com a distribuição bimodal vista no experimento com estímulo de IPIs reais (Fig. $25 \mathrm{~A}$ - verde). No terceiro controle a distribuição de IPIs apresentou IPIs mais longos de 18 - $24 \mathrm{~ms}$ com um pico em $21.5 \mathrm{~ms}$.

O comportamento elétrico mudou imediatamente após o começo e término das sessões de estímulo, alterando a frequência de disparo para ambos os casos. Assim que o estímulo foi ligado (começo da barra verde na Fig. 25 B), o peixe reagiu disparando IPIs mais curtos e aumentando a variabilidade dos IPIs de 19 - $22 \mathrm{~ms}$ antes do estímulo para 11 - 20,5 ms (IPIs em amarelo e vermelho). O mesmo comportamento foi observado na sessão com estímulo de IPIs aleatórios, mas o intervalo de IPIs foi mais curto (14 - $21 \mathrm{~ms}$; começo da barra amarela na Fig. 25 B). Quando os estímulos real e aleatório foram desligados, a média dos IPIs do peixe aumentou para $20 \mathrm{~ms}$ e $21 \mathrm{~ms}$, respectivamente e a variabilidade decresceu com descargas de 18,5 - $21 \mathrm{~ms}$ e de 18,5 - 21,5 ms, respectivamente.

A entropia e o movimento (Fig. $25 \mathrm{C}$ e D) não mostraram nenhuma relação óbvia com o comportamento elétrico como vemos em experimentos com peixes sem estímulo por vários dias, nos quais sempre que há aumento do movimento ocorrem também aumento da frequência de disparo (Fig. 20 D, E e G). Aproximadamente 10 min depois do começo da sessão de estímulo de IPIs aleatórios, observamos um valor alto de movimento e baixa entropia, isso quer dizer que o peixe estava se movimentando com mais intensidade mas estava disparando sempre os mesmos padrões de palavras.

O peixe foi submetido ao mesmo protocolo 1 duas semanas depois que chegou ao laboratório. Além do aumento da frequência média de disparo (barra verde em Fig. $25 \mathrm{~F}$ ) o peixe apresentou, para a segunda sessão de estímulo (barra amarela em Fig. 25 F), um comportamento diferente no qual a frequência e a variabilidade dos IPIs decresceram na segunda metade da sessão (110 - 120 min). A mesma tendência é vista no comportamento motor (Fig. 25 G) e também na entropia (Fig. 25 H). Neste 
período o peixe estava parado (movimento $\sim 0$ ) e disparando IPIs periódicos (entropia $\sim 0$ ).

Durante todo o primeiro experimento (Fig. $25 \mathrm{~A}-\mathrm{D}$ ) e até a metade do segundo experimento (Fig. $25 \mathrm{E}-\mathrm{H}$, barras preta, verde e metade da azul), as oscilações no comportamento motor não estavam diretamente relacionados com as oscilações da entropia, mas a entropia foi sempre mais alta quando o peixe era estimulado. 
A

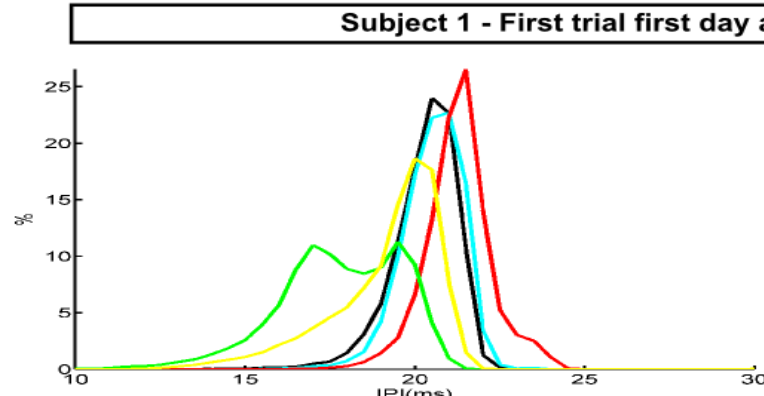

B

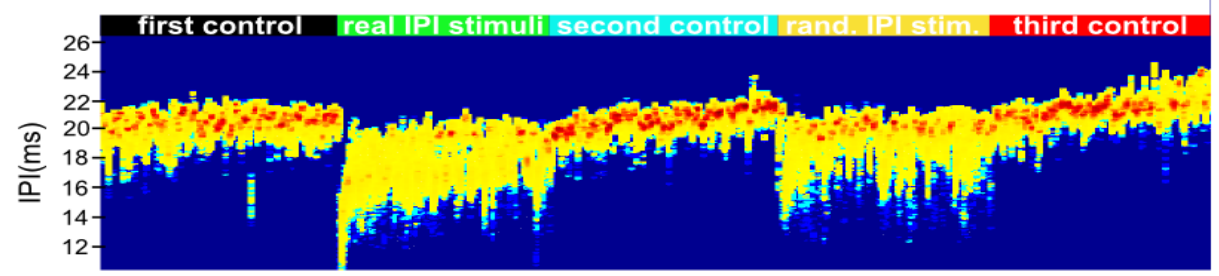

C

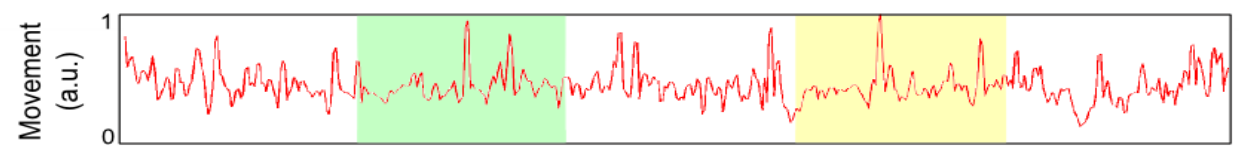

D

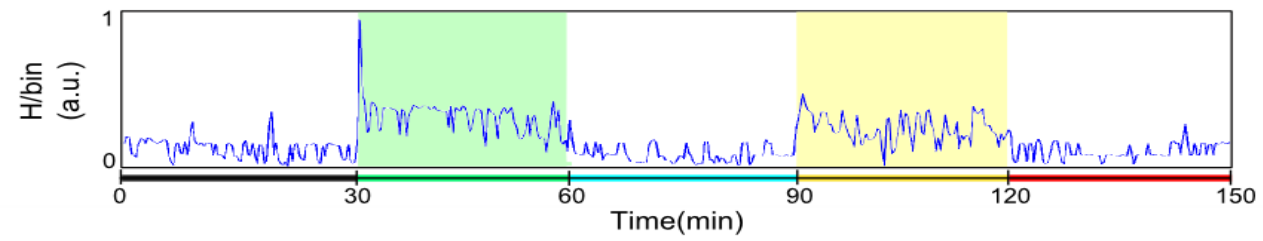

Subject 1 - Second trial two days after arrival

$\mathbf{E}$

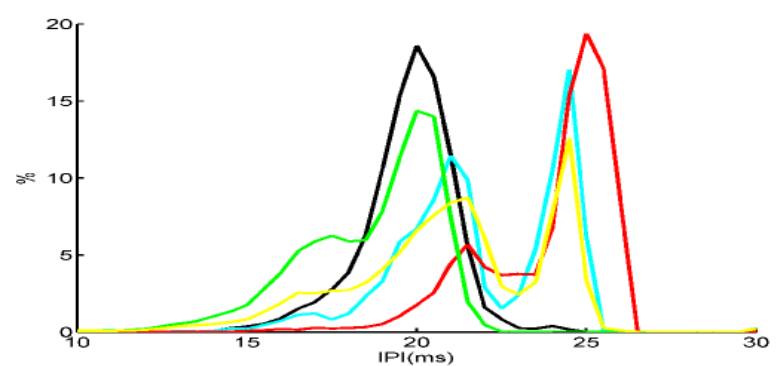

$\mathbf{F}$

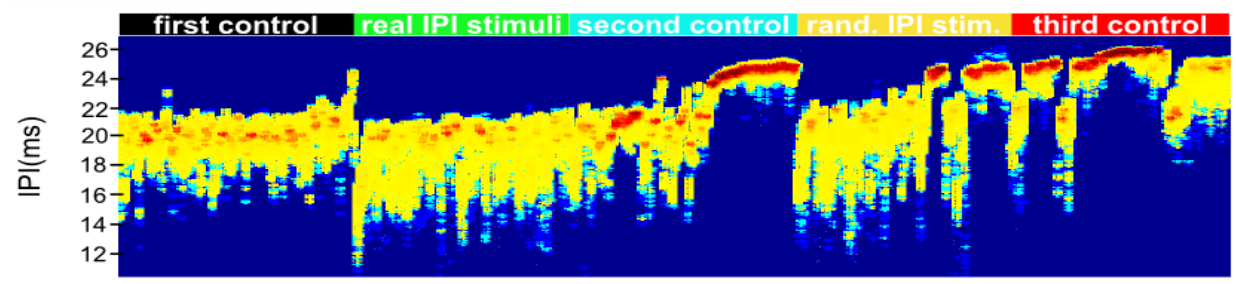

G

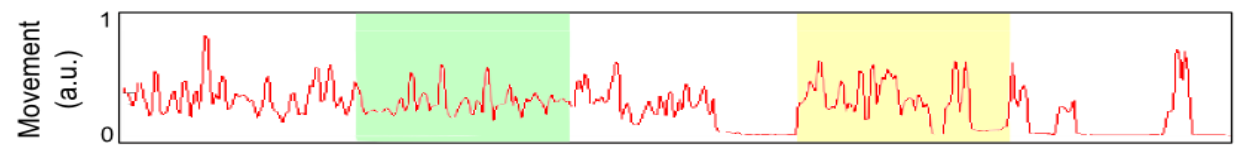

H

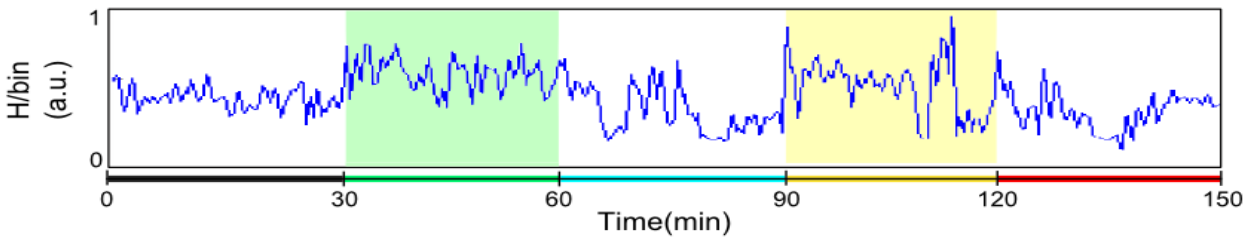


Fig. 25: O experimento para Gymnotus carapo seguiu o protocolo 1: controle 1 (sem estímulo) por $30 \mathrm{~min}, 30 \mathrm{~min}$ com estímulo de IPIs reais pré-gravados, controle 2, 30 min com estímulo de IPIs aleatórios entre 15 e $20 \mathrm{~ms}$, controle 3. A-Histograma de IPIs para cada sessão: primeiro controle (preto), estímulo real (verde), segundo controle (azul), estímulo aleatório (amarelo) $e$ terceiro controle (vermelho). Nos primeiros $30 \mathrm{~min}$, o peixe disparou mais IPIs de 20,5 ms. Em resposta ao estímulo real, a distribuição foi bimodal com 2 valores de IPIs mais prováveis $17 \mathrm{~ms}$ e 19,5 ms. Na segunda sessão de controle a distribuição mudou para um pico único em $21 \mathrm{~ms}$. A distribuição para o estímulo aleatório foi mais larga do que para a sessão anterior com um pico em $20 \mathrm{~ms}$ e no terceiro controle ele disparou IPIs de 21,5 ms. B - Histograma de IPIs no tempo (janela de tempo de 40 s). Probabilidades de ocorrência alta de 15 a 30\% (e baixa de 0-5\%) estão em vermelho (azul), amarelo representa de 5 a $15 \%$.C - Movimento inferido, e Dentropia vs tempo. O peixe reagiu a ambos estímulos decrescendo seus IPIs e aumentando a variabilidade (largura da distribuição) de 19 - $22 \mathrm{~ms}$ para 14,5 - $21 \mathrm{~ms}$. Durante o estímulo aleatório (barra amarela) os valores de IPIs mais prováveis aumentaram ao longo do tempo desde $20 \mathrm{~ms}$ a 21,5 ms, o mesmo ocorreu para o terceiro controle desde $21 \mathrm{~ms}$ a $23 \mathrm{~ms}$. O peixe estava se movimentando o tempo todo e a entropia aumentou (diminuiu) quando ligamos (desligamos) os estímulos. E-O mesmo que para A mas para o peixe medido 2 semanas depois. Nos primeiros 30 min, a distribuição de IPIs apresentou um pico único em 20 ms. Para o resto das sessões a distribuição foi bimodal com valores de pico diferentes para cada sessão. O peixe disparou IPIs mais curtos (17,5 ms) em resposta ao estímulo real (verde). A distribuição em resposta ao segundo controle (azul) e ao estímulo aleatório (amarelo) foram similares com picos ao redor de $21 \mathrm{~ms}$ e 24,5 ms. Para o terceiro controle (vermelho) o peixe disparou IPIs mais longos do que nas sessões anteriores com picos em 21,5 ms e $25 \mathrm{~ms}$. F-H-mesmo que para $B-$ $D$ mas para 2 semanas depois. $O$ mesmo comportamento qualitativo descrito acima foi encontrado, com exceção que durante o controle 2 e a sessão de estímulo de IPIs aleatórios o peixe apresentou momentos de IPIs mais longos por volta de 24,5 ms, ausência de movimento e entropia baixa.

Analisando o movimento do peixe pelas amplitudes nos dipolos como descrito na seção 2.5.2pág. 27, o peixe A mostrou preferência por ficar no fundo do aquário em ambas medidas (Fig. 26). Houve preferência por posições particulares na segunda e na terceira sessões de controle no experimento feito 2 semanas depois: o peixe passou $60 \%$ do tempo perto da parede esquerda do aquário com a cabeça apontando para a parede da frente e $48 \%$ do tempo com a cauda apontando para a parede do fundo durante o segundo controle e passou $66 \%$ do tempo com a cabeça apontando para a parede esquerda e $67 \%$ do tempo com a cauda em direção a parede da direita durante o terceiro controle. 

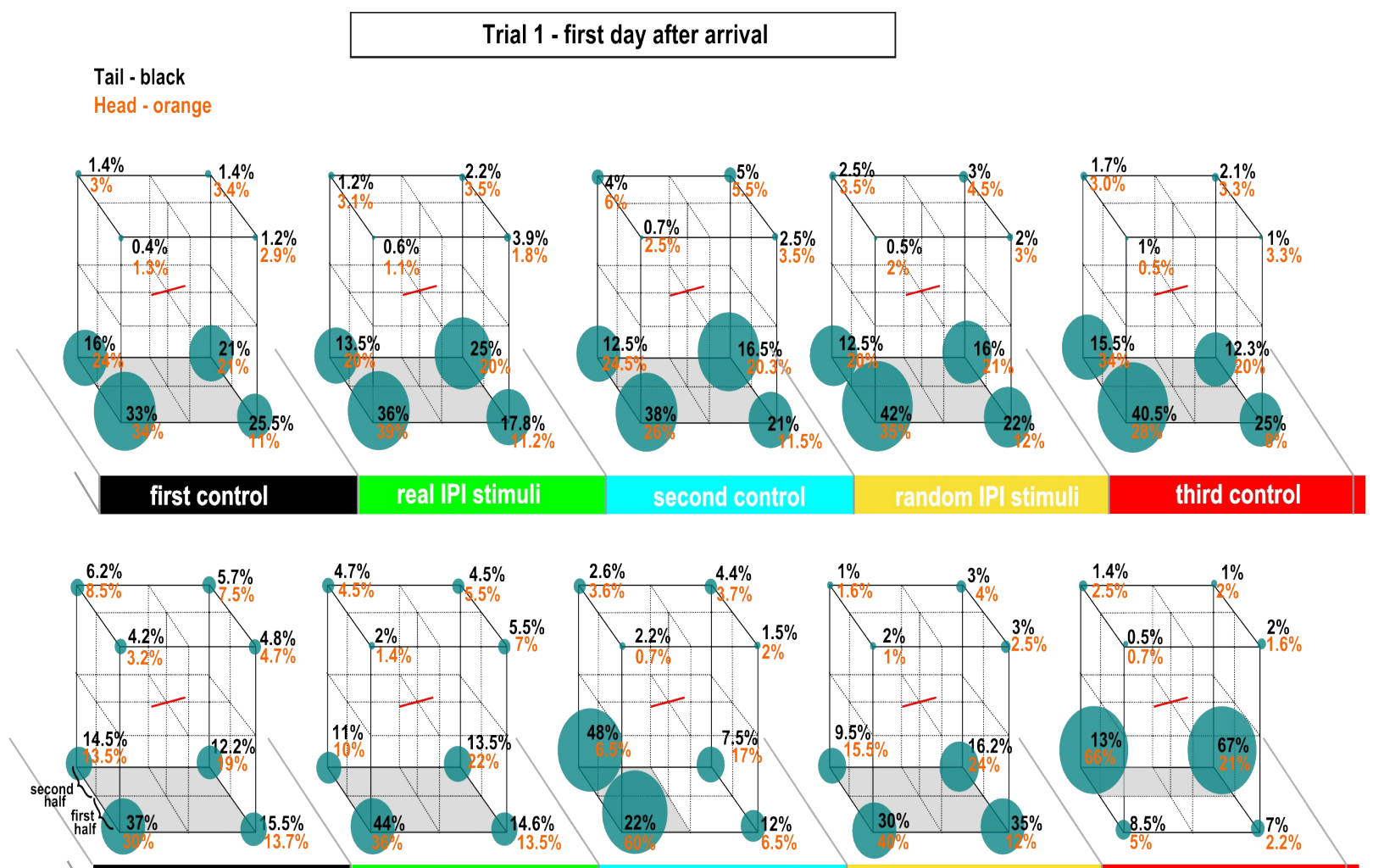

first control
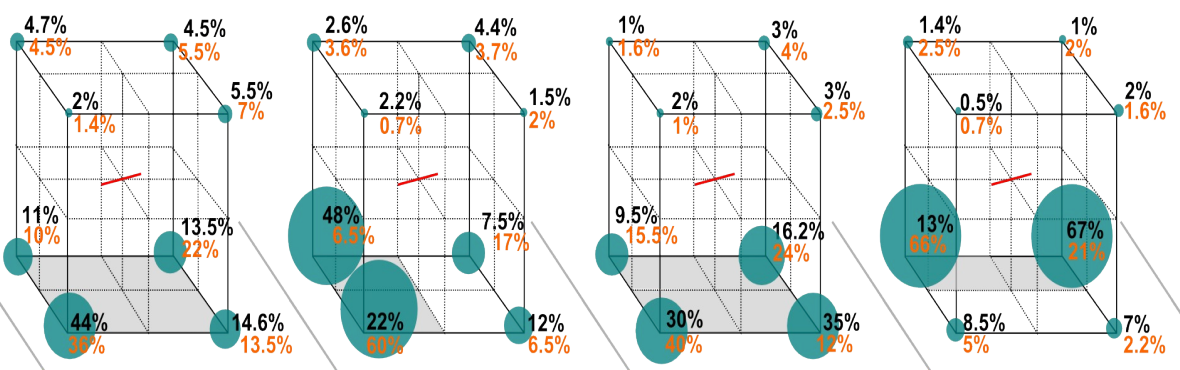

Tail - black

Head - orange

Trial 2 - two weeks after arrival

Fig. 26: Fração de tempo que um exemplar de Gymnotus carapo passou próximo a cada eletrodo, para o protocolo 1. $O$ dipolo de estímulo foi colocado no centro do aquário (em vermelho). Na primeira vez que o experimento foi feito o peixe nadou predominantemente no fundo do aquário (áreas cinza) e não mostrou preferencia por nenhuma direção específica. Duas semanas depois, o peixe também nadou mais no fundo do aquário. Algumas posições foram preferidas: durante o segundo controle (barra azul) ele passou 60\% do tempo com a cabeça na direção da parede da frente e $48 \%$ do tempo com rabo apontando para o parede do fundo e no terceiro controle (barra vermelha) ele passou 66\% do tempo com a cabeça para a esquerda e 67\% do tempo com a cauda para a direita. Não houve posição preferencial durante as sessões de estímulos (barras verde e amarela).

Para assegurarmos que os comportamentos elétrico e motor observados quando o peixe estava sendo estimulado com IPIs aleatórios eram devidos ao estímulo e não devidos a ordem no qual eram apresentados ao peixe, nós fizemos experimentos com outro protocolo, chamado protocolo 2, no qual nós invertermos a ordem de apresentação dos estímulos de IPIs reais e aleatórios em relação ao protocolo 1. Os mesmos comportamentos descritos acima foram observados para o protocolo 2 , durante a sessão de estímulo de IPIs reais, a variabilidade dos IPIs de $16-21 \mathrm{~ms}$ foi mantida durante todo a sessão (Fig.27 A - barra verde), já para a sessão de estímulos de IPIs aleatórios, nos primeiros 10 
min o peixe disparou IPIs de 15,5 - 20 ms com IPI médio de 18 ms (Fig.27 A - 1/3 barra amarela) sendo que nos restantes 20 min o IPI médio aumentou para $\sim 20 \mathrm{~ms}$ ao passo que a variabilidade diminui para 17 - 20,5 ms. Em todos os controles o IPI médio ( 21,5 ms) foi maior do que nas sessões com estímulos.

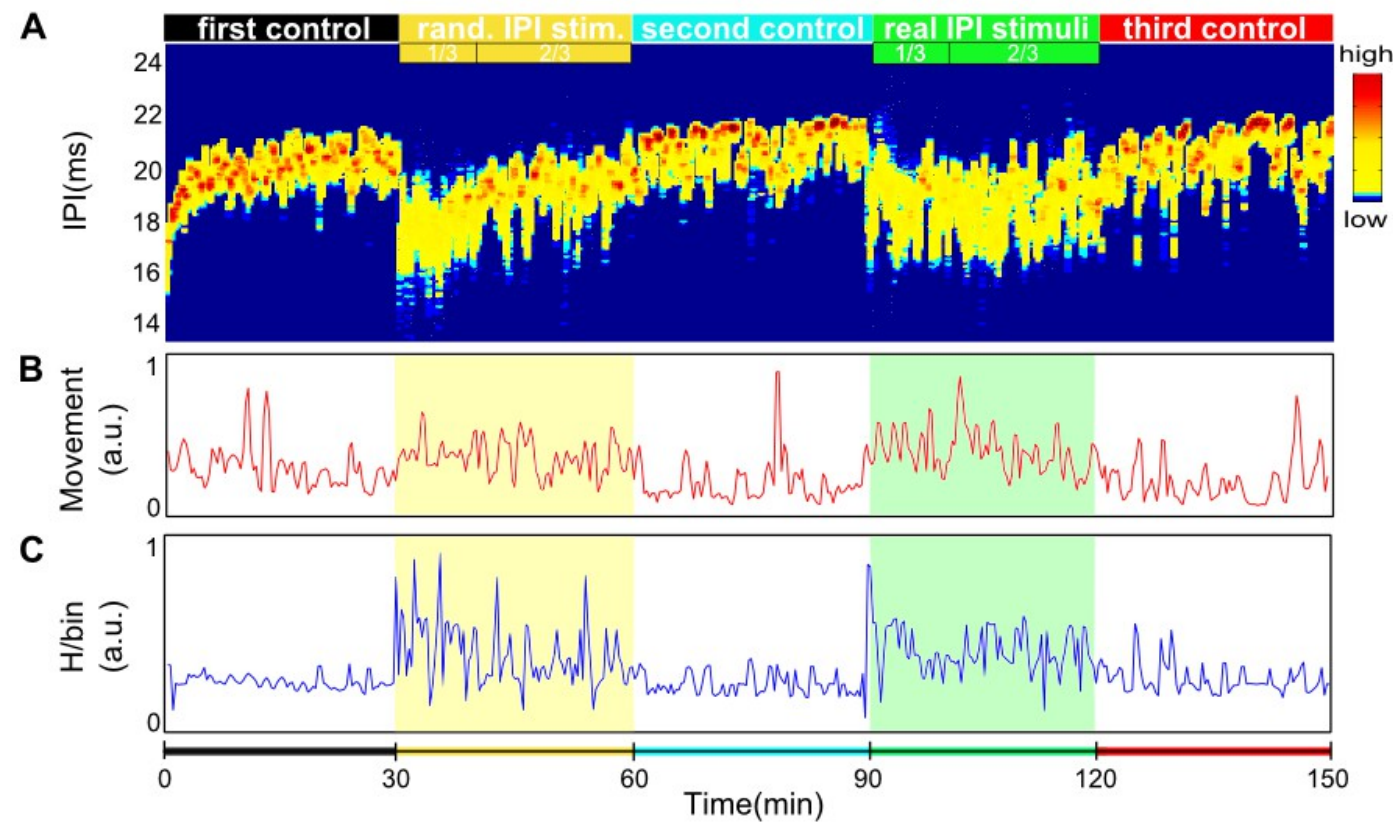

Fig. 27: Experimento para Gymnotus carapo usando protocolo 2. A sequência do experimento foi: 30 min sem estímulo (primeiro controle; barra preta), $30 \mathrm{~min}$ com estímulos de IPIs aleatórios entre $15-20 \mathrm{~ms}$ (barra amarela), 30 min sem estímulo (segundo controle; barra azul), 30 min com estímulos de IPIs prégravados de um peixe real (barra verde) e 30 min sem estímulo (terceiro controle; barra vermelha) AHistograma de IPIs no tempo (janela de tempo de 40 s). Probabilidades de ocorrência alta de 15 a 30\% (e baixa de 0-5\%) estão em vermelho (azul), amarelo representa de 5 a $15 \%$. Probabilidades de ocorrência alta de 15 a 30\% (e baixa de 0-5\%) estão em vermelho (azul), amarelo representa de 5 a $15 \%$. Quando o estímulo aleatório foi ligado (começo da barra amarela), o peixe reagiu nos primeiros 10 min diminuindo seus IPIs disparando entre 15,5-20 ms. Nos últimos 20 min o IPI médio aumentou para $20 \mathrm{~ms}$ variando entre 17 - 20,5 ms. No entanto, quando o estímulo de IPIs reais foi ligado (começo da barra verde) o peixe disparou IPIs de $16-21 \mathrm{~ms}$, mantendo esse intervalo de disparos, maior que o intervalo disparado para o estímulo aleatório, durante toda a sessão de estímulo. Em todos os controles o IPI médio ( 21,5 ms) foi maior do que nas sessões com estímulos. $B$ - Movimento (desvio padrão das amplitudes dos pulsos) e Centropia vs tempo. O peixe se movimentou sem parar durante todo o experimento, especialmente durante as sessões de estímulo. A entropia mostrou um pequeno aumento durante os estímulos. $O$ aumento (diminuição) na entropia não significou aumento (diminuição) no movimento.

Abaixo mostramos medidas dos IPIs mais prováveis, largura da distribuição, interrupções de disparo e correlação entre a entropia e o movimento para todas as seções em ambos os protocolos para 
os 20 peixes utlizados.

Os IPIs mais disparados nas sessões com estímulo foram em média mais baixos do que os disparados nas sessões de controle e as sessões de estímulos aleatórios e controle 3 apresentaram valores mais dispersos do que as demais (Fig.28). Entre as sessões com estímulo, aquelas com estímulos reais apresentaram picos de IPIs menores do que as sessões de estímulo aleatório. Entre as sessões de controle, os valores dos picos dos IPIs diminuiram do controle 1 para o 3.

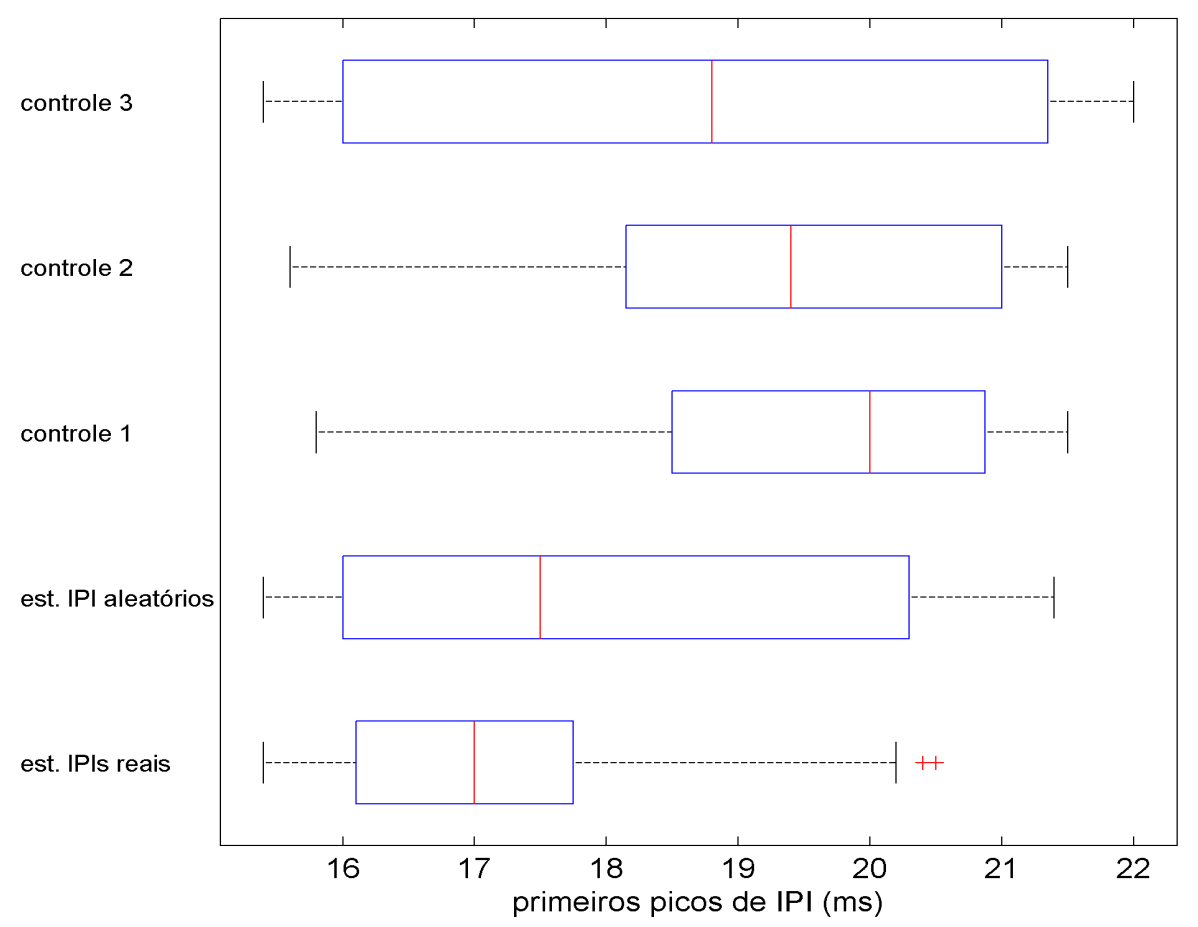

Fig. 28: boxplot dos picos (primeiros) para as sessões de estímulo de IPIs reais, aleatórios e todas as sessões de controle sem estímulo. Comparando as medianas, os valores de IPI foram em ordem crescente : 17,0 ms na sessão com estímulos reais, 17,5 ms na sessão de estímulos aleatórios, 18, 8 na sessão de controle 3, 18,4 ms na sessão de controle 2 e 19,4 ms na sessão de controle 1. O teste de Friedman $(p<<0,01)$ entre todas as sessões revelou que ao menos uma era estatisticamente diferente das demais, análises de múltipla comparação mostraram que há uma diferença estatística entre os picos de IPIs disparados nas sessões de estímulo real e todas as sessões de controle, já os picos das sessões de estímulos reais são significativamente diferentes apenas das sessões de controle 1. Entre as sessões de estímulos real e aleatórios há uma diferença estatística (Wilcoxon $p<0,01$ ). Não há diferenças estatisticamente significantes entre as sessões de controle 1, 2 e 3 (Friedman p>0,05).

As sessões são estatisticamente diferentes entre si (Friedman $\mathrm{p}<<0,01$ ), por múltipla comparação, verificamos que as sessões com estímulo real eram significantemente diferentes de todas as sessões de controle e que as sessões de estímulo aleatório eram significantemente diferente apenas 
das sessões de controle 1. As sessões de estímulos se mostraram estatisticamente diferentes (Wilcoxon $\mathrm{p}=0,0004$ ) e as sessões de controle não apresentaram diferenças significantes (Friedman $\mathrm{p}=0,4$ )

Na tabela 2 temos os dados dos valores dos IPIs mais prováveis para os 20 peixes. Em todos os experimentos em ambos protocolos, todos menos 1 peixe apresentaram valores de IPIs mais prováveis iguais ou mais curtos em resposta ao estímulo de IPIs reais do que em resposta ao estímulo de IPIs aleatórios. Usando protocolo 1, todos os experimentos tiveram IPIs mais prováveis mais curtos em resposta ao estímulo de IPIs reais. A maior diferença (24\%) foi para o peixe A, que disparou mais IPIs de 17,2 ms para o estímulo de IPIs reais e 21,4 ms para o estímulo de IPIs aleatórios. Quando usamos o protocolo 2, 8 de 12 experimentos tiveram valores iguais de IPIs mais prováveis em resposta aos estímulos de IPIs reais, em 3 experimentos (peixes J, R e T) os IPIs foram mais curtos em resposta ao estímulo de IPIs reais e apenas em 1 experimento (peixe M) os IPIs mais prováveis foram mais curtos durante os estímulos de IPIs aleatórios.

Comparando as sessões de controle, o controle 1 apresentou IPIs mais longos para os 2 protocolos: 6 de 11 experimentos para o protocolo 1 e 6 de 12 para o protocolo 2 .

Observamos que as distribuições bimodais não foram uma característica das sessões de estímulo, podendo ser encontradas também nas sessões de controle. Os estímulos podem, inclusive, fazer com que voltem a ser distribuições unimodais, como observamos para os peixes $\mathrm{F}$ e N. 


\begin{tabular}{|c|c|c|c|c|c|}
\hline & \multicolumn{5}{|c|}{ Picos de IPI(ms) em resposta a: } \\
\hline & controle 1 & estímulo real & controle 2 & $\begin{array}{l}\text { estímulo } \\
\text { aleatório }\end{array}$ & controle 3 \\
\hline \multicolumn{6}{|l|}{ Protocolo 1} \\
\hline Peixe $A-1^{\circ}$ dia & 20.5 & 17.0 e 19.5 & 21.0 & 20.0 & 21.5 \\
\hline $\begin{array}{l}\text { Peixe } A-2^{a} \\
\text { semana }\end{array}$ & 20.0 & 17.2 e 20.2 & 21.0 e 24.4 & $21.4-24.6$ & $\begin{array}{l}21.4 \text { e } 25 \\
25.8\end{array}$ \\
\hline Peixe $\mathrm{B}-1^{\circ}$ dia & 20.4 & 17.6 & 19.4 & 19.6 & 21.2 \\
\hline $\begin{array}{l}\text { Peixe } B-2^{a} \\
\text { semana }\end{array}$ & 18.4 & 17.0 e 18.6 & 19.8 & 19.6 e 20.6 & 22.0 e 23.6 \\
\hline Peixe C & 21.4 & 17.8 e 20.4 & 20.4 e 24.6 & 20.8 e 24.2 & 22.0 e 24.6 \\
\hline Peixe D & 19.4 & 20.2 & 19.4 & 20.8 & 20.6 \\
\hline Peixe E & 21.2 & 20.4 & 21.4 & 21.2 & 21.4 \\
\hline Peixe F & 19.0 e 23.2 & 16.4 & 18.6 e 21.4 & 16.6 & 19 e 21.7 \\
\hline Peixe G & 20.0 e 22.0 & 17.6 e 19.4 & 20.6 e 21.8 & 20.4 e 22.8 & 21.4 e 23.6 \\
\hline Peixe $\mathrm{H}$ & 18.8 & 16.8 & 18.8 & 17.4 e 18.6 & 19.2 \\
\hline Peixe I & 18.8 & 16.4 & 18.8 & 16.6 e 18.6 & 19.0 \\
\hline \multicolumn{6}{|l|}{ Protocolo 2} \\
\hline Peixe J & 20.0 & 17.8 e 19.2 & 21.2 & 18.8 & 20.4 e 21.4 \\
\hline Peixe K & 20.2 & 19.2 & 19.4 & 19.2 & 19.6 \\
\hline Peixe L & 15.8 & 15.4 & 15.6 & 15.4 & 15.6 \\
\hline Peixe M & 16.4 & 16.5 & 16.2 & 16.0 & 16.4 \\
\hline Peixe N & 16.5 e 17.6 & 16.5 & 16.4 & 16.5 & 16.4 e 17.4 \\
\hline Peixe $\mathrm{O}-1^{\circ}$ dia & 16.2 & 16.0 & 16.0 & 16.0 & 16.2 \\
\hline $\begin{array}{l}\text { Peixe } O-6^{a} \\
\text { semana }\end{array}$ & 21.5 & 16.0 e 21.0 & 21.5 & 16.0 e 21.0 & 21.5 \\
\hline Peixe P & 16 & 15.5 & 15.6 & 15.5 & 16.0 \\
\hline Peixe Q & 21.0 & 16.0 e 21.0 & 21.0 & 16.0 & 21.0 \\
\hline Peixe R & 19.0 & 17.0 & 18.0 & 17.5 & 18.0 \\
\hline Peixe $\mathrm{S}$ & 21.5 e 24.0 & 15.5 e 21.0 & 21.5 & 15.5 e 21.0 & 21.5 \\
\hline Peixe $\mathrm{T}$ & 21.5 & 20.5 & 20.5 & 21.0 & 20.0 \\
\hline
\end{tabular}


Tabela 2: IPIs mais prováveis disparados em resposta ao controle 1, estímulo com IPIs reais prégravados de outro peixe, controle 2, estímulo com IPIs aleatórios e controle 3.

Os peixes além da taxa de disparo, alteraram também a variabilidade dos IPIs em função do tempo. Por inspeção visual notamos que, depois de alguns minutos, quando estimulados com IPIs aleatórios os peixes disparavam menos IPIs curtos, o que não acontecia com a mesma frequência quando estimulados com IPIs de outro peixe. Para quantificar essas mudanças calculamos a largura da distribuição de IPIs (2-98 percentil) em cada janela de $40 \mathrm{~s}$ e tiramos a média para cada sessão (controle 1, estímulo real etc; Fig. 29 e Tabela 3).

Entre as sessões de controle, o controle 1 apresentou distribuições, em média, mais largas do que nos demais controles em ambos protocolos. Nas sessões com estímulo, a distribuição das larguras médias usando estímulo real foi maior do que a com estímulo aleatório (Fig. 29 A). No quantilequantile plot (seção 2.5.1- pág. 27)da largura da distribuição das sessões com estímulo (+ em azul; a linha preta é a reta $\mathrm{pa}=\mathrm{pr}$, onde $p a$ é a série com o peixe estimulado com IPIs aleatórios e pr com IPIs reais) podemos ver que maioria dos valores ficou abaixo de $\mathrm{pa}=\mathrm{pr}$, ou seja, as sessões com estímulos reais apresentaram, em média, valores maiores de largura de distribuição do que as sessões com estímulos aleatórios para valores maiores que $2 \mathrm{~ms}$, e principalmente acima de $4 \mathrm{~ms}$ (Fig. 29 B). Para larguras pequenas de até $2 \mathrm{~ms}$, as larguras das distribuições foram parecidas (pontos alinhados com a reta $\mathrm{pa}=\mathrm{pr})$.

A largura média da distribuição de IPIs, de um mesmo peixe, em resposta ao estímulo real foi maior do que em resposta ao estímulo aleatório em 83\% dos experimentos: 10 de 11 experimentos no protocolo 1 e 9 de 12 no protocolo 2 (Tabela 2). As maiores diferenças foram vistas no protocolo 1 (169,2\% para o peixe C, $48,4 \%$ para o peixe D) comparando com o protocolo 2 (25\% para o peixe J e $21,5 \%$ para o peixe $\mathrm{T}$ ). 

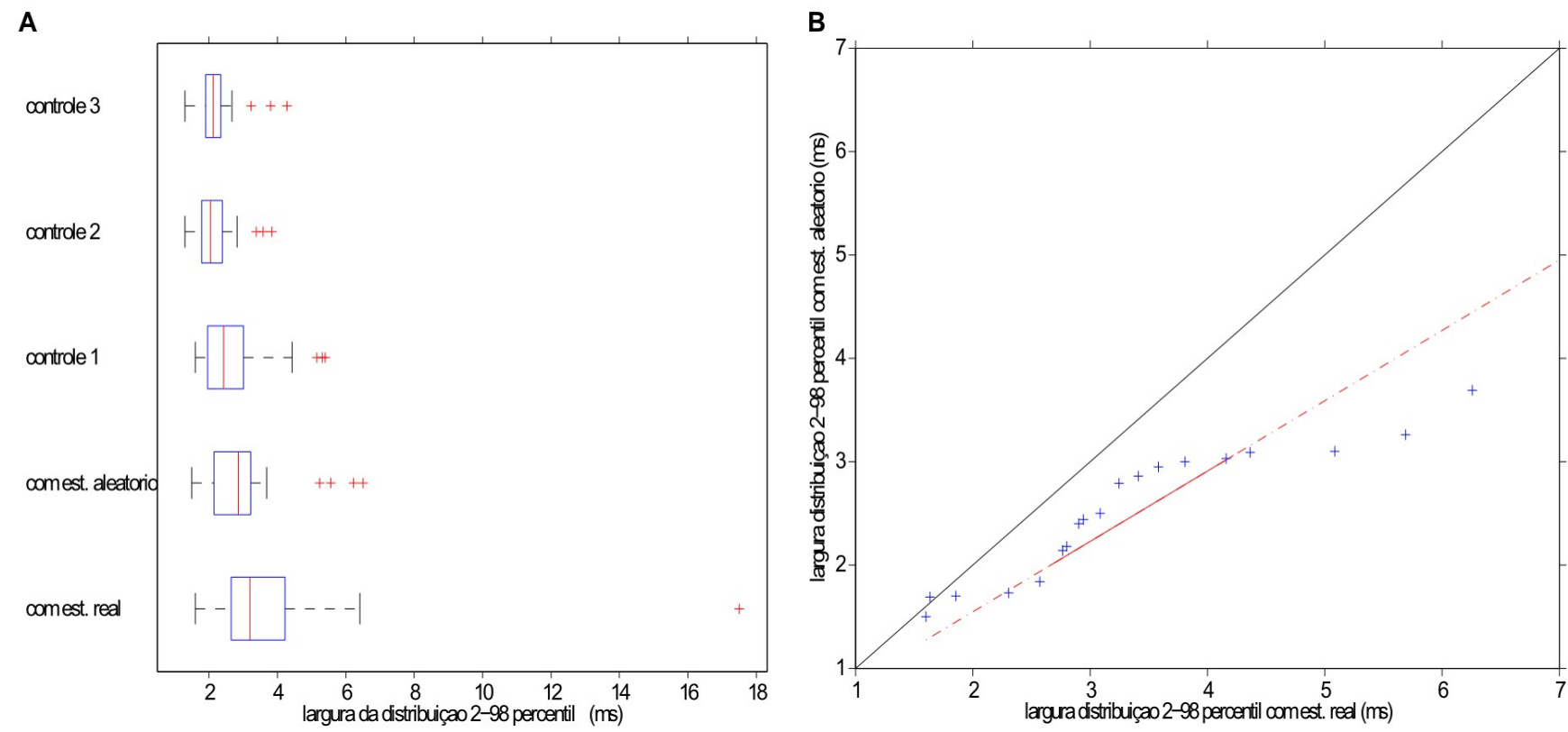

Fig. 29: A - Boxplot da largura média da distribuição (2 - 98 percentil) para e sessões com estímulo real e aleatórios e sessões de controle 1 - 3 para Gymnotus carapo. As medianas foram em ms : 3,20, 2,86, 2,43, 2,04 e 2,13, respectivamente. $O$ símbolo + em vermelho são outliers. Os 3 outliers dos controles foram valores dos peixes $O, Q$ e $S$ que apresentaram larguras médias de distribuição muito maiores do que os demais, eles também aparecem na sessão de estímulos aleatórios. O peixe C, (outlier da sessão de estímulos reais de 17,5 ms) não foi descartado das estatísticas porque ele aparece como outlier somente nas sessões com estímulo, e volta a valores normais nos controles $1-3$, a diferença desse peixe com os demais foi o tamanho, $\sim 15 \mathrm{~cm}$, o menor peixe usado no experimento. Todas as sessões são estatisticamente diferentes (Friedman p<<0,0001), por análises de múltipla comparação, verficamos que as sessões de estímulos verdadeiros são significativamente diferente de todas sessões de controle e que a sessão de estímulos aleatórios é significativamente diferente das sessões de controle 2 e 1, mas não do controle 1. As sessões de estímulo são significativamente diferentes entre si (Wilcoxon $p=0,001$ ). Entre todas as sessões de controle (Friedman $p=0,0002$ ), post-hoc testes revelaram que o controle 1 é significativamente diferente dos controles 2 e 3. . B-Quantile-quantile plot da largura da distribuição das sessões com estímulo (+ em azul), e a linha preta é a reta pa $=p r$, onde pa é a série com o peixe estimulado com IPIs aleatórios e pr com IPIs reais, a linha vermelha é a ligação do $1^{\circ}$ e $3^{\circ}$ quartil, e a linha vermelha pontilhada é essa reta extrapolada. A grande maioria dos pontos ficou abaixo de $\mathrm{pa}=\mathrm{pr}$ indicando que a sessão de estímulos reais apresentou valores maiores de largura de distribuição do que a sessão de estímulos aleatórios, principalmente para valores acima de $4 \mathrm{~ms}$. Os dados não tem relação linear uma vez que não seguiram a linha vermelha mas se espalharam em seu entorno, indicando que as sessões de estímulo de IPIs reais e aleatórios vem de distribuições que diferem na forma, dispersão e localização. 


\begin{tabular}{|c|c|c|c|c|c|c|}
\hline & \multicolumn{5}{|c|}{ Largura média da distribuição (ms) em resposta a: } & \multirow[b]{2}{*}{$\begin{array}{l}\frac{(\text { real }- \text { aleatório })}{\text { aleatório }} * 100 \\
(\mathbf{\%})\end{array}$} \\
\hline & controle 1 & $\begin{array}{l}\text { estímulo } \\
\text { real }\end{array}$ & controle 2 & $\begin{array}{l}\text { estímulo } \\
\text { aleatório }\end{array}$ & controle 3 & \\
\hline \multicolumn{7}{|l|}{ Protocolo 1} \\
\hline $\begin{array}{l}\text { Peixe } A-1^{o} \\
\text { dia }\end{array}$ & 2.56 & 4.14 & 2.12 & 3.26 & 2.28 & 26.9 \\
\hline $\begin{array}{l}\text { Peixe } \mathrm{A}-2^{\mathrm{a}} \\
\text { semana }\end{array}$ & 3.28 & 4.25 & 2.82 & 3.69 & 2.60 & 15.2 \\
\hline $\begin{array}{l}\text { Peixe } B-1^{o} \\
\text { dia }\end{array}$ & 2.43 & 3.60 & 2.33 & 3.03 & 2.37 & 18.8 \\
\hline $\begin{array}{l}\text { Peixe } B-2^{a} \\
\text { semana }\end{array}$ & 1.96 & 2.51 & 2.04 & 2.44 & 2.26 & 2.9 \\
\hline Peixe $\mathrm{C}$ & 1.98 & 17.50 & 1.94 & 6.50 & 2.19 & 169.2 \\
\hline Peixe D & 2.40 & 4.60 & 2.12 & 3.10 & 1.90 & 48.4 \\
\hline Peixe E & 2.19 & 3.46 & 1.87 & 2.86 & 1.87 & 20.9 \\
\hline Peixe F & 2.54 & 3.28 & 2.42 & 2.79 & 2.13 & 17.6 \\
\hline Peixe G & 2.64 & 3.80 & 1.75 & 2.95 & 2.14 & 28.8 \\
\hline Peixe H & 5.40 & 2.90 & 2.00 & 3.00 & 1.90 & -3.3 \\
\hline Peixe I & 2.76 & 3.20 & 2.25 & 2.28 & 2.15 & 28.8 \\
\hline \multicolumn{7}{|l|}{ Protocolo 2} \\
\hline Peixe J & 1.76 & 3.00 & 1.80 & 2.40 & 2.10 & 25.0 \\
\hline Peixe K & 2.00 & 2.80 & 2.00 & 2.50 & 1.80 & 12.0 \\
\hline Peixe L - & 1.60 & 2.80 & 1.60 & 1.70 & 1.60 & 64.7 \\
\hline Peixe $M$ & 1.60 & 1.60 & 1.30 & 1.50 & 1.50 & 6.7 \\
\hline Peixe N & 2.10 & 1.72 & 1.78 & 1.69 & 1.90 & 1.8 \\
\hline $\begin{array}{l}\text { Peixe } \mathrm{O}-1^{\circ} \\
\text { dia }\end{array}$ & 1.80 & 2.08 & 1.60 & 1.84 & 1.90 & 13.0 \\
\hline $\begin{array}{l}\text { Peixe } \mathrm{O}-6^{\mathrm{a}} \\
\text { semana }\end{array}$ & 5.32 & 6.41 & 3.84 & 5.56 & 3.23 & 15.3 \\
\hline
\end{tabular}




\begin{tabular}{|l|l|l|l|l|l|l|} 
Peixe P & 1.60 & 1.61 & 1.40 & 1.73 & 1.30 & -6.9 \\
Peixe Q & 5.15 & 5.62 & 3.58 & 5.24 & 4.28 & 7.2 \\
Peixe R & 3.05 & 2.92 & 2.60 & 3.09 & 2.67 & -5.5 \\
Peixe S & 4.43 & 5.73 & 3.38 & 6.23 & 2.80 & -8.0 \\
Peixe T & 2.88 & 2.60 & 2.06 & 2.14 & 1.98 & 21.5 \\
\hline
\end{tabular}

Tabela 3: Largura média da distribuição de IPIs (2-98 percentil) em resposta ao controle 1, estímulo com IPIs reais pré-gravados, controle 2, estímulo com IPIs aleatórios e controle 3.

Os peixes apresentaram interrupções espontâneas de disparos (Fig. 30, Tabelas 4 e 5) definidas como (IPI > 2xIPI médio). Comparando as sessões de estímulo, aquelas em que foram enviados estímulos reais apresentaram maior $\%$ de silenciamento do OE (>0,1\% dos IPIs totais; Fig. $30 \mathrm{~A})$, tempos máximos sem disparar maiores (Fig. 30 C), com média 14,6 s e mediana $2 \mathrm{~s}$, contra média $3,7 \mathrm{~s}$ e mediana 1,3 s (Wilcoxon $\mathrm{p}=0,007$ ), ao passo que, nas sessões de estímulo aleatório, houve menos silenciamentos do $\mathrm{OE}$ (de $0-0,05 \%$ do número total de IPIs), apesar dos tempos mínimos sem disparar serem maiores $(0,1-0,4 \mathrm{~s}$; Fig. $30 \mathrm{~B})$, não encontramos diferenças estatisticamente relevantes entre os tempos mínimos nas sessões de estímulo (Wilcoxon $\mathrm{p}=0,2$ )

Já entre os protocolos, no protocolo 1 todos os peixes tiverem mais interrupções quando submetidos ao estímulo de IPIs reais pré-gravado do que quando submetidos ao estímulo de IPIs aleatórios. Um único peixe (C) parou de disparar por mais de 2 min quando o estímulo de IPIs reais foi ligado. No protocolo 2,4 de 12 experimentos apresentaram mais interrupções durante o estímulo de IPIs reais.

Apesar dos peixes pararem de disparar por mais tempo durante a primeira sessão de estímulos, o maior tempo sem disparar, $150 \mathrm{~s}$ (peixe C), ocorreu para a sessão de estímulo com IPIs reais. Já o maior intervalo sem disparar para a sessão de estímulo de IPIs aleatórios foi de $43 \mathrm{~s}$ (peixe T). 

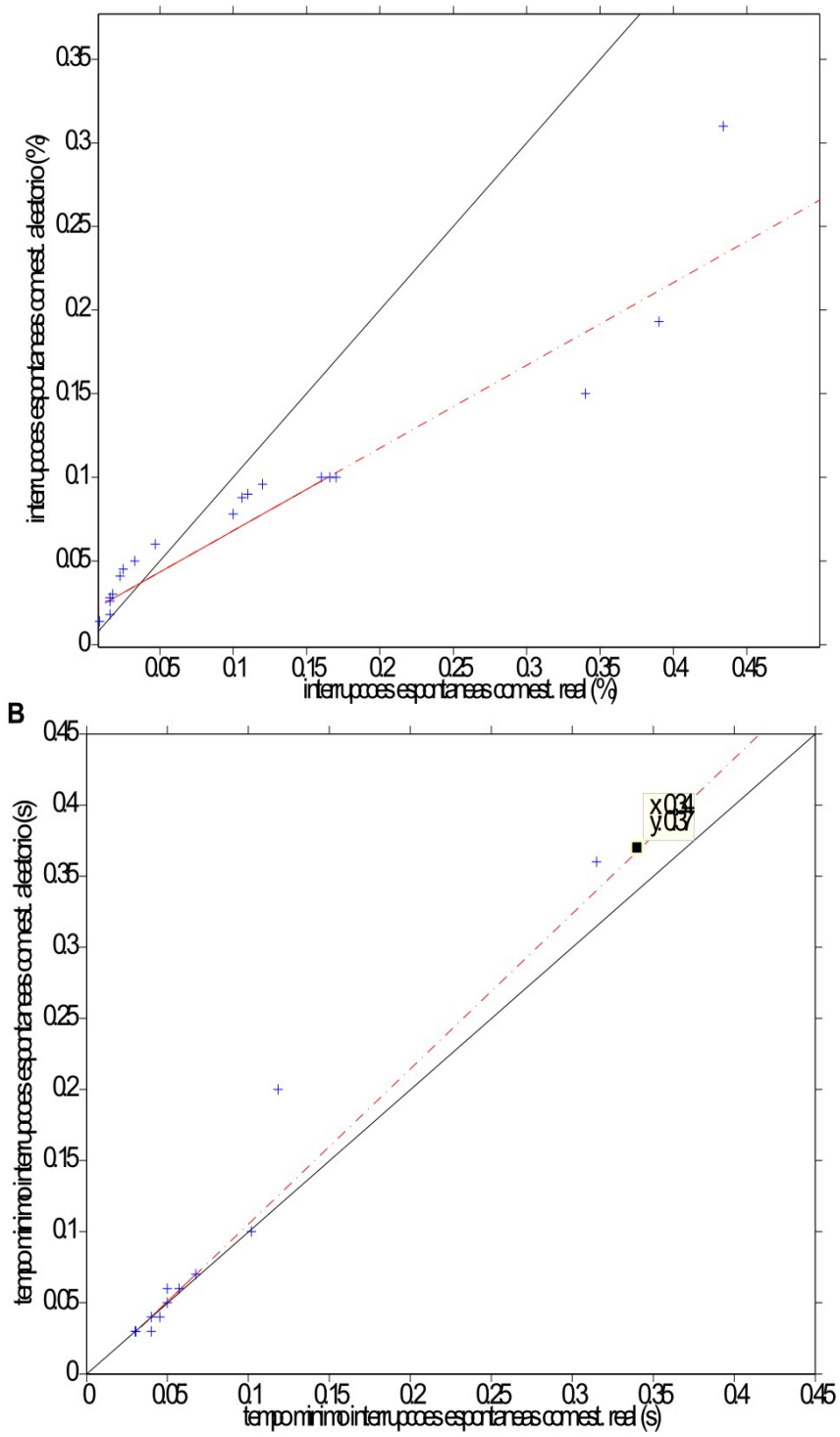

C

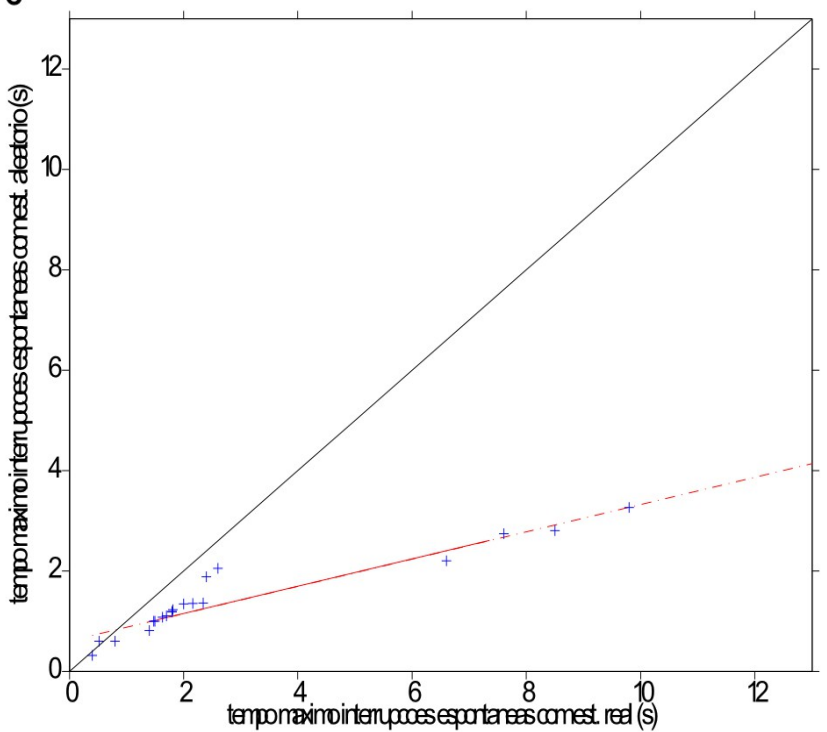

Fig. 30: Quantile-quantile plot para sessões de estímulo $A-\%$ do número total de interrupções espontâneas do $O E, B$ - tempo mínimo que o OE ficou sem disparar e $C$-tempo máximo que o OE ficou sem disparar. A linha preta é a reta $x=y$, linha vermelha é a ligação do $1^{\circ}$ e $3^{\circ}$ quartil, e a linha vermelha pontilhada é essa reta extrapolada. A - dentre os peixes que pararam pouco de disparar ( $<0.1 \%$ to total de IPIs), as interrupções foram mais longas nas sessões com estímulo aleatório do que nas de estímulo real ( + azuis acima da reta $x=y)$, já para as interrupções de mais de 0,1\% do total de IPIs, o quadro se inverteu, sendo maior a \% de silenciamentos do OE nas sessões de estímulo real. B - os tempos mínimos que os peixes pararam de disparar apresentaram, nas 2 sessões, distribuições parecidas e com uma relação linear entre elas em até $0,1 \mathrm{~s}$ (os pontos seguem a linha vermelha do $1^{\circ} e$ $3^{\circ}$ quartil). $C$ - as sessões de estímulos reais apresentaram tempos máximos sem disparar maiores do que as sessões de estímulos aleatórios (todos os pontos estão a baixo da reta $x=y$ ), não houve interrupções nas sessões de estímulo real entre 2,2 - 6,6. Podemos dizer que há um relação linear entre elas (pontos distribuídos ao redor da reta vermelha), com exceção de 2 pontos. 
Ocorreram menos interrupções espontâneas nas sessões de controle (tabela 5) do que nas sessões com estímulo e o controle 1 apresentou, em média, menos interrupções que os demais controles. 


\begin{tabular}{|c|c|c|c|c|}
\hline & \multicolumn{4}{|c|}{ Interrupções espontâneas de disparo durante: } \\
\hline & \multicolumn{2}{|c|}{ sessão com estímulos de IPIs reais } & \multicolumn{2}{|c|}{$\begin{array}{l}\text { sessão com estímulos de IPIs } \\
\text { aleatórios }\end{array}$} \\
\hline & $\begin{array}{l}\% \text { do no } \\
\text { total de } \\
\text { IPIs }\end{array}$ & duração (s) [min max] & $\begin{array}{l}\% \text { do } \mathrm{n}^{0} \\
\text { total de } \\
\text { IPIs }\end{array}$ & duração (s) [min max] \\
\hline \multicolumn{5}{|l|}{ Protocolo 1} \\
\hline Peixe $\mathrm{A}-1^{\circ}$ dia & 0.016 & {$[0.04$ 1.40] } & 14 & {$\left[\begin{array}{lll}0.04 & 1.00]\end{array}\right]$} \\
\hline $\begin{array}{l}\text { Peixe } A-2^{a} \\
\text { semana }\end{array}$ & 0.166 & [0.04 2.34] & 0.096 & {$[0.041 .88]$} \\
\hline Peixe $\mathrm{B}-1^{\mathrm{o}}$ dia & 0.004 & {$\left[\begin{array}{lll}0.11 & 0.40\end{array}\right]$} & 0.001 & 1.08 \\
\hline $\begin{array}{l}\text { Peixe B - } 2^{\mathrm{a}} \\
\text { semana }\end{array}$ & 0.018 & {$\left[\begin{array}{lll}0.46 & 0.80\end{array}\right]$} & 0.002 & {$\left[\begin{array}{lll}0.86 & 1.19\end{array}\right]$} \\
\hline Peixe $\mathrm{C}$ & 2.290 & {$\left[\begin{array}{lll}0.06 & 150.00]\end{array}\right]$} & 1.320 & {$[0.05$ 5.88] } \\
\hline Peixe D & 0.106 & [0.05 47.50] & 0.078 & {$[0.041 .35]$} \\
\hline Peixe E & 0.340 & {$\left[\begin{array}{lll}0.04 & 1.63\end{array}\right]$} & 0.150 & [0.04 2.05] \\
\hline Peixe F & 0.170 & [ 0.04 7.61] & 0.060 & {$\left[\begin{array}{ll}0.03 & 1.18\end{array}\right]$} \\
\hline Peixe G & 0.390 & {$[0.042 .16]$} & 0.310 & {$[0.043 .26]$} \\
\hline Peixe $\mathrm{H}$ & 0.160 & [0.34 1.48] & 0.100 & {$\left[\begin{array}{lll}0.36 & 1.10\end{array}\right]$} \\
\hline Peixe I & 0.100 & [0.34 2.60] & 0.090 & {$\left[\begin{array}{lll}0.37 & 1.23\end{array}\right]$} \\
\hline \multicolumn{5}{|l|}{ Protocolo 2} \\
\hline Peixe J & 0.120 & {$[0.046 .60]$} & 0.100 & [0.04 6.30] \\
\hline Peixe K & 0.110 & [0.04 2.40] & 0.100 & {$[0.04$ 2.80] } \\
\hline Peixe L & 0.009 & {$\left[\begin{array}{lll}0.03 & 1.50\end{array}\right]$} & 0.018 & {$\left[\begin{array}{lll}0.07 & 1.36\end{array}\right]$} \\
\hline Peixe M & 0.006 & {$\left[\begin{array}{lll}0.07 & 1.70]\end{array}\right.$} & 0.026 & {$\left[\begin{array}{lll}0.10 & 0.81\end{array}\right]$} \\
\hline Peixe N & 0.006 & {$\left[\begin{array}{lll}0.04 & 0.52\end{array}\right]$} & 0.004 & {$\left[\begin{array}{lll}0.20 & 0.31\end{array}\right]$} \\
\hline Peixe $O-1^{\circ}$ dia & 0.023 & [0.05 1.80] & 0.050 & {$\left[\begin{array}{lll}0.03 & 0.60\end{array}\right]$} \\
\hline $\begin{array}{l}\text { Peixe } O-6^{a} \\
\text { semana }\end{array}$ & 0.016 & [0.04 2.00] & 0.028 & [ $\left.\begin{array}{ll}0.04 & 2.20\end{array}\right]$ \\
\hline Peixe $\mathrm{P}$ & 0.033 & [0.05 9.80] & 0.041 & [ 0.06 1.34] \\
\hline Peixe Q & 0.025 & [0.05 1.81] & 0.045 & {$\left[\begin{array}{ll}0.05 & 1.00\end{array}\right]$} \\
\hline
\end{tabular}




\begin{tabular}{|l|l|l|l|l|} 
Peixe R & 0.047 & {$[0.038 .50]$} & 0.088 & {$[0.032 .74]$} \\
Peixe S & 0.016 & {$[0.041 .80]$} & 0.030 & {$[0.040 .60]$} \\
Peixe T & 0.434 & {$[0.1280 .00]$} & 0.193 & {$[0.0643 .00]$} \\
\hline
\end{tabular}

Tabela 4:Interrupções espontâneas de disparo para sessões com estímulos nos protocolos 1 e 2 .

\begin{tabular}{|l|l|l|}
\hline Média\%(StD) de interrupções de disparos durante: \\
\hline Controle 1 & Controle 2 & Controle 3 \\
\hline $0.014(3)$ & $0.012(2)$ & $0.011(2)$ \\
\hline
\end{tabular}

Tabela 5:Interrupções espontâneas de disparo para sessões sem estímulos nos protocolos 1 e 2 .

Analisando o comportamento elétrico (IPIs) junto com o motor, as oscilações na atividade motora não foram diretamente relacionadas com a variação nos padrões das palavras (entropia) durante as sessões com estímulo (Tabela 6). Somente 2 peixes de 20 apresentaram valores altos de correlação cruzada entre entropia e movimento quando estimulados com IPIs aleatórios (65\% e $45 \%$ ) ao passo que os valores mais altos quando estimulados com IPIs reais foram de $48,8 \%$ e $36,5 \%$. 


\begin{tabular}{|c|c|c|c|c|c|}
\hline & \multicolumn{5}{|c|}{$\begin{array}{l}\text { Correlação cruzada (\%) entre entropia e a movimento para atraso } 0 \\
\text { durante: }\end{array}$} \\
\hline & controle 1 & estímulo real & controle 2 & $\begin{array}{l}\text { estímulo } \\
\text { aleatório }\end{array}$ & controle 3 \\
\hline \multicolumn{6}{|l|}{ Protocolo 1} \\
\hline Peixe $\mathrm{A}-1^{\circ}$ dia & 21.0 & 6.0 & 2.0 & -12.0 & -3.0 \\
\hline $\begin{array}{l}\text { Peixe A - } 2^{\mathrm{a}} \\
\text { semana }\end{array}$ & 20.0 & -12.0 & 17.0 & 65.0 & 6.0 \\
\hline Peixe $\mathrm{B}-1^{\circ}$ dias. & 21.0 & 26.0 & 48.0 & 4.0 & 26.0 \\
\hline $\begin{array}{l}\text { Peixe } B-2^{a} \\
\text { semana }\end{array}$ & 0.0 & 4.0 & 12.0 & 25.0 & -21.0 \\
\hline Peixe $\mathrm{C}$ & -0.6 & -0.5 & 0.2 .0 & 25.0 & 21.0 \\
\hline Peixe D & 11.0 & 32.0 & -0.7 & 45.0 & 0.6 \\
\hline Peixe E & 10.0 & 0.1 & 0.8 & 0.2 & 11.0 \\
\hline Peixe F & 12.0 & 14.0 & 16.0 & 0.9 & 0.4 \\
\hline Peixe G & 0.1 & -20.0 & -0.4 & 22.0 & 0.6 \\
\hline Peixe $\mathrm{H}$ & -15.0 & -0.1 & 0.2 & -0.5 & 0.9 \\
\hline Peixe I & 0.9 & 10.0 & 0.2 & 12.0 & -30.0 \\
\hline \multicolumn{6}{|l|}{ Protocolo 2} \\
\hline Peixe J & -15.0 & 14.0 & -3.0 & 9.0 & -2.0 \\
\hline Peixe K & -5.6 & 1.5 & -4.0 & 11.0 & -4.0 \\
\hline Peixe L & 11.8 & -15 & 26.0 & 13.4 & 9.8 \\
\hline Peixe M & -37.0 & -0.4 & -18.8 & -39.0 & -30.8 \\
\hline Peixe N & -3.7 & -43.0 & -37.0 & 2.2 & -21.7 \\
\hline Peixe $O-1^{\circ}$ dia & -14.3 & -8.4 & -19.2 & -34.0 & -20.6 \\
\hline $\begin{array}{l}\text { Peixe } \mathrm{O}-6^{\mathrm{a}} \\
\text { semana }\end{array}$ & -17.1 & 48.8 & 0.1 & 33.3 & 23.0 \\
\hline Peixe $\mathrm{P}$ & -8.7 & -19.0 & -14.7 & -5.1 & 8.4 \\
\hline Peixe Q & 5.9 & 23.9 & -0.7 & 33.0 & 7.7 \\
\hline Peixe R & 22.9 & 9.3 & 0.3 & 18.0 & -3.9 \\
\hline Peixe $\mathrm{S}$ & 15.3 & 25.2 & 30.5 & -2.4 & 34.1 \\
\hline
\end{tabular}




\begin{tabular}{|l|l|l|l|l|l|}
\hline Peixe T & 33.6 & 36.5 & 4.2 & -14.6 & 37.0 \\
\hline
\end{tabular}

Tabela 6: correlação cruzada entre entropia (padrões de disparo) e o movimento (soma do desvio padrão das amplitudes dos pulsos nos eletrodos)

\subsection{2- Tempo entre pulso de estímulo e pulso resposta de Gymnotus carapo}

Construímos histogramas da fase de disparo em relação ao estímulo (PSTH do inglês Post Stimulus Time Histograms), isto é, histogramas do intervalo entre cada pulso de estímulo e o próximo pulso do peixe (Fig.16), a partir dos quais pudemos inferir a probabilidade experimental de ocorrer um pulso real após um pulso de estímulo (Fig.31).

O PSTH para estímulos reais (Fig.31 - curva verde), revelou que Gymnotus carapo apresenta maior probabilidade de disparar no intervalo de $6-12 \mathrm{~ms}$ após um estímulo e menor probabilidade de disparar no intervalo de $0-6 \mathrm{~ms}$. O PSTH obtido para estímulos aleatórios (Fig. 31 - curva vermelha) apresentou uma probabilidade de disparo uniforme. Como os valores médios dos intervalos entre pulsos eram de aproximadamente $20 \mathrm{~ms}$, não há valores de fase maior que esse.

Para generalizar as análises dos PSTHs de todos os peixes, integramos os histogramas em passos de 1 ms e calculamos o quanto do PSTH de estímulos reais se desviava do PSTH de distribuição uniforme dos estímulos aleatórios (Fig.31 - curva preta):

$$
\frac{P S T H_{\text {real }}-P S T H_{\text {aleatório }}}{P S T H_{\text {aleatório }}}
$$

Verificamos que os peixes dispararam de $3 \%$ a $5 \%$ do número total de disparos mais tarde que do observado para os PSTHs para estímulos aleatórios. 


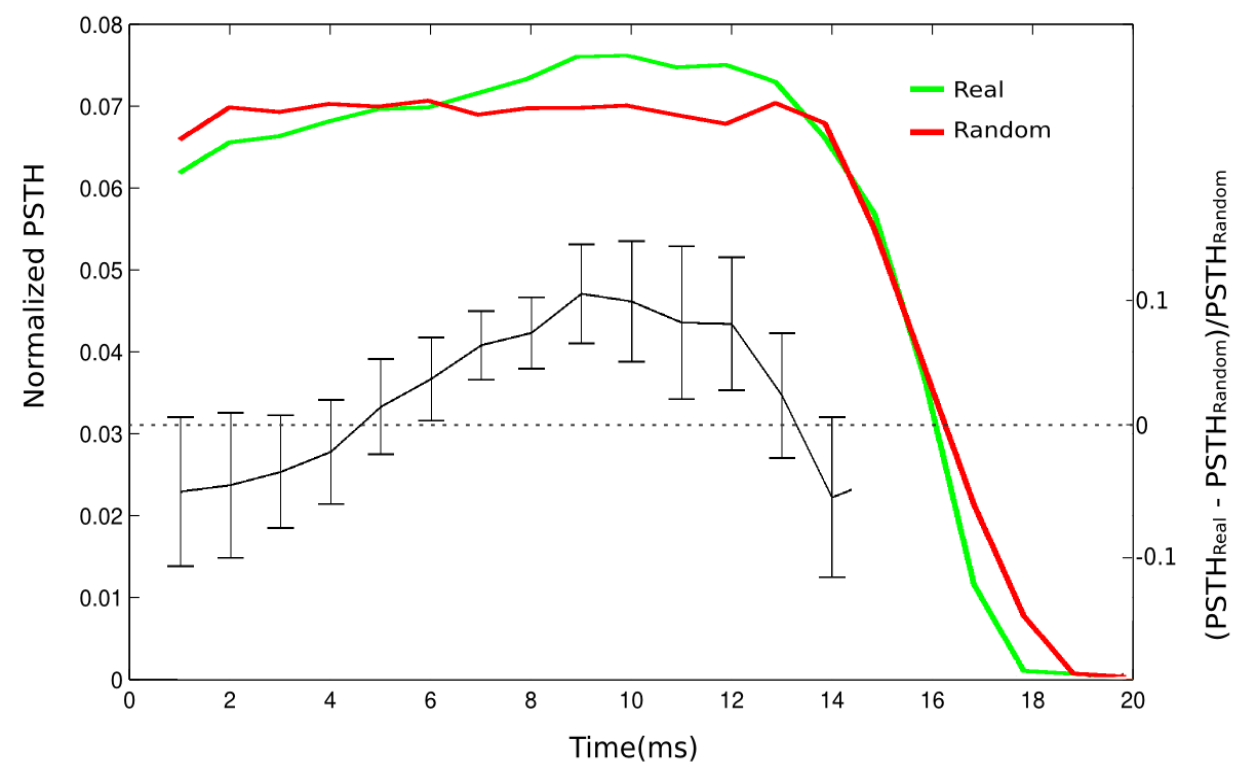

Fig. 31- Post Stimulus Time Histograms (PSTH) para Gymnotous carapo, que mostra a probabilidade da fase de disparo do peixe em relação ao pulso prévio de estímulo. Os estímulos eram tanto pré-gravado de outro peixe (linha verde) ou aleatório entre $15-20 \mathrm{~ms}$ (linha vermelha). Depois de receber pulsos de estímulos com IPIs aleatórios, o peixe apresentou fase com distribuição de probabilidade uniforme, no entanto, depois de estímulos pré-gravados, a probabilidade de disparo diminui um pouco entre $1 \mathrm{~ms}$ e $5 \mathrm{~ms}$ e aumentou no intervalo entre $6 \mathrm{~ms}$ e $12 \mathrm{~ms}$ com preferencia de disparar de 3\% a 5\% do número total de EODs. Foram feitos PSTHs para 20 peixes diferentes que foram integrados em passos de $1 \mathrm{~ms}$ para calcular quanto do PSTH de estímulos de peixe real se desvia dos PSTHs para estímulos aleatórios (curva preta). Em resposta a EODs de um peixe real a distribuição de IPI apresentou menor probabilidade de $1 \mathrm{~ms}$ a $5 \mathrm{~ms}$ que aumentou para o intervalo de 5 a $13 \mathrm{~ms}$ (ANOVA, $p<0.01)$.

\subsection{3- Experimentos com pulsos que mudam de amplitude}

Em todos os experimentos realizados anteriormente em Gymnotus carapo os estímulos empregados tinham amplitude constante, isso quer dizer que o peixe sentia os estímulos como vindo de um peixe parado na mesma posição dentro do aquário. Para tornar o experimento mais realista e analisar o quanto a amplitude influi na eletrocomunicação fizemos com que o pulso do estímulo variasse de amplitude como explicado na seção 2.4.1-pág.19 . As mudanças de amplitude do estímulo podem simular afastamento (quando a amplitude diminui), aproximação (quando a amplitude aumenta) 
ou mesmo peixes de tamanhos diferentes, por exemplo, estímulos de $1 \mathrm{~V}$ podem representar peixes de tamanhos menores que os de $5 \mathrm{~V}$.

Os experimentos seguiram o seguinte protocolo: controle de $30 \mathrm{~min}$ sem estímulo, $10 \mathrm{~min}$ de estímulo, $30 \mathrm{~min}$ sem estímulo, $10 \mathrm{~min}$ de estímulo e $30 \mathrm{~min}$ sem estímulo. Foram usados 3 peixes. Todos os peixes passaram a disparar IPIs mais curtos quando estavam sendo estimulados, alterando abruptamente sua distribuição de IPIs no início e fim das sessões de estímulo. No último controle, os peixes apresentaram IPIs mais longos que nas demais sessões. Todos se movimentaram durante quase todos os experimentos, as paradas no movimento eram curtas não superando 3 min e nunca aconteceram nas sessões de estímulo. A entropia e o movimento não estavam relacionados como mostrado nos experimentos sem estímulo (seção 3.1.1- pág. 34). 


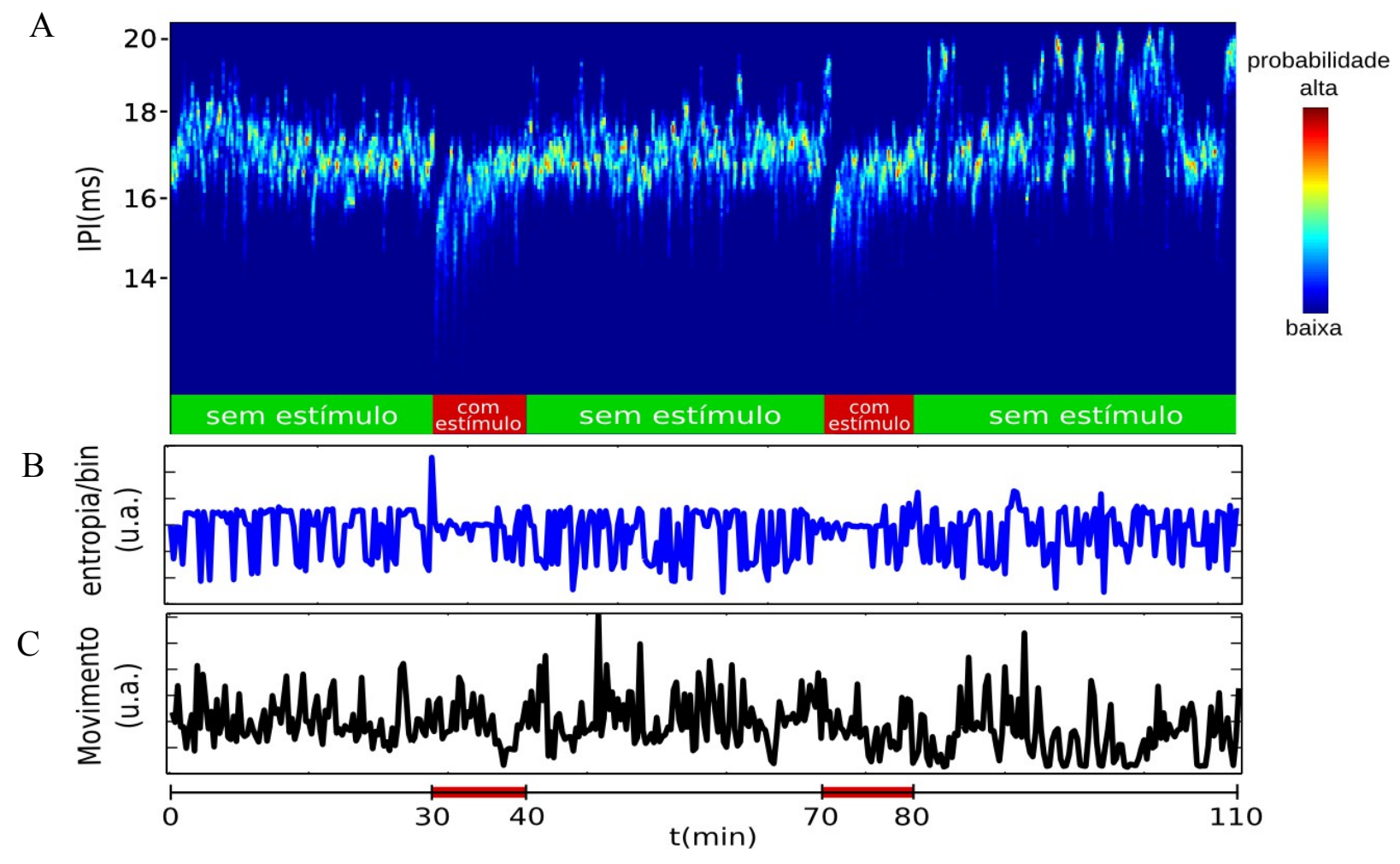

Fig.32: A - histograma de IPIs no tempo para um exemplar de Gymnotus carapo com o protocolo: controle de $30 \mathrm{~min}$ sem estímulo, $10 \mathrm{~min}$ de estímulo, $30 \mathrm{~min}$ sem estímulo, $10 \mathrm{~min}$ de estímulo e $30 \mathrm{~min}$ sem estímulo Associamos um código de cor com as probabilidades dos IPIs, azul escuro significa baixíssima ocorrência (0\%), azul (5\%), ciano (10\%) amarelo(15\%) e vermelho (25\%) indica IPIs de probabilidade mais alta alta . Ao iniciarmos o estímulo ( $t=30 \mathrm{~min})$, o peixe passou a emitir pulsos a intervalos de tempos mais curtos $(\sim 13,5$ - 16 ms e 15,5 - $17 \mathrm{~ms}$ ) isso ocorreu nas duas vezes em que o estímulo foi enviado (barra vermelha), depois os IPIs médios aumentaram para 16-17,5 ms. Imediatamente após a interrupção do estímulo da segunda sessão $(t=80 \mathrm{~min})$ os IPIs médios aumentaram $(\sim 19,5 \mathrm{~ms})$ indicando comportamento mais relaxado. Logo, voltaram para 16,5 - $18 \mathrm{~ms}$ e em seguida alteraram entre IPIs de 16,5 ms e 19,5 ms. B-entropia por bin vs tempo e Cmovimento (desvio padrão das amplitudes nos eletrodos) vs tempo. As mudanças na entropia não acompanharam as mudanças na movimentação do peixe. O peixe se movimentou durante a maior parte do experimento, na última sessão, ele ficou parado por no máximo 2 min (movimento $\sim 0$ ).

Mostramos o resultado de um experimento para um exemplar de Gymnotus carapo na Fig.32. Das 2 vezes que iniciamos o estímulo, o peixe alterou seu comportamento elétrico passando a emitir pulsos a intervalos de tempos, em média, mais curtos $(\sim 15 \mathrm{~ms}$ e $15,5 \mathrm{~ms})$ e minutos depois estes se tornaram mais longos entre 16 - 17,5 ms (Fig.32A). Imediatamente após a interrupção do estímulo os IPIs aumentaram $(\sim 16,5-18 \mathrm{~ms})$ indicando comportamento mais relaxado. Durante a segunda sessão sem estímulo houve momentos em que o peixe apresentou IPIs de 19,5 ms, maiores que seu IPI médio 
e no final do experimento o peixe alterou, diversas vezes, seus IPIs entre 16,5 e 19 ms. As mudanças na entropia (Fig.32B) não acompanharam as mudanças no movimento (desvio padrão das amplitudes nos eletrodos; Fig.32C) como ocorreu nos experimentos sem estímulos (seção 3.1.1-). O peixe se movimentou durante quase todo o experimento, ficando parado por no máximo 2 min na última seção sem estímulo.

Calculamos também a AMI para verificarmos para quais amplitudes havia mais informação transmitida entre o estímulo e a resposta do peixe, para tal usamos janelas de $20 \mathrm{~s}$ com passo de $10 \mathrm{~s}$ (seção 2.5.3-pág.30)e utilizando atrasos de $0 \mathrm{~s}$ a $5 \mathrm{~s}$ entre o estímulo e a resposta do peixe. Mostramos resultados para 2 peixes difetentes na Fig.33. Os valores da AMI foram associados a um código de cor: amarelo significa AMI alta, vermelho seria AMI alta mas mais baixa que amarelo e azul escuro significa AMI mais baixa.

A maior parte dos trechos que apresentaram AMI alta (regiões amarelas e vermelhas), ou seja, trechos onde a variabilidade da resposta do peixe estava mais relacionada com a variabilidade do estímulo, correspondem a estímulos com amplitude constante e alta de $5 \mathrm{~V}$ ou que mudaram de amplitude de $5 \mathrm{~V}$ a $1 \mathrm{~V}$ ou de $1 \mathrm{~V}$ a $5 \mathrm{~V}$. Em algumas partes do estímulo com amplitude constante baixa de $1 \mathrm{~V}$ também houve AMI alta. Os trechos com AMI baixa, foram tanto aqueles de estímulo com amplitude constante e alta de $5 \mathrm{~V}$, como também, com amplitude variável de $5 \mathrm{~V}$ a $1 \mathrm{~V}$. Houve regiões que apresentaram AMI alta para ambos experimentos, as bolinhas: verde, amarela e vermelha, mostram no gráfico onde essas regiões ocorreram, e a bolinha preta mostra onde a AMI foi baixa para os dois peixes. Obtivemos resultados semelhantes para o terceiro peixe utilizado. 


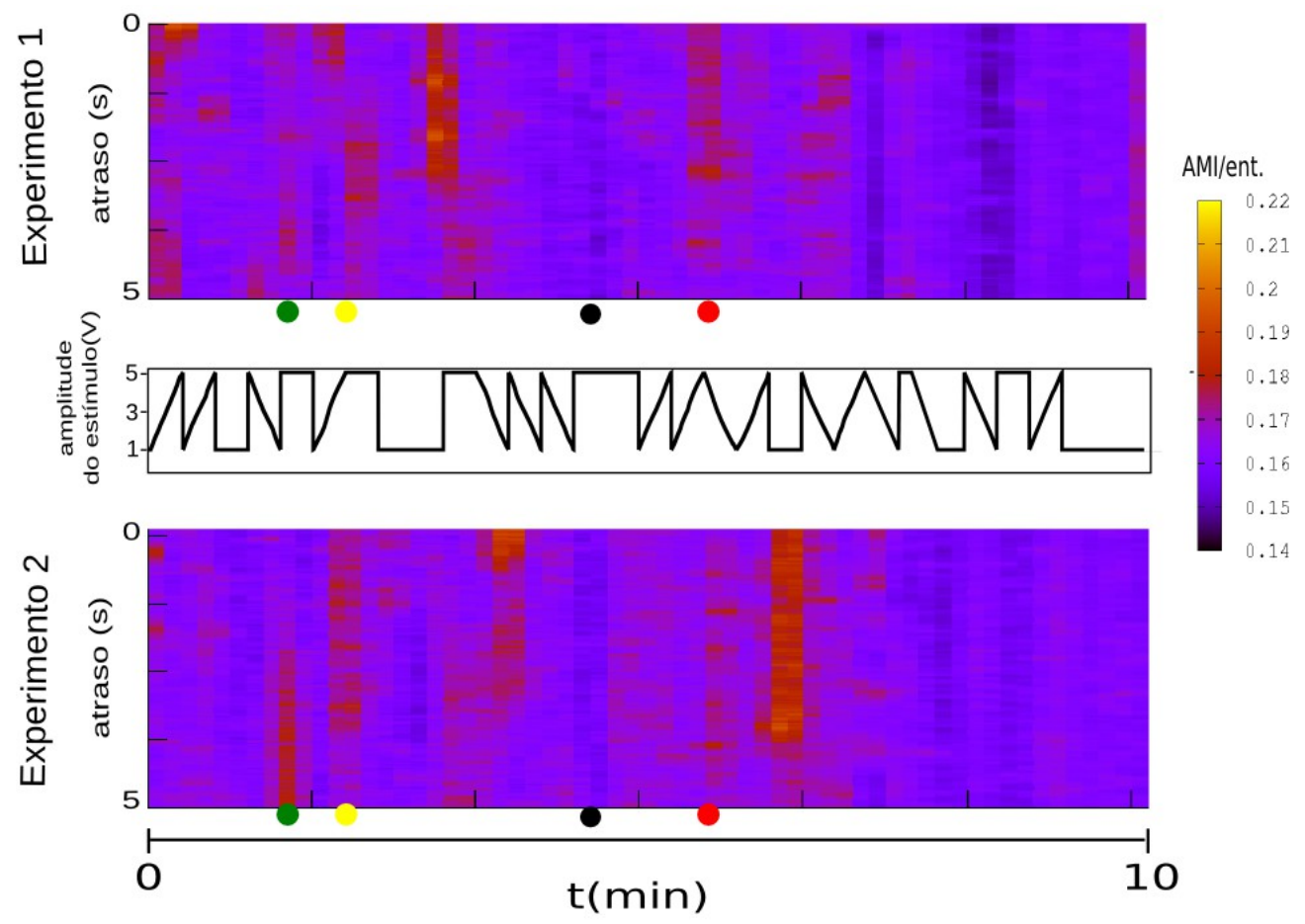

Fig.33: AMI entre o estímulo com amplitude variável e a resposta de Gymnotus carapo para 2 experimentos com 2 peixes diferentes. Os valores da AMI foram associados a um código de cor: amarelo significa AMI mais alta, vermelho seria AMI alta mas mais baixa que amarelo e azul escuro significa AMI bem baixa. Os círculos verde, amarelo e vermelho mostram onde a AMI foi alta em ambos experimentos e o círculo preto mostra onde a AMI foi mais baixa. A maior parte dos trechos que apresentaram AMI alta correspondem a estímulos que mudaram de amplitude de $5 \mathrm{~V}$ a $1 \mathrm{~V}$ ou de $1 \mathrm{~V}$ a $5 \mathrm{~V}$ e amplitude constante de $5 \mathrm{~V}$, em algumas partes do estímulo com amplitude constante de $1 \mathrm{~V}$ também houve AMI alta. No trecho com AMI baixa nos 2 experimentos, a amplitude do estímulo foi constante e alta de $5 \mathrm{~V}$ (bolinha preta).

\subsection{4- Análise do conjunto de palavras mais prováveis de Gymnotus carapo}

Dois peixes, adquiridos em São Paulo em 2008, tiveram seus pulsos gravados durante $30 \mathrm{~min}$ em 3 situações diferentes: (1) sem estímulo, (2) com estímulo pré-gravado e (3) dois peixes interagindo em tempo real (os pulsos de um servindo de estímulo para o outro). Este protocolo foi realizado duas vezes com os mesmos animais. Outros 4 peixes, um adquirido em São Paulo em 2008 e outros 3 adquiridos em São Carlos em 2012, tiveram seus pulsos gravados em sessões de 30 min sem estímulo seguida de 30 min de estímulo de amplitude pré-gravado. 
As séries de tempos de disparo das respostas dos peixes foram binarizadas usando bins de 14 $\mathrm{ms}$, valor que maximizava a entropia dos pulsos. Quando havia um disparo do peixe, colocávamos 1, e 0 quando não havia disparos. Após a binarização das séries de tempos de disparo, formamos palavras de 6 bits da seguinte maneira: os primeiros 6 bits formam uma palavra depois se translada 1 bit e a segunda palavra é formada com o bit 2 até o bit 7 e assim até o final da série, como descrito na seção 2.5.3- pág. 30.

$\mathrm{Na}$ ausência de estímulos (Fig.34 A), os 2 peixes dispararam palavras similares. Em mais de 20\% das vezes, vemos as sequências 011011,101101 e 110110, o que seria equivalente a 2 pulsos rápidos seguidos e 1 pulso longo do OE ou a 1 IPI curto seguido de um IPI mais longo. Estas palavras também apareceram em (2) e (3).

Quando os peixes foram estimulados com IPIs reais (Fig.34 B), as palavras de maior ocorrência ( 16\%) passaram a ser 110111 e 111011, ou seja, 3 pulsos consecutivos e 1 pulso longo do OE ou dois IPIs curtos seguidos de um IPI mais longo. Notamos um aumento geral da frequência de disparo com alta ocorrência de palavras com vários 1's seguidos, como, por exemplo, 111101, 111110 e 11111. Estas palavras correspondem a grandes acelerações do OE que podem ser interpretados como comportamento agressivo. Para o peixe 2, $13 \%$ das palavras foram 111111 contra $8 \%$ do peixe 1 .

Já com dois peixes interagindo em tempo real (Fig.34 C), as palavras mais disparadas por cada peixe não foram similares em sua maioria, com exceção de 010101 e 101010 que significam atividade mais ou menos periódica com pulsos a cada $28 \mathrm{~ms}$ aproximadamente. O peixe B era o menos agressivo, e notamos maior ocorrência das palavras que correspondem a IPIs mais longos, tais como, 001010,010010,010100, 100101 e 101001. Já para o peixe A, houve maior ocorrência de palavras com IPIs mais curtos, como 010110, 011010, 101011 e 101101. É interessante notar que, para esse peixe, $1 \%$ das palavras foram 000000 , ou seja, um longo silenciamento do OE. 

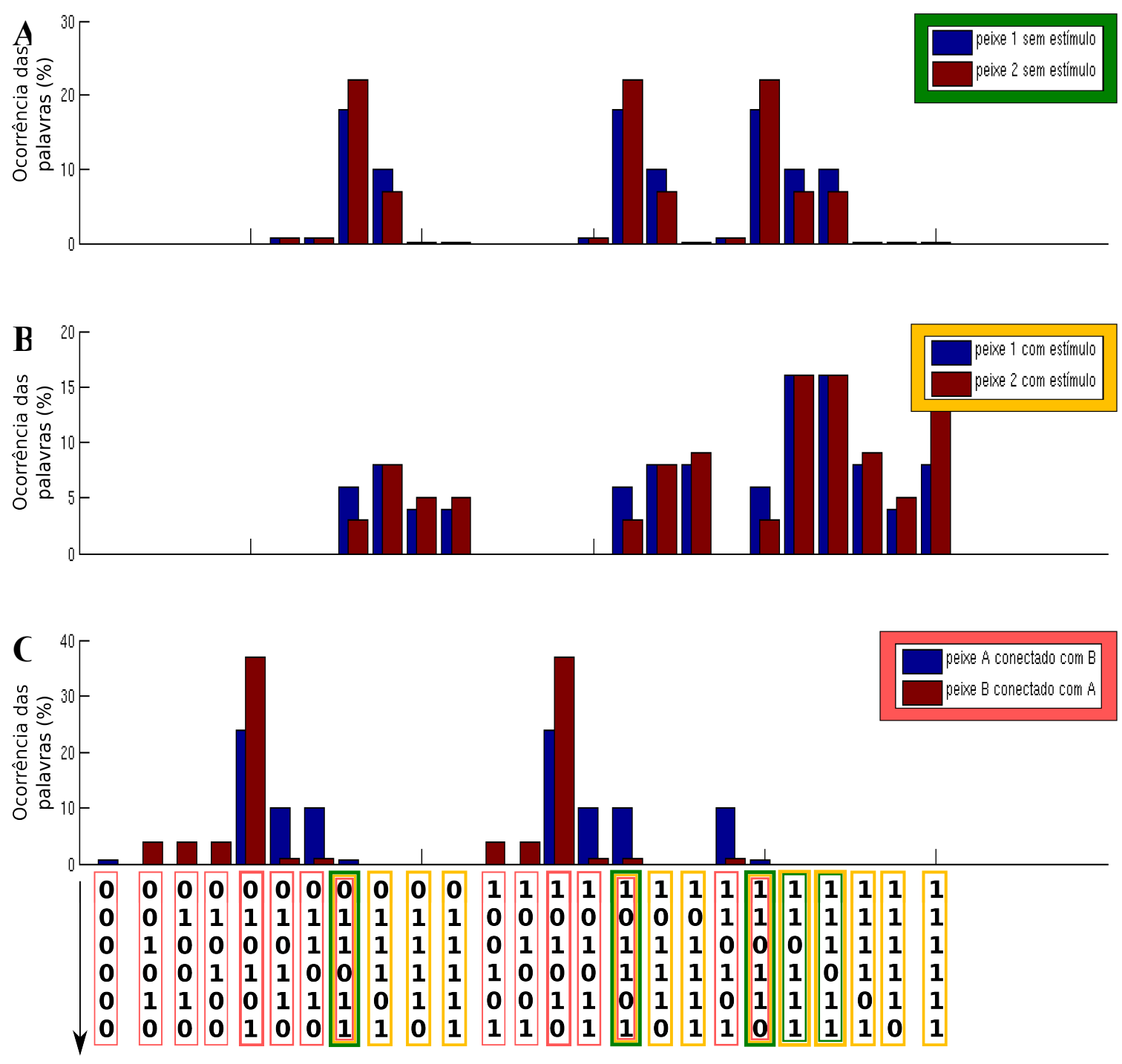

Palavras de 6 bits

Fig.34: Palavras de maior ocorrência em $A$ - peixe sem estímulo, $B$ - peixe com estímulo pré-gravado de outro e $C$-dois peixes interagindo em tempo real. A série foi binarizada com bins de $14 \mathrm{~ms}, 1$ significa que houve um pulso do peixe e 0 que não houve pulsos. As palavras mais frequentes foram similares para os 2 peixes quando estavam sem estímulo (A) e com estímulo pré-gravado (B). Em (A), as palavras mais usadas foram 011011,101101 e 110110, cada uma com mais de $20 \%$ de chance. Quando estimulados (B), houve maior ocorrência de palavras com pelo menos 3 1's em sequência, tais como, 110111, 111011,111101, 111110 e 11111. Já nos peixes conectados entre si (C), para o peixe B, houve maior ocorrência de palavras com 0's seguidos como, 001010, 010010, 010100 etc, e para o peixe A, houve maior ocorrência das palavras com 1's seguidos, como, por exemplo, 010110 e 101011. As palavras mais frequentes para ambos foram 010101 e 101010. 
Durante os 30 min sem estímulo, em todos os experimentos e para todos os peixes, as palavras que mais ocrreram foram 011011,101101 e 110110, seguidas por 110111 e 111011 , com 5 - 10\% de ocorrência. Em 5 das 9 medidas, também com 5 - 10\% de ocorrência estavam 011101 e 101110 e em 3 medidas, 110111, 111011, 011101 e 101110 tiveram menos de 1\% de ocorrência, sendo as palavras com 5-10\%: 010110, 011010, 101011 e 110101.

Com estímulos pré-gravados de um ataque, 110111 e 111011 passaram a ser as palavras mais prováveis, seguidas pelas mesmas disparadas na ausência de estímulo, somando-se a estas as palavras 101111,111101 e 011110.

\section{4 - Experimentos com estímulos elétricos em Gnathonemus petersii}

\subsection{1- Estímulos pré-gravados de Gnathonemus petersii}

O protocolo empregado nesse experimento foi: 20 min sem estímulo, 20 min com estímulo, 20 min sem estímulo e 20 min com estímulo. Foram realizados 8 experimentos em 8 Gnathonemus petersii diferentes. Todos os peixes apresentaram distribuições com 2 ou 3 valores mais prováveis, um entre $\sim 0-150 \mathrm{~ms}$ e outro entre $\sim 150-600$, ou no caso de 3 IPIs mais prováveis, entre $\sim 150-350 \mathrm{~ms}$ e $\sim 300-600 \mathrm{~ms}$. Durante o estímulo houve um aumento da probabilidade de disparar IPIs mais curtos $(30-250 \mathrm{~ms})$ do que quando não estimulados, no entanto, as larguras das distribuições não foram alteradas. Mostramos as medidas dos IPIs de um exemplar submetido ao protocolo acima (Fig. 35) 

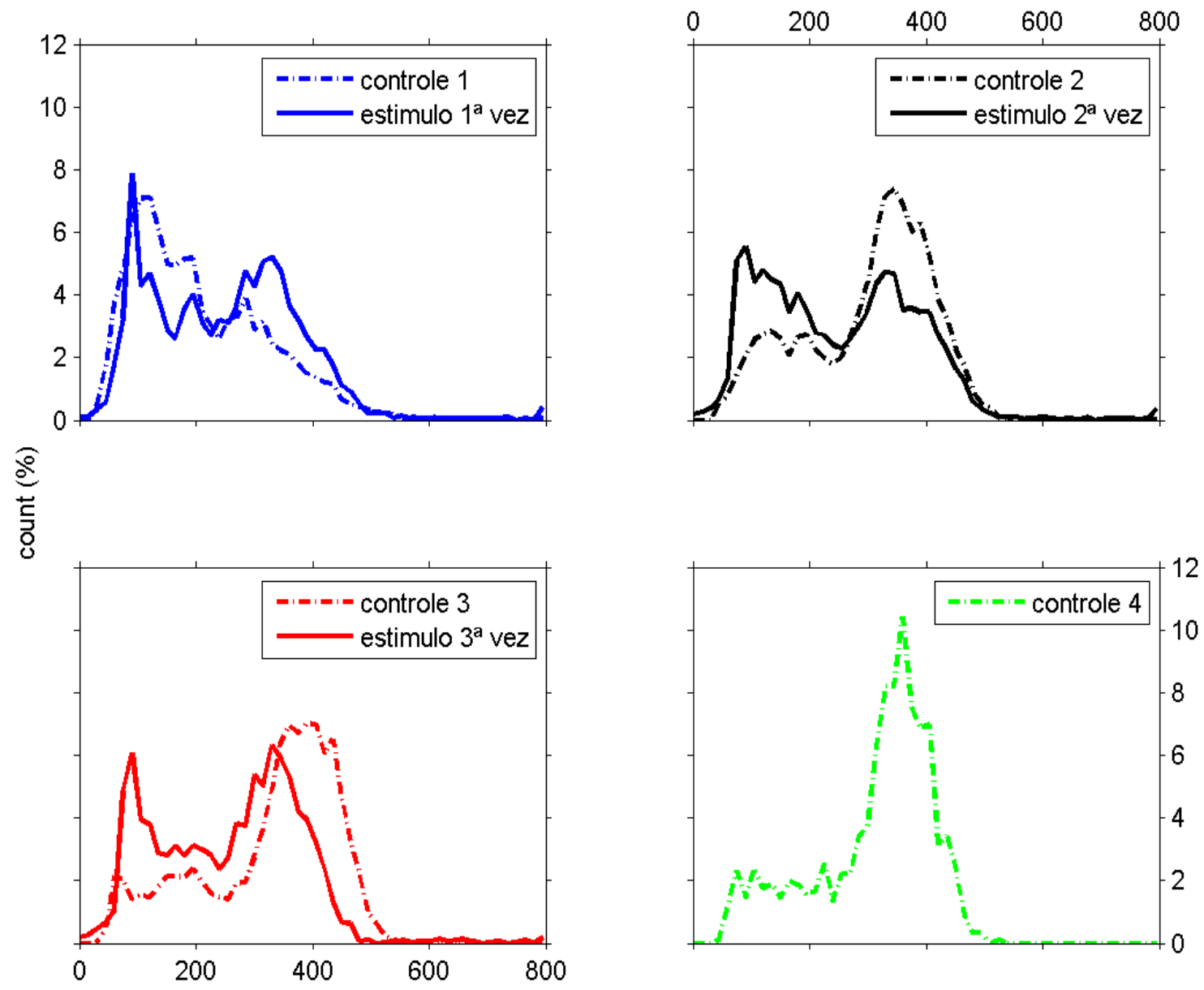

IPI (ms)

Fig. 35: Histograma dos IPIs de Gnathonemus petersii sem estímulo (linha tracejada) e com estímulo (linha cheia). Quando estimulado o OE aumentou sua frequência, disparando com maior probabilidade a intervalos de 70 ms. Ao ser retirado o estímulo, o peixe voltou a apresentar uma distribuição de IPIs similar a do começo do experimento e reagiu novamente ao ser estimulado com o aumento da frequência das EODs. Nota-se também que o peixe sempre disparou com intervalos perto de 400 ms com ou sem estímulos.

Nos primeiros 20 min sem estímulos, o peixe dispara seu OE principalmente com intervalos de $370 \mathrm{~ms}$ e também de $170 \mathrm{~ms}$ (Fig.35 linha azul tracejada). Quando o peixe foi estimulado os IPIs se alteraram e o OE passou a disparar mais vezes com intervalos de $70 \mathrm{~ms}$ mas não deixando de disparar com intervalos de 370 ms (Fig.35 linha azul cheia). Após o término do estímulo (Fig.35 Linha preta tracejada), o peixe volta a disparar como no começo do experimento com a diferença de apresentar mais IPIs de $70 \mathrm{~ms}$. Novamente durante os períodos de estímulo (Fig. 35 linha preta/vermelha cheia) o 
peixe apresenta comportamento similiar aquele da primeira sessão de estímulo.

Calculamos a AMI entre o estímulo e a resposta e mostramos a AMI para 2 animais na Fig.36.

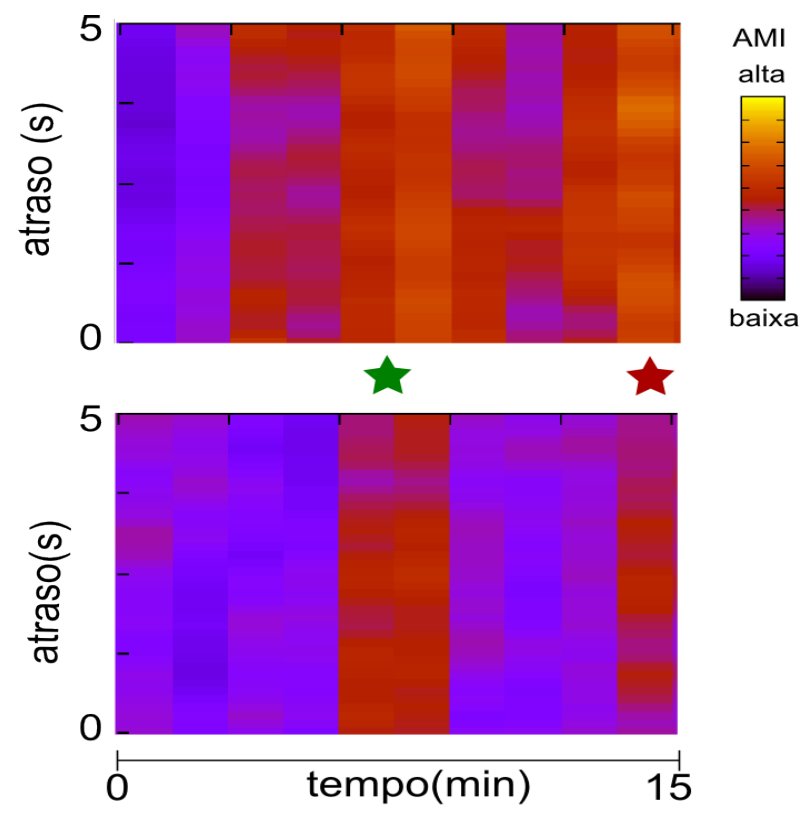

Fig. 36: AMI entre o estímulo e a resposta em 2 Gnathonemus petersii diferentes. Os valores da AMI foram associados a um código de cor: amarelo significa AMI alta (30\%), vermelho (20\%) e azul escuro significa AMI (15\%). Há regiões que apresentaram picos de AMI nos dois animais (estrela verde e vermelha).

Análises de AMI entre o estímulo e a resposta dada por Gnathonemus petersii mostraram também que, para algumas partes da série de estímulo sempre houve maior transmissão de informação em todos os experimentos realizados (estrelas verde e vermelha). Ao comparar propriedades, como a 
frequência, média, desvio padrão, etc, dessas partes "especiais" das respostas, elas não apresentaram diferenças óbvias em relação ao resto do estímulo nem entre as demais partes da resposta.

\subsection{2- Estímulos dependentes da atividade elétrica de Gnathonemus petersii}

Nestes experimentos os estímulos eram disparados de acordo com a atividade elétrica do peixe, o pulso do peixe era detectado em tempo real e depois de um intervalo $\mathrm{T}$ um pulso de estímulo era enviado, como explicado na seção 2.3.2-Fig.9.

Utilizamos o seguinte protocolo: controle de $30 \mathrm{~min}$ sem estímulo, $30 \mathrm{~min}$ com pulsos de estímulo de $3 \mathrm{~V}$ enviados $\mathrm{T}$ ms após um pulso do peixe. O protocolo foi repetido 6 vezes para cada peixe com os seguintes valores de T=10 ms, $20 \mathrm{~ms}, 50 \mathrm{~ms}, 40 \mathrm{~ms}, 70 \mathrm{~ms}, 100 \mathrm{~ms}, 160 \mathrm{~ms}, 200 \mathrm{~ms}, 280$ ms, $400 \mathrm{~ms}$. Foram usados 4 peixes no total.

Quanto menor T, ou seja, quanto menos tempo esperamos entre o disparo do peixe e o envio do pulso do estímulo, mais os peixes modificam seus IPIs comparados com os controles prévios. Houve sempre um aumento da probabilidade de disparar IPIs curtos, menores que $100 \mathrm{~ms}$ e diminuição da largura das distribuições. Nas sessões de controle posteriores a cada sessão de estímulo, as distribuições de IPIs se alteravam voltando a ter menor probabilidade de disparar IPIs curtos e aumentando sua largura. Já quando utilizamos valores de T maiores do que $100 \mathrm{~ms}$, quase não houve mudança no comportamento elétrico.

Apresentamos um exemplo usando os valores de T na sequência de 20 ms, 200 ms, 100 ms, 40 ms, 200 ms e pulsos periódicos a 200 ms (não mais enviados após a detecção de um pulso do peixe). Quando estimulado (Fig.37 - linhas cheias), o órgão elétrico aumentou a sua frequência comparando com períodos de controle (Fig.37 - linhas pontilhadas), especialmente para os estímulos enviados a 20 ms e $40 \mathrm{~ms}$ após a detecção de pulso de peixe. Estímulos enviados a após $200 \mathrm{~ms}$ não alteram a frequência de disparos, tampouco estímulos periódicos enviados com intervalos de $200 \mathrm{~ms}$.

As mudanças nas frequências do OE não foram devidas à ordem em que os experimentos foram feitos, vimos que para $\mathrm{T}=40 \mathrm{~ms}$ houve uma mudança significativa em relação à sessão de controle e para $\mathrm{T}=200 \mathrm{~ms}$ (em preto), apresentado antes que $\mathrm{T}=40 \mathrm{~ms}$, não houve mudanças grandes nos IPIs, ou seja, não é um efeito de habituação do animal aos estímulos. 

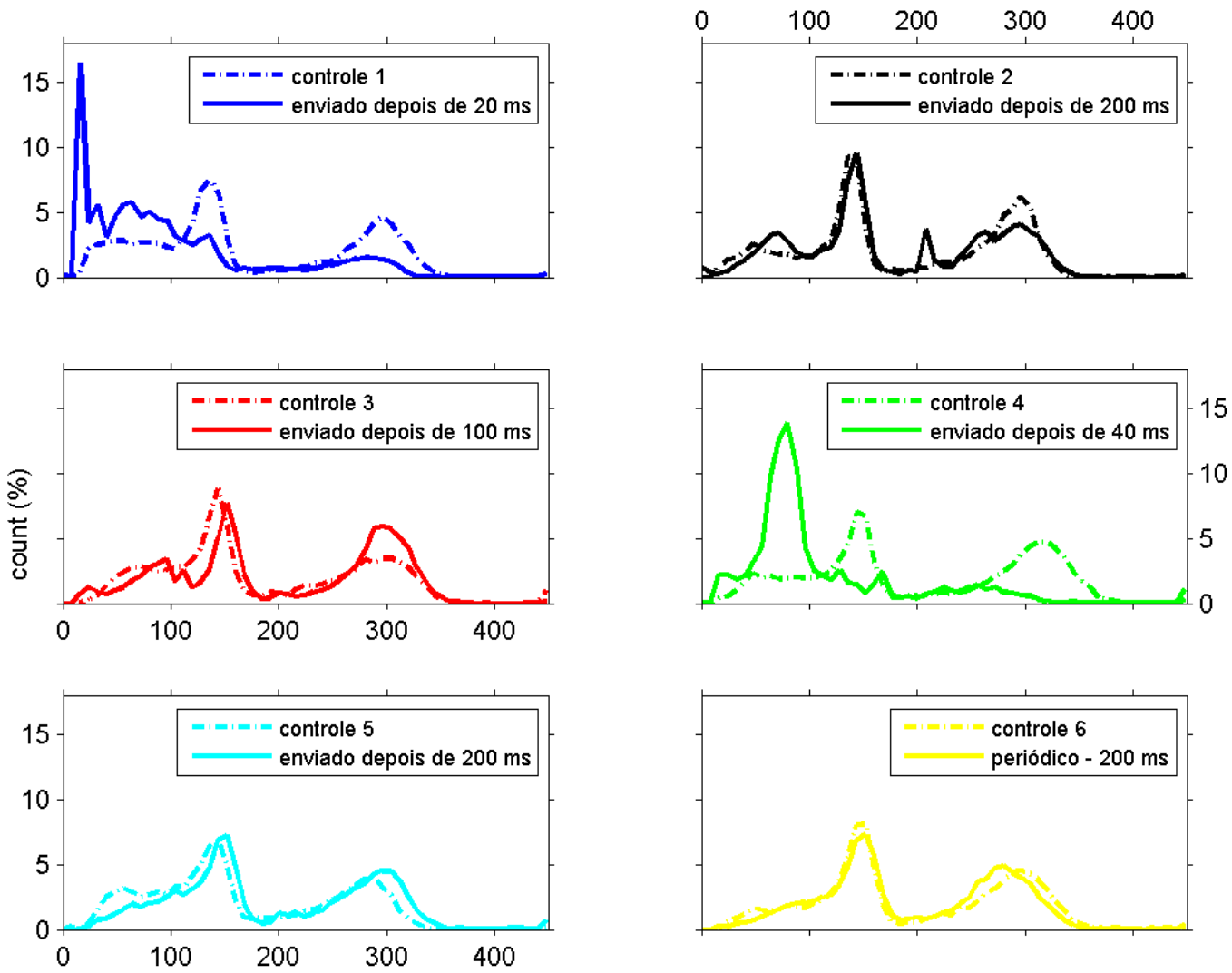

$\mathrm{IPI}(\mathrm{ms})$

Fig.37: Histograma de IPIs para Gnathonemus petersii sem estímulo (controles; linha tracejada) e com estímulos (linha cheia).O experimento consistiu de $30 \mathrm{~min}$ sem estímulo (controle 1), $30 \mathrm{~min}$ pulsos de estímulos enviados a $T=20 \mathrm{~ms}$ após um pulso de peixe (azul), $30 \mathrm{~min}$ sem estímulo (controle 2), estímulos a $T=200 \mathrm{~ms}$ (preto), $30 \mathrm{~min}$ sem estímulo (controle 3), estímulos a $T=100 \mathrm{~ms}$ (vermelho), $30 \mathrm{~min}$ sem estímulo (controle 4), estímulos a $T=40 \mathrm{~ms}$ (verde), $30 \mathrm{~min}$ sem estímulo (controle 5), estímulos a $T=200 \mathrm{~ms}$ (azul),30 min sem estímulo (controle 6), estímulos periódicos de $200 \mathrm{~ms}$ (amarelo). Durante as sessões de estímulo o $O E$ aumentou sua frequência de descarga especialmente para pulsos enviados a T=20 ms e $40 \mathrm{~ms}$ após o peixe ter disparado. Em particular, estímulos enviados $T=200 \mathrm{~ms}$ (linha preta e ciano) não provocaram grandes mudanças na frequência das EODs, bem como, os periódicos de 200 ms (linha amarela).

\subsection{3- Tempo entre pulso de estímulo e pulso resposta de Gnathonemus petersii}

Calculamos a fase entre um pulso de estímulo e o pulso resposta de Gnathonemus petersii (PSTH; seção 2.5.1- pág.24) para 16 experimentos com 5 peixes, 6 usando estímulos de IPIs reais (seções 2.4.2- e 3.4.1-) e 10 com estímulos dependentes da atividade, em que os pulsos de estímulo 
foram enviados um intervalo $\mathrm{T}$ após o disparo do peixe (Fig. Erro: Origem da referência não encontradaA).

Os PSTHs revelaram 2 fases preferenciais onde os peixes apresentaram maior probabilidade de emitir um pulso depois de receber um estímulo: $(10,3 \pm 2,7) \mathrm{ms}$ e a $(40,6 \pm 8,4) \mathrm{ms}$. Em 11 experimentos obtivemos picos entre $6-14 \mathrm{~ms}$ e em 14 experimentos picos entre $25-50 \mathrm{~ms}$. As 5 medidas que não apresentaram picos ao redor de $10 \mathrm{~ms}$ foram de um mesmo peixe e as $2 \mathrm{sem}$ picos ao redor de $30 \mathrm{~ms}$ são de peixes diferentes estimulados com pulsos periódicos.

Mostramos os PSTHs de 3 experimentos com 2 peixes (Fig.38). Acima, o peixe A que havia sido estimulado com IPIs reais, no centro e abaixo o peixe B, estimulado com pulsos dependentes da atividade elétrica com um atraso $\mathrm{T}=50 \mathrm{~ms}$ e pulsos periódicos de $90 \mathrm{~ms}$, respectivamente. O peixe A teve alta probabilidade de disparar depois de $9 \mathrm{~ms}$ e $35 \mathrm{~ms}$ de receber um pulso de estímulo. O peixe B, com estímulos dependentes de sua atividade elétrica, disparou mais pulsos depois de $12 \mathrm{~ms}$ e $33 \mathrm{~ms}$ de receber um pulso de estímulo, já quando estimulado com pulsos periódicos, ele disparou com maior probabilidade depois de $12 \mathrm{~ms}$. 

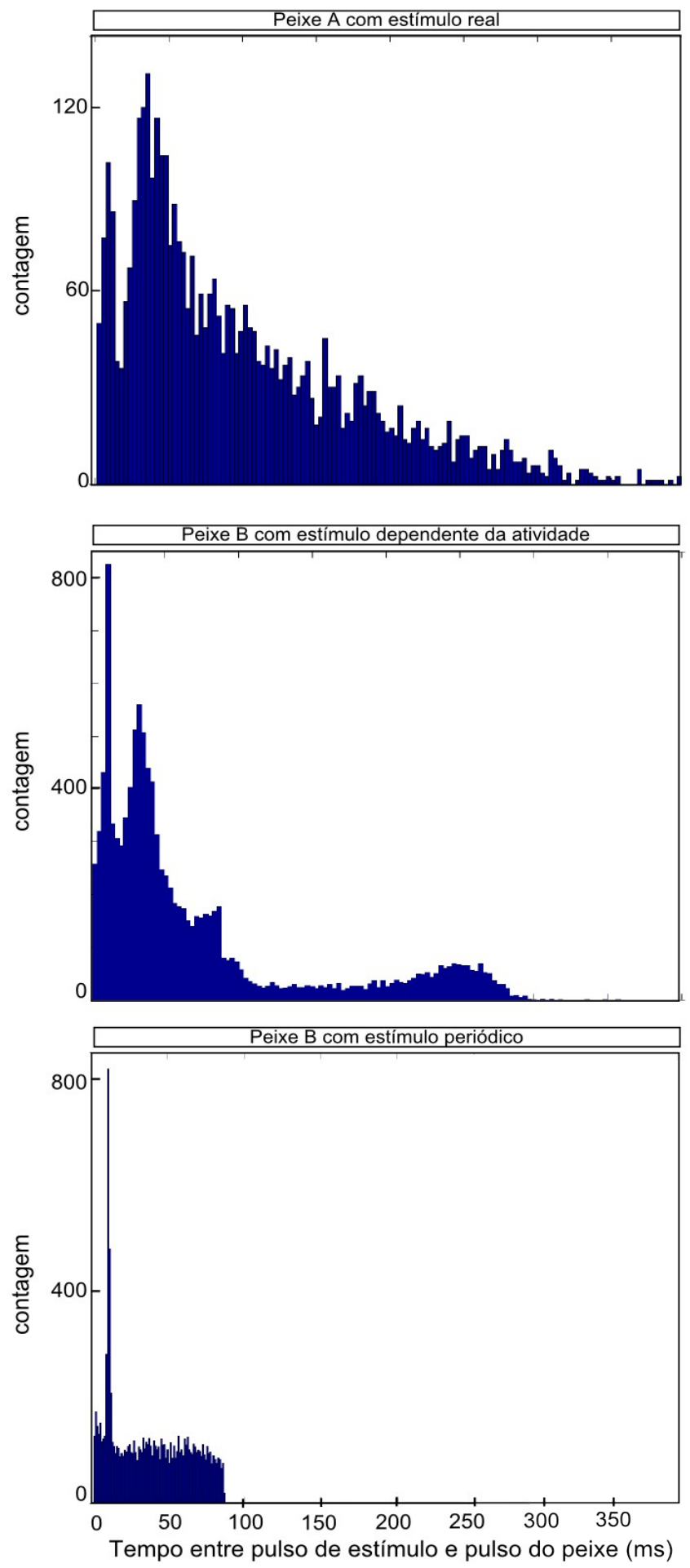

Fig. 38 PSTH para 2 exemplares de Gnathonemus petersii em 3 experimentos. Acima, peixe A, que havia sido estimulado com IPIs reais, no centro, peixe $B$, estimulado com pulsos dependentes da sua atividade elétrica enviados com um atraso de $T=50$ ms e abaixo, peixe B estimulado com pulsos periódicos de 90 ms. O peixe A disparou mais pulsos de 9 e 35 ms depois de ter recebido um pulso de estímulo. O peixe B, teve alta probabilidade de disparar de 12 e 33 ms depois de receber um pulso de estímulo dependente de sua atividade e de $12 \mathrm{~ms}$ após ter recebidos estímulos periódicos de $90 \mathrm{~ms}$. 


\subsection{4- Estímulos dependentes da posição de Gnathonemus petersii no aquário}

O experimento consistiu em tentar manter um Gnathonemus petersii em determinada parte do aquário. Assim, escolhemos um plano vertical no meio do aquário que seria o limite da gaiola virtual (Fig. 39). Denominamos "virtual" porque não existe efetivamente uma barreira física. Quando os peixes ultrapassam essa barreira sinais elétricos são produzidos no dipolo de estímulo. A detecção online da posição dos peixes foi feita por uma câmera que envia a imagem para o computador que, através de um software desenvolvido pelo $G N B$, detecta a posição da cabeça dos peixes. Maiores detalhes técnicos podem ser encontrados em Chamorro et. al, 2012.

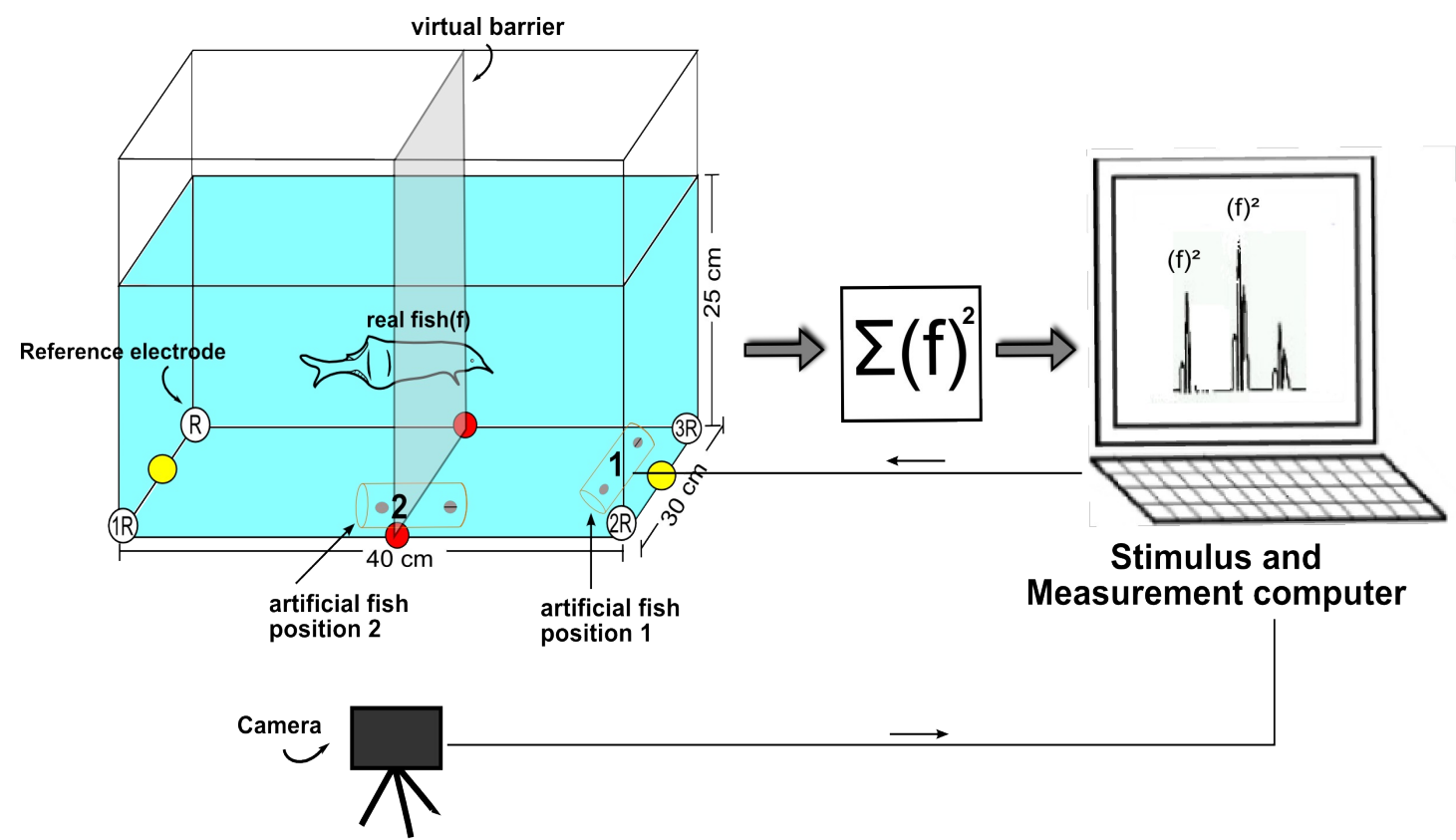

Fig. 39: Aparato experimental para a detecção on line da posição de Gnathonemus petersii e envio de estímulos de acordo com sua posição. A posição de Gnathonemus petersii no aquário foi gravada por uma câmera e enviada ao computador que através de um software detectou o peixe e gravou as coordenadas de sua cabeça. Os sinais medidos nos dipolos: (R) - (1), (2), (3) e círculos vermelhos e amarelos, foram somados e elevados ao quadrado e enviado ao computador de medida. Ao detectarmos que o peixe ultrapassou a barreira virtual estímulos elétricos são enviados a ele por um dipolo (peixe artificial). O dipolo foi colocado na posição 1 ou 2.

Como estímulos foram utilizadas ondas senoidais com frequência $500 \mathrm{~Hz}$ ou $1000 \mathrm{~Hz}$, trens de pulsos periódicos com IPIs de 1, 2, 3, 10, 40,50, 90 ms, com a forma de onda da espécie e amplitudes de até $7 \mathrm{~V}$. Se o peixe ficasse fora da gaiola virtual, receberia estímulos o tempo todo, se cruzasse a 
barreira virtual de volta e voltasse para a gaiola, só receberia estímulos por $1 \mathrm{~s}$. Foram feitos 25 experimentos com 5 peixes.

O protocolo utilizado foi: 20 min de controle sem estímulo seguido por 20 min de experimento. Os estímulos que se mostraram mais eficientes em isolar o peixe na gaiola virtual foram de $500 \mathrm{~Hz}$ e $1000 \mathrm{~Hz}$. Quando usamos estímulos de frequências baixas, tanto seno como a forma de onda de Gnathonemus petersii os peixes permaneceram bastante tempo fora da gaiola virtual. Dos 7 experimentos usando IPIs de 10 a $90 \mathrm{~ms}$, conseguimos isolar somente 2 animais na gaiola virtual. A diferença desses peixes em relação aos outros era o tamanho, tinham menos de $10 \mathrm{~cm}$.

No experimento usando forma de onda senoidal (Fig. 40 - superior) a barreira virtual foi colocada em 300 px (o comprimento do aquário era $\sim 650$ px). À esquerda temos o controle de $20 \mathrm{~min}$ gravado sem estímulos e à direita o experimento já funcionando: computador enviando estímulos enquanto o peixe permanece na região entre 300 px e 600 px. Durante o controle o peixe nadou por todo o aquário, e durante o experimento o peixe ficou mais tempo na parte direita de 0 a $300 \mathrm{px}$ (antes da barreira virtual). O mesmo aconteceu para o experimento usando o pulso com formato de onda da própria espécie (Fig. 40 - inferior) com IPIs de $50 \mathrm{~ms}$. Nesse experimento a barreira virtual foi colocada em 360 px e o peixe passou $65 \%$ do tempo antes da barreira virtual (gráfico da direita a baixo).

Os resultados obtidos foram independentes da posição do estimulador dentro do aquário. 

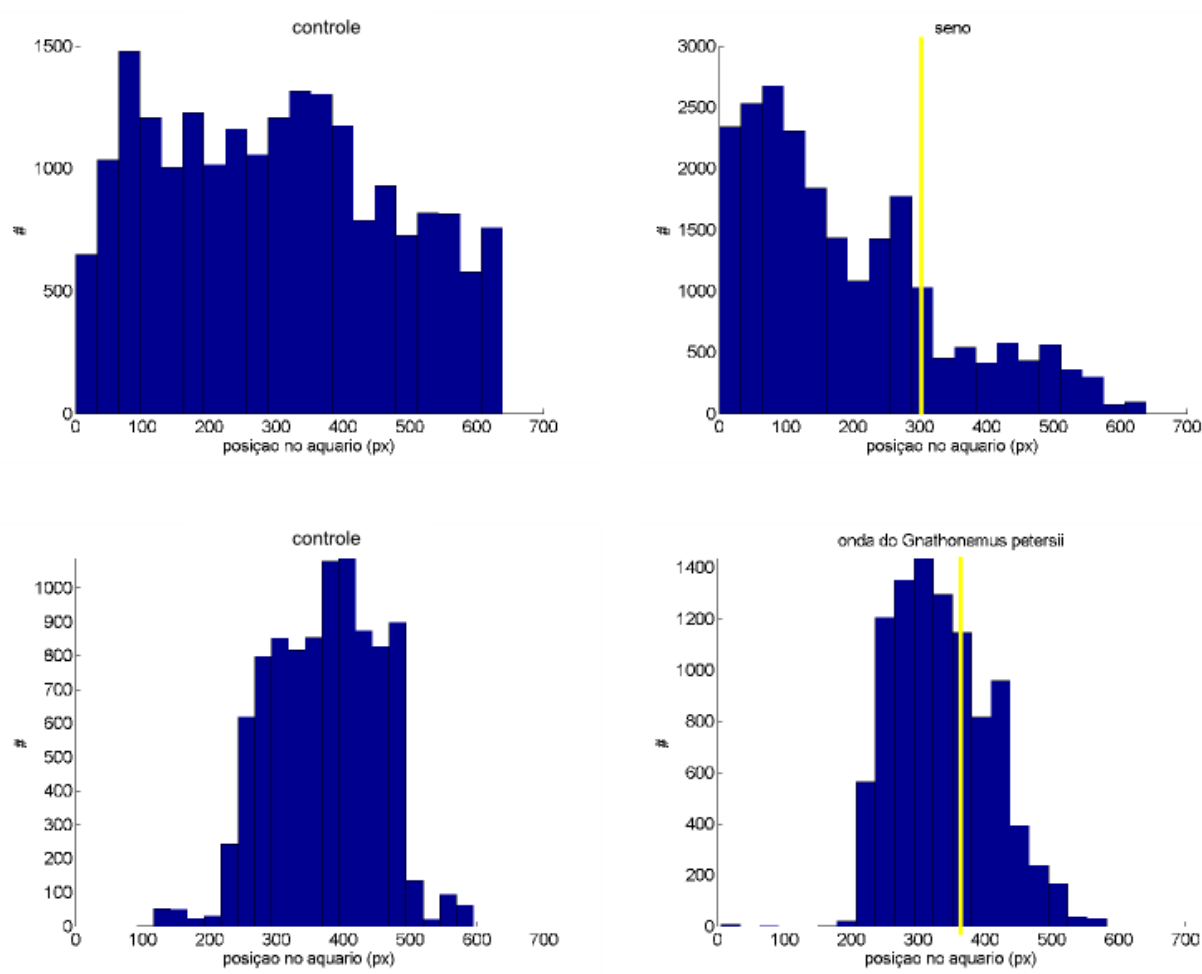

Fig. 40: Histogramas de IPIs de Gnathonemus petersii e histograma da posição no eixo horizontal do aquário. Superior esquerda: $20 \mathrm{~min}$ de controle sem estímulo. O peixe nadou por todo o aquário. Superior direita: experimento de 20 min usando o seno de $1000 \mathrm{~Hz}$ como estímulo se o peixe passasse a barreira virtual (linha amarela) posicionada a 300 px. O peixe permaneceu mais tempo na parte esquerda do aquário, antes da barreira virtual. Inferior esquerda: 20 min de controle, o peixe permaneceu entre 200 e 500 px. Inferior direita: 20 min de experimento usando trem de pulsos de 50 ms com formato de onda da própria espécie. A barreira virtual foi posta em $360 \mathrm{px}, \mathrm{o}$ peixe permaneceu $65 \%$ do tempo antes da barreira virtual.

\section{5 - Estímulos luminosos dependentes da atividade de Gnathonemus petersii}

Escolhemos usar estímulos luminosos pelas evidências de serem estímulos aversivos, já que esses peixes se encondem em tocas durante a luz do dia. A intensidade da luz variava com a atividade do peixe e foi medida com um fotodiodo colocado na parede em frente aos LEDs. Quando o peixe aumentava a frequência do $\mathrm{OE}$, a intensidade da luz era forte deixando o aquário todo iluminado e, quando o peixe emitia IPIs de baixa frequência, a intensidade da luz era bem fraca, quase não 
iluminava o aquário (Fig.7).

O protocolo foi: controle de $20 \mathrm{~min}$ sem estímulo, $20 \mathrm{~min}$ com estímulos luminosos de frequência fixa de $5-15 \mathrm{~Hz}$ ou com a luz piscando de acordo com a atividade elétrica do peixe, $20 \mathrm{~min}$ de controle e mais 20 min com um dos tipos de estímulo. A ordem em que os estímulos foram enviados mudava em cada experimento. Foram feitos 12 dias de experimentos em 4 peixes no total de 30 controles, 15 estímulos com frequência fixa e 15 estímulos dependentes da atividade do peixe.

Dos 15 experimentos em que os estímulos dependiam da atividade elétrica do peixe, em 11 os peixes passaram a emitir pulsos mais longos $(>140 \mathrm{~ms}$ ou $>250 \mathrm{~ms}$, dependendo da distribuição de IPIs inicial) quando comparados com seus controles prévios, e do que comparados com os experimentos com luz piscando com frequência fixa. Dos 4 em que isso não ocorreu, 3 medidas foram feitas com um mesmo peixe e esse peixe aprendeu a ficar perto da superfície da água onde a luz não era tão intensa. Nós, então, diminuímos a altura da água no aquário para que até a superfície estivesse bem iluminada e os peixes não pudessem mais se ocultar da luz.

Mostramos um exemplo (Fig. 41) com o protocolo: 20 min sem estímulo, 20 min de estímulo luminoso que piscava na frequência fixa de $10 \mathrm{~Hz}, 20 \mathrm{~min}$ sem estímulo e 20 min de estímulo luminoso piscando de acordo com a frequência do peixe. A frequência fixa em cada experimento foi escolhida a partir da média da frequência de disparos medida durante os 20 min anteriores (sem estímulo).

Quando estimulado com luz dependendo da sua própria atividade, houve um aumento da probabilidade de disparar IPIs mais longos, 14\% dos IPIs totais foram maiores de $140 \mathrm{~ms}$ contra $4 \%$ na sessão com a luz de frequência fixa. 


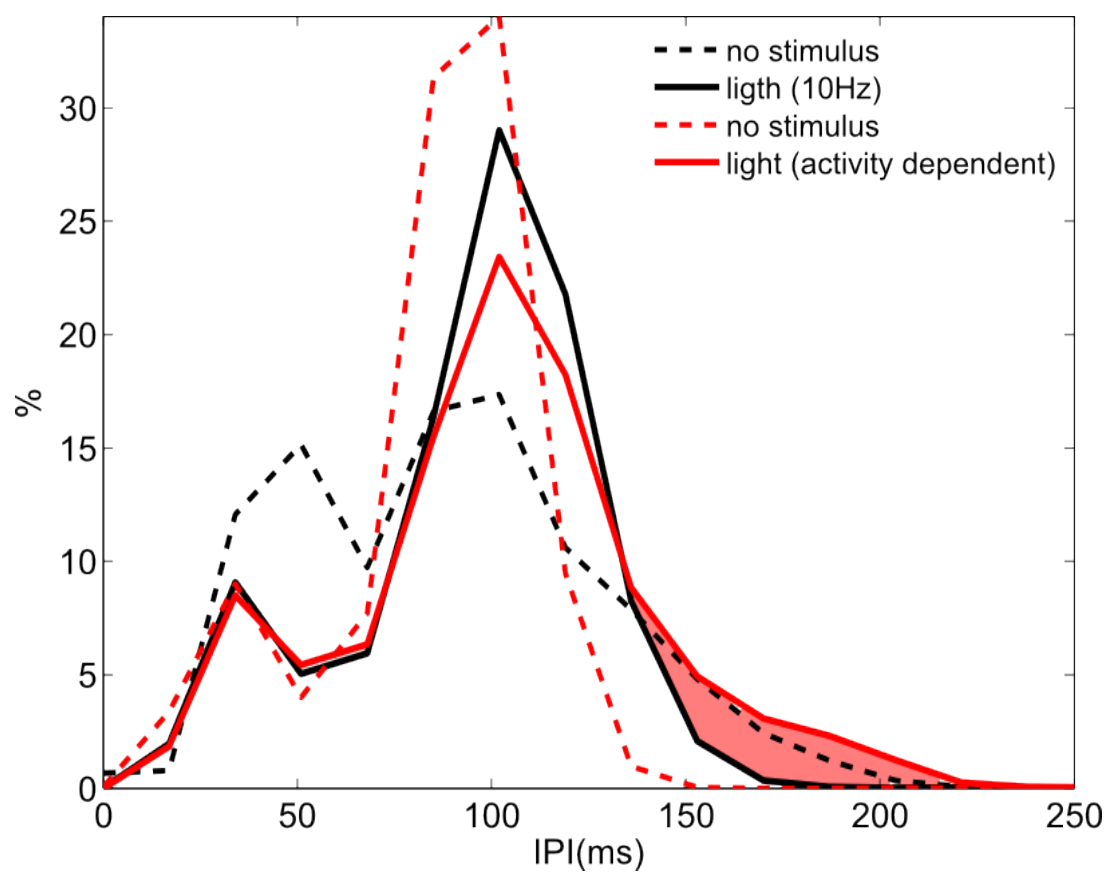

Fig. 41: Histograma de IPIs de Gnathonemus petersii em resposta a estímulos luminosos de um LED. O protocolo foi: 20 min sem estímulo (pontilhado em preto), 20 min de luz piscando com frequência de $10 \mathrm{~Hz}$ (preto), $20 \mathrm{~min}$ sem estímulo (pontilhado em vermelho) e 20 min de luz dependendo da atividade do peixe (em vermelho). A área vermelha indica o aumento da probabilidade ( $10 \%)$ de disparar IPIs mais longos (140-220 ms) comparando as distribuições de IPIs para os estímulos luminosos dependente da atividade do peixe e da luz a frequência fixa.

Comparando as distribuições de IPIs entre todas as sessões (Fig.42), na sessão com o peixe controlando a luz ele disparou mais IPIs maiores que $\sim 115 \mathrm{~ms}$ do que na sessão com a luz piscando com frequência fixa. As duas sessões apresentaram a mesma distribuição de IPIs de 23 - $110 \mathrm{~ms}$ e depois houve um desvio para baixo da reta $\mathrm{y}=\mathrm{x}$ (linha preta) indicando IPIs maiores na sessão com $\mathrm{o}$ peixe controlando a luz. $\mathrm{O}$ controle 2 e a sessão com o peixe controlando a luz seguiram a mesma distribuição para IPIs de $\sim 70-120 \mathrm{~ms}$, mas o peixe sempre disparou mais IPIs maiores quando ele próprio controlava a luz, especialmente IPIs maiores que $\sim 80 \mathrm{~ms}$. Comparando o controle $1 \mathrm{com}$ a sessão com luz piscando com frequência fixa, elas apresentaram a mesma distribuição de IPIs de $\sim 70$ $140 \mathrm{~ms}$ sendo que, no controle 1 , houve mais IPIs longos a partir de $\sim 115 \mathrm{~ms}$. Os controles 1 e 2 apresentaram a mesma distribuição de IPIs com valores de $\sim 60-150 \mathrm{~ms}$ e houve mais IPIs maiores do que $100 \mathrm{~ms}$ para o controle 1. 

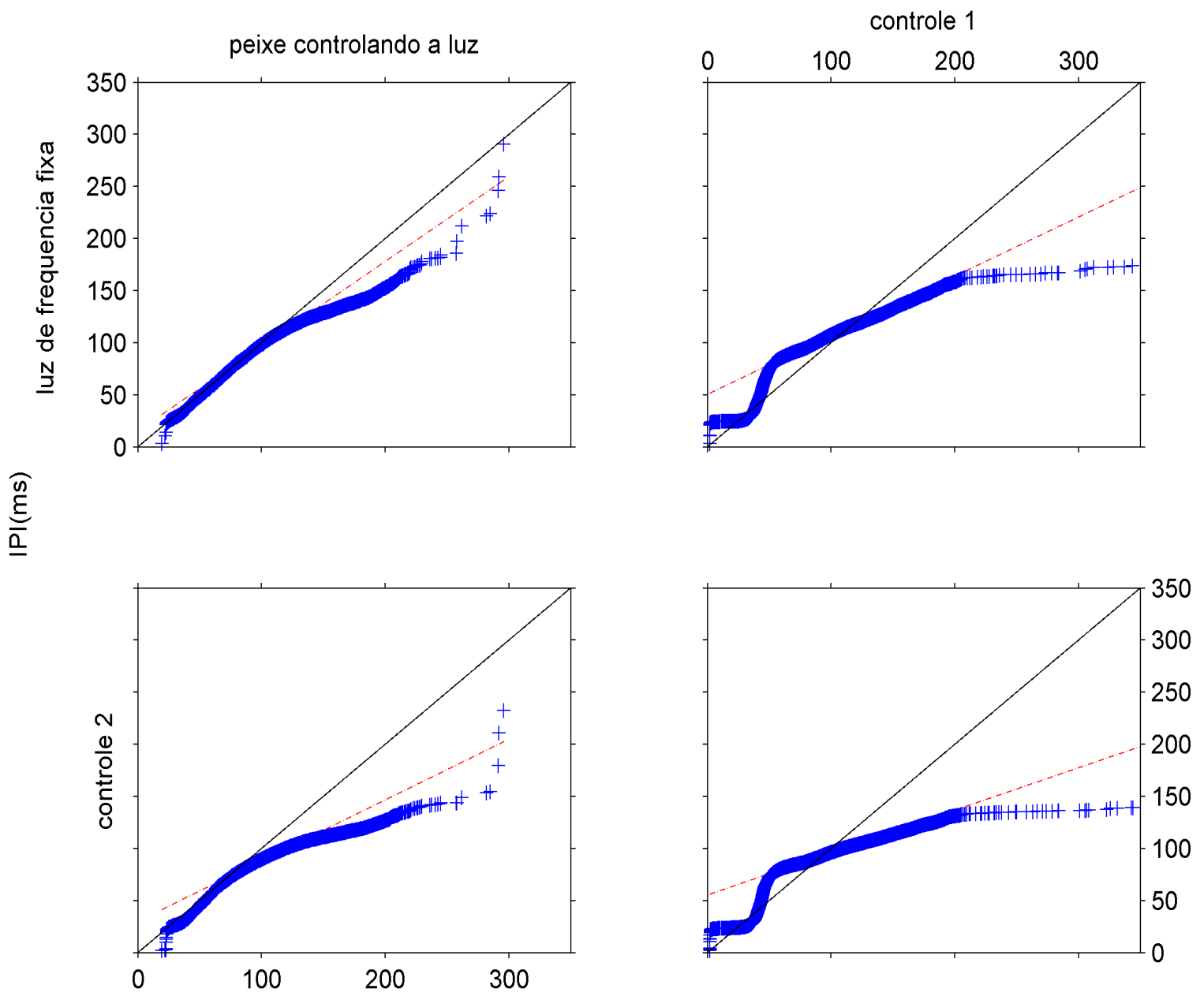

IPI (ms)

Fig. 42:Quantile-quantile plot dos IPIs (+ em azul) de Gnathonemus petersii sob estimulação luminosa. A linha preta é a reta $x=y$, linha vermelha é a ligação do $1^{\circ}$ e $3^{\circ}$ quartil, e a linha vermelha pontilhada é essa reta extrapolada. Da esquerda para a direita, de cima para baixo, qqplots das sessões: peixe controlando a $l u z$ - luz de frequência fixa, controle 1 - luz de frequência fixa, peixe controlando a luz - controle 2, controle 1 - controle 2. A sessão com o peixe controlando a luz e a luz piscando com frequência fixa seguiram apresentaram a mesma distribuição com IPIs de 23 - $110 \mathrm{~ms}$ e houve um desvio para IPIs maiores indicando que o peixe disparou mais IPIs longos quando ele controlava a luz. As sessões controle 1 e luz com frequência fixa seguiram a mesma distribuição para valores de IPIs de $\sim 60-150 \mathrm{~ms}$ sendo que a partir de 100 ms houve mais IPIs longos disparados no controle 1. O peixe disparou mais IPIs longos na sessão em que ele controlava a luz do que no controle 2, principalmente para IPIs maiores do que $80 \mathrm{~ms}$. Nos controles 1 e 2, os IPIs apresentaram a mesma distribuição de $\sim 60-150 \mathrm{~ms}$, sendo que IPIs maiores do que 100 ms foram mais frequentes no controle 1. 
Dividimos cada sessão em 3 partes (Fig. 43), em azul está o primeiro terço, em vermelho de 1/3 a 2/3 e em preto de 2/3 até o final. Quando o peixe controlou a luz, os IPIs aumentaram no segundo terço e no terceiro comparados com o primeiro terço. Na sessão de luz com frequência fixa, não houve diferença, no controle 1, o peixe apresentou IPIs mais curtos no último terço e no controle 2, is IPIs foram um pouco mais longos no primeiro terço.
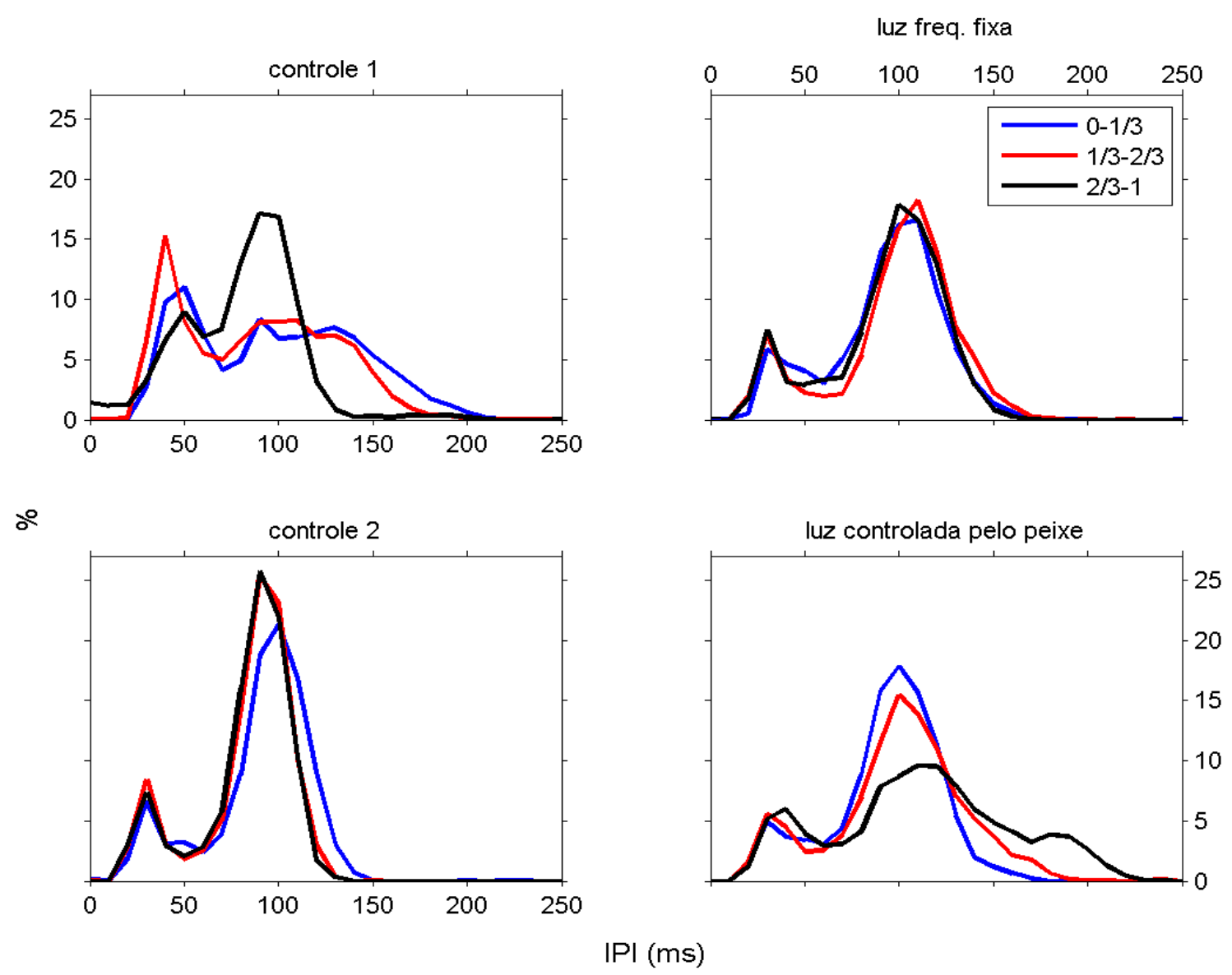

Fig. 43: Histograma de IPIs. As sessões foram dividas em 3 partes: primeiro terço de 0-1/3 (linha azul), segundo terço de 1/3-2/3 (linha vermelha)e último terço de 2/3-1 (linha preta). Nos controles 1 e 2, os IPIs se tornaram mais curtos comparando o primeiro e o último terço da sessão. Quando a luz piscava com frequência fixa de $10 \mathrm{~Hz}$ quase não houve diferença, já com o peixe controlando a luz, os IPIs foram mais longos no último terço da sessão. 


\section{4 - Discussão}

Os peixes elétricos de campo fraco, Gymnotus carapo e Gnathonemus petersii evoluíram de maneira independente na África e na América do Sul (Alves-gomes et al., 1995;Bullock et al., 2005). Ambas espécies possuem sistema eletrogênico e eletrocensório com um órgão elétrico que produz pulsos elétricos e com eletroreceptores que detectam tanto seu próprio campo elétrico quanto o de seus vizinhos (Bullock et al., 2005;Caputi \& Nogueira, 2012). O órgão elétrico pode disparar com maior ou menor frequência dependento do ambiente e do contexto comportamental (Bullock et al., 1969; Russel et al., 1974; Moller, 1970; Kramer 1979; Westby, 1979).

Os sistemas eletrogênico e eletrocensório permitem que os peixes elétricos de campo fraco formem imagens elétricas do ambiente em que estão e que também identifiquem e se comuniquem com outros peixes (Lissmann 1958; Von der Emde, 1998;Caputi \& Nogueira, 2012). Essas 2 habilidades são conhecidas como eletrolocalização e eletrocomunicação.

Estudamos a eletrocomunicação e a eletrolocalização nessas 2 espécies de peixes sem restringir o movimento dos animais em aquários fundos. Realizamos medidas por tempo longos ( dias/horas) e implementamos técnicas de estímulo realistas, utilizando formas de onda iguais às dos peixes verdadeiros. Além de experimentos com estímulos unidirecionais, também pudemos aplicar técnicas com estímulos bidirecionais dependentes da atividade motora ou elétrica do próprio animal, o que só foi possível com a aplicação de técnicas de interação entre o computador e os animais vivos em tempo real.

Desenvolvemos aparatos experimentais, com múltiplos dipolos que permitem fazer, automaticamente, medidas do peixe livre no aquário por várias horas/dias e estimulá-los com pulsos com a forma de onda característica de cada espécie.

Para medir o campo elétrico dos peixes nadando livremente usamos de 5 a 7 dipolos sensores espalhados nas paredes do aquário. Esta técnica permitiu inferir a posição do animal e sua movimentação através da mudança de amplitude do sinal induzido em cada um dos dipolos. Em alguns experimentos isso também foi feito utilizando-se uma câmera que enviava as imagens para serem processadas on line pelo computador que produzia os estímulos. 
No aparato para medir o peixe elefante empregamos menos dipolos, 5 ao invés dos 7 empregados no aparato para Gymnotus carapo. Isso foi possível porque Gnathonemus petersii tem preferência por nadar próximo ao fundo e raras vezes eles sobem para a superfície. Na verdade, a menor configuração para medir um exemplar médio é de 3 dipolos uma referência em comum, mas como muitas vezes apenas era possível encontrar peixes pequenos de pouco mais de $5 \mathrm{~cm}$, decidimos aumentar o número de dipolos, assim não dependíamos do tamanho dos peixes.

Nossos aparatos são de baixo custo e podem ser adaptados para registrar a atividade elétrica de quaisquer espécies de peixes pulsadores com tamanho arbitrário, além de permitir realizar experimentos mais realistas, pois os peixes podem estar totalmente livres no aquário e são estimulados por pulsos idênticos ao de sua espécie. Os experimentos podem durar várias horas, sendo o espaço disponível em disco rígido o único fator limitante da duração do experimento.

Em sistemas que têm que reagir rapidamente alterando sua atividade prévia e tão sensíveis a estímulos externos, como é o caso dos peixes elétricos de campo fraco, é crucial ter acesso a medidas longas da atividade elétrica pois amostras curtas da atividade podem não representar o comportamento global. Somando a esse fator, a restrição dos movimentos dos peixes, as medidas obtidas podem se distanciar muito do verdadeiro comportamento global que encontraríamos na natureza.

Além de estímulos elétricos, enviados através de um dipolo, também podemos utilizar estímulos luminosos, produzidos por um conjunto de LEDs. Podemos escolher entre experimentos com estímulos unidirecionais, com séries de IPIs pré-gravadas, geradas aleatoriamente por computador ou periódicas, e experimentos bidirecionais, onde o estímulo depende em tempo real da atividade elétrica ou motora dos peixes. O aparato para estímulos luminosos pode ser facilmente adaptado para estímulos sonoros, substituindo o conjunto de LEDs por uma caixa acústica. O uso do estímulo sonoro poderá ser útil para explorar a peculiar característica de produzir som, além de eletricidade dos Mormyrideos e sua relação com a comunicação ou mesmo para estudar as características e importância no comportamento dos peixes. A produção de som através de uma bexiga no tímpano cheia de gás é conhecida desde a década de 30 (von Frisch, 1938, Stipetic, 1939) e seu interesse foi retomado no fim da década de 90 (Crawford 1997; Crawford \& Huang, 1999; Fletcher \& Crawford, 2001).

Poder experimentar com estímulos adaptáveis à dinâmica do sistema, abre um grande leque de experimentos que antes não eram possíveis. Podemos agora obter um estudo mais rico, em loop fechado, onde a perturbação é determinada levando em consideração o comportamento dinâmico do 
próprio sistema.

Por todas essas características, acreditamos que este trabalho representa uma tentativa de dar um passo a frente nos protocolos clássicos de estimulação empregados tradicionalmente em peixes elétricos.

\section{Experimentos sem estímulo}

A maior diferença entre as 2 espécies é o fato de Gymnotus carapo apresentar um longo transiente de $\sim 10 \mathrm{~h}$ com descargas de alta frequência do OE e distribuição unimodal de IPIs logo que é colocado em ambiente novo e Gnathonemus petersii praticamente não alterar a frequência de disparo do OE mantendo sua distribuição bi ou trimodal de IPIs. Outra diferença é o tempo em que silenciam o OE, Gymnotus carapo, sem estímulos externos, silencia o OE por poucos segundos, o máximo medido foi $5 \mathrm{~s}$ e Gnathonemus petersii pode silenciá-lo por horas, $\sim 2,5 \mathrm{~h}$ foi o máximo medido. Não sabemos muito bem porque os peixes silenciariam seu OE nestes casos pois silenciar o OE foi descrito como uma característica de aceitar a dominância do outro, podendo ser interpretados como se o peixe estivesse se "escondendo" ou apenas "escutando", tentando ocultar sua presença dos demais (Bennet \& Steinbeck 1969; Moller 1970).

Como característica comum, tanto Gymnotus carapo como Gnathonemus petersii mudam sua frequência média de disparo e sua distribuição de IPIs todos os dias, não sendo possível, identificar indivíduos específicos pela distribuição de probabilidades dos IPIs ou pela frequência média do OE.

Discutimos em mais detalhes os comportamentos particulares de cada espécie a baixo.

\section{Gymnotus carapo sem estímulo nadando livremente}

Gymnotus carapo apresenta um longo transiente $(\sim 10 \mathrm{~h})$ caracterizado por IPIs mais curtos. Uma vez habituado ao aquário, os IPIs se tornam mais longos e há uma grande correlação $(\sim 80 \%)$ entre o movimento do peixe e os padrões de IPIs (entropia).

Não seria esperado que o comportamento motor estivesse relacionado com o comportamento elétrico (IPIs) por tempos tão longos uma vez que eles têm naturezas independentes: o sistema eletrogênico não está associado ao sistema esqueletético-motor. Surpreendentemente, nós observamos 
que as mudanças na entropia estavam completamente associadas com a movimentação do peixe por horas. Em Bullock (1969), há uma breve menção a essa relação, mas apenas para tempos curtos (alguns segundos) e isso foi somente observado para o início de alguns estímulos.

Uma possível explicação para o comportamento elétrico e motor estarem associados em certas circunstâncias está relacionada com a NR: quando os peixes nadam rapidamente eles precisariam de atualizações mais rápidas das imagens elétricas e fariam isso aumentando a taxa de disparo do OE e quando estão parados poucas atualizações da imagem elétrica seriam necessárias mantendo apenas disparos com IPIs constantes e/ou de baixa frequência como uma forma de economizar energia.

Foram observados também, vários períodos nos quais os peixes não se moviam, especialmente durante o dia, onde Gymnotus carapo é menos ativo, sendo seus IPIs mais longos e mais regulares (valores de entropia perto de zero) sugerindo que o peixe poderia estar descansando ou em um estado de sono comportamental.

Há pouquíssimos estudos na literatura sobre sono em peixes. Um dos únicos trabalhos a respeito de sono é de Stopa \& Hoshino, 1999 em Gymnotus carapo e Yokogawa et al., 2007 em zebrafish em que se detalham a postura e respiração de peixes nos períodos de sono e limiar de acordar. Em zebrafish, um peixe não elétrico, se mostrou que quando o peixe estava no estado de sono comportamental, eles se mantinham imóveis e limiar para "acordar" era maior do que quando eles estavam em outros estados. Seria ideal para estudar sono comportamental em peixes elétricos, um protocolo bidirecional onde se monitoraria a frequência do órgão elétrico e as variações da amplitude do sinal medido nos dipolos e estímulos seriam disparados em função dessas 2 variáveis. Nosso aparato poderia ser facilmente modificado para estudar a intensidade do estímulo necessário para acordarmos os peixes, quando eles estivessem em diversos estados, por exemplo, parado com estímulos periódicos, parado com estímulos não-periódicos, etc.

Apesar da grande variação na distribuição de IPIs ao medirmos os peixes ao longo das semanas, conseguimos identificar padrões de disparos comuns a todos Gymnotus carapo. Analisando os tempos de disparo, considerando bins de $14 \mathrm{~ms}$ (critério de máxima entropia) e palavras de tamanho fixo de 6 bits, verificamos que há palavras em comum que aparecem com alta probabilidade para todos os indivíduos, inclusive comprados em cidades diferentes. Mais da metade do total das palavras disparadas correspondem a um IPI curto seguido de um IPI longo: 110110, 101101 e 011011. As próximas palavras com alta probabilidade de ocorrência dependem do peixe: 110111, 111011, $011101 \mathrm{e}$ 
101110 ou 110101, 101011 e 010110. Peixes mais agressivos, em geral, aumentam mais sua taxa de disparo, o que nos faz associarmos palavras com 2 IPIS curtos (3 pulsos consecutivos), 110111, 111011, 011101 e 101110, a peixes mais agressivos. A probabilidade de ocorrência de cada palavra muda de peixe para peixe e mesmo em um mesmo exemplar medido em dias diferentes.

Como parece haver um código nas descargas do OE de Gymnotus carapo, nos questionamos se essas sequências de disparo mais prováveis, 110110, 101101 e 011011, seriam intrínsecas aos peixes ou se dependeriam do contexto ambiental. Elas se alterariam quando o peixe fosse submetido a estímulos externos?

\section{Gnathonemus petersii sem estímulo nadando livremente}

Ao serem colocados em um ambiente novo, o africano e o sul-americano reagem de maneira distinta: em Gnathonemus petersii quase nenhuma mudança nos IPIs foi observada, com exceção do período circadiano. A distribuição dos pulsos é bimodal ou ainda mesmo trimodal.

No aparato experimental para estudo de Gnathonemus petersii, não é possível gravar as amplitudes dos sinais em cada dipolo para inferirmos a posição. Apesar disso, pelo estudo de Belbenot (1972), sabemos que cada mudança na movimentação está associada com acelerações do OE. Mostramos que a entropia aumenta quando os peixes aceleram o OE, então é razoável supor que para Gnathonemus petersii assim como em Gymnotus carapo, as mudanças na entropia também estão relacionadas com as mudanças no sistema motor.

Percebemos que se os IPIs se tornam predominantemente longos ( $\sim 600 \mathrm{~ms})$ com distribuição unimodal é um indício de que o peixe está doente. Esse “sintoma elétrico" aparece semanas antes dos sintomas físicos padrões de doenças comuns, tais como, pontos brancos nas nadadeiras e no corpo, falta de apetite juntamente com pouca movimentação no aquário. Isso pode fazer com que Gnathonemus petersii seja uma espécie mais interessante do que Gymnotus carapo para indicador da qualidade da água (Clausen et al., 2012).

O único estudo anterior com medidas dos intervalos entre descargas elétricas por períodos mais longos $(\sim \mathrm{h})$ foi realizado em uma outra espécie da família dos Mormirídeos, o Gnathonemus niger (Moller, 1970), medido a cada $2 \mathrm{~h}$ durante um dia. Nesse trabalho a distribuição de IPIs relatada foi trimodal durante o dia com IPIs ao redor de 30 ms, 90 ms e 200 ms. Outra espécie, Pollimyrus isidori 
(Kramer, 1978), também apresenta distribuição de IPIs trimodal, com picos em 12 ms, 92 ms e 220 ms, mas não foi relatado a quantidade de tempo medida. Estimando pela quantidade de pontos no histograma seria um exemplar medido por aproximadamente $30 \mathrm{~min}$.

O estudo do código dos disparos, análises da sequência de disparos, considerando palavras de tamanho fixo está sendo feito em conjunto com o GNB da Espanha, como parte do projeto do estudante Ángel Lareo Fernández, no âmbito de protocolos de estimulação bidirecional em tempo real. Como os peixes africanos disparam IPIs muito variáveis de $\sim 10-600 \mathrm{~ms}$, uma das grandes dificuldades para formar as palavras é a escolha do bin. Bins grandes ( $>100 \mathrm{~ms}$ ) fazem com que não nem todos os disparos sejam codificados pois podem ocorrer mais de 1 disparo em cada bin, degradando o código, e bins muito pequenos $(<20 \mathrm{~ms})$ não estão perto de valores que maximizam a entropia. Estamos realizando um estudo do tamanho de bins e a quantidade de disparos perdidos para decidirmos um valor de bin ótimo que menos prejudique o código. Estamos investigando também, como os valores de bins que maximizam a entropia mudam de peixe para peixe, para analisar a possibilidade de um valor padrão de bin ou alguma normalização que facilite a comparação das sequências de disparo entre todos os peixes.

\section{Experimentos com estímulos}

Ambas espécies quando estimuladas, independentemente do tipo de estímulo e natureza do estímulo, aumentam a frequência de disparo do OE. A frequência continua alta durante toda as sessões de estimulação. Ao interrompermos o estímulo, eles abaixam a frequência de disparo do OE voltando a frequências mais parecidas àquelas de antes da estimulação. $O$ aumento da frequência assinala dominação ou tentativa de dominação e pode ter um paralelo com o comportamento de outros animais, tais como, levantar as penas em aves ou elevar a postura (Tallarovic \& Zakon, 2005).

Que os peixes elétricos de campo fraco alteravam sua frequência de disparo era conhecido há tempos (Lissmann, 1958; Bullock 1969) mas ainda se indaga o porquê dessas mudanças, se são apenas respostas mecânicas, JAR ou se os peixes realmente se comunicam assim (Moller, 1970; Russel et al., 1974; Westby 1975; Westby 1979; Kramer and Bauer 1976). Como evidência fisiológica da comunicação, Carlson (2009) encontrou células no cérebro de Mormirídeos (mas especificamente no núcleo exterolateral posterior ) que são sensíveis a padrões e respondem preferencialmente ao aumento 
ou diminuição de IPIs e sugere que pode ser um mecanismo geral para processar informação relevante contida nos padrões temporais dos IPIs. Em vários outros trabalhos é abordada a questão de efeitos de sinais de comunicação no sistema sensorial mas eles não serão discutidos aqui por saírem do escopo central da tese.

Nossos resultados com estímulos realistas (distribuição de IPIs gravada de um peixe real) contrastados com estímulos de distribuição aleatória mostram que há mais do que respostas fisiológias mecânicas do OE codificados no tempo de disparo dos pulsos e que os peixes reconhecem diferentes padrões de estímulos. Poucos estudos comparativos de IPIs foram realizados (Carlson \& Gallant, 2013) e ainda que em condições experimentais diferentes, estudos prévios sobre padrões (Carlson, 2002a; Carlson \& Hopkins, 2004; Carlson 2009) de respostas diferentes dados em resposta a estímulos prégravados de peixes parados ou atacando (Moller, 1970; Westby, 1975; Kramer, 1978; Arnegard \& Carlson BA, 2005), a quantidade de reações de surpresa e de ataques ao dipolo de estímulo do peixe (Kramer \& Bauer, 1976; Kramer, 1979; Crockett, 1986) corroboram nossas descobertas que parecem confirmar a existência de uma comunicação real entre os peixes.

Para uma melhor organização separamos a discussão desses resultados em 3 partes: comportamento de Gymnotus carapo com estímulos unidirecionais, comportamento Gnathonemus petersii com estímulos unidirecionais e com estímulos bidirecionais.

\section{Gymnotus carapo com estímulos unidirecionais}

Durante os estímulos reais e aleatórios todos os peixes aumentaram a frequência de disparo do OE. A relação entre a entropia dos padrões de disparos e a movimentação dos peixes não se manteve mais a mesma de quando não eram estimulados, onde havia alta correlação entre ambas. Apenas em 2

experimentos em alguns minutos, encontramos alta correlação entre a entropia e movimentação. É interessante que esses períodos aconteceram apenas durante sessões de estímulos aleatórios: em alguns intervalos os peixes apresentaram ausência de movimento e entropia nula, provavelmente característicos de sono comportamental.

Uma possível explicação dessa relação haver sido quebrada é que quando os peixe são estimulados, estão ativas tanto a eletrocomunicação como a eletrolocalização ao mesmo tempo, e é razoável esperar que as mudanças na movimentação do peixe não estejam mais totalmente associadas 
com as mudanças na entropia. Isso nos sugere que há mais informação sendo codificada nos IPIs do que apenas informação sobre as atualizações das imagens elétricas do ambiente durante a eletrolocalização.

Outro fator que poderia influenciar a reação dos peixes é a amplitude dos estímulos. Nossa hipótese era de que os peixes poderiam "prestar mais atenção" a peixes maiores, ou seja a estímulos de amplitudes mais altas. Se isso fosse verdade nossos resultados mostrariam que haveria maior transmissão de informação entre os peixes e os estímulos com amplitudes altas do que para amplitudes baixas. Nós observamos que, na verdade, alta AMI não depende da amplitude do estímulo. As análises com Teoria da Informação revelaram que pode haver alta transmissão de informação quando empregamos estímulos de baixa amplitude de $1 \mathrm{~V}$ e não mais $5 \mathrm{~V}$. Nossos resultados se assemelham ao encontrado por Gouvêa Junior e outros (2002), num estudo sobre a influência do tamanho dos peixes nas respostas elétricas, onde mostraram que os peixes grandes também reagiam aos de menor tamanho. Apesar do estudo de Gouvêa Junior levar em conta somente interrupções do OE imediatamente após o começo do estímulo, é um resultado interessante que juntamente ao nosso pode ser uma evidência que a intensidade dos estímulos, no caso, o tamanho do peixe, não seja tão relevante como a sequência dos disparos para a eletrocomunicação.

Os peixes parecem distinguir, não somente, se há ou não estímulos, mas também entre os tipos de estímulo. Gymnotus carapo responde de maneira diferente a estímulos de IPIs reais e a estímulos de IPIs aleatórios. Quando estimulados com série de IPIs reais, os peixes aumentaram sua probabilidade de disparar IPIs curtos, aumentaram a variabilidade dos IPIs, aumentaram a quantidade e duração das interrupções do OE e alteraram a probabilidade de disparar um pulsos após receberem um estímulo aumentando a probabilidade de disparar entre $5-13 \mathrm{~ms}$.

Os IPIs mais prováveis disparados nas sessões de estímulo real foram menores (mediana em 17 ms) do que nas sessões com estímulos aleatórios (mediana em 17,5 ms). A variabilidade também aumentou, o que se reflete na largura da distribuição maior, 3,2 ms, durante as sessões de estímulo real contra 2,9 ms nas sessões de estímulo aleatório. As interrupções do OE duraram mais tempo e foram em número maior durante as sessões de estímulos reais. Em geral os peixes menos dominantes param de disparar e as interrupções do OE podem ser interpretadas como se o peixe estivesse se "escondendo" ou apenas “escutando" (Bennet \& Steinbeck 1969; Moller 1970). 
Nossos dados com Gymnotus carapo livre mostraram que a probabilidade de disparar um pulso é, em média, maior depois de 5 - 13 ms de ter recebido um estímulo de IPIs reais é, em média, menor no intervalo de $0-5 \mathrm{~ms}$. A probabilidade de disparar um pulsos depois de um estímulo se manteve constante nas sessões de estímulos de IPIs aleatórias.

Há mais de 40 anos se discute o fato dos peixes mudarem seus disparos em relação aos estímulos. Nunca se chegou a um consenso se essas mudanças seriam apenas um mecanismo de JAR ou de comunicação (Westby, 1979; Russel et al., 1974; Schuster, 2001). Os experimentos na década de 70 , onde comportamentos similares foram encontrados, eram feitos com 2 peixes em contato por poucos minutos ou com estímulos artificiais, mas nunca com estímulos aleatórios. Nossos dados mostraram que os peixes não alteram sua probabilidade de disparo nas sessões com estímulos aleatórios, lembrando que as formas dos pulsos das 2 séries de estímulos são idênticas, sendo a sequência dos IPIs a única diferença.

Westby (1979) e Nogueira \& Caputi (2011)mostraram, que há um período de insensibilidade após receber um pulso, ou seja, um período cego no qual os peixes não sentiriam pulsos e durante o trabalho de mestrado mostramos que havia mais informação sendo transmitida entre os peixes e os estímulos reais do que entre os peixes e os estímulos aleatórios. Acreditamos que isso seja devido a que nem sempre os peixes podem quererem se comunicar, nem é sempre vantajoso que outros peixes saibam de sua presença. Por exemplo, para explorar um novo ambiente (eletrolocalização) um animal poderia escolher disparar no período refratário de outro e passar despercebido, já para se comunicar, onde ele quer o coespecífico note sua presença ele emitiria pulsos fora do período refratário.

Analisando o código de disparos dos peixes em resposta aos estímulos, onde transformamos as séries de disparos em sequências de 0 e 1 com bin de $14 \mathrm{~ms}$ e considerando palavras de tamanho fixo de 6 bits, vimos que as palavras mais prováveis para todos os peixes são aquelas contendo 2 IPIs curtos e 1 longo ( 3 pulsos e 1 silêncio), 110111, 111011 etc, representando $\sim 30 \%$ do total de palavras. Essas palavras são diferentes daquelas encontradas em experimentos sem estímulo, com apenas 1 IPI curto e 1 longo ( 2 pulsos e 1 silêncio), 110110 etc.

O número de palavras com vários l's na sequência também aumentou, tais como, $101111 \mathrm{e}$ 111101.Já sabíamos que a frequência do OE aumenta quando são estimulados, e o aumento da quantidade de 1's, nas palavras é reflexo desse comportamento. Os peixes na verdade disparam mais sequências do que as comentadas acima, mas elas eram diferentes de peixe para peixe, ou presente em 
só um grupo de animais.

Nessa primeira análise, consideramos palavras de tamanho fixo de 6 bits e estudamos a probabilidade simples de ocorrência. Se pensarmos em uma linguagem por exemplo, estudar palavras dessa maneira é uma aproximação ingênua pois os tamanhos das palavras variam bastante. Em um animal que dispara constantemente e que parece haver uma estrutura, ou ao menos, palavras em comum, seria interessante a possibilidade de dado uma sequência prever o próximo pulso. Dando sequência nas análises discutidas aqui, começamos juntamente com o Dr. Fernando Herrero Carrón, do $G N B$ da Espanha, a estudar as probabilidades de transição dos estados do peixe e a usar palavras de tamanho variável. Para tal usamos o algorítimo Causal-State Splitting Reconstruction (CSSR; Shalizi \& Klinkner, 2004) que calcula o modelo teórico que descreve as sequências de estados sem que muitas suposições tenham que ser feitas a priori.

Um trabalho de doutorado do aluno Rafael Tuma Guariento no Grupo de Neurobiofísica do Instituto de Física de São Carlos em colaboração com o Dr. Fernando Herrero Carrón, do GNB da Espanha, está em andamento combinando análises do CSSR e protocolos de Dynamic Clamp em linux.

\section{Gnathonemus petersii com estímulos unidirecionais}

Usamos estímulos elétricos pré-gravados de outros peixes e também estímulos periódicos. Nesta parte da discussão abordaremos somente os experimentos com estímulos reais e os periódicos serão abordados na parte de estímulos bidirecionais para facilitar a comparação dos resultados.

Gnathonemus petersii reage a estímulos aumentando a frequência de disparos do OE em todas as sessões de estímulo, outra característica quando estimulados é a presença de um pulso eco (Russell et al., 1974; Schuster, 2001). Quando há mais de 1 peixe, ou um sinal de outro peixe, essa espécie é conhecida por emitir um pulso depois de $\sim 10 \mathrm{~ms}$ que o peixe recebeu o pulso de estímulo. Esse mecanismo foi estudado em pelo menos 3 espécies de mormyrideos com echo responses com latências variando de 6 a 20 ms (Russel et al. 74; Schuster 2001; Gebhardt et al., 2012) e é interpretado com um reset do rítmo do $\mathrm{OE}$ ou fazer o animal distinguir entre seus pulsos e de conspecíficos (Russel et al. 1974). Nossos resultados não só mostraram a existência dessa latência de $10 \mathrm{~ms}$ mas também de outro pulso eco enviado a $\sim 40 \mathrm{~ms}$ para todos os tipos de estímulo usados, pré-gravados, periódicos e dependentes da atividade enviados com um atraso $t$. Essa diferença se deve provavelmente a que os 
trabalhos anteriores tenham sido feitos em contextos experimentais bem diferentes dos nossos, com peixes com movimentos restritos ou em repouso dentro do cano, com estímulos pré-gravados apresentados ou analisados por poucos minutos. O papel do eco na comunicação ainda não está bem definido, sabemos apenas que não serve para diferenciar machos e fêmeas e que não está relacionado com dominância (Bell et al., 1974).

Analisando os trens de disparo do peixe em relação ao trem de disparos de estímulos prégravados de outro peixe, mostramos que durante essa comunicação há informação sendo transmitida entre eles, isso significa que a variabilidade dos disparos do peixe está de fato relacionada com a variabilidade dos estímulos. Quando observamos como a informação varia ao longo da sessão de estímulo, vimos que ela não é constante havendo até momentos com pouca informação. Curiosamente há momentos na sessão de estímulos que há informação alta para todos os peixes medidos. $\mathrm{O}$ mesmo resultado foi observado em Gymnotus carapo durante o mestrado.

\section{Gnathonemus petersii com estímulos bidirecionais}

Fizemos 3 experimentos diferentes usando o princípio de estímulos dependentes da atividade. Tanto os experimentos com estímulos elétricos como os experimentos com estímulos luminosos se mostraram mais efetivos, com respostas de maior intensidade, quando usamos os protocolos bidirecionais comparados com os mesmos estímulos em protocolos unidirecionais. Conseguimos maior controle dos experimentos, podendo realizar experimentos de aprendizagem e descobrindo os tipos de estímulos que são mais aversivos.

A seguir discutimos resultados particulares de cada experimento: Gnathonemus petersii com estímulos sendo enviados com um atraso dependente da atividade do $\mathrm{OE}$ em comparação com estímulos periódicos, Gnathonemus petersii com estímulos luminosos dependentes da atividade do OE em comparação com estímulos luminosos periódicos e um experimento de aprendizagem com uma barreira virtual com a estimulação dependente da atividade motora do peixe.

Gnathonemus petersii é uma espécie noturna, se esconde em tocas durante o dia independentemente de seu tamanho. Observamos no laboratório que quando iluminados tendem a parar de mover-se, e mas não encontramos material detalhado a respeito na literatura. Para estudar como os 
peixes reagiriam diante desse tipo de estímulo e também para analisar diferentes tipos de protocolos de estimulação, fizemos 2 experimentos: um com estímulos mais realistas que se alteravam em tempo real dependendo da atividade elétrica do peixe e outro convencional unidirecional com a luz piscando periodicamente na frequência média dos peixes. Assim como ocorreu com os estímulos elétricos, os estímulos luminosos quando usamos protocolos bidirecionais se mostraram mas eficazes, com respostas mais intensas do que quando estimulamos com protocolos unidirecionais. Mostramos que os peixes, de fato, preferem ambientes escuros, quando estimulados com luz, os peixes diminuem sua frequência de disparo e, além disso, que parecem identificar pulsos de luz acionados por seus próprios IPIs daqueles pulsos de luz de frequência fixa pois aprendem a disparar pulsos de frequência mais baixas resultando em menos pulsos de luz no aquário, diminuindo a frequência de disparo do $\mathrm{OE}$ de maneira gradativa.

Mostramos que os peixes são sensíveis ao intervalo entre seus pulsos e os pulsos externos, i.e. de um conspecífico, o que seguramente deve ter consequências na eletrocomunicação dado que as variações do OE são controladas tanto por estímulos externos quanto por processos fisiológicos internos (Moller, 1970). Em nossos experimentos com estímulos elétricos enviados de 0,5 ms a mais de $200 \mathrm{~ms}$ de intervalo depois que o peixe emitiu um pulso, observamos que quanto menor $\mathrm{t}$ mais os peixes reagiam disparando IPIs menores. Os peixes disparam menos IPIs curtos quando estimulados com estímulos periódicos, i.e., IPIs periódicos de $45 \mathrm{~ms}$, do que se enviados com atraso t $=45 \mathrm{~ms}$ no protocolo bidirecional. É interessante que o peixe parece ser insensível a estímulos enviados com atrasos maiores que $120 \mathrm{~ms}$. Nos perguntamos se o peixe não responde porque não interpreta $o$ estímulo como sendo de um dominante agressivo ou se seria algo físiológico que os tornando eletricamente "cegos" nessa faixa de tempo. O caso de serem menos sensíveis a determinado tempo depois de um disparo é conhecido e foi discutido anteriormente para Gymnotus carapo, mas em Gnathonemus petersii ocorre o inverso, eles são mais sensíveis logo após dispararem seus OE.

O que nos deixa com a questão de se os peixes, além de serem sensíveis aos intervalos em que os pulsos de um conspecífico são disparados em relação a seus próprios pulos, não seriam sensíveis também a sequências de disparos do próprio peixe. Motivados pelos protocolos de estimulação em tempo real dependentes da atividade que se são mais efetivos e discriminantes para evocar a atividade realista dos peixes, sobre tudo durante a eletrocomunicação e em experimentos comportamentais, e também pelas análises de informação mútua média em que observamos trechos com alta AMI para 
todos os peixes, está sendo iniciado semestre, no GNB da Espanha, um projeto de Mestrado de Angel Lareo Fernández do curso de Engenharia Computacional, no qual os estímulos são acionados pelas palavras pré-determinadas ou pela entropia/informação calculada on-line, dando continuidade a seu projeto de fim de curso.

Além do estudo das descargas elétricas dos peixes sob estímulos elétricos, verificamos também se esses estímulos poderiam alterar o comportamento motor usando um protocolo de estimulação dependente da posição do peixe no aquário. Em experimentos em que conseguimos confinar os peixes em uma "gaiola virtual" o estímulos com frequências bem acima $(\sim 500,1000 \mathrm{~Hz})$ daquelas da espécie se mostraram os mais eficientes, especialmente quando usamos ondas senoidais e não pulsos com o formato de onda da espécie. Esses estímulos se mostram bem aversivos principalmente para peixes pequenos. Nos exemplares de tamanho maior, não foi possível isolá-los usando pulsos com a forma de onda da espécie e com IPIs da magnitude da espécie. Nos peixes mais agressivos conseguíamos o efeito oposto, eles eram atraídos para perto do estimulador. $\mathrm{O}$ fato dos estímulos de maior frequência haverem sido os mais eficazes para afastar o peixe do dipolo de estímulo é explicado pela capacidade de informação do sistema eletroreceptivo ser proporcional ao produto da taxa do OE e o número de receptores por OE, assim sendo, maior a frequência do estímulo mais eletroreceptores são estimulados (Hagiwara \& Morita, 1963; Moller, 1970) o que interfere na eletrocomunicação e os peixes se afastariam de perto do dipolo de estímulo para não houvesse muitas perdas na eletrolocalização.

\section{5 - Conclusão}

Desenvolvemos aparatos experimentais para registrar e estudar o comportamento elétrico e motor de peixes elétricos pulsadores nadando livremente por longos períodos de tempo. Utilizamos técnicas de interação em tempo real entre computadores e sistema nervoso vivo, adaptado de protocolos do tipo dynamic clamp, para produzir estímulos elétricos realistas: com pulsos idênticos aos produzidos pelos peixes e com distribuições de intervalos entre pulsos que podiam ser escolhidas a partir de distribuições obtidas de peixes reais, distribuições aleatórias e distribuições de estímulos que dependem do comportamento do próprio animal de acordo com regras estabelecidas pelo experimentador. Essa mesma técnica adaptada também permitiu produzir sinais de estímulo luminosos 
dependentes da atividade elétrica do animal. Entre outros resultados o aparato permitiu inferir a movimentação do animal e associá-la à entropia da série de pulsos do $\mathrm{OE}$.

Neste trabalho apresentamos alguns resultados da aplicação destes aparatos e técnicas ao estudo de peixes elétricos de campo fraco de espécies que pertencem a ordens diferentes e, portanto, são o resultado de histórias evolutivas distintas: o peixe sul americano Gymnotus carapo, da ordem dos Gymnotiformes e o peixe africano Gnathonemus petersii, da ordem dos Mormyriformes. A aplicação de técnicas da teoria da informação permitiu obter evidências de comunicação dos animais com o estímulo realista e estudar quais os padrões mais prováveis de disparo dos OE quando os animais estão em condição de controle, na ausência de estímulo, ou quando são submetidos a estímulos realistas ou aleatórios.

De acordo com nossos resultados, Gymnotus carapo apresenta um longo transiente ( 10h) quando exposto a um novo ambiente. Durante este transiente os peixes exibem um comportamento exploratório intenso, caracterizado por movimento constante e elevada taxa de disparo de seu OE. Assim, as técnicas tradicionais de restringir periodicamente o movimento do peixe e gravar seus disparos por alguns minutos levam o animal a um comportamento patológico, característico de stress, e muito distinto do observado na natureza e, portanto, não são adequadas para o estudo do comportamento desta espécie.

Ambas espécies, quando submetidas a mudanças no protocolo de estímulo, como o início ou o fim da sessão de estímulos, apresentaram acelerações transientes da frequência média de disparo do OE, o que é compatível com a presença de NR.

Gymnotus carapo demonstrou ser capaz de reagir de maneira diferente aos estímulos com a mesma forma de onda realista quando a distribuição de IPIs era aleatória ou pré-gravada de um peixe real. Muito embora esta espécie altere sua probabilidade de disparo após um estímulo real, o que não acontece quando o estímulo é aleatório, não observamos nenhuma evidência de que ocorra algum mecanismo do tipo JAR, já que a distribuição de probabilidades não apresenta evidências de tentativas de evitar a coincidência entre pulsos. Os animais se movimentam o tempo todo quando submetidos a estímulo com IPIs de um animal real, e observa-se os mesmos sinais de stress verificados quando o animal é submetido a um novo ambiente. Entretanto, durante as sessões com estímulo com IPIs aleatórios alguns animais apresentaram períodos sem movimentação, disparos do OE com baixa frequência e entropia nula, compatíveis com sono comportamental. Estes resultados demonstram a 
importância de se produzir estímulos realistas e são evidencias de que existe comunicação entre os peixes, o que foi confirmado pela presença de picos nos gráficos de AMI entre o estímulo e a resposta do peixe.

Diferente do ocorrido com Gymnotus carapo, nossos experimentos com registros longos da atividade de Gnathonemus petersii não demonstraram a existência de um período transiente após o stress causado pela exposição a um novo ambiente nesta espécie. A AMI calculada entre o estímulo e resposta dos animais nos experimentos com estímulos realistas também apresentou diversos picos coincidentes entre diferentes animais, o que novamente demonstra que os peixes reconhecem algo na série de estímulos. Apesar de ser uma evidência da existência de comunicação, novamente não encontramos nenhuma característica obvia nos trechos do estímulo que correspondem aos picos de AMI, nem nas séries de disparos reposta dos animais, que inclusive eram bem diferentes entre si.

Nos experimentos com pulso de estímulo emitido com intervalo fixo após o pulso de Gnathonemus petersii observamos que a reação do peixe em alterar sua distribuição de IPIs é maior quanto menor é o intervalo entre o pulso real e o pulso de estímulo, o que pode ser mais uma evidência o tempo que os peixes escolham dispararam seja devido também a comunicação e não apenas ao JAR. Entretanto quando o intervalo entre o pulso e o estímulo chega a $200 \mathrm{~ms}$ a distribuição de IPIs não se altera mais em relação a distribuição de IPIs na ausência de estímulo, como se o peixe passasse a ignorar o estímulo. Também descobrimos que além da resposta de eco relatada na literatura após $\sim 10$ ms de um estímulo, Gnathonemus petersii apresenta um segundo eco após $\sim 40 \mathrm{~ms}$. Provavelmente este segundo eco só foi revelado em nossos experimentos porque, diferindo das condições relatadas na literatura, nossos peixes estavam livres e utilizamos estímulos com forma de onda realista. Este segundo eco pode ser outra evidência de tentativa de comunicação.

Os protocolos de estímulos bidirecionais se mostraram mais eficientes em interagir e alterar a frequência do OE, permitindo inclusive controlar os movimentos dos peixes. Gnathonemus petersii pode aprender a controlar a característica de aumentar sua frequência de disparo do OE e até mesmo diminuí-la quando preparamos um experimento em que cada pulso disparado corresponde a um flash de luz disparado na direção do animal. Também pudemos demonstrar que Gnathonemus petersii é capaz de aprender a restringir seus movimentos a uma região virtual do aquário quando fora desta região ele recebe estímulos aversivos de alta frequência.

De um modo geral nossos aparatos e técnicas de análise permitiram estudar os animais em 
condições muito mais similares às naturais e acreditamos que estas técnicas podem trazer muitos progressos para o estudo do comportamento e da comunicação elétrica entre os peixes.

\section{6 - Trabalhos decorrentes do doutorado}

Artigo aceito na revista Plos One intitulado "Noninvasive Realistic Stimulation/Recording of Freely Swimming Weakly Electric Fish: Movement Detection and Discharge Entropy to Infer Fish Behavior" Forlim C. G. and Pinto R. D. (APÊNDICE A)

Artigo em andamento com colaboração com o $G N B$ da Espanha sobre estímulos luminosos em protocolos uni e bidirecionais

Apresentações em congressos internacionais:

1.FORLIM, C.G., MUÑIZ, C., PINTO, R.D, RODRÍGUEZ, F.B.,VARONA, P. Behavioral driving through on line monitoring and activity-dependent stimulation in weakly electric fish. $22^{\text {nd }}$ Annual Computational Neuroscience Meeting, Paris, France - BMC Neuroscience 2013, 14(Suppl 1):P405-[http://www.biomedcentral.com/1471-2202/14/S1/P405]doi:10.1186/1471-2202-14-S1-P405 (APÊNDICE B)

2.FORLIM, C.G., ALMEIDA, L.O.B., VARONA, P., RODRÍGUEZ, F.B., PINTO, R.D.Study of electric and motor behavior in weakly electric fish, Gymnotus carapo and Gnathonemus petersii, using Information Theory. Program No. 501.10. 2012 Neuroscience Meeting Planner. New Orleans, LA: Society for $\quad$ Neuroscience, $2012 . \quad$ Online. Lhttp://www.abstractsonline.com/Plan/ViewAbstract.aspx?sKey=aa180954-2f90-4e65-a29a28535a745836\&cKey=3e18ac55-c29d-44f6-a927-84607e99fe1a\&mKey=\%7B70007181-01C9-4DE9A0A2-EEBFA14CD9F1\%7D](APÊNDICE C)

3. FORLIM, C.G., RODRIGUES, L.B., PINTO, R. D. Neural Coding Tools, based on 
Information Theory, applied to discrete time series: from electrophysiology to neuroethology, $20^{\text {th }}$ Annual Computational Neuroscience Meeting, Stockholm, Sweden, 2011 - BMC Neuroscience 2011, 12(Suppl 1):P253- [http://www.biomedcentral.com/1471-2202/12/S1/P253](APÊNDICE D)

4. MUÑIZ, C., FORLIM, C.G. GUARIENTO, R.T., PINTO, R.D., RODRÍGUEZ, F.B., VARONA, P. Online video tracking for activity-dependent stimulation in neuroethology, $20^{\text {th }}$ Computational Neuroscience Meeting, Stockholm, Sweden - BMC Neuroscience 2011, 12(Suppl 1):P358 - [http://www.biomedcentral.com/1471-2202/12/S1/P358](APÊNDICE E)

5. FORLIM, C.G., PINTO, R. D.Study of the electrocommunication in freely swimming Brazilian electric fish Gymnotus carapo using Information Theory, $1^{\text {a }}$ School and Symposium on System Biology, Natal, RN, Brazil, 2010(APÊNDICE F)

\section{7 - Trabalhos relacionados com o doutorado}

Projeto de doutorado de Rafael Tuma Guariento intitulado "Eletrocomunicação em Gymnotus carapo: um estudo da complexidade biológica através da interface em tempo-real entre modelos computacionais e sistemas nervosos vivos " no Instituto de Física de São Carlos, USP, desde janeiro de 2013.

Projeto de mestrado de Angel Lareo Fernandez, "Stimulus-response closed-loops for multiscale and bidirectional interaction with the nervous system" da Escuela Politecnica Superior da UAM, dando continuidade ao trabalho de fim de curso terminado em agosto 2013.

Projeto de iniciação científica de Amanda Sofie Rios sobre protocolo bidirecional de estimulação com luz dependente de sequências de disparos em Gymnotus carapo, no Instituto de Física de São Carlos, USP, de junho 2012 a junho de 2013. 


\section{8 - Bibliografia}

Alvez-Gomes JA, Ortí G, Haygood M, Heiligenberg W, Meyer A (1995)Phylogenetic analysis of the South American electric fishes (order Gymnotiformes) and the evolution of their electrogenic system: a synthesis based on morphology, electrophysiology, and mitochondrial sequence data. Mol Biol Evol 12(2):298-318.

Alves-Gomes JA (2001). The evolution of electroreception and bioelectrogenesis in teleost fish: a phylogenetic perspective. J Fish Biol, 58:1489-1511

Awaïss A, Lalèyè P, Moelants, T. 2010. Gnathonemus petersii. In: IUCN 2013. IUCN Red List of

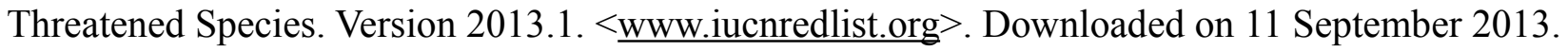

Arnegard ME,Carlson BA (2005). Electric organ discharge patterns during group hunting by a mormyrid fish. Proc Biol Sci 272: 1305-14.

Bell CC, Myers JP, Russell CJ (1974). Electric organ discharge patterns during dominance related bahavioral displays in Gnathonemus petersii. J Comp Physiol. 92:201-228

Belbenoit P (1972). Relation between motoricity and electric discharge in Mormyridae (teleostei) J Physiol (Paris) 65:Suppl:197A

Bennett, M V L \& Steinbach A B (1969). Influence of electric organ control system on electrosensory afferent pathways in mormyrids. In: Neurobiology of cerebellar Evolution and development, pp. 207214, R. Llinas (ed.). Chicago, Illinois

Brochini L, Carelli PV, Pinto RD (2011). Single synapse information coding in intraburst spike patterns of central pattern generator motor neurons. The Journal of Neuroscience 31: 12297-12306. doi: 10.1523/JNEUROSCI.1568-11.2011. 
Borst A, Theunissen FE (1999). Information theory and neural coding. Nature Neurosci 2:947-57.

Bullock TH (1969). Species differences in effect of electroreceptor input on electric organ pacemakers and other aspects of behavior in electric fish. Brain Behav Evol 2:85-118

Bullock TH (1999). The future of research on electroreception and electrocommunication. J Exp Biol 202:1455-8.

Bullock TH, Hopkins CD, Popper AN, Fay RR (2005). Electroreception, Springer, ISBN: 978-0-38723192-1 (Print) 978-0-387-28275-6 (Online)

Carlson BA (2002). Electric signaling behavior and the mechanisms of electric organ discharge production in mormyrid fish. J Physiol-Paris 96:405-19

Carlson BA (2009). Temporal-Pattern Recognition by Single Neurons in a Sensory Pathway Devoted to Social Communication. Behavior J Neurosci 29(30): 9417-9428; doi: 10.1523/

Carlson BA, Gallant JR (2013). From Sequence to Spike to Spark: Evo-devo-neuroethology of Electric Communication in Mormyrid Fishes J. Neurogenetics, 27(3): 106-129

Carlson BA, Hopkins CD (2004). Central control of electric signaling behavior in the mormyrid Brienomyrus brachyistius: segregation of behavior-specific inputs and the role of modifiable recurrent inhibition. J Exp Biol. 207:1073-84.

Capurro A, Malta CP (2004). Noise autocorrelation and jamming avoidance performance in pulse type electric fish. Bull Math Biol 66:885-905.

Caputi AA, Budelli R (1995). The electric image in weakly electric fish: I. A data-based model of waveform generation in Gymnotus carapo. J Comp Neurosci 2:131-47. 
Caputi AA, Castelló ME, Aguilera P, Trujillo-Cenóz O (2002). Electrolocation and electrocommunication in pulse gymnotids: signal carriers, pre-receptor mechanisms and the electrosensory mosaic. J Physiol Paris 96:493-505.

Caputi AA , Nogueira J (2012). Identifying Self- and Nonself-Generated Signals: Lessons from Electrosensory Systems. In: López-Larrea C, editor. Sensing in Nature, Springer,pp 107-125 DOI 10.1007/978-1-4614-1704-0_7

Chamorro P, Muñiz C, Levi R, Arroyo D, Rodríguez FB,et al.(2012).Generalization of the Dynamic Clamp Concept in Neurophysiology and Behavior. PLoS ONE 7(7): e40887. doi:10.1371/journal.pone.0040887

Clausen J, van Wijk R, Albrecht H (2012). Weakly electric fish for biomonitoring water quality. Environmental Technology 33(10):1089-1099. DOI:10.1080/09593330.2011.610827

Cleveland WS (1993). Visualizing Data. Hobart Press, Summit, New Jersey, U.S.A.

Crockett DP (1986). Agonistic behavior of the weakly electric fish, Gnathonemus petersii (Mormyridae, Osteoglossomorpha).J Comp Psychol 100(1):3-14.

Crawford J D (1997). Hearing and acoustic communication in the mormyrid electric fishes. Mar. Fresh. Behav. Physiol. 29, 65-86.

Crawford JD, Huang X (1999). Communication Signals and Sound Production Mechanisms of Mormyrid Electric Fish, J. Exp. Biol. 202, 1417-1426 .

Cole K (1955). Electrochemistry in biology and medicine, Wiley, New York, chapter Ions, potentials and the nerve impulse. pp. 121-140. 
Cover TM, Thomas JA (2006). Elements of InformationTheory, John Wiley \& Sons.

Cuddy M, Aubin-Horth N, Krahe R (2012) Electrocommunication behaviour and non invasivelymeasured androgen changes following induced seasonal breeding in the weakly electric fish, Apteronotus leptorhynchus. Horm Behav;61(1):4-11. doi: 10.1016/j.yhbeh.2011.09.003. Epub 2011 Sep 14

de Ruyter van Steveninck RR, Lewen GD, Strong SP, Koberle R, Bialek W (1998) Reproducibility and variability in neural spike trains. Science 275: 1805-8.

dos Santos J (2013). Protocolos de aplicação de drogas em tempo real e dependente do padrão a centros geradores de padrões motores: efeitos de serotonina (5-HT) e glutamato no sistema nervoso estomatogástrico de Callinectes sapidus. Dissertação de Mestrado - Instituto de Física de São Carlos USP

Engelmann J, Bacelo J, Metzen M, Pusch R, Bouton B, et al. (2008) Electric imaging through active electrolocation: implication for the analysis of complex scenes. Biol Cybern 98: 519-539.

Faraday M(1839). Notice of the character and direction of the electric force of the Gymnotus. Phil. Trans. Roy. Soc. 129:1-12

Fernandez-Vargas J, Pfaff HU, Rodriguez FB, Varona P (2013). Assisted closed-loop optimization of SSVEP-BCI efficiency. Frontiers in Neural Circuits 7: 27.

Fletcher LB, Crawford JD (2001). Acoustic detection by sound-producing fishes (mormyridae): the role of gas-filled tympanic bladders. J Exp Biol 204:175-183

Forlim, CG (2008). Estudo experimental da eletrocomunicação em peixes de campo elétrico fraco da espécie Gymnotus carapo - uma aplicação da Teoria da Informação. Dissertação de Mestrado, Instituto de Física, Universidade de São Paulo, São Paulo. http://www.teses.usp.br/teses/disponiveis/43/43134/tde-23102008-193008/ 
Gebhardt K, Böhme M, Von der Emde G (2012). Electrocommunication behaviour during social interactions in two species of pulse-type weakly electric fishes (Mormyridae). J Fish Biol 81:2235 - 54

Gouvêa Junior F, Stopa RM, de Paula HMG, Hoshino K (2002). electrolocation-communication discharges arrest and body size in the electric-fish gymnotus carapo miller, 1966 (osteichtyes, gymnotidae). Rev. Bras. Zoociências Juiz de Fora V. 4 No2 Dez/2002 p. 203 - 214.

Hagiwara S, Morita H (1963). Coding mechanism of electroreceptor fibers in some electric fish. J Neurophysiol 25:430-49

Heiligenberg W, Baker C, Bastian J (1978). The jamming avoidance response in gymnotoid pulsespecies: A mechanism to minimize the probability of pulse-train coincidence. J Comp Physiol 124:211224.

Hopkins, CD (1988). Neuroethology of electric communication. Ann. Rew. Neurosci. 1988.11 : $497-$ 535

Hupé GJ, Lewis JE (2008). Electrocommunication signals in free swimming brown ghost knifefish, Apteronotus leptorhynchus. J Exp Biol 211, 1657-1667. doi: 10.1242/jeb.013516

Jun JJ, Longtin A, Maler L (2013). Tracking of multiple free-swimming weakly electric fish via efficient localization of moving dipole sources. PLoS One (in press)

Kramer B (1978). Spontaneous discharge rythms and social signalling in the weakly electric fish Pollimyrus isidiri (Cuvier et Valenciennes)(Mormyridae,Teleostei). Behav Ecol Sociobiol 4:61 - 74.

Kramer B (1979). Electric motor response of the weakly electric fish, Gnathonemus petersii (Mormyridae), to play-back of social signals. Behav Ecol Sociobiol 6:67 - 79. 
Kramer B, Bauer R (1976). Agonistic Behaviour and Electric Signalling in a Mormyrid Fish, Gnathonemus petersii. Behav Ecol Sociobiol 1:45-61

Lissmann HW (1958). On the function and evolution of electric organs in fish. J ExpBiol 35:156-191

Marmont G (1949). Studies on the axon membrane; a new method. J Cell Physiol 34: 351-382. doi: $10.1002 /$ jcp.1030340303.

Matias P (2011). Novo método para assinatura e identificação de sinais de eletrocomunicação de peixes elétricos de campo fraco da espécie Gymnotus carapo. Dissertação de Mestrado, Instituto de Física de São Carlos, Universidade de São Paulo, São http://www.teses.usp.br/teses/disponiveis/76/76132/tde-03052011-164310/

Moller P (1970). 'Communication' in weakly electric fish, Gnathonemus niger (Mormyridae) I. Variation of electric organ discharge (EOD) frequency elicited by controlled electric stimuli. Anim Behav 18:768-86.

Muniz C, Arganda S, Rodríguez FB, de Polavieja GG, Varona P (2005). Realistic stimulation through advanced dynamic clamp protocols. Lect Notes Comput Sc 3561: 95-105 3561: 95-105.

Muniz C, Rodríguez F, Varona P (2009). RTBiomanager: a software platform to expand the applications of real-time technology in neuroscience. BMC Neuroscience 10: P49. doi: 10.1186/14712202-10-S1-P49.

Muñiz C, Forlim CG, Guariento RT, Pinto RD, Rodríguez FB, Varona P (2011). Online video tracking for activity-dependent stimulation in neuroethology, $20^{\text {th }}$ Computational Neuroscience Meeting, Stockholm, Sweden - $\quad$ BMC Neuroscience 2011, 12(Suppl 1):P358[http://www.biomedcentral.com/1471-2202/12/S1/P358]

Nogueira J, Caputi AA (2011). Timing actions to avoid refractoriness: a simple solution for streaming 
sensory signals. PLoS One 6: e22159.

Nowotny T, Szücs A, Pinto RD, Selverston AI (2006). StdpC: A modern Dynamic Clamp. J Neurosci Methods 158: 287-99.

Perrone R, Macadar O, Silva A (2009). Social electric signals in freely moving dyads of Brachyhypopomus pinnicaudatus. J Comp Physiol A 195: 501-14.

Pinto RD, Elson RC, Szücs A, Rabinovich, MI, Selverston, AI, Abarbanel, HD (2001). Extended Dynamic Clamp: controlling up to four neurons using a single desktop computer and interface. $\mathrm{J}$ Neurosci Methods 108: 39-48. doi: 10.1016/S0165-0270(01)00368-5.

Prinz AA, Abbott LF, Marder E (2004). The dynamic clamp comes of age. Trends Neurosci 27: 218 224. doi: 10.1016/j.tins.2004.02.004.

Post N, von der Emde G (1999). The "novelty response" in an electric fish: response properties and habituation. Physiol Behav 68: 115-28.

Rieke F, Warland D, De Ruyter van Steveninck, Bialek W(1999). Spikes: Exploring the Neural Code (Computational Neuroscience), MIT Press

Rodrigues L B (2011). Processamento de informação em neurônios motores de um centro gerador de padrões. Tese de Doutorado, Instituto de Física, Universidade de São Paulo, São Paulo. http://www.teses.usp.br/teses/disponiveis/43/43134/tde-02052012-121542/

Russell CJ, Myers JP, Bell CC (1974). The echo response in Gnathonemus petersii (Mormyridae). J comp Physiol 92:181-200 
Shannon CE (1948). A mathematical theory of communication. Bell Systems Tech J 27: 379-423.

Shalizi CR, Klinkner KL (2004). Blind Construction of Optimal Nonlinear Recursive Predictors for Discrete Sequences In:Uncertainty in Artificial Intelligence: Proceedings of the Twentieth Conference (UAI 2004) AUAI Press, Arlington, Virginia,pp.504—511.http://arxiv.org/abs/cs.LG/0406011

Schuster S (2001). Count and spark? The echo response of the weakly electric fish Gnathonemus petersii to series of pulses. J Exp Biol 204: 1401 - 12

Stipetic E (1939). Über das Gehörorgan der Mormyriden. Z. Vergl. Physiol. 26, 740-752.

Stopa RM,Hoshino K (1999). Electrolocation-communication discharges of the fish Gymnotus carapo L. (Gymnotidae: Gymnotiformes) during behavioral sleep. Braz J Med Biol Res 32: 1223-1228

Szucs A, Varona P, Volkovskii AR, Abarbanel HD, Rabinovich MI, et al. (2000). Interacting biological and electronic neurons generate realistic oscillatory rhythms. Neuroreport 11: 563-569. doi: 10.1097/00001756-200002280-00027.

1.

Tallarovic KS, Zakon H (2005). Electric organ discharge frequency jamming during social interactions in brown ghost knifefish, Apteronotus leptorhynchus. Anim Behav 70(6) 1355-65

Varona P, Torres JJ, Abarbanel HD, Rabinovich MI, Elson RC (2001). Dynamics of two electrically coupled chaotic neurons: experimental observations and model analysis. Biol Cybern 84: 91-101. doi: $10.1007 / \mathrm{s} 004220000198$.

von der Emde G, Schwarz S, Gomez L, Budelli R, Grant K (1998). Electric fish measure distance in the dark. Nature 395:890-4. 
von der Emde G (1999). Active electrolocation of objects in weakly electric fish.J Exp Biol 202:120515

von der Emde G, Fetz S (2007). Distance, shape and more: recognition of object features during active electrolocation in a weakly electric fish. J Exp Biol 210:3082-95.

von der Emde G, Amey M, Engelman J, Fetz S, Folde C, et al. (2008). Active electrolocation in Gnathonemus petersii: behaviour, sensory performance, and receptor systems. J Phisiol Paris 102:27990.

von der Emde G, Behr K, Bouton B, Engelmann J, Fetz S, et al. (2010). 3-Dimensional Scene Perception during Active Electrolocation in a Weakly Electric Pulse Fish. Front Behav Neurosci 28: 4:26.

von Frisch K (1938). The sense of hearing in fish. Nature 141, 8-11

Varona P, Torres JJ, Abarbanel HD, Rabinovich MI, Elson RC (2001). Dynamics of two electrically coupled chaotic neurons: experimental observations and model analysis. Biol Cybern 84: 91-101. doi: $10.1007 / \mathrm{s} 004220000198$.

Westby G W (1975). Comparative studies of the aggressive behaviour of two gymnotid electric fish (Gymnotus carapo and Hypopomus artedi). Animal behaviour 23: 192-213.

Westby G W (1979). Electrical Communication and Jamming Avoidance Between Resting Gymnotus carapo. Behav Ecol Sociobiol 4: 381-393.

Wilk MB, Gnanadesikan R (1968). Probability plotting methods for the analysis for the analysis of data Biometrika 55 (1): 1-17. doi: 10.1093/biomet/55.1.1

Wong RY, Hopkins CD (2007). Electrical and behavioral courtship displays in the mormyrid fish 
Brienomyrus brachyistius. J Exp Biol 210: 2244-52.

Yokogawa T, Marin W, Faraco J, Pezeron G, Appelbaum L et al. (2007). Characterization of Sleep in Zebrafish and Insomnia in Hypocretin Receptor Mutants. PLoS Biol. 5(10): e277. doi: $\underline{10.1371 / \text { journal.pbio.0050277 }}$

Yu N, Hupé G, Garfinkle C, Lewis JE, Longtin A (2012). Coding conspecific identity and motion in the electric sense. PLoS Comput. Biol. 8(7), e1002564

Zakon HH (1986). The electroreceptive periphery. In: Electroreception.pp. 103-56. New York: John Wiley

Zakon HH (1987). The electroreceptors: diversity in structure and function. In: Sensory Biology of Aquatic Animals, pp. 813-50. New York: Springer-Verlag.

Zupanc GKH (2009). Electrocommunication In: Squire, L.R. (ed.), Encyclopedia of Neuroscience, Volume 3, pp. 839-848. Academic Press, Oxford 


\section{APÊNDICE A}

\section{Automatic Realistic Real Time Stimulation/Recording in Weakly Electric Fish: Long Time Behavior Characterization in Freely Swimming Fish and Stimuli discrimination (DOI: 10.1371/journal.pone.0084885)}

Caroline G. Forlim ${ }^{1,2}$, Reynaldo D. Pinto ${ }^{2}$

${ }^{1}$ Lab. Fenômenos Não-Lineares, Instituto de Física, Universidade de São Paulo - Cx. Postal 66318, 05315-970, São Paulo, SP, Brazil

${ }^{2}$ Lab. Neurodinâmica/Neurobiofísica, Instituto de Física de São Carlos/USP - Cx. Postal 369, 13560970, São Carlos, SP, Brazil

contact e-mail: carolineforlim@usp.br, reynaldo@ifsc.usp.br

short title: Realistic Stimulation of Gymnotus carapo and Stimuli Discrimination. 
Keywords: Gymnotus carapo, electric organ discharge, weakly electric fish, electrolocation, electrocommunication, inter pulse interval entropy, long transient behavior when exposed to a new environment, discrimination between conspecific and random timestamp sequences of stimuli, electric organ-like discharges, jamming avoidance response, refractory period after detecting a pulse, novelty response.

List of abbreviations:
ADC - Analog to Digital Converter
DAC - Digital to Analog Converter
EOD - Electric Organ Discharge
IPI - Inter Pulse Interval
LIA - Locally Induced Amplitude
JAR - Jamming Avoidance Response
NR - Novelty Response
PSTH - Post Stimulus Time Histograms

\begin{abstract}
Weakly electric fish are unique model systems in neuroethology, that allow experimentalists to non-invasively, access, central nervous system generated spatio-temporal electric patterns of pulses with roles in at least 2 complex and incompletely understood abilities: electrocommunication and electrolocation. Pulse-type electric fish alter their inter pulse intervals (IPIs) according to different behavioral contexts as aggression, hiding and mating. Nevertheless, only a few behavioral studies comparing the influence of different stimuli IPIs in the fish electric response have been conducted. We
\end{abstract}


developed an apparatus that allows real time automatic realistic stimulation and simultaneous recording of electric pulses in freely moving Gymnotus carapo for several days. We detected and recorded pulse timestamps independently of the fish's position for days. A stimulus fish was mimicked by a dipole electrode that reproduced the voltage time series of real conspecific according to previously recorded timestamp sequences. We characterized fish behavior and the eletrocommunication in 2 conditions: stimulated by IPIs pre-recorded from other fish and random IPI ones. All stimuli pulses had the exact Gymontus carapo waveform. All fish presented a surprisingly long transient exploratory behavior (more than $8 \mathrm{~h}$ ) when exposed to a new environment in the absence of electrical stimuli. Further, we also show that fish are able to discriminate between real and random stimuli distributions by changing several characteristics of their IPI distribution.

\section{Introduction}

Weakly electric fish offer a unique opportunity to non-invasively study and interact with living intact nervous systems. Their electric organ discharges (EODs) are complex spatio-temporal signals involved in processing a plethora of environmental sensory information [1-4].

Electric signal production in pulse-type weakly electric fish has 2 basic components: the waveform and the timing of the electric pulses [1]. The pulse waveforms are species-specific and the inter EOD intervals or inter pulse intervals (IPIs) can vary from tens to hundreds of milliseconds [5]. Each EOD generates electric fields that propagate into the water, interact with the surroundings and reach a myriad of electroreceptors disposed to detect electric field changes that cause small alterations in self or conspecific transcutaneous currents [2,5].

Fish are able to localize and measure the distance of nearby objects with different impedance in the surrounding water by analyzing the alterations in the self-generated electric field; this process is called active electrolocation [4,6-10].

They can also perform electrocommunication; in this process, 1 fish's EODs are detected by 
another fish's receptors. During this process, each fish emits and receives self and conspecific EODs [11-13]. The neuroethology of electrolocation and electrocommunication remain interesting and active fields of research [8,14-16]. Electrocommunication is considered to be an important factor in brain evolution and a diversification trigger in electric fish [17].

The complex spatio-temporal pattern generated by the EODs makes experimentation difficult in freely moving fish [18]. For this reason, many previous experiments to characterize the electrosensory system were conducted by shortly moving fish to shallow tanks, restraining their movements, despite the sensitivity of the fish IPI patterns to stimuli, environment and manipulation. Studies of electrical interactions between fish were possible in species that presented an accentuated sexual dimorphism in EOD shape during breeding season [19,20], or during resting behavior $[18,21]$, or in situations where specimens of very different sizes were used $[18,21,22]$. These parameters allowed easier separation of fish's EODs from the stimuli ones; otherwise, reliable separation of the EODs depends on the fishs' relative orientation and proximity to the electrode, making automatic real-time detections very difficult [22] due to the changes in the measured amplitude and waveform [18, 23]. Recent advances have been made in measuring automatically freely moving non-stimulated fish [24,25], but no general solution has been yet presented to automatically detect, stimulate and separate each fish's EODs from conspecific's ones.

In many pulse-type species such as Gymnotus carapo, the EOD of each individual is a stereotyped pulse shape with no sexual dimorphism [9]. In such species, fish can also vary their IPIs depending on the environmental context and such variations have been associated to behavioral contexts [26, 27], as well as species recognition [28]. Nevertheless, there are only a few comparative studies linking stimuli IPI distributions and patterns to fish's electrical response [26,27,29, 30]. For example, when a new stimulus (light, sound, electrical field or vibration) is presented a transient EOD rate acceleration, called the novelty response (NR) [31-34] is triggered. A jamming avoidance response (JAR) mechanism has also been reported in which fish adjust their EOD timing to avoid discharging at the same time[35,36].

Entropy is a powerful tool to identify and analyze relevant changes in the complex spatio-temporal 
pattern discharged by the $\mathrm{OE}$ and relate such changes with fish behavior. It is a measure of uncertainty or unpredictability and characterizes how much information is available. Entropy has been widely used in neural systems $[37,38,39,40]$ and can be applied to adaptive systems with complex non-linear dynamics. It is defined as [41]:

$H(W)=-\sum_{w} p(w) \log _{2} p(w)$

where $w$ is the outcome, $p$ is the probability and $H$ is entropy

When an outcome is highly predictable, the entropy is low. That is, if fish discharge the same EOD patterns, the entropy for such a signal would be zero.

One can compute the entropy of any time series, however, to relate fish IPI entropy with behavior we must ensure that the process of recording the EODs produce the minimum disturbance possible to freeswimming animals. 
We show an apparatus that allows non-invasive realistic and controlled electrical stimulation with simultaneous recording of EOD timestamps for several days of freely moving pulse-type fish Gymnotus carapo. The apparatus is based on a simple and inexpensive circuitry than can be easily adjusted for different species of electric fish [42, 43, 44], to fieldwork, and to connect and stimulate 2 fish in real time.

We concentrated our experiments in 2 different situations: (1) non stimulated fish and (2) stimuli from an artificial fish that mimics the pulse shape of a conspecific. We could evaluate how long the stress caused by exposing the fish to a new environment distorts the patterns of electrical activity, the relation, between the locomotor and electrical activity the differences in the electrical activity when the fish are exposed to real (conspecific) or random distributions of stimuli IPIs.

\section{Materials and methods}

\section{Ethics Statement}

All experimental protocols and procedures were in accordance with the ethical principles of the Society for Neuroscience and were approved by the Committee on Ethics in Animal Experimentation of the Federal University of São Carlos - UFSCar (Protocol number 007/2009).

\section{Animals}

Adult specimens, $15-25 \mathrm{~cm}$ long, of unsexed Gymnotus carapo were acquired from local fishermen in the state of São Paulo, Brazil. The fish were maintained in individual $31.5 \mathrm{~L}(30 \times 35 \times 30$ $\mathrm{cm}$ ) unplanted tanks, exposed to natural illumination at room temperature and provided with lengths of polyvinyl chloride (PVC) pipe as hiding places. Water conductivity was $100 \pm 5 \mu \mathrm{S} / \mathrm{cm}$; similar value found in the streams or lagoons where these fish are usually captured. Fish were fed a variety of living food twice a week including: small fish, worms, and Artemia salina (brine shrimp). In total, 20 fish were used in the reported experiments, and recordings of some fish were obtained several times in different protocols. 


\section{Measurement aquarium}

The experimental setup, developed in our laboratory [45-47] consisted of glass aquarium (40 $\mathrm{x}$ $40 \times 45 \mathrm{~cm})$ filled with $64 \mathrm{~L}$ of water $(40 \times 40 \times 40 \mathrm{~cm}$; and enclosed in a double Faraday cage $(1 \mathrm{~mm}$ aluminum sheets) to shield from electrical noise and in two $3 \mathrm{~cm}$ thick layers of insulating foam confining a $4 \mathrm{~cm}$ air layer to attenuate sound waves. Other potential low amplitude, low frequency mechanical vibrations were attenuated by hanging the apparatus from steel cables attached to the ceiling.

Fish were not fed in the measurement aquarium, and the room temperature was fixed at $23^{\circ} \mathrm{C}$ to ensure that the water temperature and conductivity did not change during the experiments.

Spatio-temporal EOD was measured using a three-dimensional (3D) array of 8 electrodes, each consisting of a $0.2 \mathrm{~mm}$ diameter stainless steel wire tightly inserted through silicone glue, between the glass aquarium walls, dipping 1-2 $\mathrm{mm}$ into the water. The electrodes were placed in a cubic arrangement ( $\sim 40 \mathrm{~cm}$ on a side, Fig. 1A). Signals from 7 electrodes were differentially amplified (gain $=100 \mathrm{x}$, home-made) using the electrode at the base of the aquarium as a common reference. The time series of all differential amplifiers (containing both EOD and artificial stimulus signals) were digitized at $50 \mathrm{kHz}$ by an analog-to-digital converter (ADC) board (PCI MIO 16-E1, National Instruments, Texas) in an acquisition PC-compatible computer.

\section{Artificial stimulus generation}

A dipole electrode placed inside a $15 \mathrm{~cm}$ PVC pipe was used to generate artificial stimuli mimicking the geometry of a medium size fish. Although Gymnotus carapo EODs are more complex than the signal emitted by a dipole, for this particular study it was a good approximation. Artificial fish stimuli were generated by a digital to analog converter (DAC) board (Digidata 1200B, Axon Instruments, Union City, CA), controlled by a real-time software developed by our group [47,48] to mimic a real Gymnotus carapo EOD waveform, previously stored in a personal computer (PC;Fig. 1A), and rescaled to a fixed peak amplitude of 5V. Two stimuli timestamp sequences (30 min long) could be chosen by the experimenter: one pre-recorded from an unstimulated solitary fish just after being introduced in the tank, and one with randomly generated IPIs (flat distribution) in the same range as the 
IPI of the real fish (15-20 ms). A flat IPI distribution means that after a given IPI, the next IPI will be between $15 \mathrm{~ms}$ and $20 \mathrm{~ms}$, with all values in this interval chosen with the same probability, avoiding possible causalities (Fig. 2).

\section{Acquisition software}

Gymnotus carapo generates a multi-phasic EOD pulse [50]. A simple way to detect the timing of an EOD is to determine the occurrence of the major pulse component.

However, depending on the fish orientation, the major component can be either negative or positive for a given electrode, thus making detection difficult.

To overcome this problem, our detection software squared and summed the digitized time series registered by all 7 electrodes, compressing EOD information in a single time series. By comparing the compressed time series with a threshold level we were able to reliably detect the EODs (Fig. 1B), with a resolution of $20 \mu \mathrm{s}$. For each EOD detected, the program recorded the event timestamp and the locally induced amplitude (LIA) at each electrode, (defined here as the difference between the maximum and minimum values of voltage induced during the EOD [Fig. 1B]).

The LIA is inversely proportional to the fish-electrode distance $[18,22]$; therefore, if the fish stood still for a period, the LIA would have been practically the same from pulse to pulse, providing a low standard deviation value. Conversely, the LIA amplitude would have changed from pulse to pulse in at least a few electrodes for active fish, producing higher standard deviation values for those electrodes. By summing the standard deviations over all electrodes, we estimated if the fish were swimming or standing, disregarding their position and orientation.

In experiments with artificial stimulation, the ADC input signals from the electrodes contained both real fish and artificial pulses; therefore, we subtracted the square of the artificial signal from the summed signal to avoid recording artificial pulses as real fish pulses (Fig. 1B). The squared value of stimulus + fish pulse can show a small delay compared to the artificial stimuli of 1-3 samples due to the DAC-ADC circuitry. Elimination of the artificial stimulus from the stimulus + fish pulse will be 
maximal when there is no delay between these 2 signals.

The detection software was written in DASYlab graphic language (Dasytech, Germany).

\section{Data analyzes}

Information Theory provides invaluable tools to study neural coding [41]. Here we inferred the timestamp sequences variability by calculating the entropy $\mathrm{H}(\mathrm{T})$ as a function of time, using a direct method [51] adapted to our data.

We analyzed the timestamp sequences in $\mathrm{T}=40 \mathrm{~s}$ windows, but the same qualitative results were also found using 20 and $60 \mathrm{~s}$ windows. The first window spanned from 0 to $40 \mathrm{~s}$, the second from 20 to $60 \mathrm{~s}$, and so on, maintaining a $20 \mathrm{~s}$ time distance between the start of successive windows (Fig. 3). For each window, we calculated the probability of observing different EOD patterns and obtained the entropy from this probability distribution. To compute the entropy $\mathrm{H}(\mathrm{T})$, the time axis was discretized into $b$ sec wide bins. The presence of an EOD in each bin was represented by 1 , and the absence was represented by 0 . Thus, we encoded a sequence of EODs as a binary string (Fig. 3A).

The entropy $\mathrm{H}$ depends on the value for $\mathrm{b}: \mathrm{H}=\mathrm{Hb}$. If $\mathrm{b}$ was too small, most of the bits of our strings would be zero, and very few patterns would have been found. However, if b was too big, most bits would be set to 1, again leading to very few patterns. In both cases, the low entropy values would have not satisfactorily represented the variability of the data. Hence, an intermediate optimal value of $b$ was required to correctly express the variability of the data. In agreement with the principle of maximization of entropy [52], choosing b such that $\mathrm{Hb}$ was a maximum would have produced the least structured set of patterns consistent with the data. Intuitively, suitable values of $b$ would provide strings with similar amounts of zeros and ones. In our case, the fish average IPI was about 20-40 ms, hence b should have been of the order of 10-20 ms. To determine the "best" value of b, we computed entropy for $\mathrm{b}$ between 3 and $40 \mathrm{~ms}$, in 1-ms steps.

Next, we decided on the length $L$ of patterns, for which the probability was computed. In our analyses each pattern was represented by a word composed by $L=4$ bits. For a given $b$ we started at the beginning of the corresponding string and using a 4-bit mask we copied the first 4 bits to the word $w_{1}$. 
Then, we moved the mask 1 bit to the right and copied the bits to the word $w_{2}$ (Fig. 3A). This process was repeated until the mask reached the end of the window. $W=\left\{w_{1}, w_{2}, w_{3}, \ldots, w_{N}\right\}$ is the set of all words (patterns) from which we computed the probabilities $P(w)$ of finding each 1 of the $2^{4}=16$ different words.

To ensure a good statistical estimation of $P(w)$ one should use stationary data and the largest window length possible. However, the entire timestamp sequences are not stationary (some of them are several days long), thus we explore this feature by analyzing changes in the entropy along the sequence and relate them to the fish behavior. The parameter of $\mathrm{T}=40 \mathrm{~s}$ was long enough to provide an average number of words $\mathrm{N} \sim(40 \mathrm{~s} / 15 \mathrm{~ms}) \sim 2500$ words, giving a good statistical value of $P(w)$ for all possible 16 words and still capturing the fish behavior on a sub-minute scale.

Electrical behavior was characterized by the discharge interruptions, IPI pattern entropy, response IPI distribution histograms and their properties. Sliding window histograms and entropy were calculated according to their classical definitions and for the same sequence of 40-s windows used in the entropy computation for direct comparison.

To study the influence of different stimuli IPI distributions on the preferred latencies, we built post stimulus time histograms (PSTHs), by plotting the experimental probability that a fish EOD occurs immediately after a stimulus EOD, set as time reference (Fig. 3B).

Analysis programs were developed in $\mathrm{C}++$ language and Matlab (The Mathworks Inc., Natick, MA) and ran in free open source Ubuntu Linux 10.04 (Canonical Ltd., London, UK) based AMD64 3200MHz PC-computers. Graphics were designed with Matlab (The MathWorks, Inc., Massachusetts, USA) and Gnuplot 4.2 (http://www.gnuplot.info).

\section{Results}




\section{Non stimulated fish}

To investigate how locomotor and electrical behavior changed over long periods we acquired continuous data for approximately $48 \mathrm{~h}$ from freely moving non-stimulated fish. All acquisitions were started immediately after introducing the fish in the measurement aquarium and were performed in complete darkness. Each experiment was started at a different time of the day. Fish were moved back to the maintenance aquarium with natural illumination at the end of the experiments.

Two different behaviors were observed: a transient period characterized by low average IPI of approximately $27.5 \mathrm{~ms}$ (Fig. 4A) and a stationary one characterized by higher mean IPI (Fig. 4B). These persisted throughout the experiment, and the IPI distributions oscillated (Fig. 4C) between the same 2 main peaks, a sharper one corresponding to the higher IPI of $42 \mathrm{~ms}$ and another one corresponding to the lower IPI of approximately $27 \mathrm{~ms}$ (sharp peaks in Fig. 4A and B are represented in dark red, and IPIs with lower, but still significant, probability are represented in yellow in Fig. 4C).

The fish movement (Fig. 4D) was maximum during the initial transient and evolved to a stationary period that alternated between vigorous activity and absence of movement (LIA std near 0 ). The duration of the transient in the movement analyzes coincided with duration of the transient in EOD activity.

Analyzes of EOD patterns of entropy over time (Fig. 4E) revealed the same qualitative behaviors as described above. The locomotor activity peaks corresponded to high EOD variability timing, whereas the valleys corresponded to low variability timing, meaning that when the fish swam more vigorously its EO fired a greater variety of EOD patterns and vice-versa. When the entropy was near zero, the same pattern (periodic firing rate) was being fired.

During the transient period we found higher and generally constant values of locomotor activity and entropy (Fig. 4F). During the stationary period both locomotor activity and entropy entrained their peaks and valleys to express changes in the EOD rhythm (Fig. 4G). When the IPIs distribution over time was dominated by long IPIs $(\sim 42 \mathrm{~ms})$, the fish was stating still (locomotor activity $\sim 0)$ and firing 
periodic IPIs (entropy $\sim 0$ )

All fish presented a much flatter distribution with a single mean when introduced in the new tank. This typical transient in response to the new environment lasted several hours, corresponding to a long relaxation time $T_{R}$, defined as the time needed for the IPIs to reach the stationary state. For all fish recorded $(\mathrm{N}=3) T_{R}=(10 \pm 5) \mathrm{h}$. Despite quantitative differences all fish presented a final stationary state oscillating between 2 well defined mean IPIs. The duration of the EOD activity transient coincided with the duration of the transient in the locomotor activity analyses and their peaks and valleys were entrained.

The mean cross-correlation between EOD pattern entropy, and locomotor activity for the transient period (Fig. 5A) was much lower than that for the stationary period (Fig. 5B). Negative values of cross-correlation meant that the locomotor activity decreased when entropy increased, indicating that although the fish was swimming with less intensity, a great variety of EOD patterns were being fired. In the transient period, the cross-correlation remained approximately $10 \%$ for all lags, with a peak of $10 \%$ at lag 0 . For the stationary period, there was a sharp peak of $70 \%$ at 0 lag that dropped abruptly to approximately $20 \%$ at the next lag and then remained at $10 \%$

There were a few spontaneous cessation of firing, defined as IPIs greater than twice the mean IPI, up to $5.3 \mathrm{~s}$ (Table 1). Spontaneous discharge interruptions were longer and more frequent in the stationary period, when fish were habituated to the new environment.

\section{Stimulation Experiments}

To compare the influence of distinct stimuli IPI distributions on the fish's behavior, we used a real stimulus, pre-recorded from a fish without stimulation (black curve in Fig. 2). and a random (flat) distribution of IPIs between 15 and $20 \mathrm{~ms}$ (red curve in Fig. 2). Fish were subjected to 2 protocols consisting of 5 sessions of $30 \mathrm{~min}$ each. The sequence of the sessions in the first protocol was: first control recording (without stimulation; presented immediately after introducing a fish in the measurement aquarium), stimulation with a real IPI distribution, second control recording, stimulation 
with random IPI distribution, and the final third control recording. The second protocol was: first control recording (without stimulation; presented immediately after introducing a fish in the measurement aquarium), stimulation with random IPI distribution, second control recording, stimulation with a real IPI distribution, and the final third control recording.

For subject A, subjected to the first protocol, the mean IPI distribution changed from a sharp peak at $20.5 \mathrm{~ms}$ (black curve in Fig. 6A) for the first control session to broader bimodal IPIs distribution with peaks at $17 \mathrm{~ms}$ and $19.5 \mathrm{~ms}$ for the stimulus session with real IPIs (green curve in Fig. 6A). In the second control session (blue curve), the IPIs distribution had a shape similar to that for the first control session (black curve). The response IPI distribution for the random stimuli session presented a single sharp peak at $20 \mathrm{~ms}$ (yellow curve), in contrast to a bimodal distribution observed in the real IPI stimuli session (green curve). The probability of discharging shorter IPIs (17 ms and $19.5 \mathrm{~ms}$ ) was higher for the first stimuli session (real IPI stimuli) compared to the second stimuli session (random) (20 ms). In the third control session, the fish discharged longer IPIs (lower frequency) with a sharp peak at $21.5 \mathrm{~ms}$ (red curve).

As soon as the stimulus was turned on, the fish reacted by shortening its IPIs and increasing the variability, abruptly changing the range of the IPIs from 19-22 ms to 11-20.5 ms (beginning of the green bar, yellow and red IPIs in Fig. 6B). A broad range (14.5-21 ms) of highly probable IPIs persisted throughout the stimulation session. Similar behavior was observed for the random stimuli session, but the range of IPIs was slightly narrower than that for the real stimuli session (14-21 ms; beginning of the yellow bar, yellow and red IPIs in Fig. 6B).

Immediately after the stimulus was turned off in both real and random stimuli sessions, the mean IPIs became longer $(20 \mathrm{~ms}$ and $21 \mathrm{~ms})$, and the variability decreased to $18.5-21 \mathrm{~ms}$ and $18.5-21.5 \mathrm{~ms}$, respectively. Throughout the second and third control sessions, the IPIs gradually became longer ( $\sim 23$ $\mathrm{ms}$ ), particularly in the second half of the third control session.

The entropy and locomotor activity (Fig. 6C and D) did not show the same relationship observed during the stationary period in unstimulated fish (Fig. 4G). The entropy did not always increase when 
the fish swam more vigorously. For example, approximately $10 \mathrm{~min}$ after the beginning of the second stimuli session (yellow shade in Fig. 6C and D), there was a high value of movement but low entropy. In this case, the fish increased its movements while the EO was firing the same IPI patterns.

In experiments performed two weeks after the fish arrived at the laboratory, it fired longer IPIs. The histogram for the first control session showed a peak at $20 \mathrm{~ms}$ (black curve in Fig. 6E) and a range of 16-22 ms (first $28 \mathrm{~min}$ in Fig. 6F), but in the final minutes of this session the IPIs became longer (19$24.5 \mathrm{~ms}$ ). During the first stimulation session (real IPI distribution), the probability of firing shorter IPIs increased, and a new peak was observed at $17.5 \mathrm{~ms}$ (green curve in Fig. 6E). In the second control session and the random stimuli session, the EO fired with predominantly 2 IPIs: $21 \mathrm{~ms}$ and $24.5 \mathrm{~ms}$ (blue and yellow curves in Fig. 6E). The EO fired at longer IPIs in the last control session compared to the previous sessions, specifically IPIs of $21.5 \mathrm{~ms}$ and $25 \mathrm{~ms}$ (red curve in Fig. 6E).

Fish typically reacted differently when subjected to the stimulation protocol for the first time, a few days after arriving at the laboratory (Fig. 6A-D), and after $\sim 2$ weeks (Fig. 6E-H). In the second trial, the same increase in the EOD frequency, entropy, and movement was observed during all stimuli sessions (green and yellow bars in Fig. 6A, B, E, and F) as that observed during the first trial (conducted at the time of introduction). However, a distinct reaction was observed in the second half of the random stimuli session in the second trial (yellow bar in Fig. 6B and F); the EOD frequency and variability during this part of the session were lesser than that during the beginning of this stimulation session and the second stimulus session in the first trial. Similar tendency was observed for the locomotor behavior (Fig. 6G), as well as for entropy (Fig. 6H).

Interestingly, 2 weeks after arriving at the lab, both entropy and movement vanished, meaning that the fish was standing still and periodically firing long IPIs for periods up to 10 min when the EOD frequency decreased at the end of the random stimuli session (yellow bar in Fig. $6 \mathrm{G}$ and $\mathrm{H}$ ). This behavior is similar to that found in the stationary period in a non-stimulated fish, with the entropy and movement highly correlated (65\%). 
The fish J subjected to protocol 2 (Fig. S1) presented similar behaviors than those described above using protocol 1.

For all fish in both protocols, the most probable IPIs in response to the stimuli sessions were shorter than those to the random stimuli ones (Fig. 7). Fish discharged shorter IPIs (17.0 ms median) during the real stimuli sessions compared to those for the random stimuli sessions (17.5 ms median) (Wilcoxon $\mathrm{p}<0.05$ ). There were no differences in the response to the control sessions (Friedman $\mathrm{p}>0.05$ ). The medians for the control sessions 1, 2 and 3 were, respectively, $18.4 \mathrm{~ms}, 18.8 \mathrm{~ms}$ and 19.4 ms. The most probable IPIs in response to real stimuli session were equal to or shorter than those to the random stimuli session (Fig. 7).The highest difference was (24.4\%), discharging more often 17.2 ms IPIs for the real stimuli session and $21.4 \mathrm{~ms}$ IPIs for the random stimuli session, and the lowest (1.2\%) was $16.4 \mathrm{~ms}$ and $16.6 \mathrm{~ms}$ IPIs for real and random stimuli session respectively.

Fish vary their firing rate as well as the IPI variability over time. To quantify these changes in addition to the most probable IPIs we computed the average of spread (2-98 percentile) of the IPI distribution for all sessions (individually) by calculating the width of the IPI distribution for each 40s window and taking the average. Fish presented wider IPIs distributions when stimulated compared to those when non-stimulated (Fig. 8) .Fish responded differently to the real control sessions than to the random stimuli ones, discharging greater variety of IPIs ( $3.2 \mathrm{~ms}$ median) in response to the real control sessions compared to the random stimuli ones ( $2.86 \mathrm{~ms}$ median; Wilcoxon $\mathrm{p}>0.05)$. The highest differences between the spread of the real and random stimuli sessions were $169.2 \%$ and $48.4 \%$. Among the control sessions (Friedman $\mathrm{p}<0.05$ ), post-hoc analyzes showed that control 1 ( 2.43 ms median) was statistically different than control sessions 2 (2.04 ms median) and 3 (2.13 ms median). Control 1 presented higher width of IPI distribution in 17 out of 23 experiments.

Fish usually presented spontaneous cessation of firing (defined as IPI $>2 \mathrm{x}$ mean IPI). Fish showed longer cessation of firing when subjected to real stimuli compared to thatfor the random stimuli (Fig. 9). A singlefish (the smallest one, $\sim 15 \mathrm{~cm}$ ) stopped firing for over 2 min when the real IPI distribution stimulus was turned on, whereas, the longest cessation of firing in response to a random stimulus was $43 \mathrm{~s}$. Spontaneous brief interruptions were less likely to occur during control sessions (Table 2) 
compared to those for stimuli sessions.

To address whether fish manifested different latencies when subjected to real or random IPI distributions we built normalized Post Stimulus Time Histograms (PSTH), where we plotted the experimental probability that a fish EOD occurs immediately after an artificial EOD (set as time reference) (Fig. 3 B) for both real and random IPI stimuli distributions (Fig. 10), That is, after receiving a stimulus pulse, we questioned how long will it take for the fish's EO to discharge

After an artificial EOD from a random stimuli distribution the fish presented a flat EOD probability up to the limit of the average stimulus IPI ( $\sim 14 \mathrm{~ms}$, Fig. 10). However, after an artificial EOD from a real stimuli distribution, the fish EOD probability was lower than that for the random stimulus in the 1- to 5-ms interval and higher in the 6- to 12-ms interval.This indicates that fish were more likely to wait longer to fire after receiving a pulse stimulus from a real IPI distribution than after a random one. PSTHs for experimental sessions with the real stimuli distribution revealed a preference for firing 3\% to $5 \%$ of the total EOD number later than that observed in PSTHs for experimental sessions using the random stimuli distribution.

In order to generalize the analyses we calculated PSTHs from both conditions for 8 fish, integrated them in steps of $1 \mathrm{~ms}$, and computed how much the PSTH for sessions with the real stimuli distribution deviated from the flat PSTH for sessions with the random stimuli distribution, i.e., we calculated (PSTHReal - PSTHRandom)/PSTHRandom for each $1 \mathrm{~ms}$ bin from 1 to $14 \mathrm{~ms}$ (Fig.14). From the average behavior of 8 fish, it was clear that in response to a real stimuli distribution, EOD probability in the first $1-5 \mathrm{~ms}$ was lower and in 6-12 ms was higher than that in response to random stimuli (ANOVA, $\mathrm{p}<0.002$ ). 


\section{Discussion}

Pulse-type weakly electric fish allow non-invasive access to central nervous system patterns involved in 2 interesting but incompletely understood tasks: electrolocation and electrocommunication $[1,2,53]$. However, due to experimental difficulties in dealing with a complex spatio-temporal electrical pattern generated by a freely moving fish, most studies on the interaction between fish with dimorphic pulse shapes and different pulse amplitudes used non-realistic waveforms as stimuli [18,20,54].

We developed an apparatus that enabled us to reliably detect and record in real time the EOD timestamps of freely swimming fish in 3 dimensions over several days using a cubic arrangement of electrodes and dedicated real-time software. Real-time software allowed us to stimulate the fish in a controlled way, mimicking the pulses of a conspecific but according to a distribution of IPIs chosen by the experimenter. Our setup accepts any kind of waveforms and stimuli IPI distributions, allowing one to perform experiments with most species of electric fish [42-44] and to study how a given specie would behave in the presence of different species.

Our $48 \mathrm{~h}$ experiments with non-stimulated fish revealed that introducing a fish into a novel environment (the acquisition aquarium) triggered a transient exploratory behavior characterized by short IPIs (high frequency EODs) as well as intense movement around the aquarium. After a long period (the order of $10 \mathrm{~h}$ ) a final stationary period with the EODs oscillating between 2 main frequencies was reached.

It was known that electrical behavior and movement can be associated [54] at least for short periods. Acoustic noise or intense light startled the fish and the EODs momentarily increased and the fish swan away. Nevertheless it was not expected that movement and electrical behavior (entropy of EODs patterns) could be related for such long periods. Surprisingly, after the transient period, movement and entropy were entrained for hours, with $70 \%$ correlated. That is, most EODs contain information about electrolocation.

During stimulation experiments turning on/off the stimulus aroused almost all fish in opposition 
to the data described by Bullock [54]. A plausible explanation is the difference in the waveform used in these experiments. We used the waveform of G. carapo, whereas Bullock used rectangular pulses.

In experiments with stimulation, entropy and movement were not strongly correlated, except for a few periods of possible behavioral sleep. That is, changes in the EODs patterns are due not only to fish movement but also due to the encoding of distinct sources of information. In these controlled experiments, we know that fish are freely swimming and receiving stimuli. Thus, we hypothesize that the additional entropy could correspond to electrocommunication.

There were also low correlation values of entropy and movement for the control sessions after turning off the stimulus. This is likely because the fish were using their EODs not only for electrolocation (which would provide high correlation), but also must be trying to find the suddenly disappeared conspecific that was communicating with them.

Both stimuli with real and random IPI distribution triggered increases in the mean EOD frequency, in the IPI distribution width and in the cessation of firing. However, fish did not respond equally to both stimuli. Fish were more likely to discharge shorter IPIs (hig frequency EODs), wider range of IPIs and longer cessation of fire in response to real IPI stimulation sessions than to random IPI stimuli sessions for both protocols. Fish behavior was similar when non-stimulated (control sessions) with only one exception, the variability of IPIs during the first control sessions were bigger than those for the second and third ones due to the novelty of the environment in control 1.

Real and random stimuli have the same waveform and amplitude, differing only in terms of IPI distributions (Fig. S2). In the flat random distribution all IPIs occur with the same probability and there are no causalities. Conversely, in the real distribution, some IPI values are more likely to occur than others. Additionally, the sequence in which the real IPIs appeared are truly from a real fish, and not randomly assigned by computer. We hypothesized that the order that each IPI is fired, that is, the 
causality, play an important role in communication and fish are able to identify unrealistic sequences of IPI patterns. In future work, we will investigate how these sequences vary in response to different stimuli and behavioral contexts. Specifically, we will address how different the order in which the IPI patterns are if the fish are isolated, socially naïve, habituated, or not in a new environment.

To analyze the differences in the EOD timming under stimulation, we compared several fish EOD occurrence probabilities immediately after being exposed to a real or a random stimulus in PSTHs. The probability of an EOD after a pulse coming from a random distribution of IPIs is constant over time. However, the probability of an EOD after a stimulus pulse coming from a real distribution of IPIs is slightly reduced (3-5\% of the pulses) for short times and increased for longer times. This result is another evidence that fish are able to discriminate between these 2 distributions. Moreover, the result obtained with the real stimuli in a freely moving fish agrees with those preliminary found in an experiment with 2 real fish hidden in plastic pipes [21].

It has been hypothesized that electric fish might separate their own electric pulses from external ones $[55,56]$. It was recently shown, in brain slices, that spherical neurons at the fast electrosensory path of Gymnotus omarorum have an intrinsic refractory time of $\sim 10 \mathrm{~ms}$ which is about half the average IPIs in those fish [57]. In the same work there are also evidences, from chronically implanted fish experiments, indicating that the animal uses this refractory time to minimize the interference of conspecific pulses in the sensory pathway.

Our PSTH results for freely moving fish revealed a preference for discharging after half of the average IPI of the conspecific (stimuli from real distribution), which indicates after the conspecific refractory period. Thus, our results suggest that in our experimental conditions the fish changes the timing of the EOD to be detected by the conspecific and would have to delay its next EOD to avoid the refractory period of its own spherical neurons.

We propose that a fish estimates the refractory period of a conspecific and chooses whether to discharge within this period. For example, to electrolocate without being detected it would be interesting to discharge within the refractory period of the conspecific; whereas to communicate a fish 
would discharge out of the conspecific refractory period. If this is the case, one must take in account both refractory periods when analyzing communication between fish.

To confirm this hypothesis and to estimate the refractory period in the freely moving fish Gymnotus carapo, we are currently planning real-time experiments in which stimulus pulses will be delivered according to the fish's own EODs, as well as experiments with 2 fish in the same tank and software techniques to classify and split their pulses.

\section{Acknowledgements:}

We thank P.V.Carelli for bringing the first fish to our lab, J.C.Sartorelli for his patience and expertise in stainless steel wires and silicone sealants. This work was supported by the Brazilian agencies: Fundação de Amparo à Pesquisa do Estado de São Paulo - FAPESP (www.fapesp.br), Coordenação de Aperfeiçoamento de Pessoal de Nível Superior - CAPES (www.capes.gov.br), and Conselho Nacional de Desenvolvimento Científico e Tecnológico - CNPq (www.cnpq.br). The funders had no role in study design, data collection and analysis, decision to publish, or preparation of the manuscript. 


\section{References}

1. Lissmann HW (1958) On the function and evolution of electric organs in fish. JExpBiol 35:156-191

2. Bullock TH (1999) The future of research on electroreception and electrocommunication. J Exp Biol 202:1455-8.

3. Fortune ES, Rose GJ, Kawasaki M (2006): Encoding and processing biologically relevant temporal information in electrosensory systems. J Comp Physiol A Neuroethol Sens Neural Behav Physiol 192: 625-35.

4. Engelmann J, Bacelo J, Metzen M, Pusch R, Bouton B, et al. (2008) Electric imaging through active electrolocation: implication for the analysis of complex scenes. Biol Cybern 98: 519-539.

5. Caputi AA (2004) Contributions of electric fish to the understanding of sensory processing by reafferent systems. J Physiol Paris 98: 81-97.

6. von der Emde G, Schwarz S, Gomez L, Budelli R, Grant K (1998) Electric fish measure distance in the dark. Nature 395:890-4.

7. von der Emde G, Amey M, Engelman J, Fetz S, Folde C, et al. (2008) Active electrolocation in Gnathonemus petersii: behaviour, sensory performance, and receptor systems. J Phisiol Paris 102:279-90.

8. von der Emde G, Behr K, Bouton B, Engelmann J, Fetz S, et al. (2010) 3-Dimensional Scene Perception during Active Electrolocation in a Weakly Electric Pulse Fish. Front Behav Neurosci 28: 4:26. 
9. Caputi AA, Castelló ME, Aguilera P, Trujillo-Cenóz O (2002) Electrolocation and electrocommunication in pulse gymnotids: signal carriers, pre-receptor mechanisms and the electrosensory mosaic. J Physiol Paris 96:493-505.

10. von der Emde G, Fetz S (2007) Distance, shape and more: recognition of object features during active electrolocation in a weakly electric fish. J Exp Biol 210:3082-95.

11. Caputi AA, Budelli R (1995) The electric image in weakly electric fish: I. A data-based model of waveform generation in Gymnotus carapo. J Comp Neurosci 2:131-47.

12. von der Emde G (1999) Active electrolocation of objects in weakly electric fish. J Exp Biol 202:1205-15.

13. Doiron B, Chacron MJ, Maler L, Longtin A, Bastian J (2003) Inhibitory feedback required for network oscillatory responses to communication but not prey stimuli. Nature 421:539-543.

14. Engelmann J, Gertz S, Goulet J, Schuh A, von der Emde G (2010) Coding of stimuli by ampullary afferents in Gnathonemus petersii. J Neurophysiol 104: 1955-68.

15. Ho WW, Fernandes CC, Alves-Gomes JA, Smith GT (2010) Sex differences in the electrocommunication signals of the electric fish Apteronotus bonapartii Ethology 116:1050-1064.

16. Cuddy M, Aubin-Horth N, Krahe R (2011) Electrocommunication behaviour and non invasively-measured androgen changes following induced seasonal breeding in the weakly electric fish, Apteronotus leptorhynchus. Horm Behav, 61(1):4-11. doi: 10.1016/j.yhbeh.2011.09.003

17. Carlson BA, Hasan SM, Hollmann M, Miller DB, Harmon JL, Arnegard ME (2011) Brain Evolution Triggers Increased Diversification of Electric Fishes. Science 332:583-586

18. Westby G W (1975) Comparative studies of the aggressive behaviour of two gymnotid electric fish 
(Gymnotus carapo and Hypopomus artedi). Animal behaviour 23: 192-213.

19. Wong RY, Hopkins CD (2007) Electrical and behavioral courtship displays in the mormyrid fish Brienomyrus brachyistius. J Exp Biol 210: 2244-52.

20. Perrone R, Macadar O, Silva A (2009) Social electric signals in freely moving dyads of Brachyhypopomus pinnicaudatus. J Comp Physiol A 195: 501-14.

21. Westby G W (1979) Electrical Communication and Jamming Avoidance Between Resting Gymnotus carapo. Behav Ecol Sociobiol 4: 381-393.

22. Arnegard ME, Carlson BA (2005) Electric organ discharge patterns during group hunting by a mormyrid fish. Proc Biol Sci 272: 1305-14.

23.Cleworth PA (1970) The role of electrical discharges in the non-reproductive social behaviour of Gymnotus carapo. Anim Behav Monogr 3:1-77

24.Precision measurement of electric organ discharge timing from freely moving weakly electric fish (2011). J Neurophysiol 107(7):1996-2007. doi: 10.1152/jn.00757.2011

25. Jun JJ, Longtin A, Maler L (2013). Tracking of multiple free-swimming weakly electric fish via efficient localization of moving dipole sources. PLoS One 8(6):e66596

26.Carlson BA (2002). Electric signaling behavior and the mechanisms of electric organ discharge production in mormyrid fish. J Physiol-Paris 96:405-19

27.Carlson BA (2009). Temporal-Pattern Recognition by Single Neurons in a Sensory Pathway Devoted to Social Communication. Behavior J Neurosci 29(30):9417-9428.doi:10.1523/

28. Kramer B, Kuhn B (1994) Species recognition by the sequence of discharge intervals in weakly electric fishes of the genus Campylomovmyvus (Mormyridae, Teleostei). Anim Behav 48:435-45 
29.Kramer B (1979). Electric motor response of the weakly electric fish, Gnathonemus petersii (Mormyridae), to play-back of social signals. Behav Ecol Sociobiol 6:67 - 79.

30.Teyssèdre C, Serrier J (1986) Temporal spacing of signals in communication, studied in weakly electric fish (Teleostei,Pisces). Behav. Proc.12:77-98

31. Post N, von der Emde G (1999) The "novelty response" in an electric fish: response properties and habituation. Physiol Behav 68: 115-28.

32. Schuster S (2002) Behavioral evidence for post-pause reduced responsiveness in the electrosensory system of Gymnotus carapo. J Exp Biol 205: 2525-33.

33. Schuster S, Otto N (2002) Sensitivity to novel feedback at different phases of a gymnotid electric organ discharge.J Exp Biol 205: 3307-20

34. Aguilera PA, Caputi AA (2002) Electroreception in G. carapo: detection of changes in waveform of the electrosensory signals. J Exp Biol 206: 989-998.

35. Heiligenberg W, Baker C, Bastian J (1978) The jamming avoidance response in gymnotoid pulse-species: A mechanism to minimize the probability of pulse-train coincidence. J Comp Physiol $124: 211-224$.

36. Capurro A, Malta CP (2004) Noise autocorrelation and jamming avoidance performance in pulse type electric fish. Bull Math Biol 66:885-905.

37. Brochini L, Carelli PV, Pinto RD (2011). Single synapse information coding in intraburst spike patterns of central pattern generator motor neurons. The Journal of Neuroscience 31: 12297-12306. doi:10.1523/JNEUROSCI.1568-11.2011. 
38. de Ruyter van Steveninck RR, Lewen GD, Strong SP, Koberle R, Bialek W (1998) Reproducibility and variability in neural spike trains. Science 275: 1805-8.

39. Rieke F, Warland D, De Ruyter van Steveninck R, Bialek W(1999). Spikes: Exploring the Neural Code (Computational Neuroscience), MIT Press

40. Dayan P, Abbot LF (2001) Theoretical Neuroscience: computational and mathematical modeling of neural systems, MIT Press

41. Borst A, Theunissen FE (1999) Information theory and neural coding. Nature Neurosci 2:947-57.

42.Muñiz C, Forlim CG, Guariento RT, Pinto RD, Rodríguez FB, Varona P (2011). Online video tracking for activity-dependent stimulation in neuroethology. BMC Neuroscience 2011, 12 (Suppl 1):P358

43. Forlim CG, Almeida LOB, Varona P, Rodríguez FB, Pinto RD (2012) Study of electric and motor behavior in weakly electric fish, Gymnotus carapo and Gnathonemus petersii, using Information Theory. Program No. 501.10. 2012 Neuroscience Meeting Planner. New Orleans, LA: Society for Neuroscience, 2012. Online

44.Forlim CG, Muñiz C, Pinto RD, Rodríguez FB, Varona P (2013) Behavioral driving through on line monitoring and activity-dependent stimulation in weakly electric fish. BMC Neuroscience 2013, 14(Suppl 1):P405

45. Pinto, RD, Forlim, CG, Carelli, PV (2007) A nonlinear approach to the information processing using intervals between electric organ discharges of the weakly electric fish Gymnotus carapo. In: 37th Annual meeting Society for Neuroscience. Program No. 211.20/JJJ7. 2007 Neuroscience Meeting Planner San Diego, CA: Society for Neuroscience, Online. 
46. Forlim CG (2008) Estudo experimental da eletrocomunicação em peixes de campo elétrico fraco da espécie Gymnotus carapo - uma aplicação da Teoria da Informação (Experimental study of electrocommunication in weakly electric fish from the Gymnotus carapo species - an application of Information Theory), Master's thesis, Institute of Physics, University of São Paulo, 44 pages, available at: http://www.teses.usp.br/teses/disponiveis/43/43134/tde-23102008-193008/en.php

47. Forlim CG, Rodrigues LB, Pinto RD (2011) Neural coding tools, based on Information Theory, applied to discrete time series: from electrophysiology to neuroethology. BMC Neuroscience 12:(Supl 1)P253.

48. Pinto RD, Elson RC, Szücs A, Rabinovich, MI, Selverston, AI, Abarbanel, HD (2001) Extended Dynamic Clamp: controlling up to four neurons using a single desktop computer and interface. J Neurosci Methods 108: 39-48.

49. Nowotny T, Szücs A, Pinto RD, Selverston AI (2006) StdpC: A modern Dynamic Clamp. J Neurosci Methods 158: 287-99.

50. Castelló ME, Rodríguez-Cattáneo A, Aguilera PA, Iribarne L, Pereira AC, et al. (2009) Waveform generation in the weakly electric fish Gymnotus coropinae (Hoedeman): the electric organ and the electric organ discharge. J Exp Biol 212: 1351-64.

51. de Ruyter van Steveninck RR, Lewen GD, Strong SP, Koberle R, Bialek W (1998) Reproducibility and variability in neural spike trains. Science 275: 1805-8.

52. Shannon CE (1948) A mathematical theory of communication. Bell Systems Tech J 27: 379423.

53. Heiligenberg W (1991) Recent Advances in the Study of Electroreception, Curr Opin Neurobiol, 1:187-191. 
54.Bullock TH (1969) Species differences in effect of electroreceptor input on electric organ pacemakers and other aspects of behavior in electric fish. Brain Behav Evol 2:85-118

55. Szabo T, Sakata H, Ravaille M (1975) An electrotonically coupled pathway in the central nervous system of some teleost fish, gymnotidae and mormyridae. Brain Research 95: 459-474.

56. Caputi AA and Nogueira J (2012) Identifying Self- and Nonself-Generated Signals: Lessons from Electrosensory Systems. In: López-Larrea C, editor. Sensing in Nature, Springer.

57. Nogueira J, Caputi AA (2011) Timing actions to avoid refractoriness: a simple solution for streaming sensory signals. PLoS One 6: e22159. 


\section{Figure Legends}

Figure 1. Acquisition and stimulation setup. A- hardware: EODs from real (f) and artificial stimulus (S) fish are measured using a 3D array of 8 electrodes [(1)-(7), and (R)]. Signals are differentially amplified (x 100, (R) is the common reference) and digitized at $50 \mathrm{kHz}$ by an ADC board. The artificial fish is a dipole electrode inside a $15 \mathrm{~cm}$ PVC pipe driven by a DAC output from a computer running real-time home made stimulation software that mimics a real fish pulse shape with IPIs defined by the experimenter. B- acquisition software: the square of the digitized artificial signal are delayed of 1-3 samples due to the DAC-ADC circuitry and subtracted from the squared and summed electrode signals, because this signal contains both stimulus (S) and real fish (f) and after subtraction, only the real fish pulses will remain. Real fish pulses are then detected with a simple threshold level and the timestamps at each electrode are stored for posterior analyses. The positive and negative amplitude values at each timestamp are detected in all electrodes. The electrode corresponding to the maximum positive amplitude indicates the position of the fish's head and the electrode with the most negative amplitude indicates the position of the fish's tail.If the fish's head(tail) is in the middle of the tank, the positive (negative) amplitudes will be more or less the same in all electrodes and not as high as if the fish were near the corners of the tank or the reference electrode. The locally induced amplitude (LIA) at each electrode is defined as the difference between the maximum and minimum values of voltage induced during the EOD.

Figure 2. Stimuli histograms. Real IPI stimulus histogram (in black). The IPIs were recorded (30 min) from a non-stimulated fish immediately after being introduced in the tank. Random IPI stimulus histogram (in red). IPIs from $15 \mathrm{~ms}$ to $20 \mathrm{~ms}$ were generated with the same probability (flat distribution) by computer.

Figure 3. Data analyses: binarization, entropy and post stimulus calculations ABinarization and set of patterns for entropy calculations. The time axis is discretized into small bins. The presence of an EOD in each bin is represented by 1, whereas an absence is represented by 0 . Timestamp sequences are analyzed in bit strings obtained in $40 \mathrm{~s}$ windows. Each pattern is a 4 bit word. Starting from the beginning of the bit string a 4 bit mask is moved 1 bit to the right to extract a new 
word until the end of the window, forming the set of words $W=\left\{w_{1}, w_{2}, w_{3}, \ldots, w_{N}\right\}$. From the set of probabilities of each word $w_{i}$ we computed the entropy $H(\mathrm{~W})$. B- Post stimulus time (PST) is defined as the time intervals (in red) $t i$ between stimulus pulses (in blue) and the fish response ones (in green).

Figure 4. Non estimulated fish (48 h experiment). A- IPI histogram of the first $240 \mathrm{~s}$ after the fish is introduced to the tank. The colors are a code for highly probable IPIs (red), intermediate probable IPIs (yellow) and low probable IPIs (blue). In the beginning of the experiment the fish was more likely to fire $27 \mathrm{~ms}$ IPIs. B- IPI histogram for $240 \mathrm{~s}$ in the stationary period. The color code is the same as in A. During the stationary period the shape of the IPI distribution was bimodal with peaks in $28 \mathrm{~ms}$ and $40.5 \mathrm{~ms}$. C- Sliding window histogram (SWH) of IPIs versus time. The histograms were calculated in $40 \mathrm{~s}$ windows and colors were assigned depending on the probability as explained in A. The sliding window histogram was built taking the colorcoded histogram for the first 40s window and placing it in a vertical line in SWH, the second $40 \mathrm{~s}$ window colorcoded histogram was placed in the next vertical line in SWH and son on, allowing one to observe how IPIs evolve over time. There was a transient behavior, at the beginning of the recording, characterized by low average values of IPIs around $27,5 \mathrm{~ms}$. After $10 \mathrm{~h}$ the behavior reached a stationary state that persists throughout the experiment: the IPIs distributions oscillated over time between the same two main peaks of IPIs, $27 \mathrm{~ms}$ and $42 \mathrm{~ms}$. D. - Inferred movement versus time. The fish movement was maximal during the initial transient and evolved to a stationary state that alternated with periods of vigorous activity and total absence of movement. E - Entropy versus time. During the transient period the entropy presented intermediate values. After the transient, the entropy oscillated between higher and almost zero values. F - Detail during the transient behavior. Above: Sliding window histogram of IPIs versus time. Below: Inferred movement (black) and entropy (red) versus time. At the beginning of the transient there are low IPIs values (high EOD frequencies) with constant values of entropy and restless movement. G Same as $\mathrm{F}$ after habituating to the aquarium. In the stationary state, the IPIs oscillated between two mean values. Movement and entropy were entrained.

Figure 5. Cross-correlation between entropy and movement. A- Mean cross-correlation for the transient period. At lag 0, entropy and movement were only $10 \%$ correlated. The correlation remained low for all lags. Error bars indicate the standard deviation obtained from experiments with 3 fish. B- Cross-correlation for the stationary period. Entropy and movement were highly correlated 
$(70 \%)$ at lag 0 and it quickly decreased .

Figure 6. Experiments with stimulation. The protocol was a sequence of 5 sessions ( $30 \mathrm{~min}$ each) as follows: first control recording (without stimulation)(black), stimulation with a real distribution of IPIs (green), second control (blue), stimulation with random distribution of IPIs (yellow), and a final control (red). A- Histograms of the response IPIs for each session: first, second and third controls in black, blue and red respectively. Response to real stimuli in green and to random one in yellow. In the first $30 \mathrm{~min}$, fish discharged mostly $20.5 \mathrm{~ms}$ IPIs. In response to real IPI stimuli, the IPI distribution was bimodal with 2 equally probable values: $17 \mathrm{~ms}$ and $19.5 \mathrm{~ms}$. In the second control session the IPI distribution changed presenting a single sharp peak in $21 \mathrm{~ms}$. The distribution in response to a random stimuli was broader than for the control session with a single peak in $20 \mathrm{~ms}$. The fish reacted to the third control session firing mostly longer IPIs with a peak in $21.5 \mathrm{~ms}$. B - Sliding window histogram of IPIs versus time. High (low) probabilities are shown in red (blue). The same colorcode (red/yellow/blue) associated with high/intermediate/low probability explained in Fig.5 is used here. C - Inferred movement, and D - entropy versus time. Fish reacted to both stimuli by decreasing the IPIs values (increasing the EODs frequency) and increasing its variability from 19-22 $\mathrm{ms}$ to $14.5-21 \mathrm{~ms}$. During random stimuli (yellow bar) fish presented a slight relaxation with the peak of IPIs tending to higher values over time from $20 \mathrm{~ms}$ to $21.5 \mathrm{~ms}$ as well as in the third control session from $21 \mathrm{~ms}$ to $23 \mathrm{~ms}$. The fish was restlessly moving throughout the experiment with no simple relation to the stimulation sessions. The entropy clearly increased (decreased) when both stimuli were turned on (off). E- Same as A but 2 weeks later. For the first 30min, the IPI distribution presented a single sharp peak in $20 \mathrm{~ms}$ (black). For the rest of the sessions the IPI distribution were bimodal differing in the peak values. The fish fired shorter IPIs $(17.5 \mathrm{~ms})$ in response to a real IPI stimuli session (green). The IPI distributions in response to the second control (blue) and random stimuli (yellow) were very similar with peaks around $21 \mathrm{~ms}$ and $24.5 \mathrm{~ms}$. For the last control session fish fired longer IPIs compared to the previous sessions with peaks in $21.5 \mathrm{~ms}$ and $25 \mathrm{~ms}$. F-H D-F - same as A-C B-D but for an experiment performed 2 weeks later with the same individual. The same qualitative behavior was found with the remarkable exception that during the stimulation with a random distribution fish presented several epochs characterized by: very high IPI values around $24.5 \mathrm{~ms}$, absence of movement, and very low entropy values, probable sleep-like state that was expected only during control sessions. 
Figure 7. Most probable IPIs for control and stimuli sessions. The most probable IPIs discharged during the stimuli sessions were smaller than those for the control sessions, the medians were $17.0 \mathrm{~ms}, 17.5 \mathrm{~ms}, 18.4 \mathrm{~ms}, 18.8 \mathrm{~ms}$ and $19.4 \mathrm{~ms}$ for the real IPI stimuli session, random IPI stimuli session, control 3, control 2 and control 1, respectively. Fish responded differently to the real IPI stimuli sessions compared to the random IPI stimuli ones discharging smaller IPIs (Wilcoxon $\mathrm{p}<0.05$ ). However, there were no differences among the most probable IPIs discharged during the control sessions (no stimuli sessions; Friedman $\mathrm{p}>0.05$ ).

Figure 8. Average width of IPI distributions. Fish discharged greater variety of IPIs (wider distributions) during the stimuli sessions compared to the control sessions, medians were $3.2 \mathrm{~ms}$ and $2.86 \mathrm{~ms}$ for the real and random IPI sessions and $2.43 \mathrm{~ms}, 2.13 \mathrm{~ms}$ and $2.04 \mathrm{~ms}$ for control session 1, 3 and 2 respectively. Between the stimuli sessions, the average width of the IPI distributions for the real IPI sessions were wider (Wilcoxon $\mathrm{p}<0.05$ ). For the control sessions (Friedman $\mathrm{p}<0.05$ ), post-hoc analyzes revealed that control 1 was statistically different than control sessions 2 and 3 . The width of the distribution were calculated as the 2-98 percentile measure in 40s sliding windows.

Figure 9. Cessation of fire. Fish presented longer cessation of fire during the real stimuli sessions compared to those for the random stimuli ones (Wilcoxon $p<0.05$ ). The longest cessations of fire lasted $150 \mathrm{~s}$ for the real stimuli sessions and $43 \mathrm{~s}$ for the random stimuli ones. The medians were $2.0 \mathrm{~s}$ and $1.3 \mathrm{~s}$ for the real stimuli sessions and random stimuli sessions, respectively. Cessation of firing was defined those IPIs 2 times longer than the mean IPI.

Figure 10. Normalized Post Stimulus Time Histograms (PSTH). The PSTH for stimuli from a random distribution of IPIs (red) presents a flat shape up to the limit of the mean IPI $(\sim 17 \mathrm{~ms})$, whereas the PSTH for a real distribution of stimuli IPIs presents a peak probability of approximately 10 ms. The PSTH change (black) when the random stimuli distribution is replaced by real stimuli shows an average decrease of probability $(\sim 5 \%)$ in the $0-5$ ms-range and the probability in the range of 6-12 $\mathrm{ms}$ increases $\sim 10 \%$. Error bars indicate the standard deviation, obtained from experiments with 8 fish. 
The changes correspond to $3 \%$ to $5 \%$ of the total number of EODs and is evidence that fish discriminate between real and random stimuli distributions (ANOVA, $\mathrm{p}<0.002$ ).

Figure S1. Experiments with stimulation using the second protocol. A - Sliding window histogram of IPIs versus time. The histogram was also calculated in $40 \mathrm{~s}$ windows and colors are assigned depending on the probability as explained in Fig. 3A. The second protocol was: first control session (without stimulation; black bar), stimulation using the random IPI distribution (yellow bar), second control (blue bar), stimulation using the real IPI distribution (green bar) and third control (red bar). When the random stimulus was turned on (beginning of the yellow bar), the fish reacted in the first $10 \mathrm{~min}$, shortening its IPIs firing in the range of $15.5-20 \mathrm{~ms}$. In the last $20 \mathrm{~min}$, the IPIs became longer $\sim 20 \mathrm{~ms}$ changing the rang of IPIs to $17-20.5 \mathrm{~ms}$. Nevertheless, when stimulated with the real IPI distribution, a broad range (16-21 ms) of highly probable IPIs persisted throughout the stimulation session. Responses to real stimuli sessions usually presented broader IPIs distributions than those to random stimuli in both protocol (for protocol 1 see Fig 8 B and F). For all control session the mean IPI was longer $\sim 21.5 \mathrm{~ms}$ compared to the stimulation sessions. B- Inferred movement, and C- entropy versus time. The fish was restlessly moving throughout the experiment, specially during stimulation sessions. The entropy showed a small increase for the stimulation sessions. Increased (decreased) in entropy and movement were not entrained.

Figure S2. Real and random stimuli over time - Sliding window histogram of IPIs versus time. The histograms were also calculated in $40 \mathrm{~s}$ windows and colors are assigned depending on the probability as explained in Fig. 3A. In the real fish IPI distribution the most probable IPIs (in red and yellow) change over time mostly from $15 \mathrm{~ms}$ to $20 \mathrm{~ms}$ and in the final minutes from $20 \mathrm{~ms}$ to $21.5 \mathrm{~ms}$. In the random IPI distribution, all IPIs between $15 \mathrm{~ms}$ and $20 \mathrm{~ms}$ occurred with the same probability avoiding possible causalities.

\section{Tables}

Table 1: Cessation of firing for $48 \mathrm{~h}$ non stimulated fish 


\begin{tabular}{|c|c|c|}
\hline & Cessation of firing & \\
\hline & $\begin{array}{l}\text { Total number ( } \% \text { of total } \\
\text { IPIs) }\end{array}$ & $\begin{array}{l}\text { Duration }(\mathrm{s})[\mathrm{min} \\
\mathrm{max}]\end{array}$ \\
\hline Fish 1 & $34(0.0018)$ & {$\left[\begin{array}{lll}0.07 & 1.80\end{array}\right]$} \\
\hline Fish 2 & $114(0.0050)$ & [0.05 3.05] \\
\hline Fish 3 & $186(0.0093)$ & {$[0.105 .30]$} \\
\hline
\end{tabular}

Table 2: Cessation of firing

Mean $\% \pm$ StD cessation of firing during:

$\begin{array}{lllll}\text { First control } & \text { Real IPI } & \text { Second } & \text { Random IPI } & \text { Third control sessions } \\ \text { sessions } & \text { stimuli } & \text { control } & \text { stimuli } & \\ & \text { sessions } & \text { sessions } & \text { sessions } & \\ 0.01 \pm 0.03 & 0.18 \pm 0.47 & 0.01 \pm 0.02 & 0.12 \pm 0.27 & 0.01 \pm 0.02\end{array}$




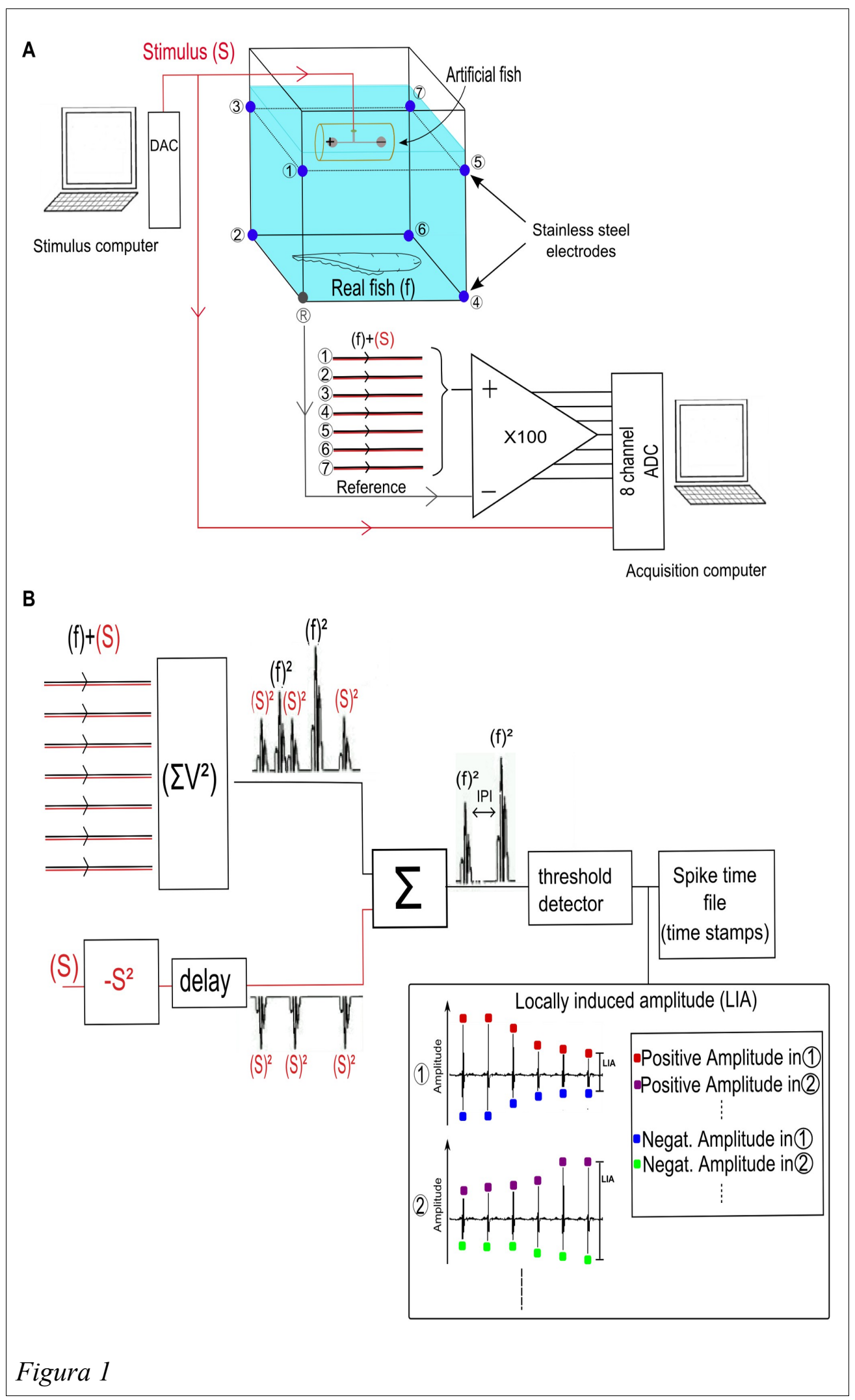




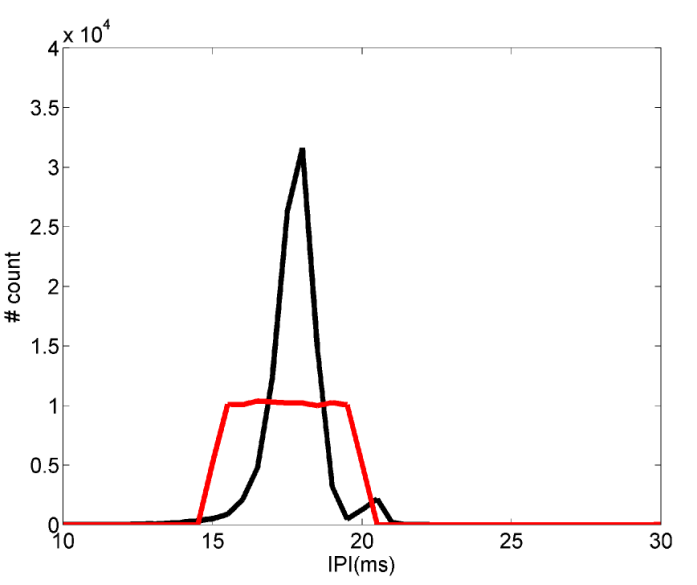

Figura 2 


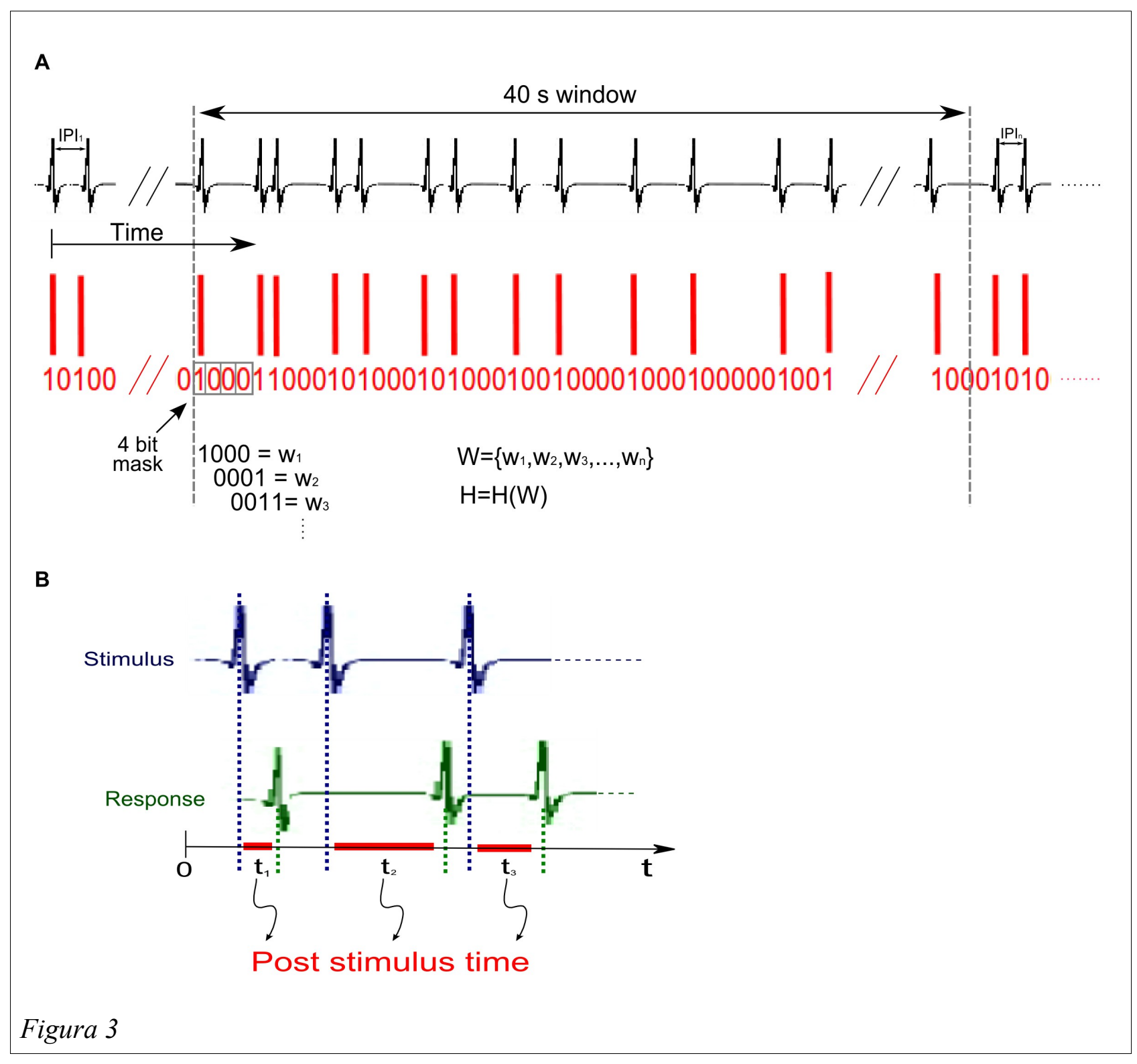




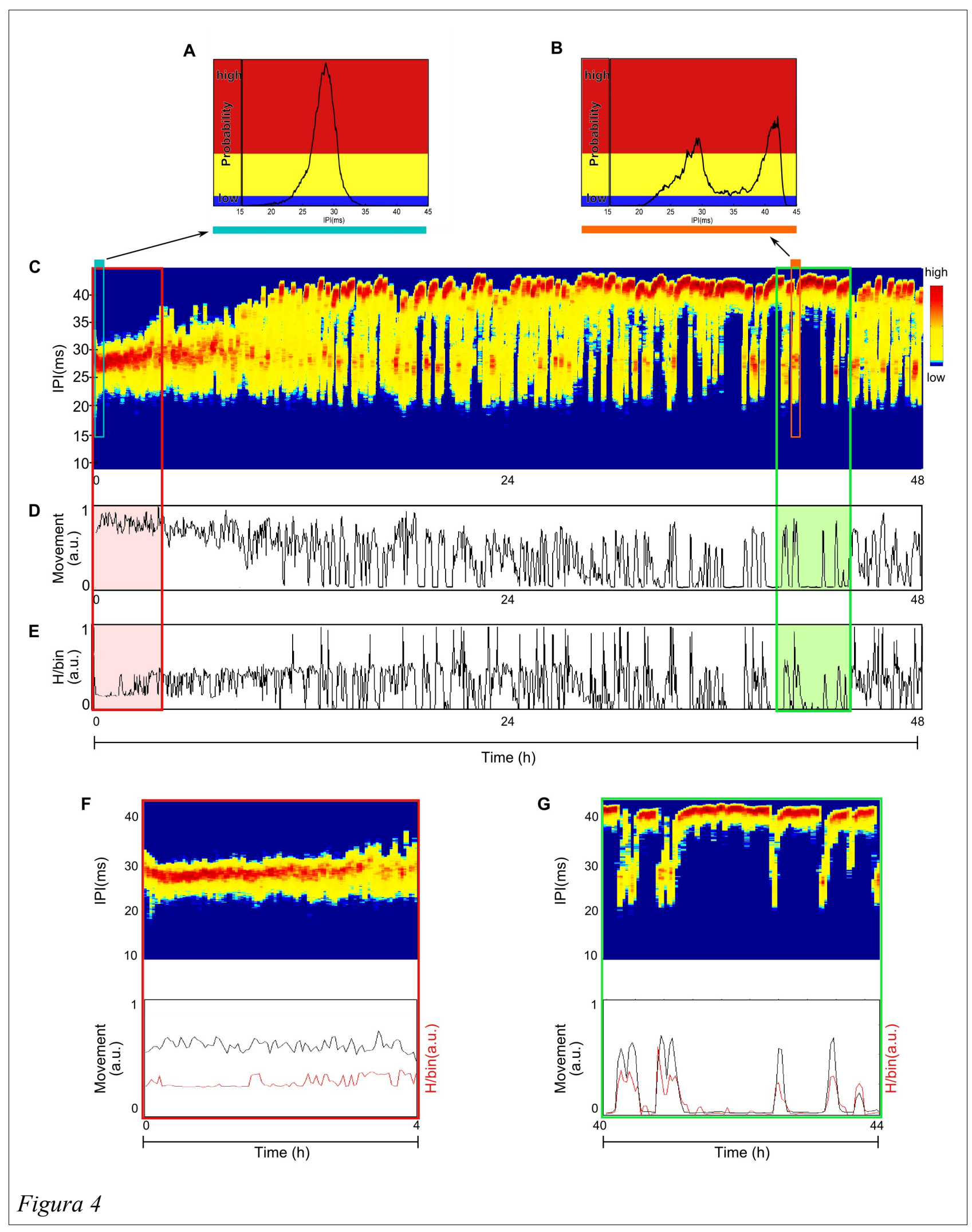




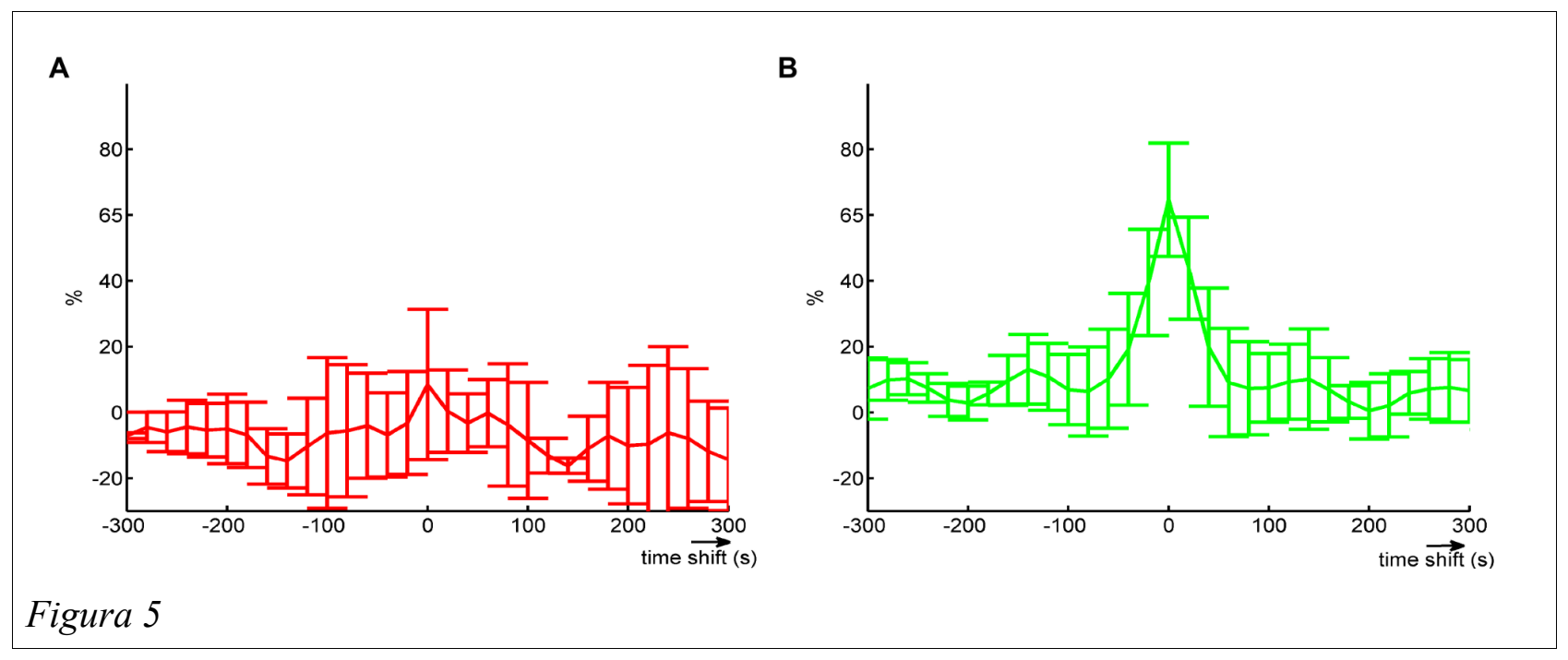




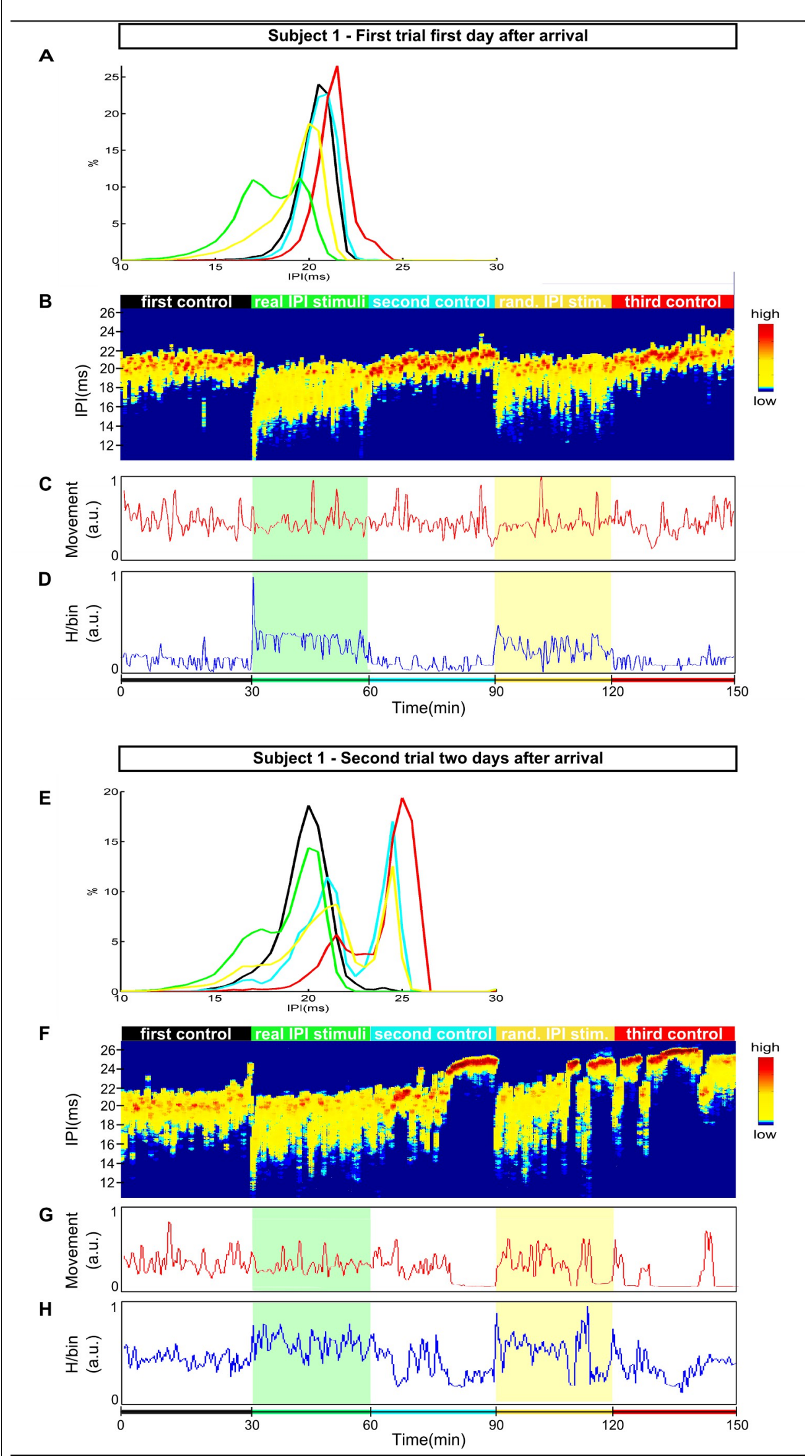




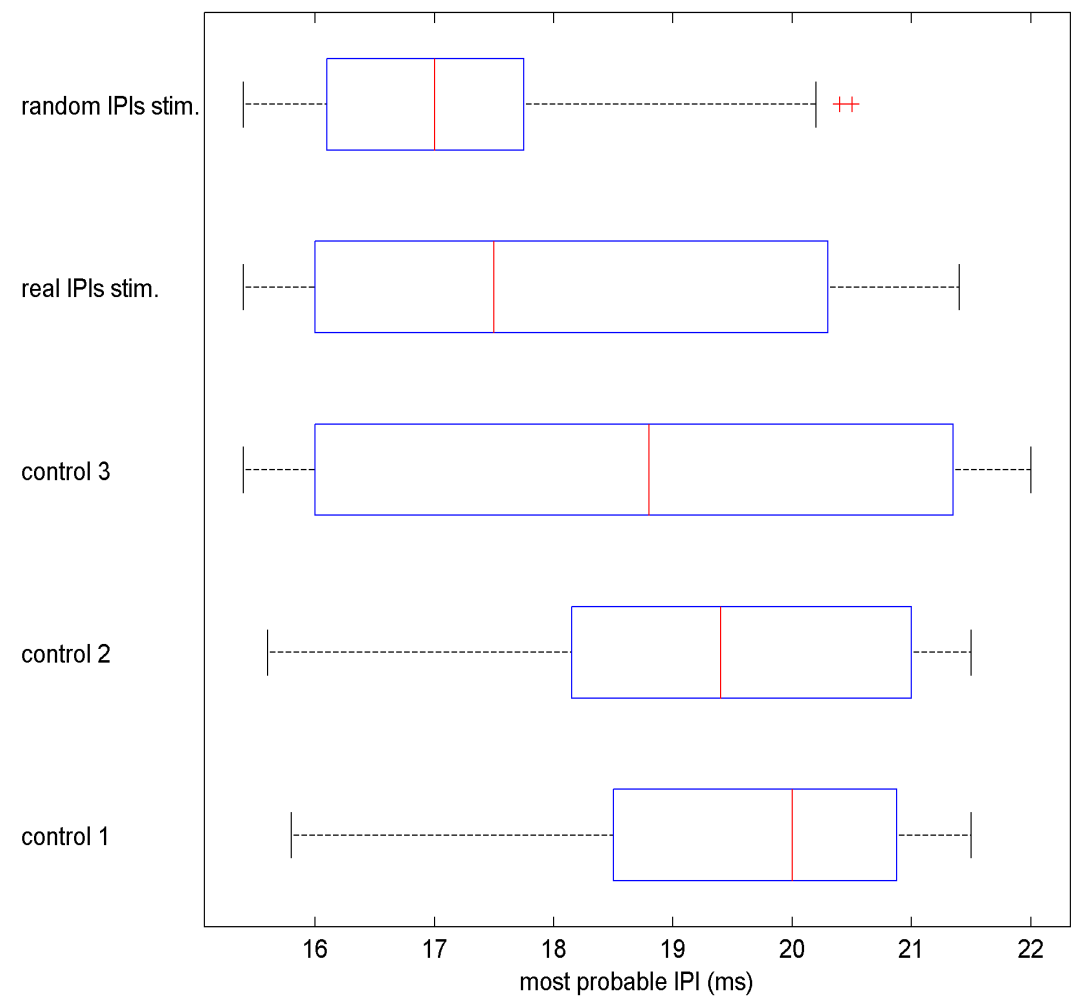

Figura 7 


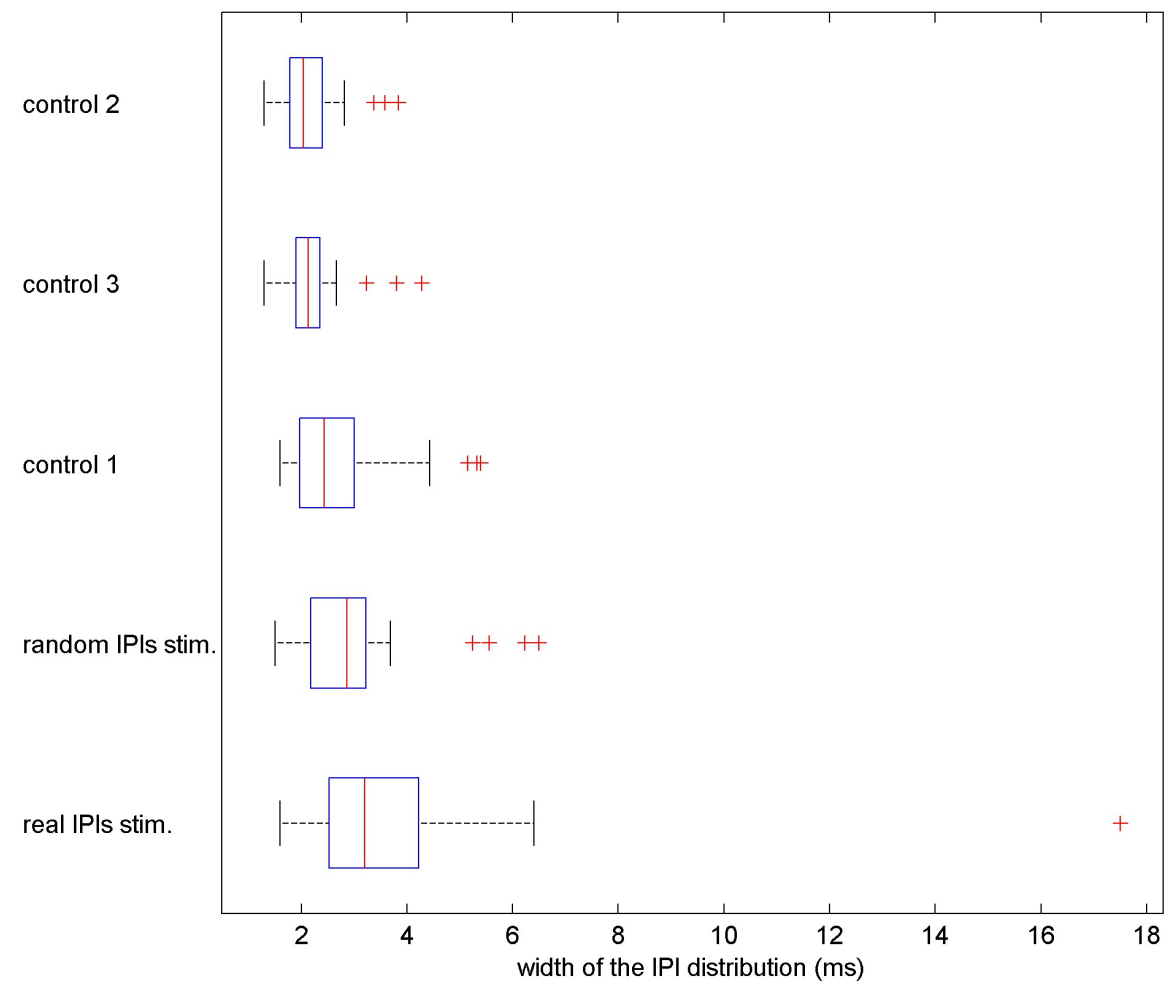

Figura 8 


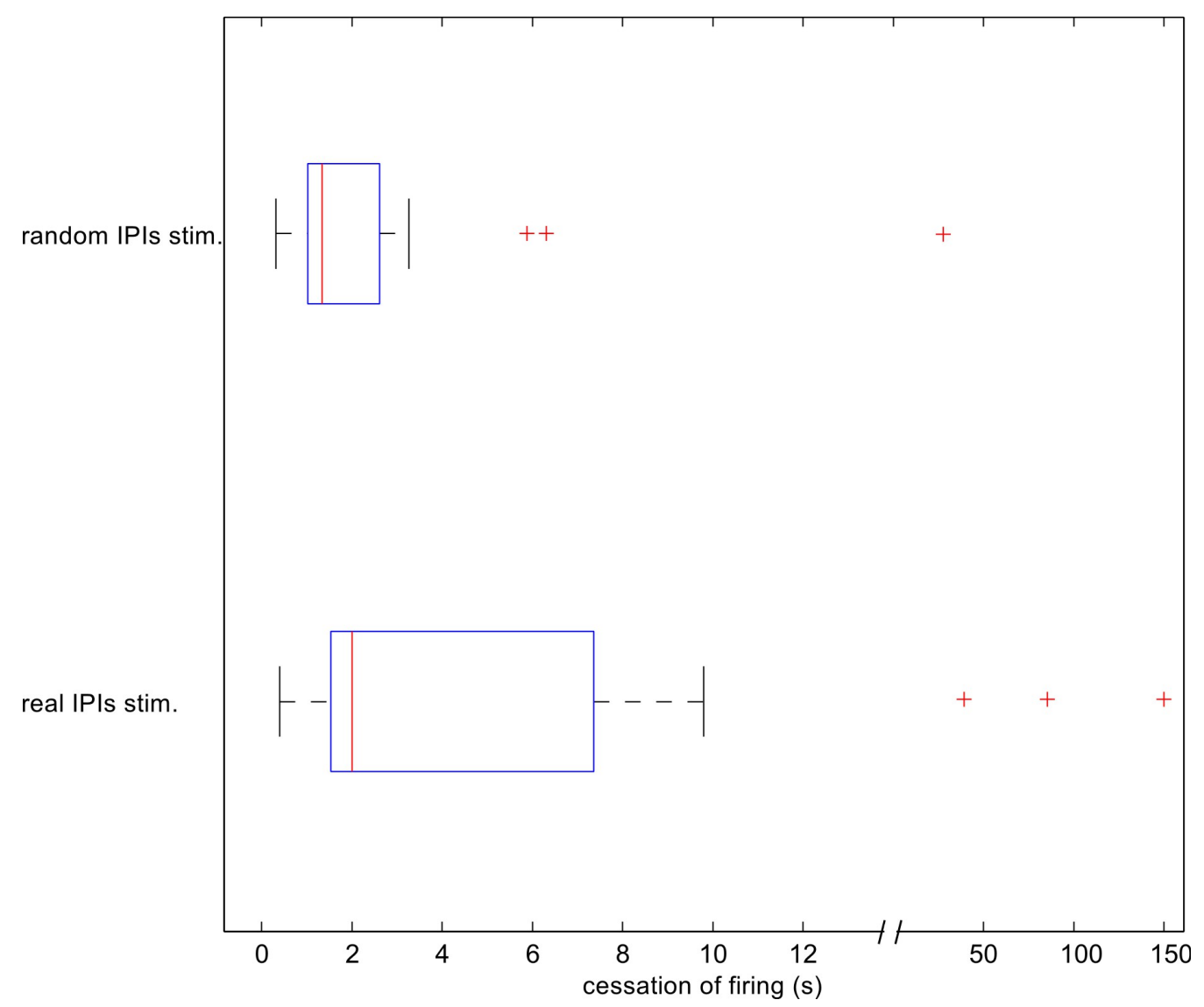

Figura 9 


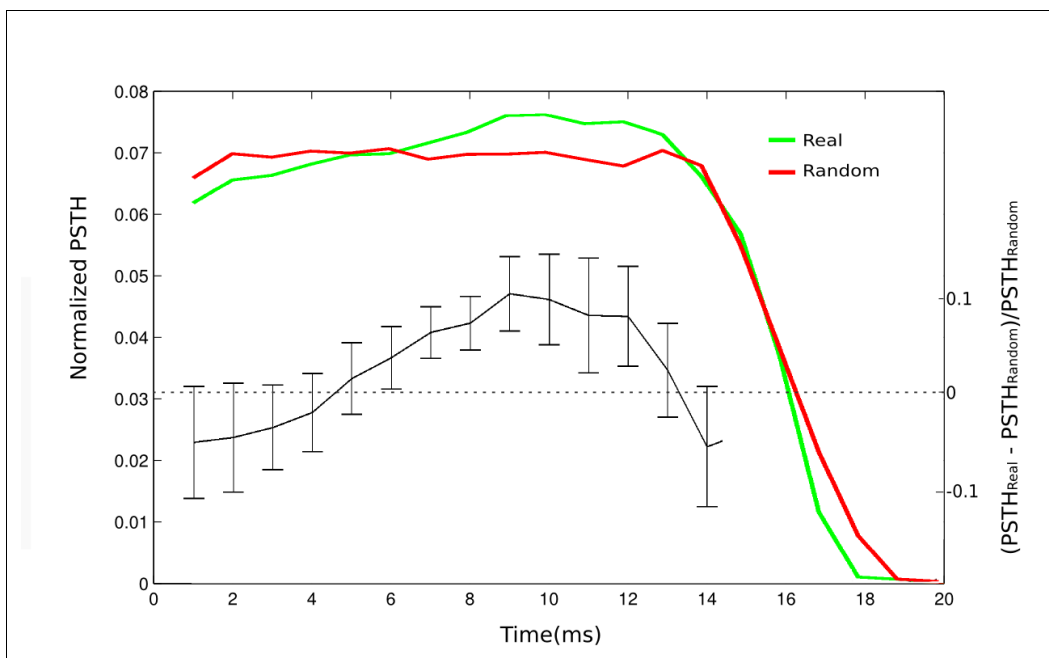

Figura 10 


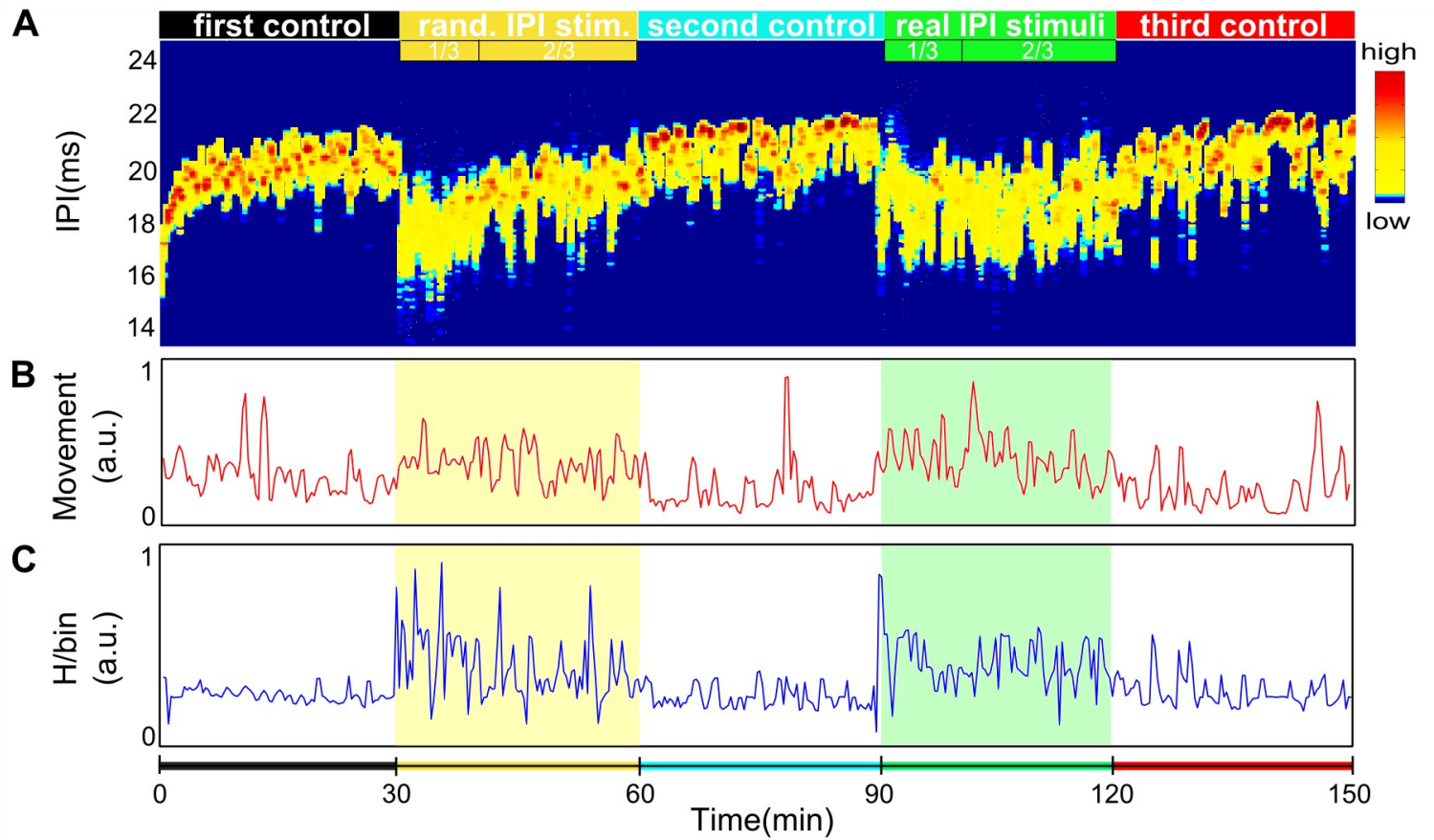

FiguraS 1 

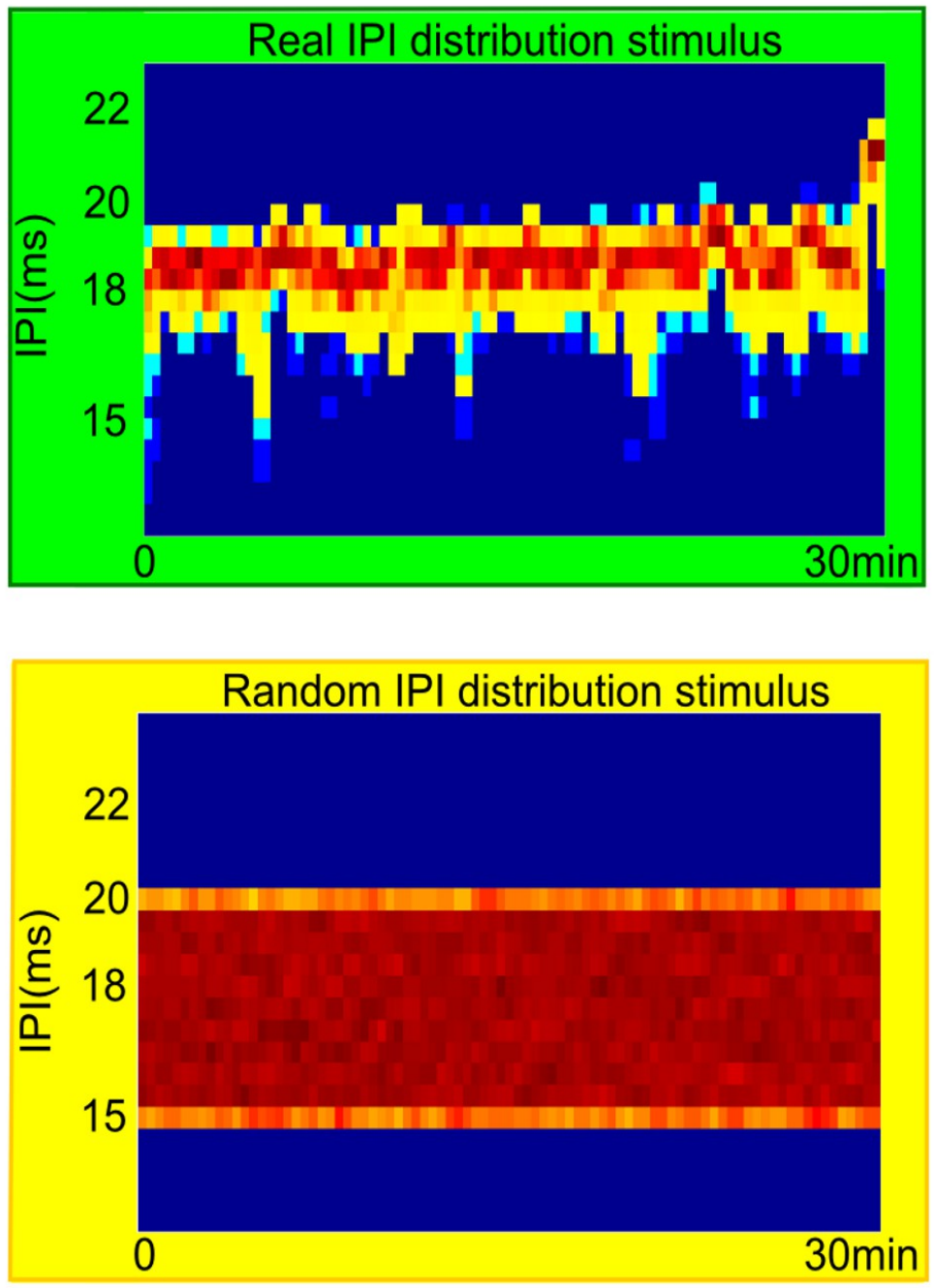

FiguraS 2 


\section{APÊNDICE B}

\section{Behavioral driving through on line monitoring and IA activity-dependent stimulation in weakly electric fish

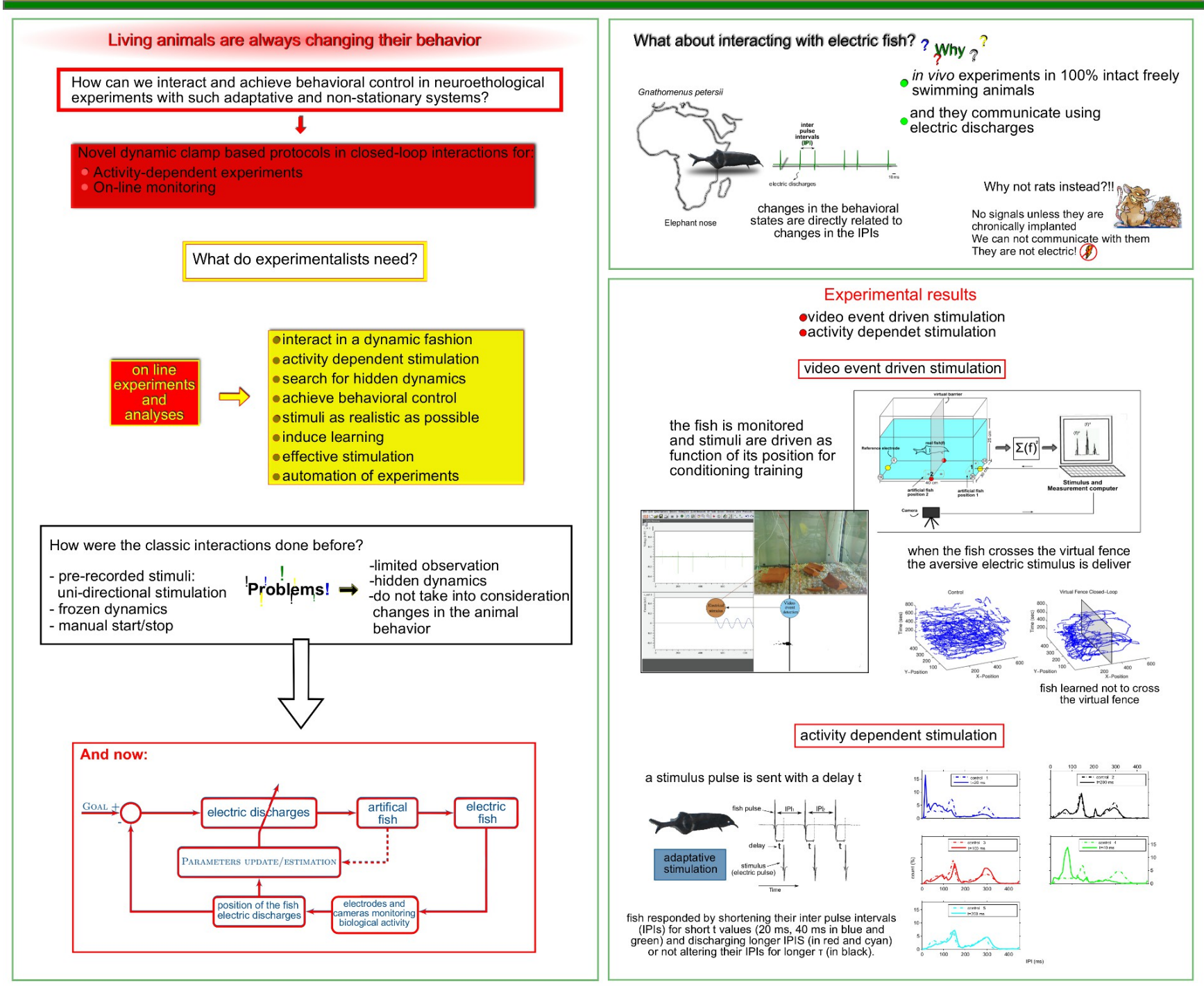

References:

Bullock TH, Hopkins CD, Popper AN, Fay RR. Eletroreception. 1. Springer; 2005

Chamorro P, Muñiz C, Levi R, Arroyo D, Rodriguez FB, et al. : Generalization of the Dynamic Clamp Concept in Neurophysiology and Behavior. PLOS ONE 2012 7(7): e40887. doi:10.1371/ journal.pone. 0040887 , Varlim CG, Almeid Theory. Program No. 501.10. 2012 Neuroscience Meeting Planner. New Orleans, LA: Society for Neuroscience, 2012. Online.

Acknowlegments::

This work has been supported by Brazilian agencies FAPESP, CNPq, CAPES and grants MINECO TIN 2012-30883 and TIN 2010-19607 and $7^{\circ}$ Convocatoria De PROYECTOS de COOPERACION INTERUNIVERSITARIA UAM-SANTANDER con America Latina 


\section{APÊNDICE C}

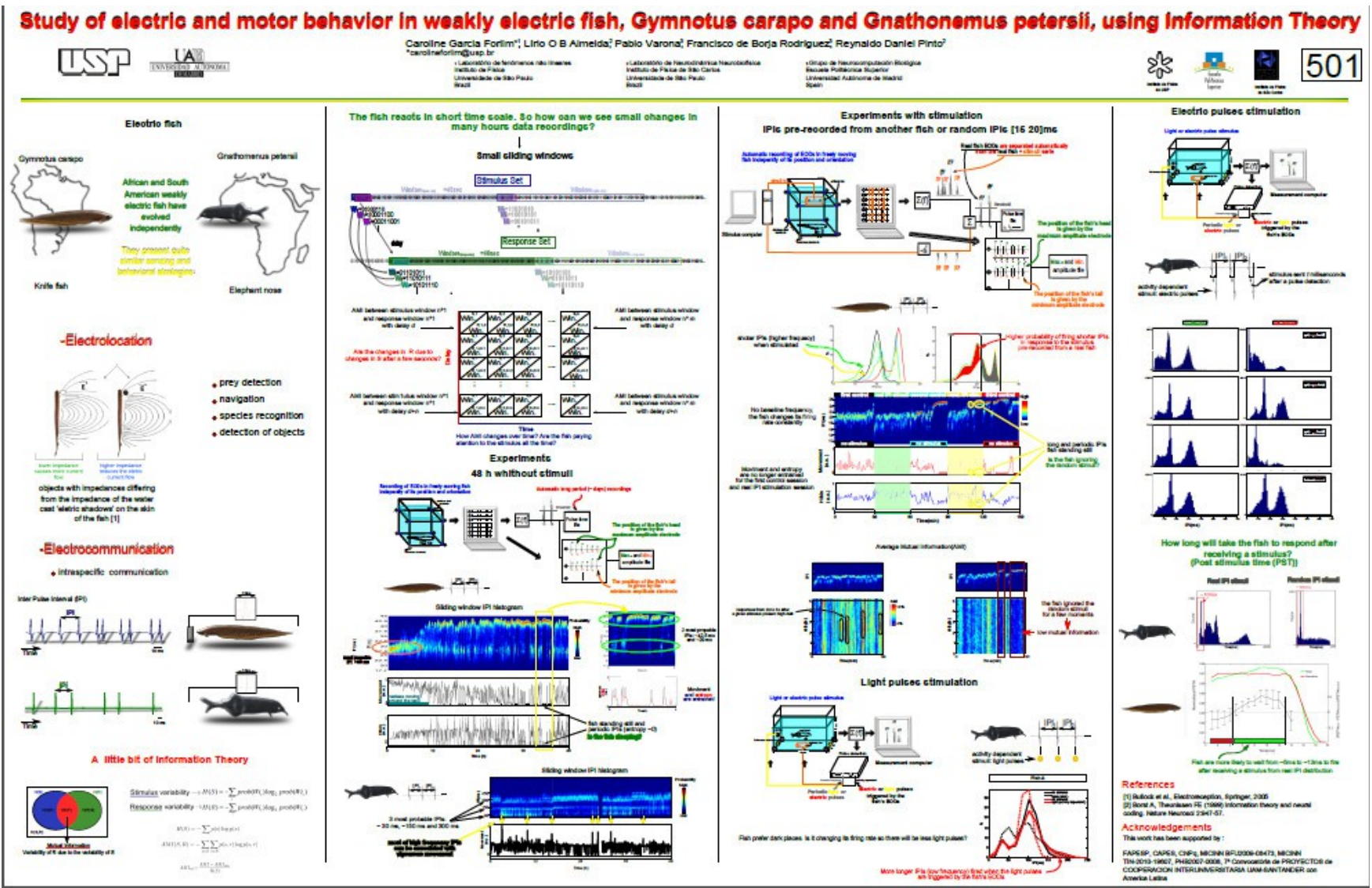




\section{APÊNDICE D}

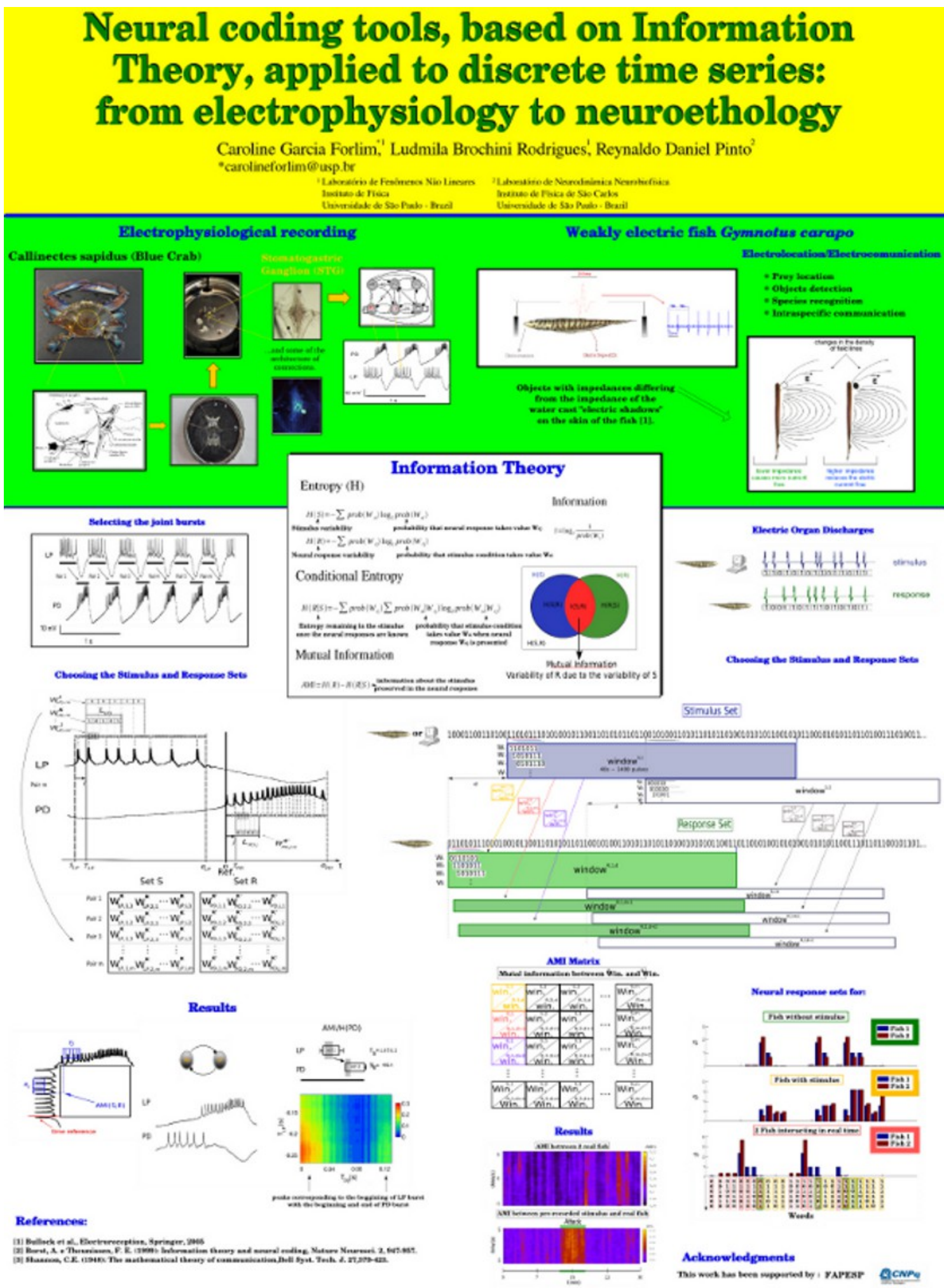




\section{APÊNDICE E}

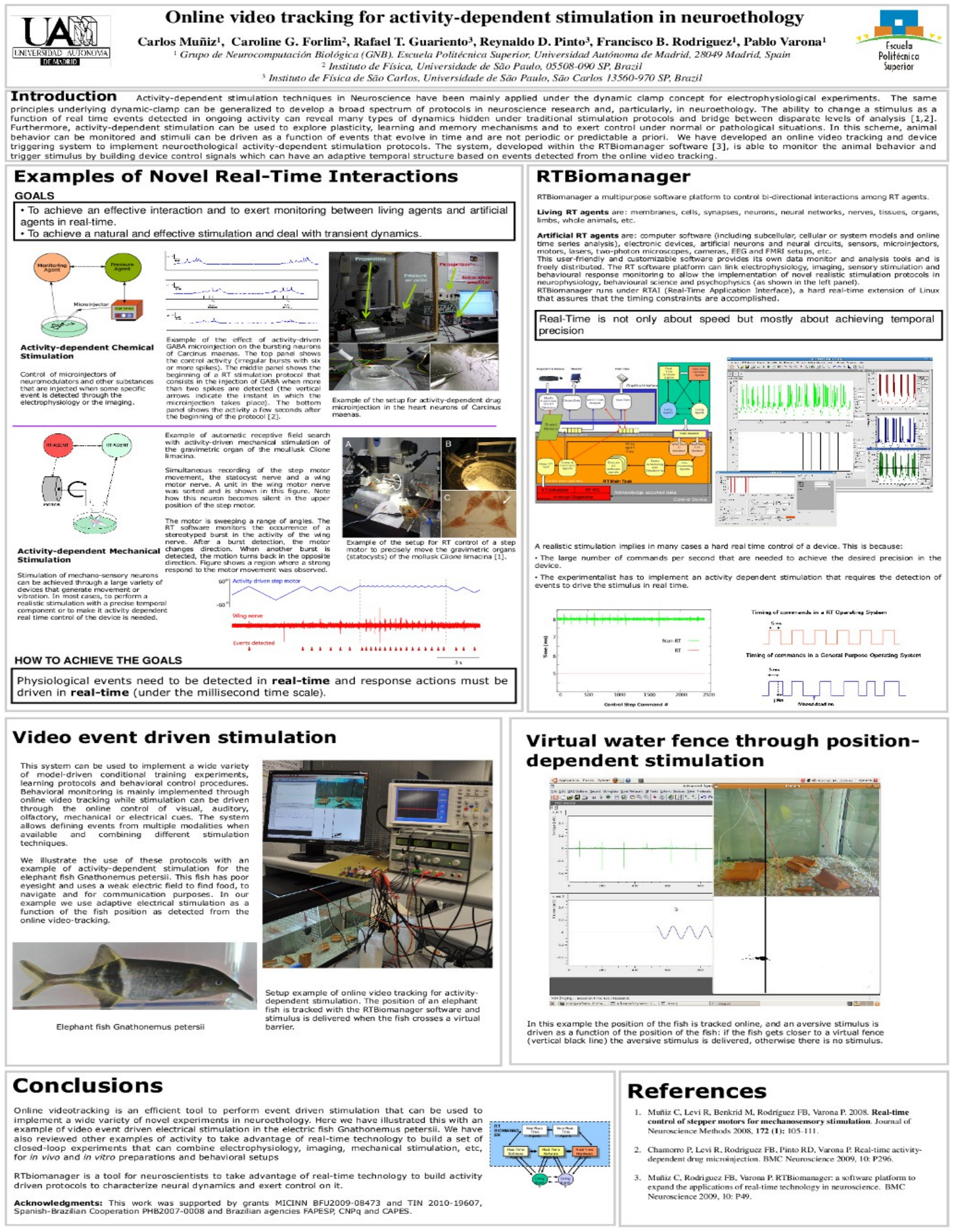




\section{APÊNDICE F}
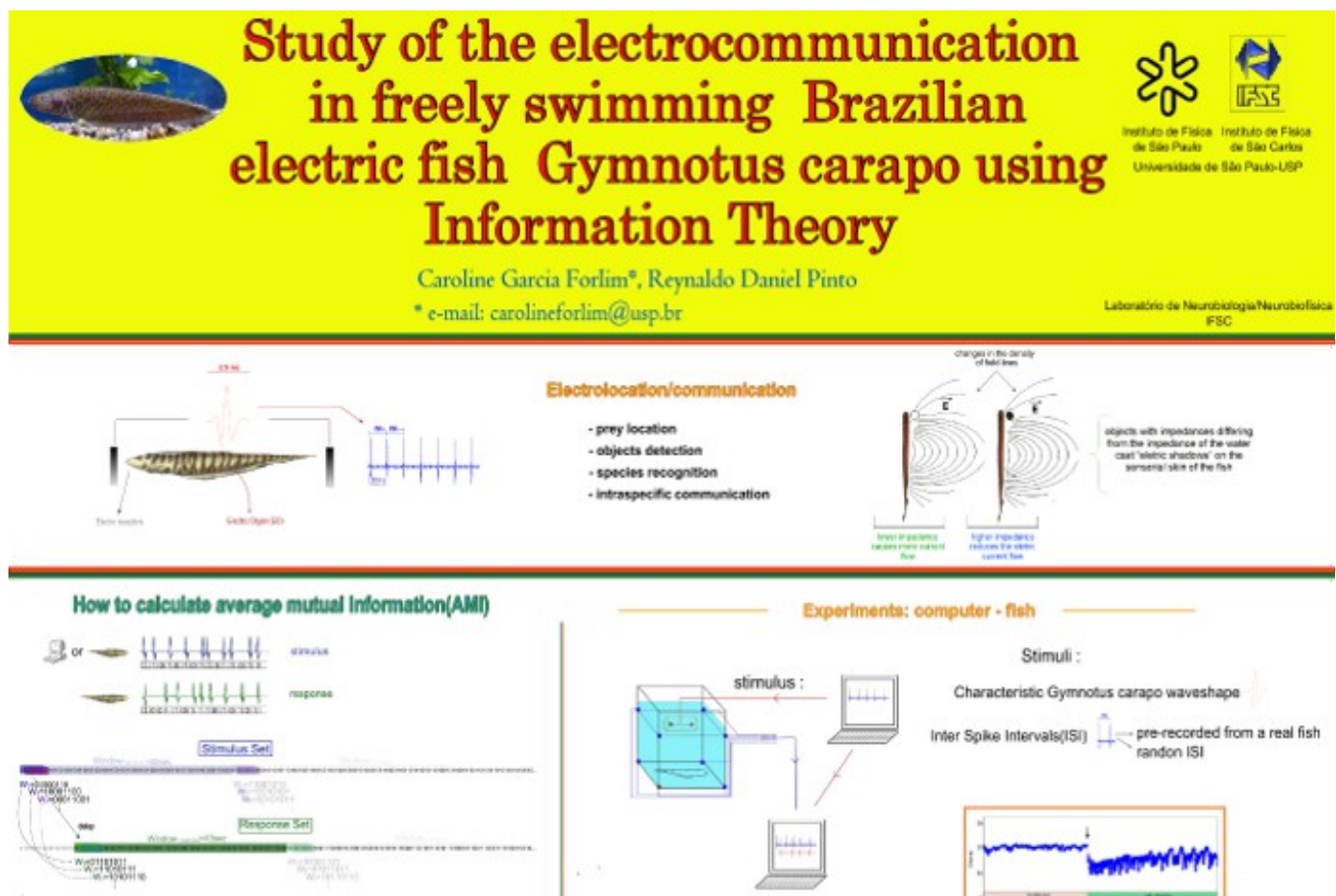

Stimulus variability $\rightarrow H(S)=-\sum$ prodan, $)$ log, $\operatorname{prod}\left(W_{1}\right)$

Ressense variability $\rightarrow H(R)=-\sum$ prot $\left(W_{i}\right)$ log, $p$ rab $\left(W_{i}\right)$

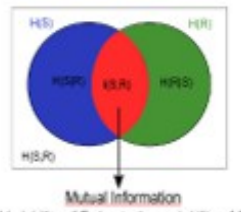

Variacility of $R$ das to the variability of $\$$

Experimenta: flah-flah conected

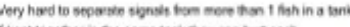

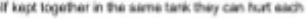
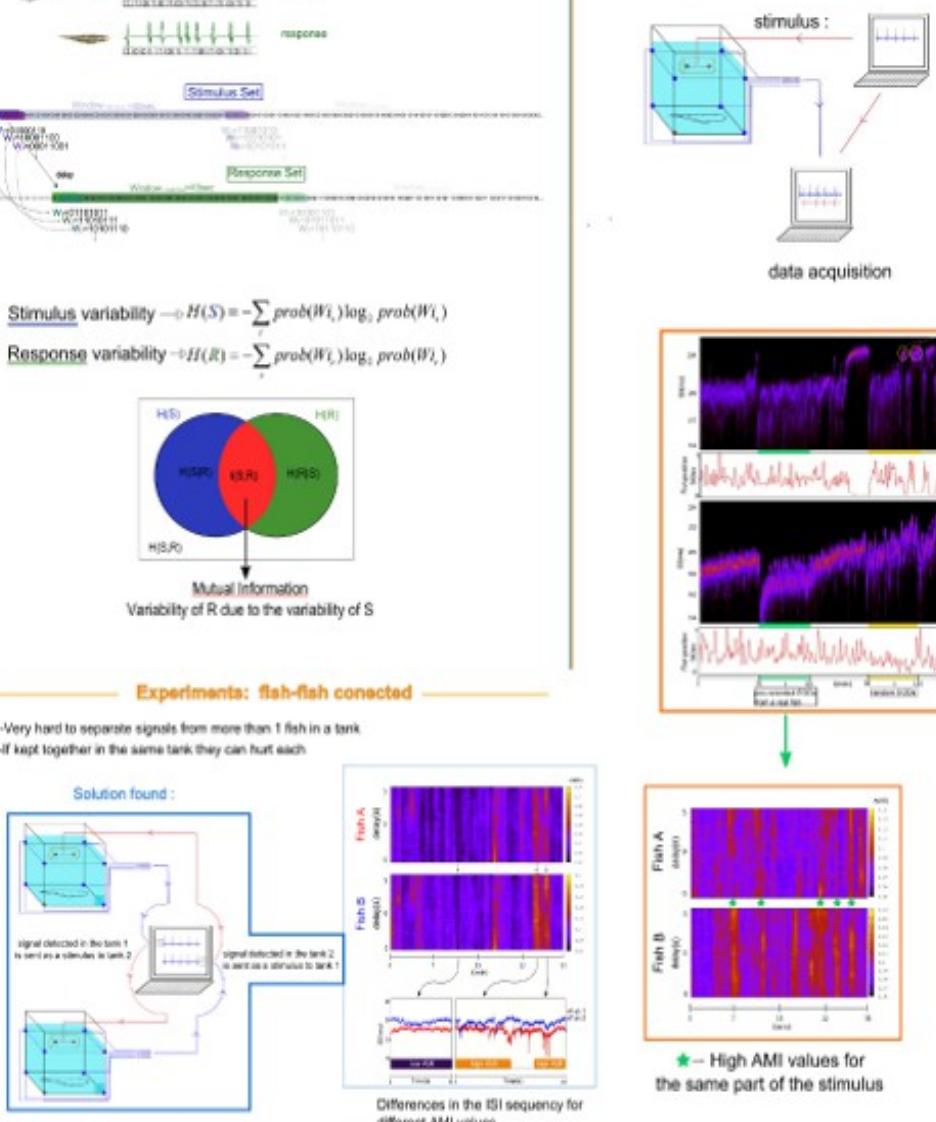

Stimuli :
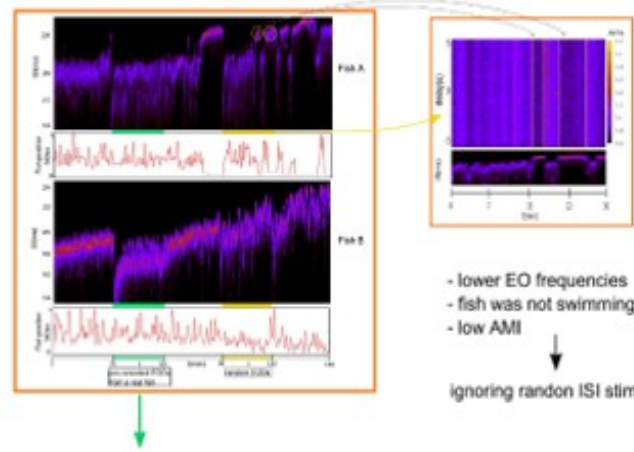

- lower EO frequencies

- flish was not swimming around

- low AMII

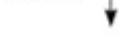

ignoring randon ISI stimulus Grareace Nall väues
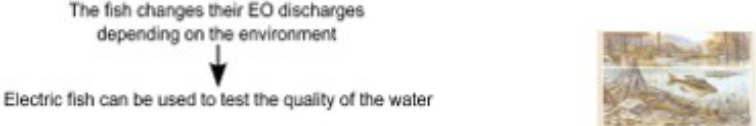

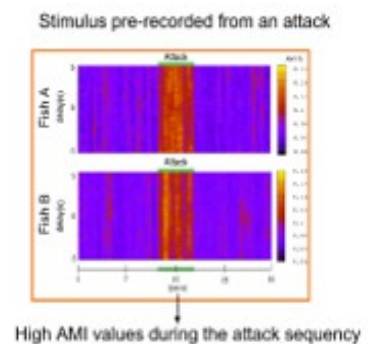

Acknowledgements

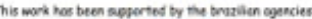
FAPESP PCNPq E:PSI 